\title{
The European study of referrals from primary to secondary care
}

Citation for published version (APA):

Fleming, D. M. (1993). The European study of referrals from primary to secondary care. [Doctoral Thesis, Maastricht University]. Thesis Publishers. https://doi.org/10.26481/dis.19930617df

Document status and date:

Published: 01/01/1993

DOI:

$10.26481 /$ dis. $19930617 \mathrm{df}$

Document Version:

Publisher's PDF, also known as Version of record

\section{Please check the document version of this publication:}

- A submitted manuscript is the version of the article upon submission and before peer-review. There can be important differences between the submitted version and the official published version of record.

People interested in the research are advised to contact the author for the final version of the publication, or visit the DOI to the publisher's website.

- The final author version and the galley proof are versions of the publication after peer review.

- The final published version features the final layout of the paper including the volume, issue and page numbers.

Link to publication

\footnotetext{
General rights rights.

- You may freely distribute the URL identifying the publication in the public portal. please follow below link for the End User Agreement:

www.umlib.nl/taverne-license

Take down policy

If you believe that this document breaches copyright please contact us at:

repository@maastrichtuniversity.nl

providing details and we will investigate your claim.
}

Copyright and moral rights for the publications made accessible in the public portal are retained by the authors and/or other copyright owners and it is a condition of accessing publications that users recognise and abide by the legal requirements associated with these

- Users may download and print one copy of any publication from the public portal for the purpose of private study or research.

- You may not further distribute the material or use it for any profit-making activity or commercial gain

If the publication is distributed under the terms of Article $25 \mathrm{fa}$ of the Dutch Copyright Act, indicated by the "Taverne" license above, 
THE EUROPEAY STUDY OP RETERRALS FROM PRIMARY TO SECONDARY CARE 


\section{THE EUROPEAN STUDY OF REFERRALS}

\section{FROM PRINARY TO SECONDARY CARE}

\section{PROEFSCHRIFT}

ter verkrijging van de graad van doctor aan de Rijksuniversiteit Limburg te Maastricht, op gezag van de Rector Magnificus, Prof. mr. M. J. Cohen volgens het besluit van het college van Dekanen, in het openbaar te verdedigen op donderdag 17 juni 1993 om 16.00 uur

door

Douglas Munro Fleming

geboren te Birmingham (UK) op 9 december 1936 


\section{Promotores :}

Prof.ar. J. van der Zee

Prof.dr. J. A. Knottnerus

Beoordelingscommissie:

Prof.dr. F. Sturmang (voorzitter)

Prof.dr. P. Backer (University of Copenhagen, Denmark)

Prof.mr.dr. R.T.P.M. Grol

Prof.dr. J. Heyrman (Katholieke Universiteit Leuven, Belgie)

Prof.dr. E. Philipsen

This study was sponsored by the Commission of the European Communities, DG XII, 4th Medical and Health Services Research Programme, Contract No: MR4-0080-UK(CH). 


\section{CONTENTS}

\section{Page}

Preface

Chapter 1 The Referral Process 1

Chapter 2 The Measurement of Referrals 16

Facts about Referrals and Referral Behaviour 20

$\begin{array}{lll}\text { Chapter } 3 & \text { Background and Design of the Study } & 29\end{array}$

Study Protocol $\quad 32$

Chapter 4 Method Considerations 44

Chapter 5 International comparisons of 52

consulting and referral patterns
Analysis by healthcare structure

Chapter 6 Comparison between the Highest and Lowest 66 Groups of Referring Doctors

$\begin{array}{lll}\text { Chapter } 7 & \text { Conclusions } & 73\end{array}$

Chapter 8 Summary 80

$\begin{array}{ll}\text { Samenvatting } & 86\end{array}$

Acknowledgements $\quad 93$

$\begin{array}{lr}\text { References } & 95\end{array}$

Appendix:- National Data 102

UK 103

Belgium 111

Denmark 116

France $\quad 120$

DDR 123

FRG $\quad 126$

Hungary 131

Republic of Ireland 136

Italy 140

Netherlands $\quad 146$

Norway 153

Portugal 157

Spain 163

Switzerland 170

Yugoslavia $\quad 175$ 
This report presents the results of the European Study of Referrals from Primary to Secondary Care. This study has been the product of a long collaboration between members of the European General Practice Research Workshop - a group of general practitioners dedicated to promote research in primary care especially where concerned with national differences.

The report is laid out in a series of chapters. Chapter 1 commences with a brief introduction to the study and follows with a general consideration of the consultation and referral processes and the factors influencing them. National differences are considered which influence the interpretation of the data.

In Chapter 2 the problems of measuring the referral process are first considered. Thereafter, information is presented about some of the variables specifically related to the referral behaviour of individual doctors or groups of doctors. There is of necessity some overlap here with the more general overview of the referral process outlined in Chapter 1.

Chapters 3 and 4 are concerned with the background and protocol for the European Study. Chapter 5 presents an international comparison of some of the major resulta from this study. In Chapter 6, relevant information is extracted from the national material and represented in a way which allows comparison of some of the characteristics of doctors with high and low referral rates. The conclusions from the study are presented in Chapter 7 . A sumary is provided in both English and Dutch in Chapter 8 . The data for each country are presented with a commentary as an appendix. 
CHAPTER 1

THE REFERRAL PROCESS

INTRODUCTION

Research starts with curiosity, proceeds through a stage of distilling available information, moves on to define a hypothesis to be tested and concludes with a scientifically acceptable procedure for examining that hypothesis. All steps in this process are necessary. The definition of important hypotheses and the design of appropriate surveys are as important as the ultimate test.

The process of delivering medical care has evolved differently in the countries of Europe. Those differences include cultural differences in the expectations of patients; differences in function of doctors and related medical staff; differences in the availability of doctors ; differences in access to doctors in both primary and secondary care and ; differences in the way medical services are funded. Such differences are not undesirable. Some of them may be entirely appropriate to particular national circumstances. However, where differences exist, there are opportunities for learning. It is extremely unlikely that all potential benefits of a healthcare system are optimised within any one national system and equally unlikely that individual national systems cannot be improved by taking note of procedures in others. This study therefore sets out to examine one aspect of the delivery of healthcare - the referral from primary to secondary care, with the primary purpose of defining quantitatively the referral process. It has been conducted against the background of a European study of the Interface between Primary and Secondary Care (COMAC-USR, 1990) concerned particularly with the function of doctors working in primary care.

The referral variables measured are considered in relation to the following attributes of national health care structures:

1. Physician density - general practitioners;

2. Physician density - specialists;

3. Remuneration system - general practitioners;

4. Remuneration system - specialists;

5. Means of access to specialists;

6. Training systems for general practitioners.

The method of study is based on general practitioners. A study based on a population sample in each country might have provided additional information especially when considering referrals in relation to the means of access to specialists, but such a study presents considerable logistic problems and is very expensive. Operational research has to be conducted in data which can be obtained at acceptable cost. By using the indirect approach from the perspective of general practitioners, we were able to obtain 
good primary data from participating general practitioners at no cost, and at the same time were able to study characteristics of individual general practitioners in relation to their referral performance. These include the obvious variables of sex, age and type of practice etc., but also rather more subtle characteristics such as the doctor's workload and the extent to which his decisions were influenced by the patient. By examining these aspects within each national data set, the study shows the common ground in the various national data sets which is a powerful way of reaching truth.

A dimension of the referral process considered almost uniquely in this study as compared with other national surveys concerns the delay between referrals and specialist appointment. Differing methods of communication between general practitioners and specialists in the various countries influences the interpretation of the data to a small extent, but in this area of study, the referred patients are recruited virtually at random and therefore statistical tests of distribution could be applied with confidence. However, in reality, some of the differences were so large that statistical tests were redundant.

The European Referral Study for Primary to Secondary Care was based on 30 consecutive referrals made by individual general practitioners in 14 European countries. The general practitioners were mostly self selected, the patients recruited to the study were not. Information was provided about the doctor and his practice. Each act of referral was described in several ciinical and administrative details. The age and sex profile of patients consulting during the study period was obtained to provide a denominator for relevant measurements in the study but also used to provide valuable information about general practitioner consulting workload. The immediate objective of the study was to shed light on the referral process in European countries in order that both the process and the healthcare systems could be compared. The long term objective is the desire to explain variations in a way that might lead to the enhancement of the guality of medical care delivered to the population at large. The importance of the study stems partly from the realisation that both over referral and under referral may adversely affect the health of individuals but also because of the economic implications of the referral process. Healthcare is expensive and it is incumbent on us all to use healthcare resources efficiently.

\section{THE BOUNDARY BETWEEN PRIMARY AND SECONDARY CARE}

The act of referral from primary to secondary care is the essential focus of this report but its proper appreciation calls for a consideration of the entire medical consultation and referral process. The triangle of healthcare (Figure 1.1) conceptualised by Fry (1965) places general practice between self care and specialist care. 
Fig.1.1 THE TRIANGLE OF HEALTHCARE (Fry, 1965).

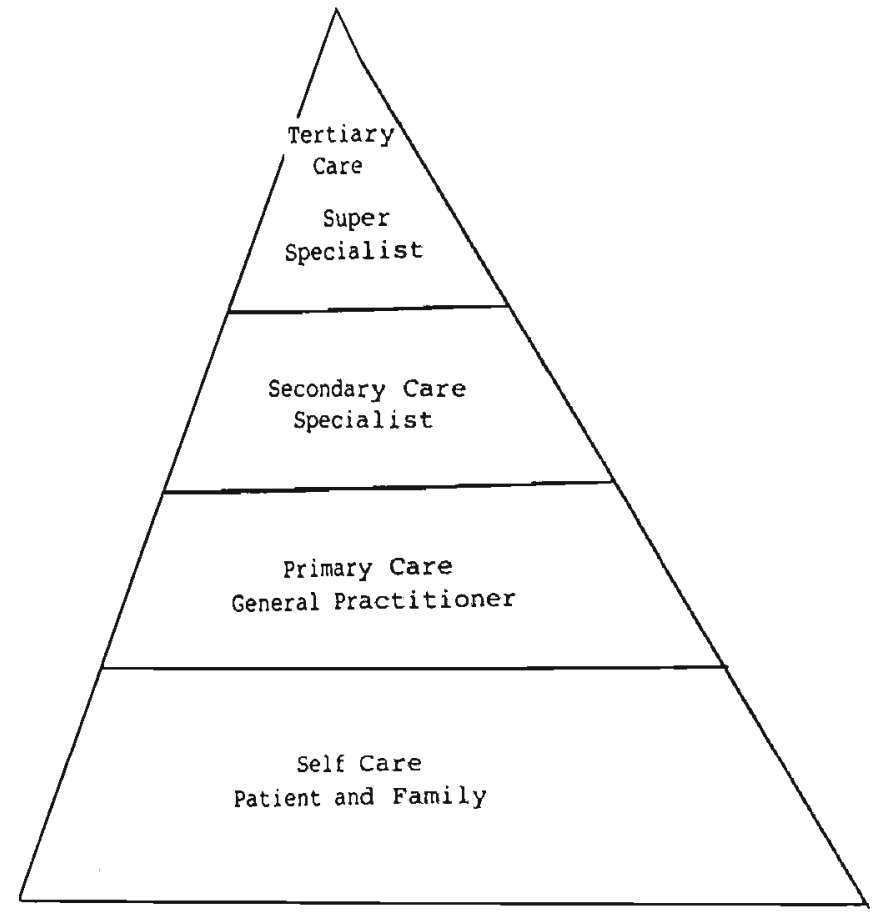

Fig. 1.2 THE DYNAMIC INTERFACE BETWEEN SELF CARE, GP CARE AND SPECIALIST CARE (After Horder, 1954)

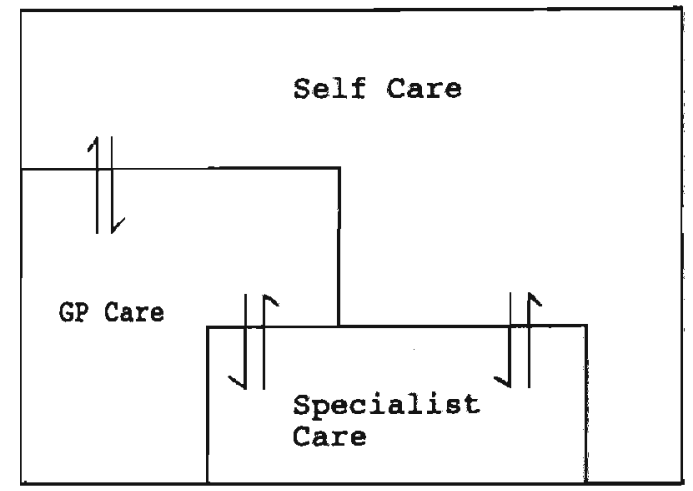

This model implies a rigidity of structure which may be a theoretical ideal but in reality it does not exist. A model 
closer to conventional practice (Figure 1.2) is based on that originally introduced by Eorder (1954) but includes two modifications. Firstly, Crombie (1975) dislodged the box of "specialist based care" away from its cocooned position as introduced by Horder to interface directly with the public as well as with general practice. The position and relative size of this "box" is one of the national variables, And secondly, Howie (1985) added the opposing arrows to draw attention to the dynamic nature of the boundaries between the sectors of care. The arrows are the forces that take people in and out of the various sectors and can be summarised under four headings - Demand/Need; Functional Division; Competence ; Resources. Though not mutually exclusive. these headings will be used in this Chapter as a framework to consider the issues relating to specialist referral.

The simplest framework which might have been considered involves the allocation of all relevant factors either to demand or supply sides, a division employed by van der zee(1982) in his examination of general practitioner services. Paterson (1959), offered a framework based on the general practitioner's reason for making referral. Aulbers (1985) elaborated on Paterson's structure to develop a model of clinical decision making. Anderson and Aday (1978) developed a model for quantitative examination of access to medical care in the USA. This model had three sequential components, the predisposition to use services, the ability to secure services and the patient's perceived need of services. These various models have been used to examine the referral process within a single healthcare system, within a practice or from a limited perspective. None leave room for the historical and cultural components in the evolution of healthcare services which are the product of a nation's perception of health matters but also are a major determinant of how they are accessed and used.

The axis of demand/need

"Traditionally, contact between patient and doctor is initiated by the patient. In this way the general practitioner is exposed to medical demand. His diagnostic role is concerned with relating demand to need, both for the individual consulting and for the total practice population. He must be prepared to seek out need which is not reflected by demand and where necessary control excessive demand." (Morrell et al, 1970).

The general practitioner is only involved with a relatively small proportion of total ill health. Many circumstances determine whether patients consult and no doubt the entire spectrum of patient attitudes will exist in each European country. Nevertheless, national statistics on healthcare utilisation rates demonstrate how differently the general practice services are used. In the Federal Republic of Germany, the BVAS study (Robra et al 1991), estimated that patients consulted their general practitioners with a frequency of about 13 times a year. Estimates given by the NCBS (1989) covering the years 1981 to 1983 were FRG 10, France 6 and USA 2. A comparable figure for the UK is 3.4 (Fleming, 1989), and for the Netherlands 3.2 (Boerma, 1992 -Personal communication). Even though some of these consultations are physician generated and in some cases reflect the working style of the general practitioner (Buygen et al 
1992), the extent of the disparity between the countries points more to fundamental differences in the healthcare system than to differences in morbidity. Even within individual countries, there is evidence of large differences in demand for intervention by general practitioners where the prevalence of morbidity in the population is similar. Using a recent example, Jones and Lydeard (1989) reported similar prevalence of dyspeptic symptoms among the population of Southampton but widely different practice consultation rates.

Demand for healthcare and the response of supply are not necessarily beneficial to individuals. Grol and his colleagues (RCGP, 1983) describe how somatic fixation builds up from a base of patient demand through inappropriate general practitioner response, exaggerated by excessive investigation. Demand is fuelled by the expectations of patients and thus health care professionals must try to ensure that these are appropriate and based on sound principles.

Demand is easily recognised but not so need. The issue is simple when considering persons with life threatening conditions but some people actually need professional support with minor conditions if they are to achieve a reasonable quality of life. Psychological problems particularly, may be viewed differently on the axis between demand and need. The distinction between demand and need has been neatly compartmentalised by Alderson and Dowie (1979) in relation to the appropriate use of health services (Figure 1.3).

Fig. 1.3 SCHEMATIC REPRESENTATION OF THE RELATIONSHIP BETWEEN NEED, DEMAND AND USE OF HEALTH SERVICES

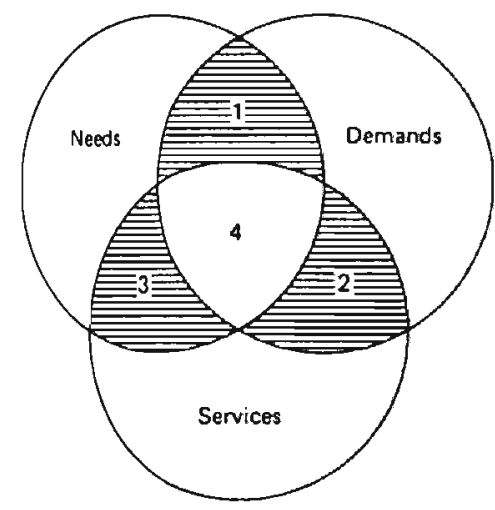

1. Need exists, demand expressed, no service available - Discontent

2.No real need, demand expressed, services available - Misuse

3. Need exists, no demand expressed, services available- Underuse

4. Need exists, demand expressed, services available - Correct use 
This model is concerned almost exclusively with demand and need in relation to individuals. Need is not necessarily defined in terms of the individual. Some of the most important needs of healthcare are related to communities. As an example, the concept of universal immunisation/vaccination in order to eradicate a disease involves an entire community and not just individuals concerned with their own welfare. Preventive medicine is concerned more with the needs of individuals and of communities but not with their demands. Medical care has changed direction during the last twenty years. Bitherto, patients consulted doctors of their own initiative whereas now it is incumbent upon doctors to seek opportunities for delivering healthcare. This attitude has received support by the British Department of Health in the provision of financial inducements for general practitioners to achieve certain standards of preventive care. While on occasions, need for care may be evident, patients may not make any demand. Particular symptoms may indicate the need for prompt medical care but their importance may go unrecognised and demand not made. Some patients consult other perhaps non medical persons; some deny need out of religious conviction; others deny need out of ignorance. The availability of alternative services of healthcare and the direct costs associated with obtaining these influences the extent to which patients consult (and need referral). The availability of osteopaths for example, will influence the extent to which persons consult general practitioners for back problems. Particular symptoms may indicate the need for prompt medical care but their importance may go unrecognised and demand is not made.

The relationship between demand and need, as well as having individual and community components, has a national norm which is a product of national culture, attitudes to healthcare and availability of services provided. The differing national relationships limit direct comparison of national statistics for referral.

\section{Functional Divisions}

By definition, the term general practitioner implies a capacity to do everything. Loudon and Stevens (1980) model the evolution of healthcare professionals over the last century from the mixture of educated gentlemen (the physicians of the 18th century) and the tradesmen (chemists and druggists) to the highly trained professionals of today (Fig.1.4).

\section{Fig.1.4 THE EVOLTUION OF THE GENERAL PRACTITIONER AND CONSULTANT}

\section{9th Century and before Present day}

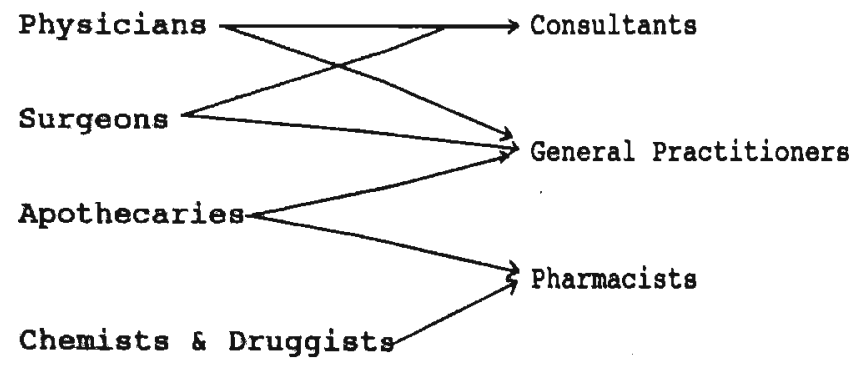


The model gives to the general practitioner the broadest pedigree with three sets of roots. Assuming the validity of this model in the other European countries, it is not surprising that there are national differences in general practitioner function which bear on the referral process.

In the Interface Study (COMAC-HSR, 1990), the functions of general practitioners in differing countries were evaluated using structured interviews conducted by a roving researcher. The study centred on a set of specific clinical situations and doctors in the various countries were asked to state how these were managed. Some examples of these differences include:-

- In Germany, Italy, Portugal and urban Denmark, general practitioners are not commonly involved in emergency medical work.

- In the Netherlands, general practitioners are more involved in domiciliary obstetrics than in any other European country. Also in the Netherlands, patients need to consult general practitioners to authorise refraction.

- In urban areas of Spain and in Italy, children are registered with paediatricians rather than general practitioners.

These differences reflecting the evolution of healthcare in the various countries make for difficulties in both the numerator and denominator when studying aspects of referral. Differences which impede direct comparison of referral rates. In the broader context of health utilisation studies, timescale provides a further complication. During the last ten years there have been many changes in the delivery of healthcare. In Spain, there has been considerable development of health centres in urban communities : in urban Denmark there has been a shift from an item of service system of remuneration to one based on capitation : In the United Kingdom there has been a change towards much greater financial accoountability of general practitioners : the political changes in Germany have resulted in the virtual collapse of the former Eastern system of delivering primary care : In Portugal there has been a notable increase in primary care services in rural communities.

Notwithstanding the differences between the functions of general practitioners both between countries and between times, there are also the differences amongst specialists and other medically related staff. Some of these relate to the important differences in access. In the United Kingdom at one extreme, access to primary healthcare in the National Heatlh Service is controlled by patient registration and access to secondary care almost completely controlled by referral from primary care. (This includes access to private specialists). France and Belgium at the other extreme allow complete freedon for the patient to choose to consult a family doctor or a specialist whenever he is ill. Between these two extremes there are a variety of arrangements.

In the Netherlands, patient registration is usual and access to secondary care largely controlled by general practitioners, but for persons treated outside the public insurance system, direct access to specialists is possible. In Denmark a syotem of patient 
registration exista for primary care but some specialista (e.g. dermatologistal, operate in primary care with open access to patients with skin problems.

Where specialists are available as primary care physicians with open access to patients, there will be a consequent impact on the distribution of health problems brought to the general practitioners and a knock-on effect on his referral pattern. By the same token, these specialists are likely to be less specialist in function consulted by a comparatively unsorted group of sick patients. At the minimum, the filtering effect of referral ensures that patients arrive at an appropriate specielist department and patients with less severe illness are excluded.

The Alma Ata Declaration (WHO, 1978), emphasise the fundamental role of primary healthcare in moving towards the goal of equality of health (or at least of healthcare). Today's national differences are not compatible with that goal, though it would be foolish to consider movement towards this objective without considering all the other related facts, especially those concerned with differences in medical manpower.

\section{Competence}

"Competence defines what a doctor is capable of, whereas performance is concerned simply with what he does", (Senior, 1976).

The competence of the doctor consulted is of course highly relevant to the referral process. It is necessary not only to consider his actual competence, but also his perceived competence. At the extreme, a patient may not consult if he believes the doctor is not competent to deal with his problem or, if he consults, may demand referral believing his problem calls for more specialist attention. Attitudes change with time (Cartwright and Anderson, 1981) and so does competence. Competence is the product of training and experience. Modern training for general practice in countries such as the Netherlands and the United Kingdom, includes the conventional academic training, experience in a range of junior hospital specialty posts, an apprenticeship in general practice and a continuing programme of educational activities, some of which provide additional specific qualifications. Since training opportunities in some countries are much more limited, so also is the competence of the general practitioner.

Specialisation has always involved extended training and this applies in all countries. The status as specialist implies a degree of competence greater than that of generalist. In some countries, the description "specialist in general practice" (for example Switzerland, Yugoslavia), is used to distinguish those doctors who have undertaken the programe of training for the purpose.

There are legal issues surrounding judgements of competence (Jost, 1990). In the eyes of many doctors, these have been an overhanging cloud influencing the way they practice (perform). Performance has to be seen in relation to competence appropriate to function. A neurologist is more competent and would be 
expected to perform at a higher level than a general practitioner in the management of a neurological problem but the decision to refer reflects on the competence of the general practitioner.

A number of studies in the referral process have involved examination of the reason for referral. One of those commonly identified is the need for reassurance. A study in the Dutch Sentinel practices (Gloerich et al, 1989) identified that 5.6\% of active referrals (2.58 of active and passive referrals combined) were generated because of the need for reasgurance. Coulter et al (1989) reported a study from oxford in which 1.88 of referrals were occasioned by the need for reassurance of the general practitioner and 2.88 for reassurance of the patients. Grace and Armstrong (1986) looked in more detail at the reason for referrals as assessed by patients, general practitioners and consultants. In less than $10 \%$ of all referrals, reassurance was given as the reason in all three evaluations. In the Dutch study, referrals for reassurance were more frequent in solo than partership practice (Gloerich et al, 1989).

There is a danger in the interpretation of data about referral both for reassurance (especially for reassurance of the general practitioner) and for further investigation which can easily become confused with issues related to competence. Referral for reassurance may be an expensive indulgence for a perguasive patient rather than anything to do with either the competence or the performance of the general practitioner. A referral for further investigation will favourably reflect on the competence if that further investigation was necessary and outside the general practitioner's control. If these conditions are not fulfilled, the opposite is implied. Studies involving conaideration of relative proportions of patients in these categories inform little about competence but more about consultation style.

Regardless of the difficulties of reassuring a small minority of patients, the approbation of one's peers is an instinctive need (Darwin, 1874) and thus, one might anticipate general practitioners actively seeking reassurance for their actions. John Fox (1985) quite specifically includes patient anxiety about disease as a reason for referral, contrasting with the general tenor of Grol's thesis about somatic fixation. Nevertheless, it has to be recognised that whether or not competence is questioned, it is very difficult to manage some patients without referral for reassurance.

In the study reported here, performance is measured and not competence, though competence remains an essential element of the boundary between primary and secondary care.

\section{Resources}

"...the main constraints on health care are now more financial than medical or technical, and the separation of clinical judgement from financial responsibility will soon end". (Appleby 1987).

There is a prevailing attitude that general practitioners are wasteful of resources in the way they initiate referrals (Todd, 1972, Marinker et al, 1988). Certainly, the general practitioner 
as the first physician to see the patient, has a particularly important role in determining management and therefore in determining how much money is spent (White, 1989). A perspective of the cost generated in providing healthcare for 2000 persons in 1987 is presented in Table 1.1. (The average general practitioner in the United Kingdom looks after approximately 2000 persons.) It is easily forgotten that the costs generated in secondary care are five times those in prescribing, though there is no implication here that the general practitioner has more than a very limited control of either field of expenditure.

TABLE 1.1 HEALTH COSTS PER 2000 PERSONS - UK (1987)

$\begin{array}{lr}\text { Hospital Sector (588) } & 500,000 \\ \text { Community Health (6.48) } & 55,000\end{array}$

Family Practitioner Committees (22.88)

Pharmaceutical Services 91,000

General Medical Services 66,000

General Dental Services 37,000

Ophthalmic Services 6,000

200,000

Others

TOTAL $\quad \frac{110,000}{865,000}$

( $\$ 432$ per capita)

Source: Compendium of Health Statistics,OHE 1987.

Although the term "resources" implies a concern for financial matters, there are other factors which are equaliy relevant to the provision of healthcare.

Manpower: - The critical resource is the number of available doctors and their relative distribution as between primary and secondary care.

"...efforts to micromanage the doctor-patient relationship and teach physicians to practice cost effective care, do not really address the issue of capacity. In a market with an increasing supply of resources and particularly of physicians themselves, one should not under estimate the ability of physicians to come up with new ideas." (Wennberg, 1990).

In Table 1.2, data are assembled from a number of Western European countries illustrating the marked differences with regard to physician supply. 


$\begin{array}{lcccc} & \begin{array}{c}\text { Population } \\ \text { (m) }\end{array} & \begin{array}{c}\text { Active } \\ \text { general } \\ \text { practitioners }\end{array} & \begin{array}{c}\text { All } \\ \text { doctors }\end{array} & \begin{array}{c}\text { General } \\ \text { practitioners } \\ \text { all doctors }\end{array} \\ \text { Belgium } & 9.8 & 163 & 357 & 46 \\ \text { Denmark } & 5.1 & 67 & 268 & 25 \\ \text { France } & 51.0 & 102 & 222 & 46 \\ \text { Germany(DDR) } & 16.5 & 127 & 252 & 50 \\ \text { Germany(FRG) } & 61.1 & 49 & 290 & 20 \\ \text { Hungary } & 10.6 & 78 & 331 & 24 \\ \text { Repub. of Ireland } & 3.5 & 63 & 149 & 42 \\ \text { Italy } & 57.0 & 102 & 388 & 26 \\ \text { Netherlands } & 14.7 & 43 & 235 & 18 \\ \text { Norway } & 4.2 & 66 & 230 & 29 \\ \text { Portugal } & 10.3 & 61 & 274 & 23 \\ \text { Spain } & 39.0 & 50 & 336 & 15 \\ \text { Switzerland } & 6.6 & 58 & 171 & 34 \\ \text { United Ringdom } & 56.9 & 54 & 130 & 42 \\ \text { Yugoslavia } & 23.1 & 70 & 166 & 42\end{array}$

Source: CSDM (1987) supplemented by information from NIVEL

The table includes information about the national population, the numbers of general practitioners and of all doctors. Though the contents of this table will be discussed in more detail later, it is sufficient to report here that the mere existence of such differences in manpower resources means of necessity, a competition for work. If we assume that persons in each European country have approximately equal health status and therefore equal health needs, the main differences between the differing countries will relate to the interaction between patient demand and physician supply. Equally relevant are the large differences in hospital bed provision with all the attendant manpower resource implications. Some of these are illustrated in Table 1.3 with recognition of the year on which the data are based.

TABLE 1.3 - INPATIENT MEDICAL BEDS PER 1000 POPULATION (RECENT YEAR SPECIFIED)

$\begin{array}{lrc}\text { Belgium } & 9.5 & (82) \\ \text { Denmark } & 7.4 & (83) \\ \text { France } & 11.6 & (83) \\ \text { Germany (FRG) } & 11.1 & (82) \\ \text { Ireland } & 9.7 & (80) \\ \text { Italy } & 7.7 & (83) \\ \text { Netherlands } & 12.0 & (83) \\ \text { Norway } & 6.5 & (83) \\ \text { Portugal } & 5.1 & (82) \\ \text { Spain } & 5.4 & (81) \\ \text { Switzerland } & 11.5 & (82) \\ \text { United Kingdom } & 8.1 & (81)\end{array}$

Source: Measuring Healthcare 1960-1983, OECD, 1987. 
Investiqation facilities:- Thirty years ago, a general practitioner in the United kingdom could not request a haemoglobin level, a blood urea or a urine culture without referral to a specialist. This is no longer the case and most general practitioners in the United Kingdom have access to good pathology services, but there remain substantial differences in the access to endoscopy services and to the newer radiological procedures. Differential access to facilities for investigating patients directly influences both the extent to which general practitioners investigate patients and the extent to which they refer patients to specialists in order that these investigations can be undertaken. Major national differences in the provision of facilities or in the funding arrangements for investigating patients in primary care must be recognised when making international comparisons of performance in relation to specialist referrals.

Training:- This issue was discussed earlier under the heading "Competence", but it is included here, emphasising the resource implication. If training facilities do not exist for general practitioners to acquire the necessary skills to fit intrauterine contraceptive devices (as an example), then persons requiring this method of contraception will have to be referred to secondary care.

Financial Resources:- There are considerable differences in the expenditure on health and therefore availability of money for competing health priorities between the different countries (Figure 1.5).

FIg. 1.5 HEALTH SPENDING PER HEAD OF POPULATION IN SELECTED OECD COUNTRIES, 1977 and 1984 (Source OHE, 1987).

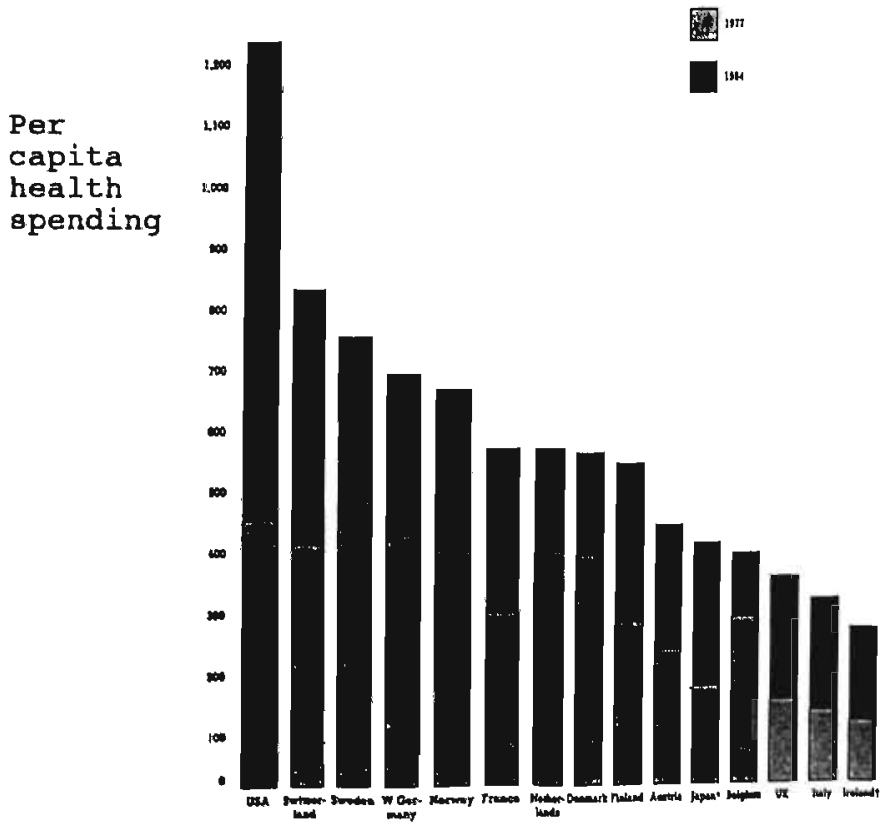


There are also differences in the increasing rates of expenditure (compare France and the Netherlands in this figure). Although there are some differences in rank ordering when expenditure is regrouped and presented as a percentage of gross national product, it is evident that expenditure in the Federal Republic of Germany is 508 greater than in the United Kingdom (1984). Increasing costs are maximal in hospital based care (OECD, 1987). In the mid $1980 \mathrm{~s}$ in the United Kingdom, hospital based expenditure accounted for 608 of all healthcare expenditure. Though the cost of general medical services (essentially the cost of organising and delivering healthcare through a network of family doctors) has increased substantially since the mid 1970s, it has remained roughly constant as a proportion of total health service costs (approximately 78). The same can be said for expenditure on pharmaceutical services (mainly general practitioner prescribing) accounting for approximately 88 of total health service cost.

Expenditure in secondary care, is strongly influenced by what is referred from primary care. Reporting from the Second National Morbidity Survey in the United Kingdom (Crombie \& Fleming, 1988a) drew attention to the enormous differences in costs implicit in the wide variation that existed in general practitioner referral rates. For this comparison, it was necessary to make the rather simplistic assumption that there was such a thing as a unit cost of referral and that a doctor referring four patients would necessarily generate four times the costs of a doctor referring only one. This is not necessarily the case, because the doctor referring only one case may actually refer the only high expenditure case in the series. Until better data are available, the proposition that costs relate directly to numbers referred must be assumed. Ross and colleagues (1983) in a study in North Staffordshire(England) involving orthopaedic referrals, found similar proportions of patients referred for surgery and physiotherapy regardless of whether the general practitioner referred few or many patients. In the introductory paragraphs of the report from the OECD (1987) covering the finance and delivery of health care, numerous examples are given of surgical procedures being undertaken with markedly different frequencies without good evidence of differing prevalence of morbidity. Wennberg (1990) estimated that the medical resources available in Boston hospitals were sufficient to meet the needs of a city twice that size.

In the United Kingdom, general practitioners are now required to monitor referrals and primary care is moving towards a system of accountability, with general practitioners responsible for a specific budget. Though there remain problems as to how that budget is to be calculated (based on previous practice experience, national norms, or local estimates of morbidity prevalence), the fundamental principle of accountability effectively excludes the "unnecessary referral". From an economist's viewpoint, it is an appropriate and desirable objective, but no one makes the correct decision every time and there is a danger from a mistaken diagnosis leading to a consequent failure to refer and an endpoint of litigation.

It is implicit in the discussion so far, that resources are met from some central or state funds and perhaps resources put into healthcare by private individuals, either through insurance or by direct payment, should not be included. One man may prefer to 
spend his money on a fast motor car or expensive holiday, why should not another spend it on buying privileged healthcare? The availability of independent access to healthcare, even at personal cost, is perhaps the greatest stimulus to the provision of a good service in the insured or state sectors. However, few would have said that during a period of food rationing, persons should be entitled to use additional money to buy food essentials and thereby circumvent the principle of rationing. Whilst this is not an argument for denying the option to purchase additional facilities such as the use of a private bedroom or bathroom whilst in hospital, it is an argument that essential health needs must be met on an equal basis, whether persons are able to pay independently or not. The costs of training medical students, and the capital costs of universities and teaching hospitals are met from national funds and these are critical to the development of health services in a country.

The equitable distribution of resources, appropriate and necessary rationing procedures and an establishment to deliver these are essential to the effective government of a democratic state. Comprehensive examination of the referral process must include examination of all these elements. On the structural side, the means whereby a nation controls and allocates resources, and the way in which it legislates for universal provision of healthcare are all part of the framework for comparison.

Financial Management: In the foregoing there has been a concentration on the total resources available for healthcare. Equally important is the way in which the finances are distributed, a matter which has been comprehensively reviewed in Western Europe very recently by Groenewegen and colleagues, (1991). In the Netherlands and the United Kingdom, general practitioners are remunerated chiefly by capitation through a National Health system. In France, patients are reimbursed to agreed amounts for the general practitioners' fees in respect of consultation and treatment. In Germany the principle of reimbursement is similar but the details are extended to cover each item of service. As this report makes clear however the level and method of remuneration are only part of the picture. The arrangements for ancillary services, the necessity for patient co-payments, the relationship between general practitioners and specialist remuneration, the provision of pensions, the taxation structure are all relevant and bear on both the motivation and performance of doctors. In general, high density of general practitioners per population and relative restriction of the general practitioner's function, are associated with reduced income for the general practitioners.

Patient referral can be pressurised by the arrangements made for reimbursement. The new system of accountability in the United Kingdom can militate against referral in borderline cases. In circumstances where there is keen competition to attract patients (e.g. Italy and in parts of Germany), doctors are anxious to please patients and thus more likely to acceed to patient demand. Within the national health care system of some countries, specialists are paid almost exclusively by salary (for example, United Kingdom and portugal). In others, an item of service structure predominates (Denmark and the Netherlands). The mix of private and national health care with corresponding fee for service and salary payment structures results in a mixed 
remuneration system for specialists in FRG, Ireland, Italy and Spain. This classification of specialist remuneration will be used later in the context of national comparisons.

The subtle pressure imposed on us all by the direct relationship between work done and reward gained makes it inevitable that remuneration arrangements will influence the work done. Though theoreticaliy it should not influence the numbers referred to specialists if these were based exclusively on need, it is easy to see how personal relationships, willingness to see patients urgently and a welcoming approach to patients referred, would be influenced by an item of service payment structure and hence influence the extent to which patients are referred in the first place.

Structural resources: Matters concerning the financing of health services and the remuneration of doctors have been considered but there is also the physical structure of health facilities. In the Interface Study (COMAC-HSR, 1990) a detailed account was given of the place of work of both general practitioners and specialists in the European countries. In Bungary, doctors work in large clinics and facilities for patients to consult general practitioners exist alongside those for consulting specialists. This intimate working relationship is very different from that in France for example where general practitioners may tell patients to go and see a specialist and perhaps not even make any formal referral arrangement. Here both the general practitioners and specialists would be working in quite independent premises which they finance personally. In the United Kingdom, some general practitioners work in their own private premises and others in state financed health centres; specialists mainly work in hospitals, where several may be working in the same place at any one time. The working arrangement for specialists lends itself to cross referral between specialists. Both Crombie (Birmingham Research Unit/RCGP,1977) and Dowie (1983) considered that as many as half of all referrals in the United Kingdom were from one specialist to another rather than from the general practitioner.

\section{SUMMARY}

The purpose of this chapter has been to provide an overview of factors relating to a study of the referral process in differing countries. It has not been the intention simply to generate lists of variables that are known to be associated with referrals in individual countries but to try and bring to the fore those factors which are germane to the proper interpretation of the data available about national differences.

The framework chosen of the four driving forces at the boundary between primary and secondary care may present the issues in a different way to that seen in other studies but focusses on those areas where there are indeed national differences. It allows the presentation of the variables in a context that is not dissimilar to the referral process itself starting with the patient (demand/need) moving to the general practitioner (functional divisions) and to the specialist (competence) and finally health service administration (resources).

This overview presents a broad perspective of the consultation and referral process and is not confined to the variables considered in this study. 
Many statistics are used to describe referrals, but insufficient attention is given to the appropriateness of the statistic and its definition. Consider the example of a man referred to an outpatient specialist clinic with urinary problems. After assessment, the specialist decides he needs a prostate operation and places him on a surgical waiting list. Before he is admitted for planned surgery, he develops acute retention of urine and is referred as an emergency for hospital admission. Is that one or two referrals? Suppose the emergency admission was to a different hospital and under the responsibility of a different specialist than the one seen first. Does this make a difference in how referrals should be counted? Suppose as a result of the patient's general condition, the urologist requested the opinion of a cardiologist before undertaking surgery. Is that another referral? This example is given to illustrate the need for better definitions. National statistics for hospital activity in the United Kingdom are gathered from data in which there is no patient linkage and therefore events are counted. In this example, there is one man and referral to two or three specialist departments, (depending whether the admission was to the same surgeon/hospital as the initial outpatient referral).

\section{REFERRAI PERSPECTIVES}

An appropriate measurement depends on the purpose for which information is needed. The referral process can be examined from three perspectives: the individual patient and the event of referral; the general practitioner or practice who largely control access to secondary care and $i$ the health service managers who determine resource allocation to meet the needs of patients entering secondary care. For the individual patient; the underlying reason for referral, the expectations of both patient and doctor, and the appropriateness of the referral action are all important. From the general practice perspective, the explanation for the widely variable referral rates with special reference to practice determined variables is of major importance and, for the health administrator, demographic and epidemiological information are required.

\section{REFERRAL NUMERATORS}

The basic statistic for providing information about referrals must be the person referred. In routine national statistics, about referrals in the United Kingdom, the only source of person specific information is the general practice based morbidity surveys covering England and Wales. Even here, there is no linkage with hospital data concerning patients who attend Accident and Emergency departments following self referral, nor is this information source sufficient to monitor subsequent onward referral from one specialist to another. These so called secondary referrals were estimated by the Birmingham Research Unit (1977) to account for approximately half of all hospital 
referrals. A similar figure was reported from Dowie's studies of general practitioners and consultants (1983). The reliability of the recording of referrals within the practices recruited to the morbidity surveys of England and Wales has been challenged (RCGP et al, 1986). It was estimated that between $10 \%$ and $15 \%$ of referrals were not entered by participating doctors. Similar under scoring occurred in the Dutch Survey (Gloerich et al 1989) which, incidentally, also provided person specific data.

Because of the difficulty for maintaining information systems with patient linkage, most referral data are concerned with counts of referrals as events and not with counts of persons. Using morbidity survey data from 1972, these two methods of counting were compared (Fleming et al, 1991a). In this study there were 18,325 persons referred to outpatient departmenta, 87.58 of whom were referred on only one occasion. The minority (12.58) for whom additional referrals were made by the general practitioner, were distributed uniformly between the practices and thus had little differential impact on practice rank orders whichever statistic was used for examining practice referral rates. Thus for practical purposes where practice referral activity is under consideration, it does not matter which statistic is chosen. However, if abuse of health services is to be detected, it is necessary to define those persons (or groups of persons) who are especially high users of services.

There is also the distinction between first and subsequent referrals. The first referral for a problem is clearly the most important but administrative requirements may generate a need for a subsequent referral. A person may, for example, be referred a second time because of failure to make progress after an initial referral. He also may need to be re-referred simply to satiofy an administrative procedure authorising an extension of a referral period. Though this is not the case in the united Kingdom, the concept of referrals for a specified period of time is widespread in mainland Europe and notably includes The Netherlands, Switzerland, the Federal Republic of Germany and Italy. The general practitioner in many countries also authorises secondary care in some circumstances in which he may not be very closely involved. The passive referral in the Netherlands which includes a large number of referrals for refraction provides an example. However, the principle of authorised referral is carried to an extreme in the Federal Republic of Germany where the general practitioners authorise as many referrals as they initiate following consultation. These national differences provide problems when interpreting data, but equally, they point to the fact that a simple person count without more detailed information about the referral is rarely sufficient for any but the most superficial examination of the referral process.

\section{REFERRAL DENOMINATORS}

Given an agreed numerator for counting referrals, a denominator is needed for expressing rates. Ideally, numerator and denominator should be in the same "currency" - e.g. persons or like events. In both the United Kingdom and the Netherlands, general practitioners care for defined populations and it is therefore possible to express referred persons as a percentage 
of the total population surveyed. If there is no defined patient list and patient access to different practices is readily available, it is almost impossible to define the proportion of patients referred to specialist care. In the United Kingdom, the population registered is only valuable when examining data relevant to an entire practice, because patients commonly see members of the practice partnership other than the nominally registered partner. Other denominators include consultations and persons consulting. In the third morbidity survey (RCGP et al, $1986), 718$ of all registered patients consulted during the study year and on average each of those consulted 4.78 times (equivalent to 3.40 per 1000 population). In studies of practice variability, much greater consistency has been found in the proportion of patients who consult than the frequency with which they consult. In Table 2.1, the median value and the values ranked 5 th and 55 th out of the total of 60 practices are presented for a number of consulting statistics.

TABLE 2.1 - Consulting statistics from the Third General Practice Morbidity study in England and Wales showing the extent of variation between practices

5th ranked Median 55th ranked

Persons consulting

8 of population

Conaultations per person registered

Consultations per person consulting

Persons consulting is theoretically a preferable denominator to registered list because there is always some degree of list inflation in practices and because a doctor has no opportunity to refer a non consulting patient. Persons consulting is also theoretically a more precise denominator for examining practice referral rates. In a study comparing practice referred person rates using registered persons and persons consulting as denominators, there were very few differences in the rank ordering of the practices (Fleming et al, 199la). Given that the registered list is much more readily available than persons consulting, there would not appear to be sufficient justification for recommending the use of persons consulting as a denominator since it is a much more difficult statistic to collect. It is also inappropriate to use persons consulting as a denominator for examining referral activity of individual doctors working in partnerships.

The most practical denominator for expressing individual general practitioner referral rates is the consultation, but when interpreting data about an activity, it is essential that the variability in consultation frequency is considered. Using individual practice data from the Second Morbidity Survey, some practices were ranked differently using consultations as denominator compared with registered patients or with persons consulting, but there were no examples where a high referrer based on consultations as the denominator was a low referrer based on the other two denominators (or vice versa). Roland et al (1990) when considering similar issues also concluded that 
there was no logical alternative to use of consultations as the denominator for examining individual doctor referral rates.

A simple count of referred persons or referrals may be the most basic statistic to compare referral rates but there are many other factors describing the referral which will be dealt with later. Similarly, a denominator of total persons or consultations is also a rather basic statistic and for most analyses of the referral process, more information is required. At the least, information is needed about the age and sex composition of consultations. In the absence of such information, it is impossible to make comparisons between practices or doctors who may be providing care for different populations. For example, female doctors generally see more female patients than their male colleagues: doctors working in the resorts of the south coast of the U. K. care for relatively more elderly persons than doctors in other parts of the country.

\section{DISTRIBUTIONS}

Referrals can also be examined as distributions grouped by specialty. It is difficult to interpret information from studies based on individual practices using distributions in this way, because of the differences in practice populationg. However, in large regional studies where it is reasonable to assume that data are available for representative practices or populations, much can be inferred from comparisons of distributions. Though there are some differences in the prevalence of morbidity in different regions of the United Kingdom, they are small compared with the differences in healthcare introduced by doctors. Hence differing distributions can inform about bias in healthcare in a region, especially if there is cause for concern established from other sources. The point is important because it is much more economical to obtain data simply about the numerator (referred persons) than the denominator which is obviously concerned with all persons. One must be careful however, to avoid looking at distributions that are not person based. A distribution of outpatient attendances as opposed to persong attending outpatient departments, presented without complementary data is too skewed by differing patterns of attendance to provide firm information about referral processes.

\section{SAMPLING}

Finally, it is also necessary to consider sample size and sampling methods. More will be said later in the context of this particular study but it is sufficient to stress here that sample size must be related to the unit of analysis. Samples for the analysis of individual doctor performance must mean a sufficient sample produced by each doctor. Population based samples must be recruited from representative populations. Referrals must be sampled over an adequate time span and examined over a range of seasons to deal with the effects of seasonal variation in the incidence of disease. The same restraints apply to each specialty within the total of all referrals.

It is also important to recognise that where outcome differences between samples are immeasurably small, other differences may remain important. For example, there may be no differences in outcome attributable to referral rates but the financial implications of widely differing referral rates remain. 


\section{FACTS ABOUT REFERRALS AND REFERRAL BEHAVIOUR}

In this section, information will be brought together about those factors which have been examined in relation to the referral process. The subject has been widely studied and there are numerous publications. Here however, efforts will be concentrated on identifying the positive findings from referral studies rather than with detailed discussion especially of negative material. The subject will be examined from the perspectives outlined earlier - the patient and act of referral ; the doctor and practice; and the health service management perspective especially concerned with demographic information. Though the three perspectives are not operationally separate, they provide a framework for the issues to be discussed even if some points made apply equally to other sections defined in this way.

\section{PATIENT AND ACT OF REFERRAL}

Major aims of the study reported here have not been particularly concerned with qualitative aspects of the referral process, except for the measurement of the perceived influence of the patient on the referral decision. With that exception, qualitative aspects of the referral process are not considered in detail, especially so since these have been comprehensively summarised by Wilkin and Dornan (1990) in the United Rindom and by Gloerich et al, (1989), in the Netherlands.

Decision making- The referral decision has been studied by a number of researchers, but intensive study of individual events can only be undertaken in individual practice settings and it is difficult to extrapolate from these results. Nevertheless, the concept of an individual general practitioner threshold for referral first proposed by Morrell et al (1971), and further advanced by Cummins et al (1981), though rather a refuge for concealing our ignorance has never been contradicted. Such a threshold may reflect the unique weighting that each doctor applies to such intangible issues as the fear of making a mistake, the desire to please a patient, or the academic challenge of leaving no stone unturned.

The influence of the patient on the referral decision:Cartwright and Anderson (1981) studied the opinions of patients, general practitioners and specialists on the perceived influence of the patient on the referral decision. The results were contradictory. In some cases, the patients thought they influenced the general practitioners' decisions while the general practitioners thought they made the decision without being influenced particularly. The common ground was the fact that the referral decision was often the result of patient/doctor interaction and not of clinical problem/doctor interaction. Grace and Armstrong $(1986)$, also examined the perception of patients, general practitioners and consultants on the necessity and suitability of referral. They found little agreement between the three parties.

In a more recent paper, Armatrong et al (1991) also examined patient influence on the referral process gathering the doctor's opinion about the referral consultation. They concluded that 398 
of referrals from a large group of practices in the South East Thames area of England recording for a one week period, were perceived to be influenced by patient pressure. The authors went on to examine the influence of patient pressure as between groups of high referring and low referring doctors. They concluded that patient influence was a discriminating factor when comparing high and low referrers. However, the study could be criticised becaune of the very short recording period in which doctors were defined in the low referring category and because of the lack of validation of the recording procedures in individual practices. Gloerich et al (1989) observed that general practitioners who were more inclined to share responsibility with patients refer less for reassurance and for diagnosis, which though not quite the same thing as the perceived influence of the patient on the referral decision, is related to it.

Reason for referral:- The reasons for referral, whether for further treatment not available in primary care, for more specialist attention because of the gravity of the illness, or simply for reassurance have been the subject of several studies. These also are generally conducted in a small number of practices and generalisation from the findings is difficult because of the uniqueness of the circumstances in each practice and each referral decision. Factors such as local professional relationships, specific medical interests, access to investigation facilities, all have a bearing on the results. Gloerich et al (1991), studied the reasons for referral and showed differing degrees of explained variance among doctor/practice characteristics when compared by reason. Grace and Armstrong $(1986)$, examined the reasons for referral to hospital from the three perspectives referred to above and though there was little agreement in individual cases, it was surprising that the reasons were perceived in approximately equal proportions by all three parties.

Choice of specialist:- Two issues are relevant. Firstly, how the general practitioners choose a specialist and secondly, how much does the availability of certain specialists influence the referral decision? Roland and Morris (1988), discussed the influence of the availability of consultants on local general practice referrals and considered it a relevant parameter. In North America, the availability of a large number of specialists not only increases local referrals but also very substantially increases interventions. The impact of new hospitals in an area with the introduction of new specialists (Noone et al, 1989), has also been examined. However, these reports have not touched on the importance of the personal relationship between the specific general practitioners and specialists involved. Dowie (1983) studying general practitioner opinions on referral behaviour considered this factor important. The issue of choice is particularly significant in an international survey since in some countries (e.g. Norway, Spain and several East European countries), choice of specialist is not available in the national system of referral. Referral in these countries is to a specialist department and the general practitioner (much less the patient, ) has no say in the choice of specialist. Intuitively, the degree of mutual respect between a general practitioner and a specialist must influence behaviour and this is essentially a relationship between individuals and not between practices and hospital departments. 
Communication in referral:- Communication between general practitioners and specialists (and vice versa), is both to inform and to educate. Communication is usually by letter in each direction and thus by anonymisation and photocopying, there is a readily available instrument for analysis. Referral letters from primary to secondary care have commonly been analysed to expose deficiencies, but the definition of deficiency is quite arbitrary. It could indeed be argued that verbosity and excessive detail rather than enhancing the referral is more likely to harm it. The relevant facts for many referrals can be reduced to very few lines of text.

The major problem for communication studies however, is the capacity to write an impressive highly informative letter about an inappropriate referral, or perhaps, a referral to an inappropriate specialist. Inter personal relationships between general practitioners and specialists should encourage the use of well written letters, but patient care may have nothing to do with this. For this reason, the prospect of judging the quality of referrals according to the letters written seems to be a nonstarter. Hull and Westerman (1986), in a comparative study of referral letters in Birmingham and Amsterdam drew out some differences between the structure of the letters, but the step between that structure and either the quality of referral or the quality of care delivered, is difficuit to take. Nonetheless, studies in communication are likely to improve the referral process and certainly the commonly held viewpoint that a general practitioner should specifically state the reason for his referral, has come to the fore out of studies of referral letters.

Computerisation in practices has introduced a move towards a standardised referral letter and attempts are being made to define a minimum data set appropriate for the purpose. There is however, a widespread dislike of standardised letters which tend to undermine personal relationships between patients and general practitioners and between general practitioners and specialists.

Delays:- The study reported here contains a lot of information about delays in the referral process. Three potential delays are considered - the interval between referral and specialist appointment, the interval between specialist appointment and communication with the general practitioner, and the interval between specialist appointment and definitive surgery (where appropriate). Delays in receiving outpatient appointments and for definitive surgery are well known to be particularly long in the United Kingdom. There are however, three further delays which are highly important to optimal healthcare. There is first the delay between the onset of an illness and the patient's appreciation of the need for professional help; secondly, there is the delay between patients seeking help and general practitioners providing it; and thirdly, there is the additional delay between the first consultation with the general practitioner and subsequent specialist referral. There is a lot of published material in relation to acute myocardial infarction in which immediate delays are quantified, though these delays are not particularly relevant to the study reported here. Delays between the recognition of clinical symptoms and referral by the general practitioner have been reported as a way of measuring the quality of medical care (Stower, 1988). 
Failed appointments:- Failed appointments are wasteful of resources. The study reported here includes estimates of failed appointments. It is common for doctors to think only of the wastefulness by patients who do this. Frankel et al (1989), in a study of failed appointments concluded that client factors were less important than aspects of the service in explaining nonattendance at outpatient appointments. All illnesses have the potential to remit spontaneously and where patients have a long wait for appointments, it is not surprising that some patients consider they no longer need advice.

Outcome of referral:- In the interest of comprehensiveneas, outcome is included within this section. The study reported here is not concerned with the outcome of referral. A detailed resume of outcome studies is available in Wilkin and Dornan (1990).

There are several difficulties concerning good outcome studies. In particular, there is a problem of first defining the input (Crombie and Fleming, 1988b) and ensuring that comparisons between groups (however defined), are also comparable at the stage of input. Reference has been made to a study of orthopaedic referrals (Ross et al 1987) which in a sense, addressed the issue the opposite way round. These authors reported similar outcome (surgical intervention and courses of physiotherapy) among groups of patients whether referred from high or low referring practices. It may be possible to describe the outcome of referral for a specific subgroup of patients $(e . g$. patients with back problems (Coulter et al, 1991), but it is difficult to interpret the findings from the perspective of a service general practitioner who may refer such cases excessively by comparison with his colleagues or only in extreme circumstances.

Quality:- A popular English television comedian has used the catchphrase "Never mind the quality, feel the width". Nothing could more simply summarise the endeavours of so many medical researchers (including myself) in tackling the problem of quality in medical care. The concept of quality has so many subjective components including those which are patient determined, those general practitioner determined and those specialist determined, that we give up and try to measure the width instead.

The yardstick by which quality must be judged is peer performance (Crombie \& Fleming, 1983). That is not to say that peer performance is necessarily the ideal but it is the consensus and is derived from objective scientific measurements interpreted by individual professional and skilled persons responding to the pressures of demand (though, very unfortunately not necessarily need). In so many circumstances doctors, either as individuals, or as members of a group (partners, academic colleagues, etc), may feel part of an intellectually superior viewpoint about quality. Some may marshall their arguments better than others. However, there is such a large subjective component in the definition of quality that the consensus is the only realistic yardstick whereby it can be assessed. Though the definition of quality might determine the desirable direction of movement of a particular norm, the degree of movement necessary to achieve quality, cannot be anticipated.

In making a referral decision, a general practitioner is necessarily influenced by factors outgide the immediate clinical 
situation: as examples, these might include the illness of relatives, previous failure in management of a patient, the aggressive behaviour of a patient. The recognition of these is part of good guality care in the broadest sense but might not actually represent quality in terms of referrals.

Quality assurance is nevertheless a burning issue for medicine in this current decade. The main thrust for quality assurance in the United States has been along the lines of chart review. In England video tape consultation and practice activity analysis have had their devotees (RCGP - 1986, Crombie and Fleming, 1988b). Guidance has been given to Family Health Service Authorities in relation specifically to general practitioner referral rates (Coulter et al,1991). In the Netherlands, the pursuit of quality has been even more vigorous: simulated patients have been used (Rethans et al, 1991); video tape consultations have been studied to examine the quality of communication between patient and doctor (Bensing, 1991) and a number of studies undertaken involving chart review. In a study of the quality of referrals, Knottnerus et al (1990) used referral letters (to and from specialists), information about patient's previous healthcare and investigations, to assess the quality of referrals. The assessment involved the judgements of an expert panel. These authors emphasise the inadequacy of referral rates as a judgement of referral quality, but expressed caution about this much more detailed form of examining the quality of referrals because of the time involved. Such a method is unrealistic on a large scale and depends on the cooperation of the doctors concerned. It is doubtful if such a level of cooperation could ever be achieved where there was serious doubt about the quality of the performance of some doctors.

However quality is assessed, one must be careful not to confuse referral rates as a proxy for quality. A high referral rate does not imply poor quality referrals or inappropriate referrals (Reynolds et al, 1991). Low referral rates might indicate poor quality care (Wilkin and Smith (1987).

\section{DOCTOR/PRACTICE PERSPECTIVE}

Age and sex of doctor:- Though some referral studies have provided data separately by the age and sex of the referring doctor, it is quite exceptional for the age and sex of the patients to be standardised in a way that enables true comparison of the referral behaviour of doctors in differing age and sex groups. For example, an older general practitoner may be consulted preferentially by older people and will have a referral pattern appropriate to an elderly population. The study reported here will explore this area.

Payment systems of doctors:- Differences in general practices activity throughout Europe are believed by many to be influenced by the way that the practitioners are paid. The extent of variability amongst general practitioners within a country, or within a healthcare system, is so great that it is difficult to define small differences existing within it. Sandier (OECD, 1987) considered the effect of the method of general practitioner remuneration on health service utilisation rates was outweighed by other factors. Hull (1988) questioned whether the insurance aystem of physician reimbursement, influenced general practitioner referral rates. 
One study providing some convincing evidence was reported by Flierman (1991) who investigated the change of payment structure of Copenhagen general practitioners which occurred in October 1987. He compared urban general practitioners who were involved in the change from a capitation dependent payment structure to one which included a large element of fee for service. Doctors outside the city of Copenhagen had experienced a fee for payment structure for some years and being unaffected by the change were available as controls. As a result of this payment change, there were significant decreases in referrals from urban general practitioners to rehabilitation specialists, gynaecologists and obstetricians, surgeons, and non classified specialists. This was a well designed study also measuring general practitioner consultation rates, which were unaffected by the change.

During the last two years, British general practice has seen the introduction of fund holding as a means of improving financial control in the health service. It is particularly relevant in this context, to draw attention to the novel approach to monitoring general practitioner performance described by Heaney et al (1992), in which notional prices were attached to general practitioner activities. Though the price used as the estimate for costing outpatient referrals seemed totally unrealistic (E13 per outpatient attendance and only first attendance costed), the method outlined in this paper provides a way forward in the assessment of change in general practice.

Case-mix:- The case-mix of patients presenting to a doctor or practice may influence his referral pattern. At the simplest, doctors seeing a relative excess of children and of old people will have different patterns of referral. Although referral studies commonly examine rates of referral in age specific groups, few go so far as to examine case-mix in both numerator and denominator. Morrell et al, (1971) conducted a small study along these lines and concluded that case-mix did iron out some of the inter-practice variation. The morbidity surveys in England and Wales are based on recording from all consultations in a twelve month period. Data from the second survey were used to examine case-mix in relation to referral (Fleming et al, 1991b). Referral rates for each practice and for referrals in each chapter of the International Classification of Disease were calculated using persons consulting as denominator. These were ranked and the rankings were examined for concordance. Practices were highly concordant across chapters. The practices referring frequently in one area of medical activity referred frequently in others, and this conclusion was reached after very careful standardisation according to the numbers of consultations undertaken in each morbidity grouping. The resultant analysis strongly supports the view that case-mix is not a major determinant of a general practitioner's referral pattern.

Distance from hospital:- The Dutch Sentinel practices identified distance from hospital as a relevant variable (Gloerich et al, 1989). Referral rates were higher among practices near tó hospitals. Noone et al (1989) examined referral activity in relation to its development of a new hospital in Milton Keynes a new town forty miles north of London, built in the last fifteen years. The combination of a new and nearer hospital certainly influenced local referral activity but there was no sustained effect which could be related to the distance of patients from the hospital. 
Security:- Using a questionnaire developed to assess general practitioner attitudes, Grol et al (1990) reported the association between the attitudes of general practitioners with a variety of measureg of performance. In particular they identified a group of doctors who were "more willing to take risks" than their colleagues and for these, referral rates were lower. The fact that this analysis was not focussed on a nul hypothesis, may seem to over estimate its significance. Nevertheless, this study is important since it identifies a small positive element in the search for explaining variation in general practitioner performance.

Practice workload:- The pressure of work and the amount of work undertaken are important variables for the study of activity, but it is not easy to define these. The simplest measurement in the context of general practice is the number of consultations though such a statistic conceals factors such as the duration of the consultation and work done outside the consulting room. For example, in British general practice, this might include parttime employment independent of the immediate provision of general medical services. Another statistic which can be used as a proxy for workload, is the registered list of patients. This statistic is a hard definition of a doctor/practice responsibility but it takes no regard of the differing style of care or amount of care delivered to patients. Nor is it available for individual doctors working within a partnership, since so much healthcare is delivered on a basis of shared care between the partners. Notwithstanding these reservations, and given a large number of participating doctors, both of these statistics can be used as a reasonable proxy for workload. Studies involving only small numbers of doctors should be interpreted with caution.

The most detailed examination of the importance of workload was undertaken by Butler and Calnan (1987). These authors reviewed the literature concerned with the use of a doctors time in relation to list size and concluded that there was no evidence suggesting that a smaller list would release more time to be epent with the patient. By inference therefore, one would not expect patients to be investigated, managed or referred to any different extent in circumstances where workload (list size) was substantially different.

In the programme of practice activity analysis undertaken by the Birmingham Research Unit, the possibility that a doctor's workload influenced his referral rate was considered (Birmingham Research Unit 1978). General practitioners undertaking few conaultations had higher referral rates. In a comparison of the performance of general practitioners in Belgium and the United Kingdom this trend was not confirmed at a statistically significant level (Fleming 1983). Both these studies however can be criticised since the measure of workload and the expression of referral rates were both based on the numbers of consultations and were therefore not independent. Notwithstanding this statistical limitation, there is little alternative to the way in which referral rates can be defined. Gloerich et al (1991). examined workload effects using list size as denominator and identified no differences. These authors did however consider there was room for doubt among referrals initiated because of the need for reassurance. Here, there were higher referral rates amongst doctors with a reduced workload as measured by the number 
Parameters which relate to population characteristics are particularly relevant to the allocation of health resources and to the planning of facilities in a neighbourhood.

Age:- Referral rates (regardless of denominator) are influenced by the age of patients with generally increasing rates with advancing years. (RCGP et al, 1986, Gloerich et al, 1991, Fleming et al $1991 \mathrm{~b})$.

Sex:- In a very detailed study using data from the second morbidity survey conducted exclusively among patients for whom social class data were available and who were present for the full twelve month period of survey, the overall rates of referral per 1000 population were marginally higher among females than males (91 per 1000 registered patients in females compared with 81 per 1000 in males Fleming et al, 1991b). However, when using persons consulting as a denominator, the rates were identical - 128 per 1000 . Since females consult more frequenty than males, referral rates based on consultations as a denominator were less among females. The General Household Survey (OPCS,1986) reported a review of referrals over several years and found similar proportions in both sexes. Sex therefore was not a major determinant for referral. However, detailed examination by sex in the individual age groups showed one or two small differences. In both the second and third morbidity surveys in England and Wales, population based referral rates in male pre-school children were higher than in females and so were consultation rates. In the age group $15-44$ years, rates were higher among females largely for obstetric and gynaecological reasons and among the elderly (aged 65 years and over) rates were slightly higher in males. The latter difference may relate to the differing life expectancy of the two sexes : any population of elderly males is bound to contain a greater proportion of them in the terminal twelve months of life and therefore more likely to need secondary medical care.

Social class:- In the analysis of the second morbidity survey already mentioned, social class had very little bearing on the referral process. A small difference was found in the two categories for social class III - skilled workers. Referral rates amongst the manual persons of social class III were higher than non manual. Interpretation of the social data is however very difficult because the study did not contain any information about private referrals outside the national health service, nor about self referrals to Accident and Emergency Departments. Private referrals are more likely to take place in social classes I and II and against that, referrals to Accident and Emergency Departments are more likely (at least for males) among the social classes based on manual occupations. The General Household survey for 1986 reported over 208 of people in professional and managerial classes were insured privately for secondary healthcare compared with 38 or less in the manual social classes. The survey also reported a surprising number of persons who were insured privately but who nevertheless had made use of national health secondary care facilities.

Morbidity is known to vary with social class but the interpretation of relevant data is again notoriously difficult. Firstiy, because few data are available which also include 
person specific information about smoking habits and life style: secondly, because the pressures to consult doctors on social classes IV and $V$ are greater than those in social classes $I$ and II because of the differential need for sickness certification and because of the importance of free prescriptions to the household economy of persons in lower social classes: thirdly, because doctors label illnesses differently when dealing with persons of differing social classes (RCGP et al, 1982). Thus if referral is related to need and need is defined by the prevalence of morbidity, one would expect persons in social classes IV and $V$ to require referral more frequently than those in social class I. It is evident from available information that social class has little impact on referral though there remains some room for doubt about a possible small influence. The problems for interpreting data about social class are considerable because available data are not sufficiently comprehensive.

Regional area of residence:- Within any country there are regional or local differences in the extent to which patients consult doctors. Though it is likely that these will impinge on practice referral rates, no information is available in sufficient detail to suggest that there are regional differences. Referral rates were similar in urban and rural areas in the morbidity surveys of England and wales.

Morbidity:- Obviously a patient's morbidity is a reason for explaining referral. A general practitioner will usually refer a patient with cancer. However, our information systems are largely based on labels supplied by doctors and the diagnostic label can in fact be a rationalisation of activity (Howie, 1972).

\section{SUMMARY}

Although many pieces of information are needed to describe the referral process in all its details, the fundamental statistic must be based on persons. In this regard, both the numerator and the denominator for expressing rates should be person based. The ideal is unattainable in most national healthcare systems and thus a proxy has to be used. For the individual doctor, the choice of statiatic may influence his own relative position within the spectrum of general practitioner referral activity but not to an extent that would make a substantial difference when studying the referral practice of large numbers of doctors. By ranking doctors on rates based on referral events relative to consultations, a satisfactory distinction can be drawn between high and low referring doctors.

This chapter has included a summary of relevant literature concerned specifically with the variables considered in this study relating to the individual referral decision which have not been addressed in the wider perspective outlined in the first chapter. 
In his preface to the Interface Study, (COMAC-BSR, 1990), van Etten referred to the increasing importance of primary health care as an issue in health policy but pointed out that there had not been any major shift in resource allocation from hospital based care to primary care. He also observed that primary care research was at a relative disadvantage to hospital based research. The importance of primary care and of monitoring what is going on in the community is fundamental to the targets of Health for All by the year 2000. This World Health Organisation programme emphasises the right of individuals for equal access to good quality health care and stresses the need to have adequate data to see that this is achieved.

The Concerted Action Committee on Health Services Research (COMAC-BSR) has been particularly concerned with the initiatives in primary health care since 1985. This study emerges out of that initiative.

\section{BUROPEAN GENERAL PRACTICE RESEARCH WORKSHOP (EGPRW)}

The EGPRW is an organigation of general practitioners coming from various parts of Europe with a common interest in practice based research (tull, 1982a). It is an open organisation and any interested person may join. It was founded in 1970, just after the Leeuwenhorst group and there was some degree of overlapping cormon interest. In the early days, the members were self selected but in recent years, the group has a more formalised establishment with national representation from several countries. The group meets twice yearly moving around the countries represented. The meetings are all concerned with the results of research projects undertaken in general practice or with research methods and study design. The group formulated a policy which has been published and which is summarised in eight articles (Editorial, JRCGP, 1983).

Co-operative research has always been uppermost in the activities of the group and many recent topics have been examined in small international co-operative efforts. Hull compared the management of vaginal discharge (1978), of sore throats (1981), and of low back pain (1982b) in various countries and also examined the gap between a doctor's objective opinion and his observed performance. Fleming Maes (1980) studied a variety of practice activities among the doctors in the United Ringdom and the Flemish speaking part of Belgium. These studies, though comparatively small, showed that the mean rates of some basic activities were similar in the two national groups. Perhaps more importantly, so was the degree of variation among recorders, regardless of the fact that they were working in different healthcare systems and in very different environments for healthcare delivery. In more recent yeara, the group have examined the impact of Aids on practices, especially with regard to health education and perceived knowledge. 
Most of the studies described above, have been undertaken by the members acting on their own initiative and with little or no external funding. Prior to the study described in this book, two studies have been conducted by the group with external financial support. The study of immunisation procedures within Europe was designed to examine and compare national policies for immunisation (Crombie, 1983). The study was conceived as the firat in a series which might be extended to examine related issues including immunisation uptake rates, adverse effects of immunisation and subsequent reported incidence of the relevant diseases in national populations monitored by the practitioners concerned. The aspirations of the group in this direction were not realised immediately, largely because an infrastructure had not been established in which such studies could be prosecuted. The Eurosentinel Project (Van Casteren,1989) with which the group is associated with several persons belonging to both organisations, has the infrastructure necessary for this purpose and we hope that sometime in the not too distant future, the group's intentions for immunisation related studies will be realised. A second major study undertaken with financial support from the EEC was the Interface Study (COMAC-HSR, 1990).

\section{The Interface Study}

During the fifteen years 1970-85, members of the EGPRW gained increasing insight into the medical care and delivery structure in each of the European countries. Initially, as a group, we were conscious of those gross differences which affected our every day working life; nearly half the consultations in Belgium took place in patients' homes ; in the Federal Republic of Germany (FRG), the payment structure was determined by items of service, whereas in the United Kingdom it was largely based on capitation; patients had unrestricted access to specialists in Belgium and the FRG but not in the Netherlands, Spain and the United Kingdom; in the Netherlands, rural general practitioners also undertook dentistry. As experience was shared, we began to realise that there were very fundamental differences in the structure of our healthcare systems. Even the term "primary care" had different meanings : in the United Kingdom, many people considered it synonymous with general practitioner services; in Denmark it embraced the community health services provided by nurses, midwives, health visitors etc. In some countries, the distinction between the term 'ambulatory care' and 'primary care' may also cause confusion. The term 'ambulatory care' is used in some countries almost to the exclusion of the term 'primary care'. In its broadest sense, 'ambulatory care' includes health services for all ambulatory (non hospitalised or institutionalised) patients. In the interpretation of healthcare data, the interface between general practitioners and specialist is sometimes difficult to appreciate because the specialists may function both in the ambulatory care and hospital settings. In spain for example, primary care and ambulatory care have almost the same meaning. General practitioner and specialist paediatric care is universal but in some areas, ambulatory care includes a major specialist provision whereas in others, the specialists are
hospital based.

This study was concerned primarily with the observations of service general practitoners on various aspects of health care delivery. The need for measurement was stressed and the study reported here was a logical development from it. 
Until recently, the majority of medical training has taken place in hospitals and even today in some countries, opportunities for medical students to see patients in the community scarcely exist. In addition to the obvious economic case in favour of management outside hospitals, there are the sociological arguments of family support and cohesion in times of illness. By concentrating training in hospital, students see an excess of patients badly managed at home and can be denied the opportunity of seeing patients who are well managed. They are also receiving inappropriate opinions about the management of common conditions, especially those for which neither intensive investigation nor therapeutic measures are necessary. The decision to refer a patient to specialist care is important and both trainee general practitioners and medical students must be given a breadth of experience in order to decide wisely. The wide variation between doctors which exists today is an indictment on the practice of medicine, which aspires to standards in the quality of care.

\section{MEDICAL AUDIT}

The economic argument may be the most important in making referral a priority subject for audit of general practitioner activity, but there are also issues related to the quality of care. As public awareness of professional variation increases, questions are asked as to the quality of the advice received from general practitioners. A recent paper on the epidemiology of shingles (Glynn et al, 1990) referred to the fact that all patients in the Cheltenham area of England were sent for physiotherapy when shingles was diagnosed : there can be few other areas in which such a routine is adopted. Differences such as this one beg the question as to the appropriateness of medical intervention and in general the public look upon greater intervention, more costly intervention, and new treatments as "better medicine". The problem here is the difficulty of defining acceptable standards of care. There is no immediate prospect of defining acceptable standards for referral. Delayed referral in the presence of cardinal symptoms has been examined in relation to quality (Stower, 1988) and perhaps this is an area where progress will be made.

\section{THE LEGAL ISSUE}

Until recently, doctors in Europe were inclined to think that the law and medicine only clashed on the other side of the Atlantic. Certainly this situation is changing rapidly. Many areas of legal controversy surround the boundaries of clinical responsibility and point of referral. In the United Kingdom, patients do not have independent right of access to specialists either within the national health service or even privately. the general practitioner has absolute discretion in this matter, though of course he is answerable in law for any adverse decision for which he is alleged to be negligent. In the Netherlands and Spain, the position is theoretically somewhat similar to that in the United Ringdom but in most of the other countries, the situation is less rigid. Further consideration of the legal issue is available in Jost's book on quality assurance (1990).

Much has been said already about the consumer perspective in relation to the structure of healthcare in individual countries 
but it has to be remembered that consumers are also the financers of healthcare and if costs are to be contained, there will have to be some control over demand for high cost care. In some countries, cost sharing formulae have been developed but they provide no answer for the poorest sections of our communities. We can not on the one hand encourage a consumerist approach to the motor car of medical care and on the other expect doctors to apply the brakes. Detailed investigation for many medical problems has become very safe and it is rare nowadays to withhold investigation on the probability that the potential for harm from the investigation is greater than the probability of missing a specific diagnosis.

Desirable or not, referral has become a sensitive issue in some countries and both doctors and healthcare systems will be judged by individuals according to the ease of access to high cost specialist care. Naively, resources devoted to a problem are seen by many consumers as some sort of yardstick of quality instead of the cost effectiveness or cost utility.

\section{THE COPENHAGEN CONFERENCE}

An important step in the development of this study was the conference of experts held in Copenhagen in November 1987 (COMACHSR, 1990). The conference was convened to consider the preliminary results of the Interface study and to make recommendations about further studies including the one reported here. In this connection, the issues discussed were the referral documentation, desirable sample sizes and the choice of a disease classification. The main recommendations included:

1. National samples of 28 of general practitioners should be sought;

2. Individual doctor based samples should include 30 consecutive referrals;

3. The International Classification of Primary Care - ICPC (WONCA, 1987) should be used wherever possible;

4. The study should also gather data about indirect referrals.

\section{STUDY PROTOCOL}

\section{AIMS OF STUDY}

There were four main aims:

1. To define and compare national referral patterns.

2. To identify cohorts of general practitioners in each country with high and low referral patterns and to compare practice/doctor characteristics in each group both within each country and internationally.

3. To examine delay patterns for specialist consultation and for surgical treatment.

4. To provide individual general practitioners with summarised

The study involved the collection of information about thirty consecutive referrals to medically qualified specialists made by not specified general practitioner. The commencement date was got specified though in most countries, the recruitment of general practitioners and therefore, the study commencement dates
were spread over six months. 
During the preliminary discussions in Copenhagen, the national representatives of the European General Practice Research Workshop (EGPRW) discussed the possibility of recruiting a random sample of general practitioners. Previous experience of recruiting random samples of general practitioners had not been successful in most countries. In this study, no payments for participating general practitioners were planned, whether recruited as a random sample or as volunteers. For this extra reason, we considered the prospect of obtaining full co-operation from a truly random sample as remote. Nevertheless, some of the national representatives agreed to try and recruit doctors at random. It was also agreed however, that we would accept data from any general practitioner willing to provide it.

The objectives of the study concerned the act of referral and the issues of variation between general practitioners and between countries. Variables examined in relation to individual general practitioner referral rates included the age, sex, status and experience of the referring doctor, the location of the practice (Urban, Rural Mixed) and the distance from the nearest hospital providing a wide range of specialist services.

In order to make comparisons, a denominator was required for calculating referral rates. In some countries patient registration is usual and here an estimated list was theoretically possible. In the United Kingdom there are some limitations in estimating the population cared for by an individual general practitioner as opposed to the population cared for by a practice. The registered list is often a poor indicator of his actual share of the practice workload in a given period. "Persons consulting" is theoretically a better denominator (Fleming et al, 1991a) when considering the actions of a general practitioner. With additional data available about the age and sex composition, standardisation of rates is possible. However "persons consulting" are difficult to collect reliably : a count of consultations is much simpler. Experience from the programme of practice activity analysis in the United Kingdom (Crombie \& Fleming, 1988b) has shown that general practitioners found no dificulty in counting consultations with age and sex breakdown. Gervas et al (1990), reported similar experience in spain. The objection to consultations as a denominator is based on the variation between doctors in the style of their consulting pattern. Some doctors encourage patients to make follow-up consultations to ensure recovery to a much greater extent than others. The referral study was expected to last about four weeks in most countries. In a study of consulting frequency among 49 general practitioners in the United Kingdom Fleming (1985) established that in the analysis of a practice activity over a two week period, the choice of denominator as between persons consulting and consultations was relatively unimportant: studied over a twelve month period however, there were significant differences (Fleming, 1983). After consideration of all the issues, consultations was chosen as the denominator for this study and these were collected in age and sex specific groups. Consultations at the practice office were recorded separately from home visits. This exercise of collecting information about all consultations has provided considerable additional information about the average working week of general practitioners in the countries concerned. 


\section{REFERRAL DATA}

The description of referrals included the age and sex of the patient and other variables which are described here.

\section{Type}

Referrals were categorised by "type" - New or Re-referred. For the purpose of this study a re-referral occurred when the patient was referred to a specialist with a problem for which he had been referred in the previous three years. This distinction was arbitrary but was introduced recognising that in some countries an initial specialist referral has to be renewed at annual intervals if continuing specialist care is needed.

\section{Specialty}

Referrals were categorised by specialty. For analysis purposes these were divided into medical, surgical and others (Fig 3.1).

\section{Fig.3.1 SPECIALTY CODES}

\section{MEDICAI}

20 Internal Medicine

21 Paediatric Medicine

22 Geriatric Medicine

30 Dermatology

31 Cardiology

32 Allergy/Immunology

33 Neurology

34 Gastroenterology

35 Rheumatology

36 Respiratory Med.

39 Medical Specialty nec.

\section{SURGICAL}

40 General Surgery

41 Ophthalmology

42 Otolaryngology

43 Orthopaedics

44 Genito-Urinary Surg.

45 Plastic Surgery

46 Neurology

49 Surgical spclty nec.
OTHER

50 Obstetrics

51 Gynaecology

60 Psychiatry

61 Mental subnorm.

70 Emerg. \& Trauma

80 Oncology/ Radiotherapy

81 Pain Relief

90 Specialty nec.

The classification of specialties was derived empirically after discussion among the national representatives. Most of the specialties fit logically into one of the three major groups but the correct location of gynaecology presented some difficulty. In some countries the work of a gynaecologist involves cervical cytology, family planning and the management of common conditions such as vaginal discharge. Additionally, obstetrics and gynaecology are often combined into one specialty. For these reasons, gynaecology was not included as a surgical specialty.

\section{Mode}

The classification of mode included outpatient department, private specialist office, clinic, accident and emergency department, inpatient admigsion and domiciliary consultation. The classification of mode of referral reflected the options available in all the European countries. Referral to the Accident and Emergency Department is universal following serious accidents but in some countries and hospitals, medical and surgical emergencies are sometimes first referred to the emergency room before any decision is made about admission. In the presentation of results which follow, the mode of referral may have specific meaning appropriate to the country concerned and this will be explained as the national data are presented. (The classification 'private' caused some confusion since relevant information was more specifically described in the 'costs responsibility' section.) 


\section{Urgency}

When the referral was made the general practitioner was asked to specify if any special degree of urgency was expressed. Urgency was described in three levels, - immediate (same day), urgent, routine.

\section{Patient influence}

The general practitioner was asked to describe the influence of the patient on the decision to refer. Three options were available - nil, small, large. In selecting the appropriate option, the recorder entered 'nil' where the decision for referral was essentially his own and not subject to any influence by the patient other than the fact of his illness and ita severity. Thus a new referral for an acute appendicitis would usually attract a 'nil' entry because that would clearly be the general practitioner's decision whether or not the patient tried to influence him.

\section{Cost responsibility}

Four options were available - National Bealth Service or atate insurance, employer insurance, private insurance and costs borne directly by the patient. The distinctions between insurance scheme alternatives were not easy to define in all countries.

\section{Referral problem and data of referral}

Recorders were asked to record the problem occasioning the referral in diagnostic terms wherever possible. Symptom descriptions were acceptable where no diagnosis could be formulated.

\section{Referral follow-up}

The follow-up data appropriate to each referral included three dates, an indication of surgical intention and a referral check code. Dates included were the date of first appointment with the specialist, the date of first communication received from the specialist and the date of surgical intervention where appropriate. The follow-up data sheets were generally completed as the relevant information became available or when the individualised referral summary was received by each general practitioner (between four and six months after recruitment). On completing the follow-up data sheet, recorders were asked to specify (in an alpha coded form) any difficulties experienced in providing the necessary data. For example, data might not be available because the doctor had loat contact with the patient (Code G).

\section{Indirect referralo}

This study was primarily concerned with referrals made by general practitioners following face-to-face encounters. However, early discussion suggested that it would be considerably restricted if information about indirect referrals was excluded. The definition of the indirect referral is one in which a general practitioner is concerned in the referral process and authorises it for the purposes of a health insurance scheme but does not necessarily see the patient. Indirect referrals were known to be common in the Federal Republic of Germany but also to occur in countries such as the United Kingdom. For example, a school doctor or a doctor from a family planning clinic or an optician may identify a problem but is only in a position to refer the person back to his registered general practitioner. In such circumstances, the general practitioner may well refer a patient 
to a specialist without first seeing him. In Spain, authorisation of referrals to Accident and Emergency departments is an administrative requirement and is commonly given without direct encounter.

\section{COMPARISON BETWEEN HIGH AND LOW REFERRING DOCTORS}

A major aim of this study concerned the exploration of practice/doctor determined variables which might contribute to explaining variability among general practitioners in the referral process. The analysis involves comparisons of recorders who were in the highest and lowest quintile groups of referrers within each country, and of the highest and lowest quintiles from all countries combined. In order to identify these reliably, data from individual general practitioners were atandardised by the age and sex distribution of all consultations (see below). The comparison between the two extreme groups did not limit us in the exploration of the remaining data but differences which were not demonstrable in a comparison between the extreme groups, are unlikely to be important.

\section{DELAY PATTERNS}

The analysis of delay patterns is directed towards interspecialty differences within countries and differences between countries in the way specific problems are dealt with. It was for this reason particularly, that we wished doctors to record in diagnostic terms if possible, since, for some conditions, (e.g. cataract), we proposed to examine national differences in considerable detail.

\section{INDIVIDUAL DATA}

Finally we proposed to collect and analyse data at an individual level thus providing something for each recorder about his own performance and generally encouraging the philosophy of personal audit of activity (Crombie \& Fleming, 1988Bb).

\section{ORGANISATION}

The study was organised in Birmingham, United Kingdom with D. M. Fleming of the Birmingham Research Unit of the Royal College of General Practitioners as Project leader. Professor Paul Backer was chef de file representing the interests of the COMAC-HSR. In each country the national representative for EGPRW was responsible for publicity and recruitment, for circulating data collection booklets, collecting and coding them and for liaising with the project leader.

Printing of the recruitment booklets, data entry and preliminary analyses were undertaken in Birmingham. Computerised programmes for analysing the data were written by Veer Ghasi and Robert Lancashire of Birmingham University. Liaison between the project leader and the national representatives was maintained chiefly at the regular biennial meetings of the EGPRW though a meeting was held in Brussels to brief national representatives at the commencement of the study.

The main study was preceded by a pilot study in which recording documents were tested. 
In the prosecution of this study we required data from as many European countries as could be included. For this purpose, and in accordance with the EBC policy, the recording booklet was printed in all appropriate languages including:

$\begin{array}{lllll}\text { Danish } & \text { Dutch } & \text { English } & \text { Flemish } & \text { French } \\ \text { Italian } & \text { Portuguese } & \text { Spanish } & & \end{array}$

The booklet was designed to facilitate the recording of information on two occasions (recruitment and follow-up) and to facilitate central analysis. In discussing the arrangements made to achieve these particular objectives. the emphasis will be placed upon the problems encountered, the solutions adopted and the degree of success achieved. This section is provided especially for the benefit of others who may follow similar research protocols.

\section{Recording booklet}

Each individual doctor was provided with a recording booklet containing a total of 54 sheets. The sheets were perforated separating the booklet into three sections. The left hand section was chiefly concerned with instructions but also included a list of referred patients to be retained within the practice. The central section was concerned with the follow-up phase and the right hand section with the recruitment phase of the study. This design was adopted in order to separate the booklets through the perforations after each phase of the study. Thus, after the recruitment phase of the study, the right hand section of the booklet was forwarded to the National Coordinator. Recording sheets were printed in differing colours (white, pink, yellow. green) defining the sections in which the data were to be collected. On the reverse side of each sheet, instructions, coding systems and recording examples were provided to assist the recorder. The booklet was spirally bound and when open and laid flat, the instructions were positioned next to the sheet for data collection as illustrated below in Fig.3.4.

Details are provided here about the structure and content of the English language version of the recruitment booklet drawing attention to salient points from each recording sheet. 


\section{3}

\section{BOOKLET STRUCTURE}

The booklet is in three sections: the right hand section is concerned with recruitment data, the central section with follow-up date. and the left fiond section with patient identification

Complete the practice profile (this pege) now. The next eight pages contain scoregrids for monitoring encounters during the exact period necessary to recrult 30 direct referrals. Data concerning the first 30 referrats are recorded on the yellow pages. The green page towards the ind of the booklet, concerns summarised dats recruitment of 30 direct referrals. some GP's may have arcess to encounter dota on a compurer but these dal must contorm Sometimes. practice sncillary roff may be used to record encounter data but it is advisable nol to dismember the booklet to achieve this.

\section{PRACTICE PROFILE}

The right hand side of this sheet is used to describe yourself and your proctice. Complete these details now to ensure that they are not overlooked. Enter numbers or tick the boxes as appropriate. In describing the status of the general proctitioner:-

a PRINCIPAL is in control of his own prartice.

An ASSISTANT is a trained GP working in another doctor's practice

- TRAINEE is O GP who has not yet finished the usual training arrangements generally adopted in his
- Name.

- Stotus Principal $\square$ Assistant $\square$ Trainee $\square$

- Address

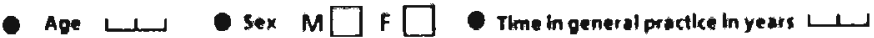

- Names of any of your partners participating in this study

- The total registered practice popula tion (spectfy only if svallable in your country) $4,1,1,1$,

- Number of GP's in practice Principals $\longrightarrow$ Assistants $\longrightarrow$ Trainees $U$

- Distance from main practice premises to nearest district general hospital. polyctinic or other centre provlding a comprehensive range of spectalbst servkes (nearest km.) L., $\mathrm{kms}$

- Practice Environment urban $\square$ Mixed $\square$ 


\section{ENCOUNTER SCOREGRID}

MALES

on rece encounners

- WeEkbegining $\frac{1}{\text { day }}$ month FEMALES

030405

$11121314151617181920 \quad 0607080910$

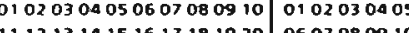

\begin{tabular}{|l|l|l|}
\hline 11121314151617181920 & 0607080910 \\
\hline 01020304050607080910 & 0102030405
\end{tabular}

\begin{tabular}{|l|l|l|}
11020304050607080910 & 0102030405 \\
11121314151617181920 & 0607080910 \\
\hline 0102030405060908910 & 0102030405
\end{tabular}

\begin{tabular}{|l|l|l|}
11121314151617181920 & 0607080910 \\
\hline 0102030405060708910 & 0102030405
\end{tabular}

1127314151617181920 0607030910

$21222324252627282930 \quad 1112131415$

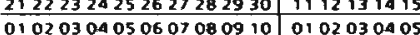

\begin{tabular}{|l|l|l|}
11121314151617181920 & 0607080910 \\
21222324252627282930 & 1112131415 \\
\hline
\end{tabular}

010203040506070809100102030405

$11121314151617181920 \quad 0607080910$

\begin{tabular}{|l|l|l|}
\hline 01020304050607080910 & 0102030405
\end{tabular}

111213141516171819200607080910

Transfer final number in each box to summary opposite 010203040506070809100102030405 $21127314151617181920 \quad 0607080910$ $21222324252627282930 \quad 1112131415$ 010203040506070809100102030405
ENCOUNTER SUMMARY

MALES

$$
\text { OFICE ENCOUNTISTS }
$$

visnts

\begin{tabular}{ll|l}
01020304050607080910 & 0102030405 \\
11 & vistrs
\end{tabular}

\begin{tabular}{ll|l}
11121314151617181920 & 0607080910
\end{tabular}

$01020304050607080910 \mid 0102030405$

$11121314151617181920 \quad 0607080910$ \begin{tabular}{lll|l}
01020304050607080910 & 0102030405
\end{tabular} \begin{tabular}{ll|l}
11121314151617181920 & 0607080910 \\
\hline
\end{tabular} 010203040506070809100102030405 $\begin{array}{lll}11 & 121314151617181920 & 0607080910\end{array}$ $11121314151617181920 \quad 0607080910$ 010203040506070809100102030405 $11121314151617181920 \mid 0607080910$ Arice

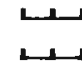

L.

.1.

1

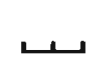

L.

1.

1

Lـ

1

1

65.14

.

3.

لــL

Yes $\square$
S

- Week beginning ț day

FEMALES OSFE EMCOUMTERS

1 L

니

.

$\longrightarrow$

나

L.

LI.

لـــ

B overleat 
Fig. 3.4 To illustrate recording of direct referrals

\section{DIRECT REFERRALS}

DEFImITION - A referrsl to apecialist following o direct encounter between pationt and GP

\section{For each direct referral}

Enter the name brlef address and date of ceferral in the Practice Reference Libt. This list is solety for practice use and must be retained fter the initial recruitmemt phase in order to complete the follow-up study and fo subsequent reference if any of the dota equire to be checked:

Complete the referral details in the recruitment date section. Identify the speciality by one of the codes listed on the right;

Alter 30 direct referrals have been obtained, stop recording encoumter data:

- Record details from indirect referrals in the next section - green page:

- Complete the follow-up section as

opportunities are presented or when advised

by your nutions

\section{PRACTICE REFERENCE LIST}

(for retention in practice)

Patient Name..$\ldots \ldots \ldots \ldots \ldots \ldots$

Brief Address $\ldots \ldots \ldots \ldots \ldots \ldots$

.........................

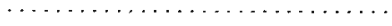

Telephone No.

Date of referral

\section{FOLLOW UP STUDY OF RELEVANT DATES}

On receipt of a reminder from your notionel coordinstor, complete all required follow-up dotes and the final check code. Enter any comments retevent to each referral.

FINAL CHECK CODES in order of preference are:-
a) All data provided;
b) Potient died before specialist appointment;
c) Potient died before surgical intervertion:
d) Patient did not keep appointment:
-) Potiem not yet seen by specialist:
i) Specialist seen, report not yet recelved.
g) I have lost contact with the patient.

\section{FOLLOW UP STUDY}

- Date of first appointment with day month

- Date of receiving first communication (hefter or telephone call) from the spesialist or hospital Lᄂ, L

- Is surgical intervention planned?

res $\square$

No

Not known

- If Yes, enter date of intervention

- Final check code $\square$

- Comments (ff ary)

\section{SPECIALTY CODES}

SURGICAL

20 Internal Medikin

21 Paediatric Medicine

22 Gerlatrk Medicine

30 Dermatology

31 Dermatolowy

31 Cardiology

33 Neurology

34 Gastroenterology

34 Gastroenterology

35 Rheumatology

39 Medical Speciolty not elsewhere classified

40 General Surgery

41 Ophthalmology

42 Otols

22 Otolstyngology

44 Genito-Urinary Surgery

45 Plestk Surgery

45 Plostk Surgery

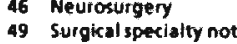

Surgical specisity not
elsewhere classified

OTHE

50 Obstetrics

60 Psychiatry

61 Mental subnomality

70 Emergency o Trauma

80 Emergency Trauma

81 Pain Relief

90 Specialty not elsewhere

\section{DEFINITIONS}

Relerral type - distinguishes a NEW REFERRAL from a RE-REFERRAL which opplies if o pottent has been referred during the previous three years for a rabled problem.

Mode of referral - describes the access arrangement to specialist care.

Urgency of referral - describes the arrangement specified by the GP when making the referral

Patient influence - describes the influence of the patient on the GP's decision to refer.

costs respansibilty - describes the body or organisation responsible for meeting the specialist's costs

The problem - for which the patient is referred should be described in diagnostic terms wherever possibte.

\section{RECRUITMENT DATA}

- sex $M \square F \square$ Age $\longrightarrow$ years

LEAVE BLANK

- Speciality Code - Type New $\square$ Re-referral $\square \square--$

- Mode Outpatient Dept $\square \quad$ Private $\square \quad$ Clinic $\square$

Inpatient Dept $\square$ A\&E Dept $\square$ Domiciliary $\square$

- Urgency immediate (sameday) $\square \quad$ Urgent $\square \quad$ Routine $\square$

- Patient influence Nil $\square \quad$ Small $\square \quad$ Large $\square$

NHS or
- Costs
responsibility $\quad$ State Insurance $\quad$ Employer Insurance $\square$

- Problem (possible diagnosis).

Directly by Patient $\square$

- Date of Referral

$$
\underset{\text { day }}{L} \underset{\text { month }}{L}
$$




\section{INDIRECT REFERRAIS}

DEFINITION - A reterral to a specialist withorised by \& GP without direct encoumer are authorised by practice ancillary staft

- Record referral decails for these patien until the sheet is complete with entry numbor 60 , or until you have already recrunted 30

- Identify the specialty using the code number adjacent.

- Record type and mode using codes as follows:

Type:

$\mathrm{N}=\mathrm{New}$

R = Re-referral

Mode:

Cle = Chnic

Pie - Private Office OC. = Domiciliary Con

IP - in.Patient

ABE - ACCEngy Dpt.

The number of indirect referrals varies

considerably. In some countries there are very

large numbers and in others scarcely any

please record indirect reforrats cur efully.

\section{MEDKCAL}

20 Internal Medicine 34 Gastroenterology 21 Paediatric Med. 35 Rheumatology 22 Geriatric Medicine 36 Respiratory Med. 30 Dermatology 39 Medical Specialty
31 Cerdiotogy
n.e.c.

Allergynmmunology

SURGICAL

40 General Surgery

41 Ophthalmology

44 Genito-Urinary Soy.

43 Orthopaedics

45 Plastic Surgery

46 Neurosurgery

9 Surgical specisity

OTHER

50 Obstetrics

51 Gynsecology

60 Psychiatry

80 Oncology/Rodiotpy

$$
81 \text { Pain Relief }
$$

61 Mentsl subnormality

70 Emergency Irauma

90 Other specialty n.e.
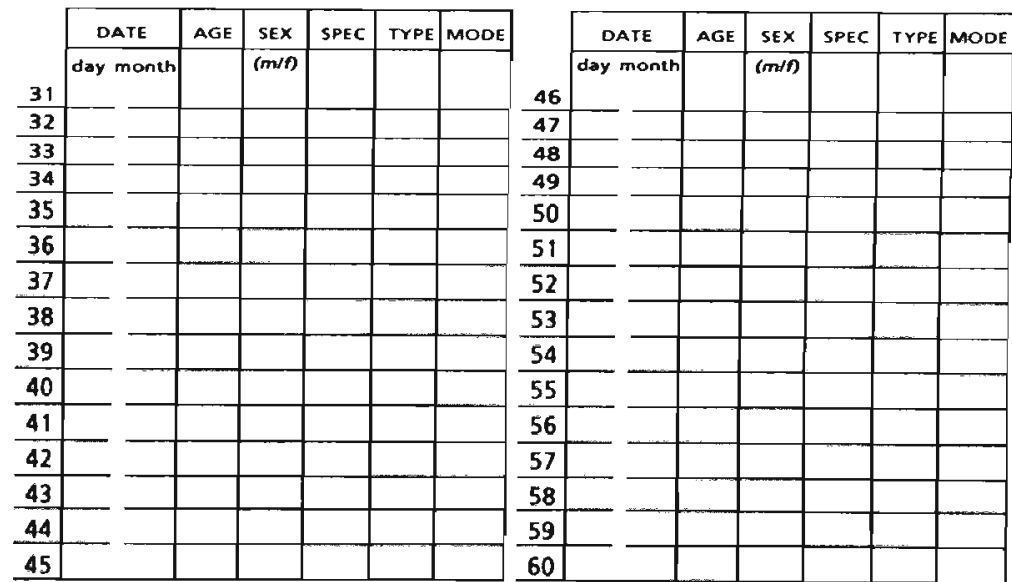
- Unique gp code number on all three sections.

- Description of booklet structure for each gp.

- Personal details of the recording gp/practice.

Pages 2-9 - Encounter Scoregrid (pink Fig.3.3);

- Male and female patients consulting were scored separately by age group and location after each direct encounter.

- The normal working week question : here we were concerned to identify normal working weeks in order to quantify the number of consultations undertaken.

- Encounter data were summarised for data input.

- Commencement date.

- On the reverse face of each of the encounter sheets, the instructions were recorded and recording illustrated.

Pages 10-39 - Direct Referrals (yellow Fig.3.4).

- On the left hand side of the sheet there was a practice reference list. The patient's name and address allowed the gp to refer back to the patient records after the initial referral so that the follow-up study could be completed.

- The middle section was concerned with dates for the follow-up study.

- The recruitment data for each referral.

- A section left available for coding by national coordinators.

- On the reverse face of each sheet, instructions and definitions were given.

Page 40 - Indirect Referrals (green Fig.3.5):

o Definitions and instructions.

- Medical Specialty coding.

- Summary data for each person referred for specialist consultation during the recruitment period of 30 direct referrals or until 30 indirect referrals had been recruited.

\section{Comments on printing}

In retrospect, the design of the recording booklet contributed to the success of this study and its development provides a model for international studies of this type. It has facilitated the conduct of a study among recorders using several different languages and by using numeric codes to describe the data, we were able to make quick and simple data entry at a single agency. There were problems in printing the book however. The layout was prepared using a computerised system but the length of text varied according to the language concerned. Initial booklets were printed in English and the space occupied by the equivalent German text was too long. This created a problem which we resolved by inserting extra pages of descriptive text where necessary. For all other languages the length of the text did not present a problem.

There were small practical problems in handling so many versions of the booklet from the differing countries at the same time. The procedure started by sending each national representative a copy of the English version and by asking him to translate or arrange translation of it. There was a communication chain starting with 
the project leader and the English version of the book going through to the national representative, to the translator, back to the national representative, on to the project leader, from the project leader to the printer and round the same cycle for any amendments. This procedure meant that several versions of each translation were circulating at one time and mistakes were made. For example, after a revision had been made in one particular section of the German language version, the amended version instead of the revised version was cancelled from the computer screen. This and other similar problems arose partly because the printing was undertaken by a person with no other language than English and partly because of the sheer volume of paper work involved in the various revisions and several translations of the book. The only book which was unsatisfactory and had to be reprinted was the Flemish version. The complexity of the printing exercise led to delays in the commencement of the study in some countries.

Taking an overall view of this part of the project however. we regard the printing of this booklet in the several languages as a precedent for undertaking other European studies. The printing of the booklets took place at the West Midlands Regional Health Authority in Birmingham.

\section{FUNDING}

Funding for the study came chiefly from the European Economic Commission grant (Euro-Contract No. MR4-0080-UR (CH). The national representatives were assisted in the prosecution of this study in their own countries by specific national grants which are acknowledged with each national report. 


\section{CHAPTER 4}

\section{METHOD CONSIDERATIONS}

\section{STATISTICAL CONSIDERATIONS}

The statistical issues relating to each of the objectives must be considered separately since the samples appropriate for each objective are different.

The first objective was to define national referral patterns. The act of referral involves two parties - patients and doctors. It is extremely unlikely that a study identifying a series of thirty consecutive referrals from each general practitioner could result in a biassed group of patients in details such as the age and sex, the problems concerned or the specialties to which they were referred. The sampling problem therefore concerns the doctors. Some of the national representatives had previous experience of trying to recruit random samples of doctors. It was accepted that this was impossible on a wide scale in any situation in which no payment was made to the recorders. In the English experience of practice activity analysis, in which groups of willing doctors participated in studies of practice activities chosen without reference to the participants, both the mean activity rates and the ranges of results(measured by the standard deviation) were usually similar where a minimum number of twenty doctors participated (Crombie \& Fleming, 1988b). Given this background, we decided to proceed with the study accepting returns from doctors wherever recruited, but national co-ordinators were encouraged to approach a random sample of doctors where possible. Notes appropriate to the samples achieved are given in the respective national data sets. The national samples of recorders have been compared with national data with regard to age and sex and practice characteristics wherever possible. Though most recorders were self selected, we have no reason to believe that their referral patterns are atypical.

In the design of this study, one option would have been to obtain a small number of referrals (perhaps five) from as many recorders as possible rather than thirty from a much reduced number. Given the constraints imposed by addressing four objectives rather than only one, and the relatively fixed overhead costs of contacting each participating doctor, it was preferable to obtain a reasonable number from all participants. To achieve the first objective, a random sample of 1000 referrals in 20,000 consultations provides a referral rate of 50 per 1000 consultations with a 958 confidence interval between 47 and 53 per 1000. A subset of 100 referrals in 20,000 consultations (e.g. a commonly used specialty), with an overall referral estimate of 5 per 1000 consultations is associated with a $95 \%$ confidence interval between $4 \& 6$ per 1000 .

From these basic considerations, and also recognising that doctors and not patients were in the sampling frame. We decided that any national data set should contain a minimum of 1000 referrals but that we should aim at collecting more to ensure an adequate number continuing to complete the follow-up stage.

At the Copenhagen meeting already referred to, a decision was made to recruit thirty consecutive direct referrals from each 
recorder. This is an example of a practical decision stemming from statistical considerations and also from experience of the researchers in gathering data from general practitioners receiving no financial reward. It is self evident that a sample of sixty referrals would provide a more confident estimate of an individual doctor's referral rate than a sample of thirty referrals. We already knew that in the United Kingdom a doctor with a low referral pattern had a rate of approximately 30 per 1000 consultations, the average doctor, a rate of 50 per 1000 and a high referring doctor 100 per 1000 . With these estimates in mind, we have calculated the 958 confidence intervals surrounding these estimates based on $20,30 \& 60$ referrals in selected numbers of consultations (Table 4.1).

Table 4.1 RATES PER 1000 CONSULTATIONS AND $95 \%$ CONFIDENCE INTERVALS DERIVED FROM SELECTED REFERRAL/CONSULTATION COMBINATIONS

$\begin{array}{rrrrr}\begin{array}{c}\text { REFERRALS/CONSULTATIONS } \\ \mathrm{n}\end{array} & 300 & 600 & 1000 \\ 20 & \text { Rate/1000 } & 67 & 33 & 20 \\ & 958 \text { C.I. } & 38-96 & 18-48 & 11-29 \\ 30 & \text { Rate/1000 } & 100 & 50 & 30 \\ & 958 \text { C.I. } & 65-135 & 32-68 & 19-41 \\ 60 & \text { Rate/1000 } & 200 & 100 & 60 \\ & 958 \text { C.I. } & 154-246 & 76-124 & 45-75\end{array}$

A study based on 20 referrals separates the doctor who reaches this number in 300 consultations from one reaching it in 1000 consultations, but neither is statistically distinct from the doctor who reaches it in 600 consultations. A study based on sixty referrals separates all three of the doctors in the example, but the doctor with a low referral rate $(30$ per 1000$)$ would need to continue in the study until he had undertaken 2000 consultations which for many doctors could involve 6 months continuous recording. A study based on 30 referrals is sufficient to distinguish between the highest and lowest referring doctors with 958 confidence and with 908 confidence to distinguish the 300 consultation recorder from his 600 consultation counterpart. The distinction between the 600 and 1000 consultation recorders is achieved with 958 confidence. The highest and lowest referring doctors would recruit 30 referrals in approximately 300 and 1000 consultations respectively, which seemed reasonably attainable within the time contraints of this study.

The third objective was concerned with delay patterng. There were many unknowns in making appropriate estimates. Those particularly relevant to our considerations were the losses between recruitment and the dates of consultation, appointment and of surgical intervention. First of all there was likely to be a loss of recorders in recruitment and follow-up stages. Having decided that recording could be based on 30 referrals, it was anticipated that most doctors would be involved in one month's recording. It was also probable that recorders would start at different times and thus recruitment phasing would introduce 
practical problems for delays in the prosecution of the study. In a study of delay patterns, it was also necessary to make comparisons between specialties and we hoped to make international comparisons for a few commonly occurring conditions.

After consideration of these various issues, a it sample of recorders recruiting referrals over a one month period was deemed adequate data base in which to examine delay patterns. In order to achieve a 18 sample, coordinators were asked to seek a 28 a ample and to do their best to ensure the minimum of 18 proceeding through to follow-up.

For some of the objectives, it was possible to amalgamate data from different sources. For example, in the comparison of doctors with high and low referral patterns, it was possible to aggregate data from the various countries to examine the influence of age and distance from hospital etc.

The fourth objective of the study was to provide individual summary data for doctors to engage in audit by peer review or by aelf evaluation. For many recorders, this was perhaps their first opportunity to receive data which was individually specific and presented in a framework in which comparisons with colleagues could be made. From the figures presented in Table 4.1, a doctor with an average referral rate of 50 per 1000 consultations (58) who recorded thirty referrals, would obtain an estimate with a 958 confidence interval between $32 \& 68$ per 1000. If twice the standard error, expressed as a percentage of the estimate is regarded as a rough measure of the accuracy of the exercise, then thirty referrals presents an estimate with a 368 accuracy (twice the SE divided by the mean estimate 8 ). By similar calculation, a numerator of twenty is comparable with an accuracy of 438 and a numerator of sixty with an accuracy of 258. There is obviously some advantage in continuing until sixty referrals are recruited but we were aware that in the United Kingdom, there were practical difficulties for maintaining interest in this type of recording over long periods. For most doctors in the United Kingdom, thirty referrals would be recruited in about a month and sixty referrals in two months. This estimate applied in most countries except where the consultation frequency was low as for example in Portugal. For all these reasons, the study period was defined by the number 30 referrals or a maximum of 8 weeks recording.

\section{Standardisation}

The referral pattern of a doctor/practice depends on the age and sex composition of the patients consulting. By collecting consultation data in age and sex specific groupings, it was possible to standardise the practice referral rate to allow valid comparison between general practitioners with widely differing consulting patterns. The indirect method of standardisation was used in which an expected number of referrals was calculated in each age and sex group by applying the age/sex specific referral rates in the appropriate national data to the individual numbers of consultations reported by each doctor. The expected numbers of referrals in each group were totalled and the sum obtained was used to calculate the standardised referral ratio (SRR) which equals the observed divided by the expected and indexed to 100 . 
Monitoring this study involved the liaison pathways presented schematically in Fig 4.1. where the person responsible for the various functions is described together with the appropriate communication links.

Fig. 4.1 LIAISON BETWEEN PARTICIPANTS AND THE RELEVANT TASKS

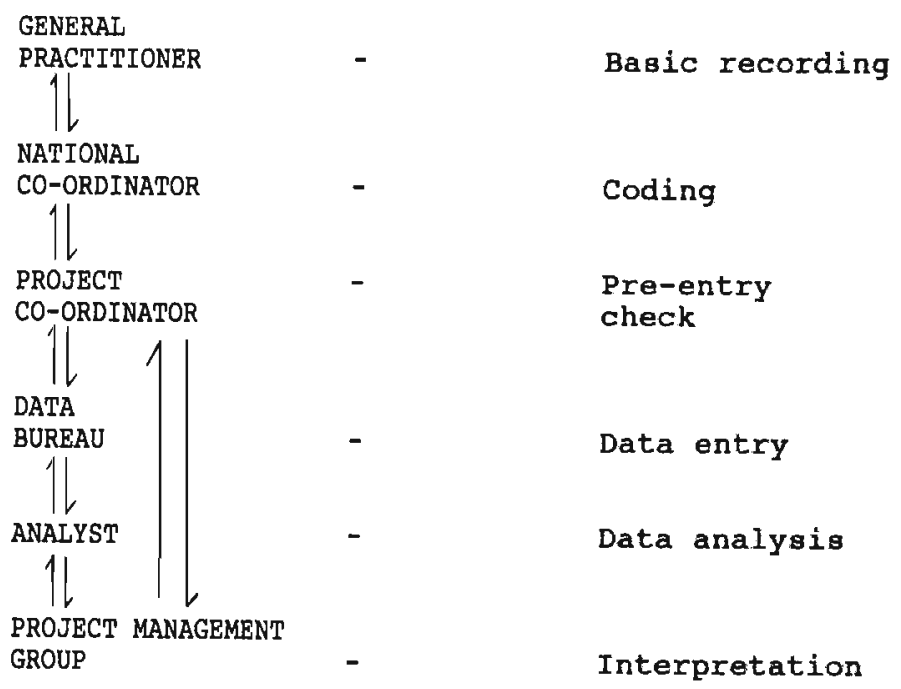

Basic recording

General practitioners were required to recruit thirty direct referrals and to monitor consultations as they occurred during that period. It was not possible to check if they had undertaken the tasks exactly as specified, but the data generated presented several opportunities for internal comparison and for comparison with other data which will be reported where appropriate. Some items of information were coded at this stage. For example, the general practitioner was required to code the specialty and for this purpose he had a ready reference of twenty seven specialty codes printed on each recruitment page.

\section{Coding}

Data booklets were prepared for data entry by the national coordinators and their staff. The tasks involved included:

1. checking the booklet for omissions in basic practice details and liaising with the practitioners for further details where necessary ;

2. checking that entries were legible and not confused by erasures or overwriting;

3. transposing such details as sex, age, type, mode of referral etc. from the "tick boxes" into simple numeric codes on the right of the recruitment sheet;

4. coding morbidity problem data into the three character (single alpha and double numeric) code of the ICPC;

5. entering " 0 " where necessary to complete a numeric data get (e.g. a record of 2 in some instances was unacceptable and should have been recorded " 02 ". 

information where there was potential confusion with a "0" entry.

These tasks as undertaken by the national co-ordinators were not checked or duplicated prior to data entry. In some cases, there were retrospective checks of specific items after data entry.

\section{pre-entry check}

Each national data set was referred to the project co-ordinator in preparation for data entry. At the recruitment stage, the checks undertaken were chiefly concerned with the completeness of the data. Even so, it was difficult to include all the data submitted by each national co-ordinator. Where obvious uncertainty occurred, clarification was sought by contact with the national co-ordinator.

At the follow-up stage, an additional and unexpected problem emerged. The middle section of the booklets containing the follow-up data disintegrated in some instances. For the majority it was possible to reassemble the booklet completely with the practice identifier but in a few instances, the follow-up section had to be abandoned.

There were two shortfalls in the follow-up phase. Firstly, some recorders failed to continue through to the follow-up phase. This was envisaged at the beginning of the study and where there had been good recruitment, no particular action was necessary. Secondly, some recorders provided follow-up data for only some of the thirty referrals. Again this was anticipated, especially in those countries where we knew that patients had easy opportunity to change doctors between referral and follow-up. For these reasons therefore, it was necessary to code follow-up data sheets to indicate the maximum potential data that might be expected following each referral. This coding procedure was checked at the project co-ordinating level.

\section{Data entry}

Data entry was undertaken by a commercial concern (Data Entry International, Birmingham). Critical data (characteristics of doctor and practice, age and sex of patients, specialty and date of referral), were subjected to a double entry procedure. Mismatched data identified on second entry were checked for accuracy by the data entry bureau. We had hoped to use the proportion of mismatches identified in these parameters as an approximate guide of mismatches in other data fields such as the mode of referral, patient influence, urgency etc. However, the data entry bureau did not retain these estimates for us.

\section{Analytical validation}

A series of preliminary validation exercises were undertaken prior to the main analysis. Data identified as doubtful were checked by re-examination of source documents.

Reqiotered list:- For those countries in which practice populations were recorded, extremes were identified and checked. In a few cases, an additional zero had been entered: for example, 
a five doctor practice with 95,000 persons instead of 9,500. This check was simple to undertake and errors easily corrected.

Date sequences:- Two data sequences were examined. The first concerned the dates of recruiting thirty referrals by each doctor. The second concerned the sequencing of the dates of referral, appointment, comunication and surgical intervention. In some cases, this examination led to small corrections. In others, the examination identified a few referrals which were allegedly made after the date of specialist appointment. These occurred in the Netherlands and Belgium especially and were probably due to retrospective authorisation of referral by the doctor. These data were excluded from the follow-up analysis.

Limit values:- The total data were examined by country, from which cell limit values were derived for consultatons/visits in specific age groups. Values outgide these limits were checked in source records. For some values, global limits could be applied and these included:

a) office encounters to exceed home visits;

b) male consultations not to exceed $60 \%$ of total;

c) consultations in the age group 5-64 years to account for a minimum of $50 \%$ of all consultations.

It was particularly evident when looking at a computer programme in which limit values were inserted, that errors in one cell were associated with errors in another and the same records were identified each time.

Digit sequences:- Entries from cells in consultation counts were checked if three successive counts were multiples of ten (e.g. $40,30,60)$. This sequencing suggested transposition of digits within the score grids which were checked and errors corrected.

Diqit preferences:- Because of the different style of writing in European countries particularly for the numbers 1 \& 7 and 4 \& digit preference in terminal digits was examined. No problems were identified which might suggest poor quality data entry.

Doubtful data:- Referrals which seemed inappropriate were quantified. In the data from 'All Countries' concerned with referrals to paediatricians, there were 25 persons aged 15-24 years and 15 persons aged over 25 yeara out of 905 altogether: for Geriatric Medicine, 7 out of 445 referrals were aged less than 44: for Obstetrics and Gynaecology there were 68 males in a total of 4240 referrals. On first sight these might seem anomalies. However, adults are referred to paediatricians for genetic counselling, handicapped young persons are sometimes referred to geriatric specialista becauge of the resources available for major disability, males are sometimes referred to obstetricians and gynaecologists as part of the investigation of an infertile couple. Given the relative numbers in each of the examples quoted, these results are more likely to reflect reality than error.

Partitioned analysis:- Each doctor was required to collect thirty referrals. Relevant data were examined for the first, second and third group of ten patients. In particular, the distributions of referrals between the different types, modes of referral and specialties were examined. No important differences were 
identified suggesting that the quality of data capture had remained consistent throughout the study.

Excluded data:- Data from doctors recording less than 100 consultations and those from recorders with recruitment booklets containing numerous corrections were excluded.

The net effect of these various data checks produced only marginal changes in the statistics generated in this report for each country.

\section{Interpretation}

The interpretation of the data was made by the Project Management Group. The final say on the interpretation of each national data set was vested in the respective national co-ordinator and for the international analysis in the project leader. A major part of data validation was undertaken indirectly by comparing results with national data from other sources. Comparisons of items of information such as the age of the doctor was used to examine the representativeness of the sample. Distribution for some statistics, for example consultation and home visit data, are well known in most countries and these were used where appropriate to validate the recording methods of the study.

\section{ICPC CODING}

It was agreed at the outset that we should use the International classification of Primary Care should be used where possible. The decision had particular bearing on the classification of the health problem and also on the classification of items of information such as the specialty and the mode of referral. At the launch of the study there was no established classification of specialties nor of aspects of the referral process. In a sense therefore, the study has broken new ground in the establishment of a coding of specialties and of the referral process. These features will be self evident in the relevant sections of this book (Chapters $3 \& 5$ ). This report however is more concerned with the use of ICPC in describing the health problems.

The development of the ICPC emerged out of the recognition of the inadequacies of the International Classification of Diseases (ICD) in addressing some of the problems of primary care. The ICD is a classification with greatest potential use in the retrospective mode : the diagnosis is settled wherever possible at the end of an observation process and not at the beginning. It is therefore appropriate for describing health problems at the end of a period of hospitalisation but may not be so valuable in describing the problem prior to hospitalisation. For similar reasons, illnesses which are minor and usually only call for one consultation are often only capable of loose symptomatic descriptions. To this extent however, both classifications permit adequate descriptions of symptoms where more precise pathology cannot be specified and both retain a structure in which symptoms can be linked to the relevant diagnostic chapter of the classification.

The ICPC has been designed with continuous morbidity registration in mind. It focuses on the episode of illness as the central unit of analysis and each episode contains the elements - reason for 
encounter, process of care, diagnosis and disposal (referral etc). The concern of this study was the medical reason for referral which is neither the reason for encounter nor the established, nor even likeliest diagnosis. Referral is commonly made to exclude a specific diagnosis. Many skin lesions are biopsied because the doctor recognises the possibility even if unlikelihood of malignancy. Neither the ICD nor the ICPC are ideal classifications for this purpose. The ICPC classification was chosen because of its international acceptability in Europe and recorders were requested to specify the diagnoses, (probable or possible) which prompted the referral, but if it was not possible to be this precise, then the most appropriate single symptom should be specified.

The coding of the health problem was required to meet two objectives: firstly, to recognise national differences among frequent health problems referred to specialists and; secondly, to analyse delay patterns in differing countries for problems which were commonly encountered in several countries. A report on the use of ICPC in the study and some of these details will be published separately. (Lamberts et al, 1992). 


\section{INTRODUCTION}

This chapter commences with some information about general practitioner recruitment in each country and explains briefly the content of national data available in the appendix. Some examples are given explaining how the data can be used to make comparisons.

The meat of the chapter is concerned with an analysis of healthcare structures in relation to the findings which are reported under five headings - Consultations and visits, Referrals, Reported urgency and patient influence on the referral decision, Referral by major specialty group, and Delays in the referral procesa. Statistical data are presented in a similar format for most of the findings - using bar charts ranking countries in relation to the average value reported by each gp in the national sample. The results are discussed systematically by each of the healthcare structure variables.

\section{RECRUITMENT}

Recruitment in each country is sumarised in Table 5.1 in which data are presented alphabetically by country. The table includes the numbers of doctors participating in the recruitment phase and those returning follow-up documents. A few data sets were of unacceptable quality and were excluded from the study. The differences between follow-up and recruitment reflect administrative differences in the national arrangements for securing follow-up.

TABLE 5.1 G. P. RECRUITMENT AND FOLLOW-UP DATA SETS BY COUNTRY

$$
\text { Recruitment Follow-up }
$$

$\begin{array}{lrrrrr}\text { Belgium } & 45 & 31756 & 1222 & 24 & 698 \\ \text { Denmark } & 54 & 24087 & 1583 & 37 & 1081 \\ \text { France (DDR) } & 27 & 16215 & 421 & 15 & 225 \\ \text { Germany (FRG) } & 23 & 16746 & 688 & - & - \\ \text { Germany (FRG } & 71 & 37712 & 2095 & 65 & 1915 \\ \text { The Netherlands } & 55 & 35410 & 1586 & 49 & 1428 \\ \text { Eungary } & 74 & 63538 & 2217 & 65 & 1948 \\ \text { Ireland } & 20 & 12574 & 530 & 15 & 405 \\ \text { Italy } & 215 & 92846 & 6214 & 142 & 4132 \\ \text { Norway } & 33 & 11338 & 926 & 28 & 791 \\ \text { Portugal } & 124 & 58301 & 3248 & 99 & 2572 \\ \text { Spain } & 250 & 127208 & 7031 & 198 & 5566 \\ \text { Switzerland } & 37 & 28546 & 1096 & 36 & 1066 \\ \text { United Kingdom } & 407 & 250824 & 11888 & 253 & 7392 \\ \text { Yugoslavia } & 113 & 53126 & 3389 & 68 & 2040 \\ & & & & & \\ \text { All Countries } & 1548 & 860227 & 44134 & 1094 & 31259\end{array}$


Each national data set is summarised into three figures and three tables and presented with a commentary as an appendix. The data set for each country includes:

Fig.1 Percentage distribution of recruited doctors by age with national comparable data where available.

Fig.2 Percentage distribution of consultations by age and sex.

Eig.3 Age/sex specific referral rates per 1000 consultations.

Table 1 Numbers of referrals by specialty, percentage of total referrals and rates per 1000 consultations by sex.

Table 2 Percentage of referrals in each sex distributed by mode, type, urgency, patient influence on the decision to refer.

Table 3 Delay patterns between referral and first appointment in major specialty groups.

From these national data sets, many individual comparisons can be made which throw light on the referral process. For example:-

In both Portugal and Switzerland, gps recruited were reasonably representative by age of the national pattern. In Portugal, 538 of gps were aged less than 34 years whereas in Switzerland, all the gps recruited were aged over 35 years of age. Among the Portuguese recruits, $52 \%$ were female compared with only 38 in Switzerland, (national estimate 148).

In the Republic of Ireland, $30 \%$ of male consultations and 218 of female consultations were for children aged 0-14 years compared with 108 and 68 respectively in FRG. The every day experience of working gps in these two countries involves different patient clienteles.

In Italy, 408 of referrals were "re-referrals" authorising continuing specialist care - a much higher figure than in any other country.

Referral rates to dermatologists were virtually the same for both male and females in each of the countries. However, they were widely variable between countries : in Denmark for example, the rates of 12.0 per 1000 for males and of 11.2 per 1000 for females are more than twice the rate in any other country, yet in Denmark, patients have open access to dermatologists.

In the more southerly countries, (France, Italy, Portugal and Spain), there were more females referred to cardiologists than males, whereas in the north, there were more males.

\section{ANALYSIS BY GEALTHCARE STRUCTURE}

The main analyses presented in this chapter are concerned with the relationship between six structural variables and measurements of consultations and referrals. The allocation of countries to each of these variables (Table 5.2) has been based on information from various sources and consolidated at NIVEL(Groenewegen et al, 1991, ,1993 and allocates each country according to the predominant arrangement 
within it. In some countries, data are not sufficiently specific to distinguish active and retired doctors, full and part-time doctors and doctors in research or training posts. When considering remuneration systems, there is no country in which a capitation system of payment completely excludes some fee for service payments: or when categorising by access to specialists, no country is so rigid in the application of a general policy that exceptions do not occur. Thus an element of judgement has been necessary in order to make the allocation.

The national data for $g p$ and specialist density have been presented in approximate rank order (high to low) within each

category. Remuneration has been categorised into fee for service, capitation and a mixed category. Allocation according to the current arrangement for gp training is not necessarily indicative of the training experience of general practitioners contributing to the study. The countries of the former Eastern European Socialist States (Bungary, Yugoslavia \& DDR), have not been included in most of these analyses since the data available are less secure for the purpose of allocating doctors to the various categories.

TABLE 5.2 DISTRIBUTION OF WESTERN EUROPEAN COUNTRIES BY SELECTED ITEMS OF HEALTHCARE STRUCTURE

General practitioners per 100,000 population

$\begin{array}{lll}\text { High } & (>90) & \text { Belgium, Italy, France } \\ \text { Medium } & (60-89) & \text { Ireland, Denmark, Norway, Portugal } \\ \text { Low } & (<59) & \text { U.K. Switzerland, Spain, FRG, NL. }\end{array}$

\section{Specialists per 100,000 population}

$\begin{array}{lll}\text { High } & (>90) & \text { FRG, Denmark, Belgium, Italy, France, Norway. } \\ \text { Low } & (<89) & \text { Spain, Portugal, Ireland, Switzerland, NL, UK. }\end{array}$

Remuneration System for General Practitioners

$\begin{array}{ll}\text { Fee for service } & \text { Belgium, France, FRG, Switzerland. } \\ \text { Mixed } & \text { Denmark, Ireland, Italy, Spain. } \\ \text { Capitation/salary } & \text { NL, Norway, Portugal, UK. }\end{array}$

Remuneration Systems for Specialists

Fee for service Mixed

Capitation/salary

Belgium, Denmark,France, NL, Norway, Switzerland. FRG, Ireland, Italy. Portugal, Spain, UK.

\section{Access to Specialists}

$\begin{array}{ll}\begin{array}{l}\text { Open } \\ \text { Mixed }\end{array} & \text { Belgium, France, Switzerland. } \\ \text { Closed } & \text { FRG, Ireland, Italy, Portugal. } \\ & \text { Denmark, NL, Norway, Spain, UK. } \\ \text { Programmeg for Training in General Practice } \\ \text { Weak } \\ \begin{array}{ll}\text { Strong } & \text { Belgium, France, FRG, Ireland, Italy, Spain, Switzerland. } \\ & \text { Denmark, NL, Norway, Portugal, UK. }\end{array}\end{array}$




\section{CONSULTATIONS AND VISITS}

Data are given in Figure 5.1 sumarising the average nutbes of consultations (including home visits) undertaken by gps is normal working week. This calculation was made for each coctor individually based on weeks described by the recruited doctor as: "normal" and then the average value for each doctor was averaged to provide a national figure. In Figure 5.2, the average numbers of home visits are presented similarly and in Figure 5.3 , the proportions of all consultations involving a home isit are summarised. The relationship with each of the variables considered in turn.

Figure 5.1

Average number of consultations in a normal working week

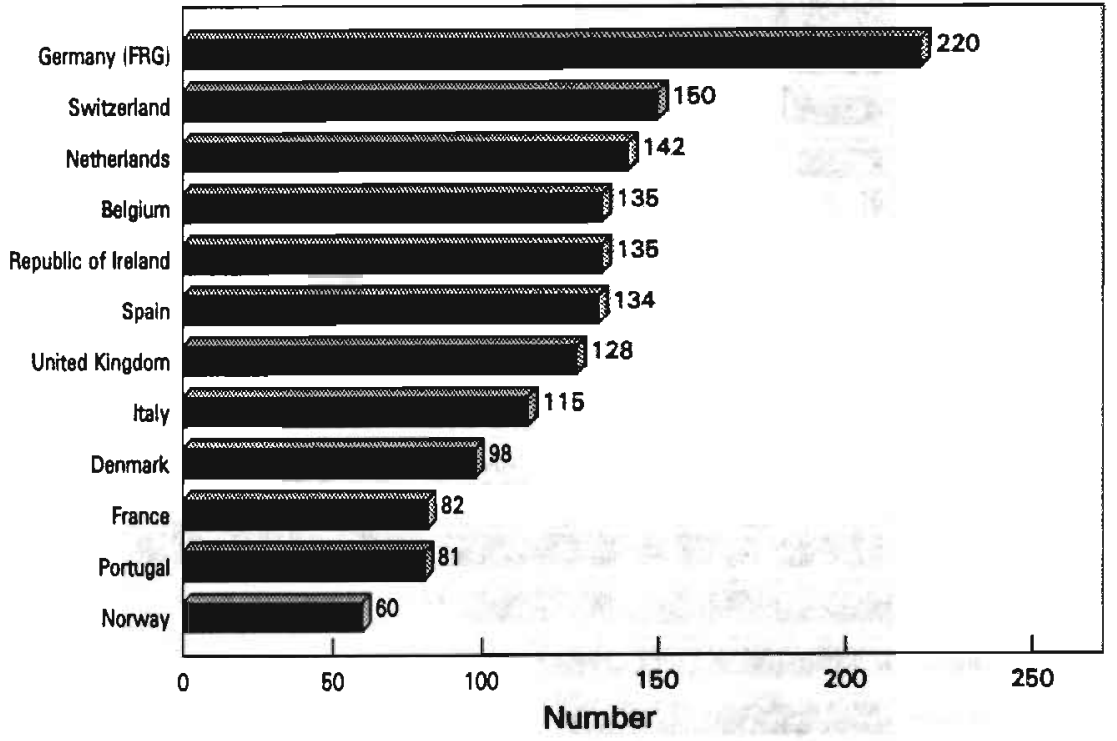




\section{Figure 5.2}

Average number of visits in a normal working week

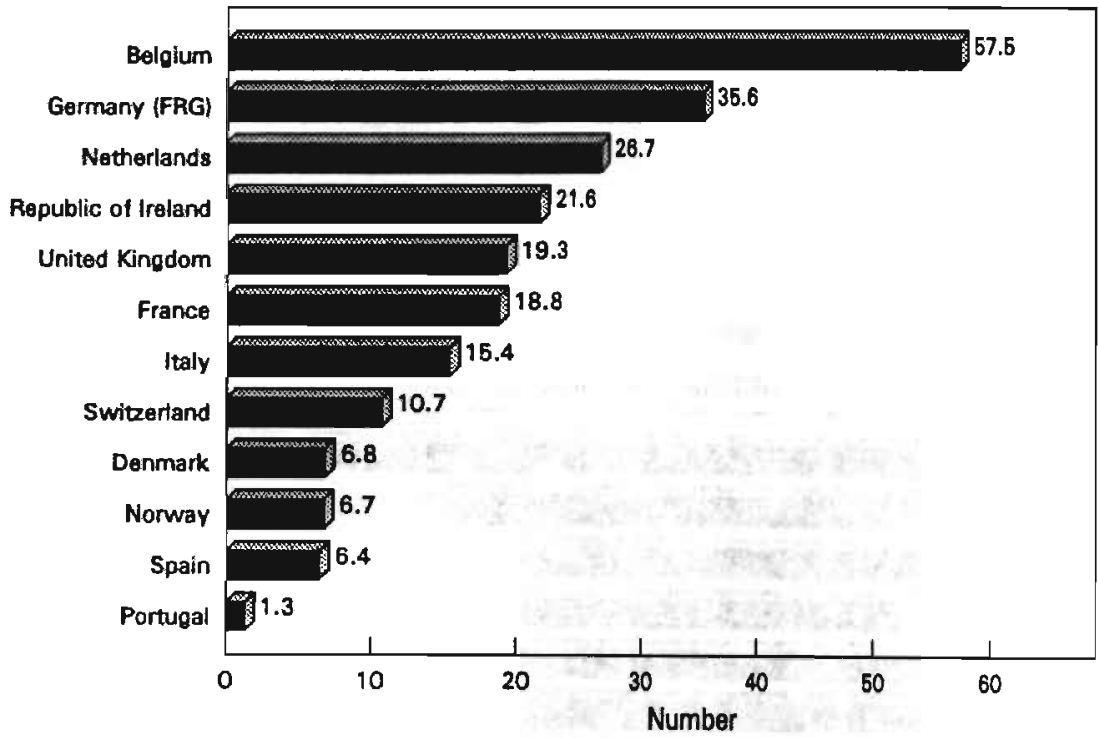

Figure 5.3

Visits as a percentage of consultations

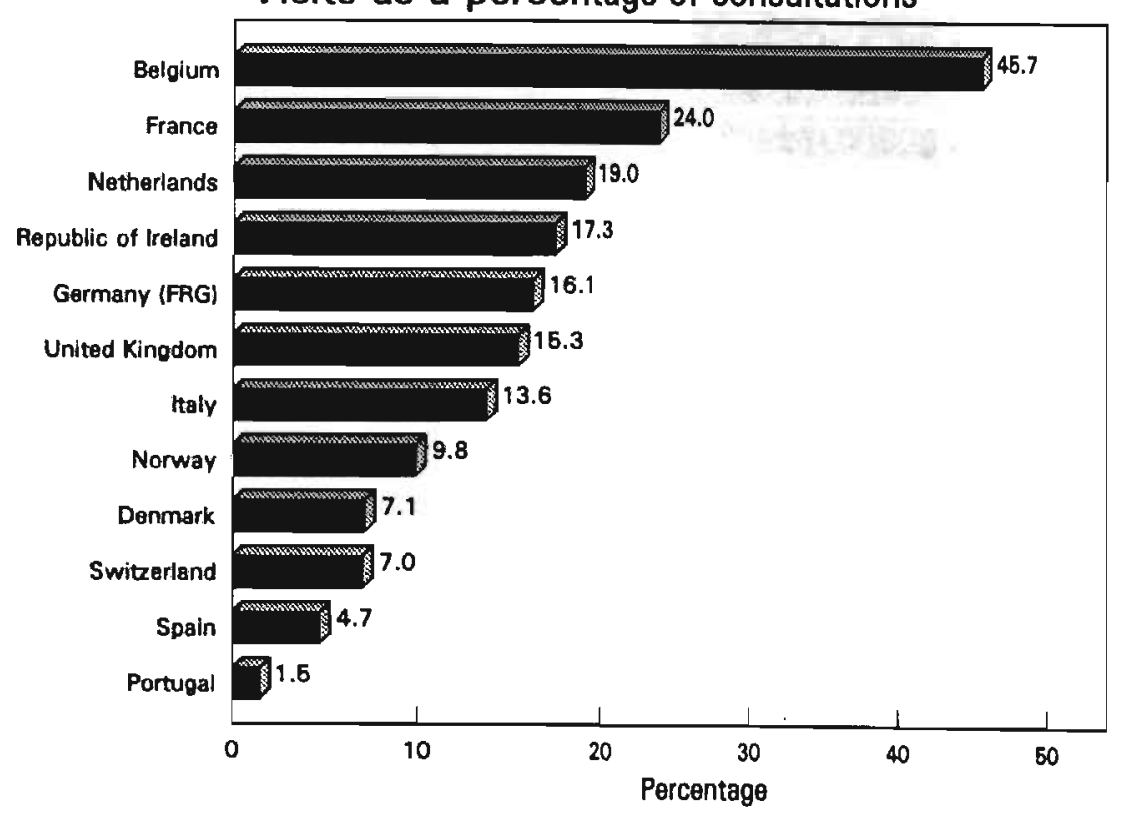


Density of gps:- The highest numbers of consultations per week were recorded in FRG, Switzerland and the Netherlands and these countries have a low density of gps. Belgium and Italy have the highest density of gps and they were in the middle ranks for this statistic. The least number of consultations were recorded in countries in the middle range of general practitioner density. The highest number of home visits was undertaken in Belgium where 45.78 of all consultations involved a home visit. The visiting patterns in France and Italy which also have high density of gps, does not differ from that in most other European countries. The workload of a gp relates in the obvious way to the density of gps in the country (low density, high workload), though the relationship is variable in countries with a high density of gps.

Density of specialists:- There are no relationships between gp consultation patterns and the density of specialists.

Remuneration of gps:- In FRG, Switzerland and Belgium, gps are remunerated by fee for service and these countries were ranked first, second and fourth for the average number of consultations in a working week. Though the results for France were not similar, the French sample in this study was small and not nationally representative. FRG and Belgium were also ranked high for the numbers of home visits and the relative proportion of home visits as a percentage of all consultations. The Netherlands was ranked third for both statistics: here the method of remuneration is predominatly by capitation, the gps obtain approximately 258 of their income from fees for services.

In Portugal and Norway, both the total numbers of consultations and of home visits were lower than in most other countries. In the U.R. where capitation is also the predominant method of $\mathrm{gp}$ remuneration, consultations and visits were about average for Europe.

Fee for service does influence the number of services (consultations and visits) provided by gps.

Remuneration of specialists:- There are no relationships between the consulting and visit patterns of gps which relate to the remuneration of specialists.

Access to specialists:- In Belgium and France where there is unrestricted access to specialists, the proportion of consultations undertaken as home visits was high.

Training for aps:- In general, countries with strong training programmes undertook fewer consultations than those with weak programmes, but no differences were evident in the analysis of home visits separately.

\section{REFERRALS}

The average numbers of referrals in a normal working week are given in Figure 5.4 and the average referral rates per 1000 consultations in Figure 5.5 . 


\section{Figure $\mathbf{5 . 4}$}

Average number of referrals in a normal working week

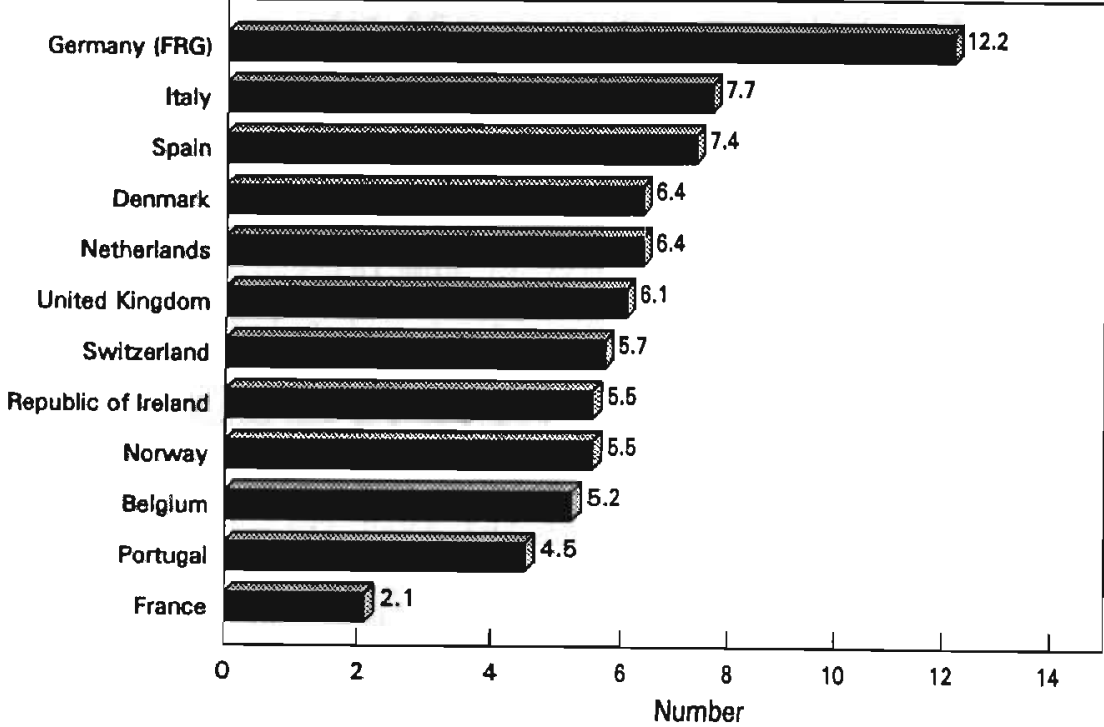

Figure 5.5

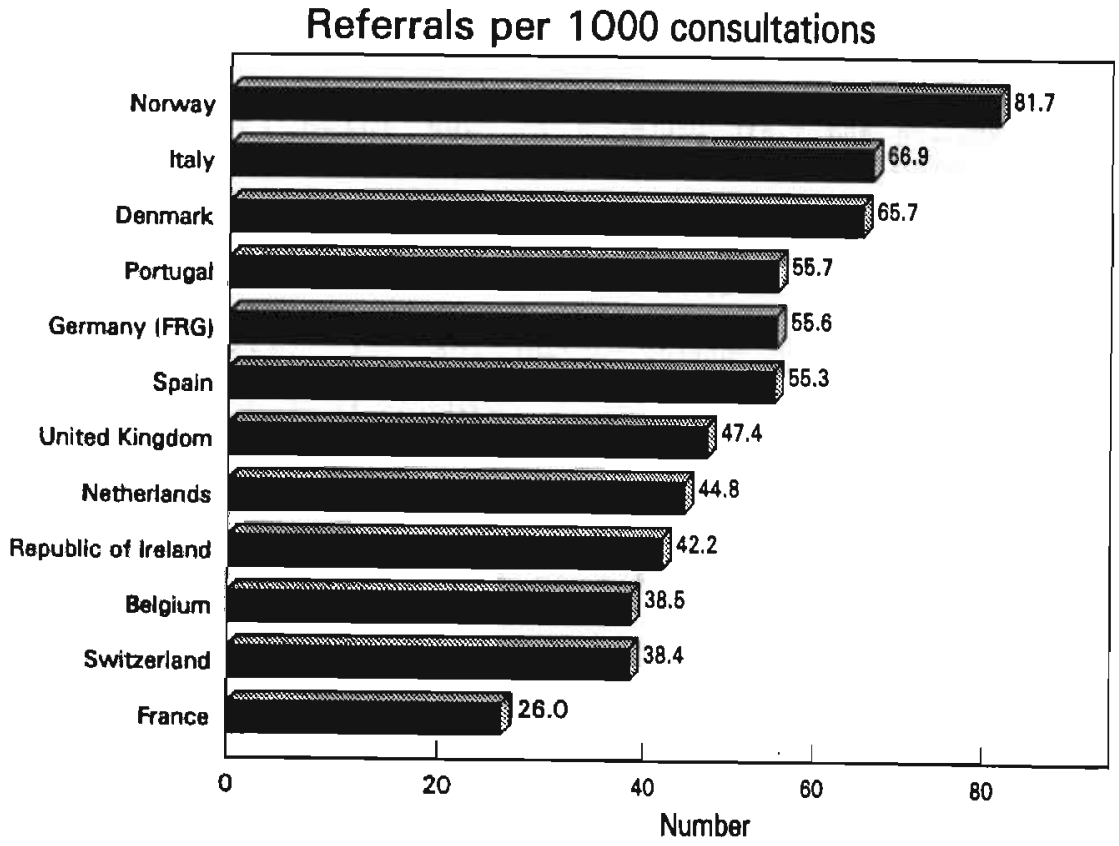


Density of gps:- With the exception of FRG, gps in low density countries referred similar numbers of patients to speelalistes though there was a slightly greater variability when referrale were examined as rates per 1000 consultations. The result in FRG is especially notable because gps in this country also recorded the highest rate of indirect referrala.

Density of specialists:- The distribution of referrals in normal working week bears no conaistent relationahip to the density of specialists. As a proportion of consultations however, the first three ranked countries Norway, Italy and Denmark, were all countries with a high density of speciallsts. In these countries, there is at least some control over access to specialists via gps whereas in Belgium where there is also a high density of specialists, there is no control and referrals were not so great either in number or as a rate per consultation.

Remuneration of gps:- Neither the number nor the rate of referrals appears to be influenced by the remuneration system for gps.

Remuneration of specialists:- There were no consistent relationships between gp referral activity and the remuneration system for specialists.

Training for gps:- Countries with well established training programes are in the middle of the rankings for the average number of referrals in a normal week and also (excepting Norway), for the proportion of consultations leading to referral.

Access to specialists:- Countries with maximum opportunity to consult specialists directly (Belgium, France and Switzerland) disclosed low referral rates from primary care.

\section{REPORTED URGENCY AND PATIENT INFLUENCE ON THE REFERRAL DECISION}

Data were obtained about the degree of urgency in individual referrals and about the influence of the patient on the decision to refer. Urgency was described as immediate, urgent or routine and patient influence as nil, small or large. The analysia concerned with the proportions of referrals described as immediate or urgent is given in Figure 5.6 and that concerned with the proportions described by the gp as influenced at least to some extent by patient pressure, in Figure 5.7.

Density of gps:- The countries with a low density of gps were widely distributed across the range of results for the proportion of referrals described as immediate or urgent. There was a possible association with the proportions of referrals reported to be influenced by the patient in this group of countries(the five countries occupied first, second, sixth, seventh and tenth ranked positions).

Density of specialists:- The urgency of referral was not related to the density of specialists. Four of the countries with a high density of specialists (FRG, Denmark, Belgium and Norway), showed relatively high rates of patient influence on the referral decision. Patient influence was strongest in the Netherlands which, though not having a particularly high density of specialists, nevertheless has twice as many specialists as gps. 
Figure 5.6

\section{Proportion of referrals described}

as immediate or urgent

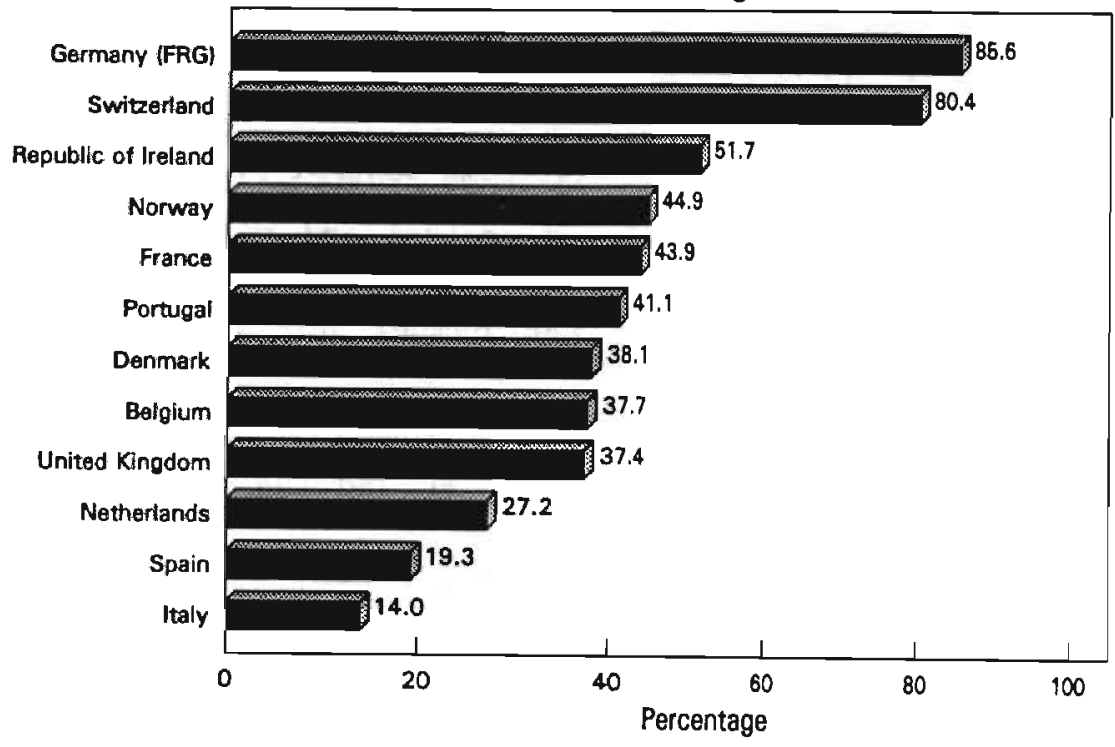

Figure 5.7

Proportion of referrals influenced by patient pressure

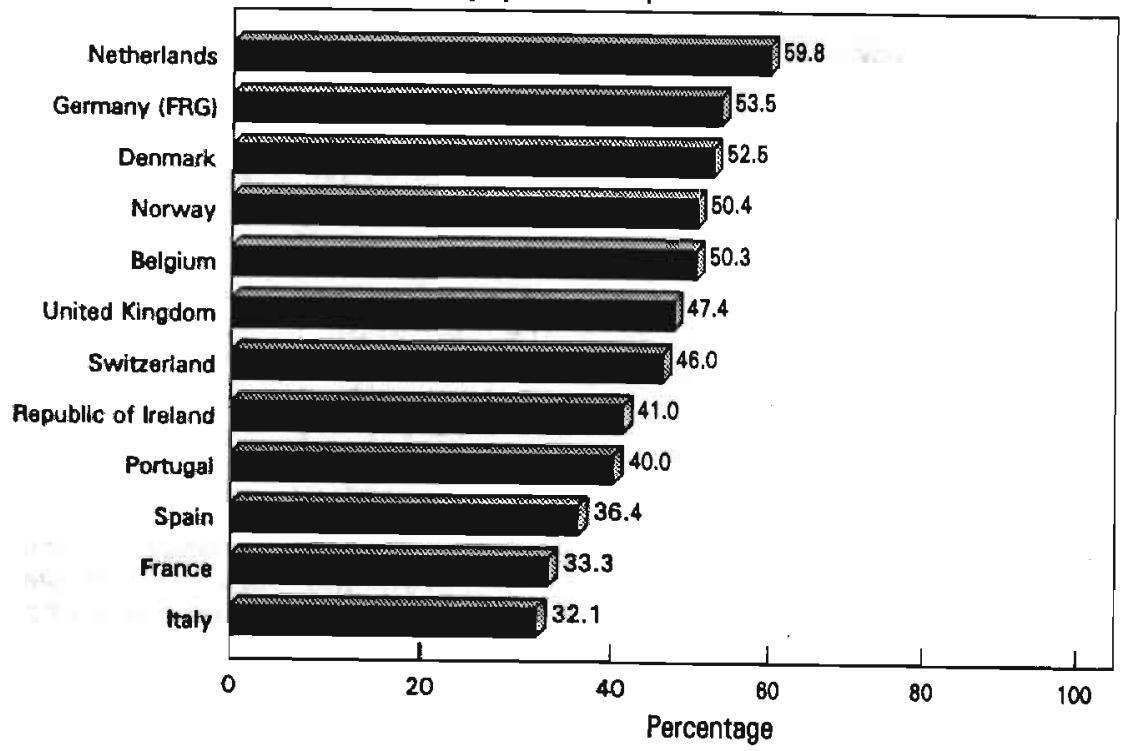


It seems reasonable to conclude that where there is a high density of specialists, patients exerted a greater degree of influence on the referral process. (The results from countries with completely open access to specialists cannot be evaluated in this analysis).

Remuneration of gps:- In Switzerland and FRG, there were many more referrals described as immediate or urgent. The interpretation of the word "urgent" into German caused some confusion and therefore the results must be interpreted with caution. There is no obvious relationship between the request for urgent specialist appointment and the remuneration system of gps. Neither is there any evidence to suggest that the influence of the patient on the referral decision differed according to the way gps were paid.

Remuneration of specialists:- There were no clear relationships in the method of specialist remuneration and the request for urgent appointments or the extent to which patients influenced the referral decision.

Access to specialists:- There were no obvious associations between access opportunity and requests for immediate or urgent appointment nor between access and patient influence on referral decision.

Training for gps:- Countries with a strong gp training programme disclosed results in the middle of the range for the proportion of referrals described as immediate or urgent. In general, these countries showed increased proportions of referrals in which the decision was perceived to be influenced by the patient.

\section{REFERRAL BY MAJOR SPECIALTY GROUPS}

The proportion of referrals made to the major specialty groups (Medical, Surgical, other) is given in Table 5.4 with countries ranked by the proportions to medical specialties.

TABLE 5.4 DISTRIBUTION ( $)$ OF REFERRALS BY MAJOR SPECIALTY GROUP Medical Surgical Other

$\begin{array}{llrr}\text { France } & 54.0 & 36.9 & 9.1 \\ \text { Belgium } & 46.4 & 39.9 & 13.7 \\ \text { Spain } & 44.9 & 37.6 & 17.6 \\ \text { Switzerland } & 43.0 & 45.0 & 12.0 \\ \text { Denmark } & 39.4 & 44.5 & 16.1 \\ \text { Netherlands } & 36.8 & 51.9 & 11.3 \\ \text { Italy } & 36.2 & 52.7 & 11.1 \\ \text { Germany (FRG) } & 35.7 & 52.9 & 11.5 \\ \text { Norway } & 33.8 & 46.0 & 20.2 \\ \text { Republic of Ireland } & 29.9 & 39.0 & 31.0 \\ \text { United Kingdom } & 29.8 & 44.9 & 25.3 \\ \text { Portugal } & 28.5 & 49.8 & 21.7\end{array}$


Density of gps:- There are no close relationships with the distribution by major specialty group.

Density of specialists:- There are proportionately more referrals to medical specialties in countries where the density of specialists is high.

Remuneration of gps:- Countries in which there is a fee for service payment structure refer relatively more patients to medical specialties. The capitation system is associated with relatively less referrals to medical specialties.

Remuneration of specialists:- Countries with fee for service specialist payment structures disclosed relatively greater proportions referred to medical specialties.

Access to specialists:- There was a trend between those countries in respect on the one hand of the proportion of referrals to medical specialties and on the other hand the extent of open access: countries with unrestricted access to specialists reported the highest proportion of referrals to medical specialties and those with closed access the lowest.

Training for gps:- The countries with a strong gp training programme were associated with a smaller proportion of referrals in the medical specialties than those countries in which training was weak.

\section{DELAYS IN THE REFERRAL PROCESS}

The delay between referral and first appointment with a apecialist is described in three statistics:-

the proportion seen within 4 weeks;

the proportion not seen within 16 weeks;

the mean delay (days) of persons known to have been seen within 16 weeks.

The results (Table 5.4) are ordered by the proportions seen in 4 weeks. The mean delay, being restricted to those persons seen within 16 weeks, tends to under estimate the delay where substantial numbers of persons are not seen within that period. In those countries in which patient registration is not usual, the proportion not seen within 16 weeks may include patients with whom the gp has lost contact. In Figure 5.8, additional information is given concerning the mean delay in medical, surgical and other specialties. This figure shows that mean delays were similar for each specialty group in any specified country.

Two other delays were examined, the delay between specialist appointment and communication with the gp and the delay between specialist appointment and surgical intervention where planned. Information about these secondary delays has been published (RCGP, 1992) and will not be considered in detail here. Though it is worth making the point that those countries with long delays for specialist appointment also reported long delays for surgical intervention. 
TABLE 5.4 DELAYS BETWEEN REFERRAL AND FIRST APPOINTMENT

$\begin{array}{lccc} & \begin{array}{c}\text { Seen within } \\ 4 \text { weeks }\end{array} & \begin{array}{c}\text { Not seen within } \\ 16 \text { weeks }\end{array} & \begin{array}{c}\text { Mean delay } \\ \text { in days }\end{array} \\ \text { France } & 92.2 & 4.3 & 6.3 \\ \text { Italy } & 87.4 & 2.4 & 10.7 \\ \text { Belgium } & 86.9 & 7.7 & 7.5 \\ \text { Switzerland } & 86.1 & 1.9 & 12.5 \\ \text { Spain } & 85.1 & 2.5 & 12.0 \\ \text { FRG } & 83.3 & 12.3 & 6.9 \\ \text { Netherlands } & 70.9 & 20.6 & 10.8 \\ \text { Denmark } & 59.4 & 9.1 & 26.2 \\ \text { Ireland } & 49.1 & 16.2 & 27.4 \\ \text { Portugal } & 46.4 & 22.8 & 28.5 \\ \text { Norway } & 41.6 & 13.4 & 33.7 \\ \text { U.K. } & 39.1 & 15.3 & 36.3\end{array}$

Figure $\mathbf{5 . 8}$

Delay between referral and appointment by major specialty group

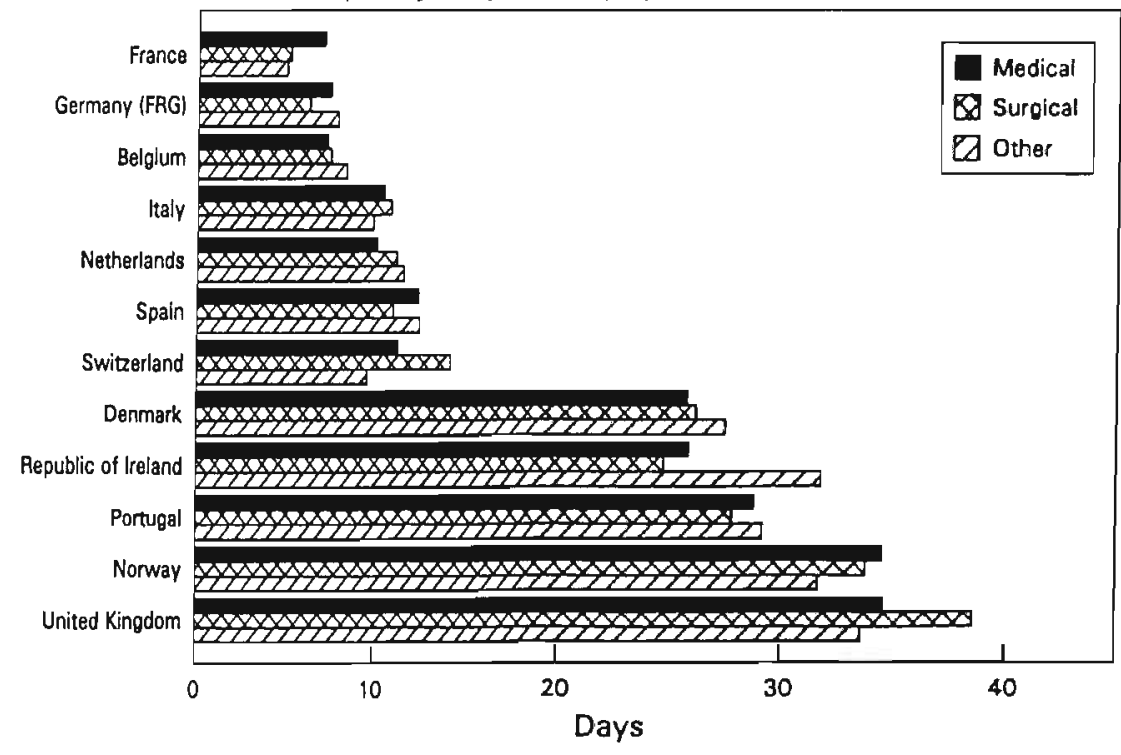

Density of gps:- The three countries with the highest gp density (Belgium, France and Italy), disclosed particularly short delays in the referral process, though there were no other discernable relationships between gp density and delay. 
Density of specialists:- With the exception of Norway, countries with a high density of specialists experienced least delays.

Remuneration of gps:- There was a trend with least delays in the countries remunerating gps by fee for service and greatest delays in countries with a capitation system of remuneration.

Remuneration of specialists:- There was a trend with least delays in countries where the specialists were remunerated by fee for service and greatest delays where remuneration by salary predominated. The data disclosed a doubling of mean delay between the ranking of the Netherlands and Denmark. Among the five countries reporting these markedly increased delays, only in Norway were specialists remunerated by fee for service.

Access to specialists:- Delays were generally shorter in those countries with open access to specialists.

Training for gps:- Four of the five countries with the longest delays (U.K., Norway, Portugal, and Denmark), have strong gp training programmes. Mean delay in the Netherlands where there is also a strong training programme, was substantially less than in these countries.

\section{SUMMARY OF RESULTS BY STRUCTURAL CHARACTERISTICS}

Density of gps:- Low density of gps was associated with increased average numbers of consultations and an increased recognition of patient influence on the referral decision.

Density of specialists:- High density of specialists was associated with greater patient influence on the referral decision and with relatively greater proportions of patients referred to medical specialties. Delays in countries with a high density of specialists were comparatively reduced.

Remuneration system of gps:- The numbers of consultations and visits are influenced by the remuneration system with higher rates linked to fee for service structures. The remuneration had a amall influence on referrals to medical specialists with a greater proportion recorded where there were fee for service payment structures for gps. Delays for specialist appointments were less in countries where a fee for service payment system predominated.

Remuneration system of specialists:- There were relatively more medical referrals and shorter delays for specialist appointment where specialists were paid by fee for service.

Access to specialists:- Referral activity was generally lower where maximum opportunities for direct access to specialists exist, but the proportions referred to medical specialties were greater. Such a conclusion could arise because patients would more readily recognise the need for surgical specialist opinion and where open access to surgeons existed, they took advantage of it. However, there is an equally plausible argument that communities in which open access to specialists exist, would tend to favour a more extensive use of specialists, have more specialists available, and would accept a lower threshold of referral from primary care. The study has not examined data from 
patients consulting specialists by self referral and therefore cannot be used to decide between these alternatives.

countries with open access to specialists disclosed shorter delays for patients referred from general practitioners compared with those countries where access was controlled by the gps.

Training of gps:-Countries in which there was a strong tradition of gp training recorded fewer consultations in a normal week. Doctors in these countries also appeared to recognise greater patient influence on the referral decision. Of those referred, a smaller proportion were to medical specialties. In general, there were longer delays in countries where stronger training traditions existed. GP training appeared to have a "normalisation effect" with the countries in which gp training was strong disclosing results in the middle of the rankings for many of the statistics.

\section{Comments}

The characteristics of healthcare structure considered here are not independent of each other and in turn depend on separate and national characteristics, nor are they equal in importance. It is thus impossible to examine them as a set of independent variables. Put together, the results indicate high rates of referral where specialist density is high and fee for service payment systems predominate. This is also the situation in which referral delays are minimised.

Countries with strong gp training programmes disclosed lower consultation rates than those where training programmes were weak and yet they permitted a greater influence of patients on the referral decision. There were less referrals to medical specialties but delays were longer. In general, these results can be regarded as evidence that the presence of a gp training programme is associated with more equal delivery of healthcare which is less demand driven than in countries without such programmes. However, in countries which have established gp training programmes, there possibly also has been the same interest to establish control of recruitment to medicine whether as specialists or as gps and hence there is a tendency for higher density of specialists where gp training programmes are weak. There is thus a trade off in planning a logical healthcare structure as between the total number of gps available in a country and the efforts made to provide gp training. It is obviously essential that adequate numbers of both specialists and gps exist, but in order to achieve cost effective healthcare, manpower resources must be appropriately tralned and properly managed.

There was some association between fee for service payments for general practitioners and high consultation rates. There are difficulties in interpreting the referral data because of the confounding effects of open access to specialists coexisting with fee for service payment arrangements for gps. However, they suggest optimal delivery of healthcare in a combination of $\mathrm{gp}$ remuneration by capitation, strong training programes for general practice, restricted access to specialist care and fee for service remuneration of specialists. Such an arrangement can only work where there is controlled recruitment to medicine. 


\section{CBAPTER 6}

\section{COMPARIBOX BETWEEN THE HIGHEST AND LOWEST GROUPS OF REFERRING DOCTORS}

The objective to compare the characteristics of the highest and lowest referrers was included to investigate potential explanations of variations in referral behaviour. A considerable range of referral rates has been identified in numerous general practice based surveys with comparatively little identified to explain the variation. In a very detailed analysis of practice referral patterns extending over twelve months observation in England and Wales, the age, sex, social class and case mix of patients attending the practices contributed only marginally to explaining inter-practice variability (Fleming et al, 1991b). In this survey, the authors established that the ratio of referral rates between the 80 th and 20 th centile practices was 1.6 regardless of how the referral rate was calculated. Practices in the Highest quintile of referrers referred patients twice as frequently as those in the Lowest quintile. Grol et al (1990) identified a weak association between the defensive attitude of doctors towards risk taking and referral behaviour but this is one of very few studies purporting to provide any explanation for the variation between general practitioners.

The standardisation of the referral data for individual general practitioners based on the average national consultation pattern provided the means of direct comparison between groups of doctors within countries. "Highest" referring doctors (the 208 highest ranked doctors) in each country were grouped together and aspects of their personal detailg and their referral performance were compared with those of the "Lowest" referring doctors (the 208 lowest ranked doctors). The tables in this chapter present data for the average among the recorders within each category. Appropriate statistical comparisons between the Highest and Lowest referral groups have been made (chi square test of distributions or Mann Whitney $U$ test of rankings). Where any differences were identified, examination in greater detail was made by looking for trends in all five referral groups in the consolidated European data.

\section{RESULTS}

\section{Variation}

The extent of variation in each of the national data sets is considered in Table 6.1 . The values of the standardised referral ratio which identified the upper limit of the Lowest quintile group of recorders and the lower limit of the Highest quintile group, and the ratio between these vaiues is presented for each country. 


$\begin{array}{lccc} & \begin{array}{c}20 \mathrm{TH} \\ \text { centile }\end{array} & \begin{array}{c}80 \mathrm{TH} \\ \text { centile }\end{array} & \begin{array}{c}\text { Ratio } \\ 80 / 20\end{array} \\ \text { Belgium } & 70 & 161 & 2.3 \\ \text { Denmark } & 78 & 156 & 2.0 \\ \text { France } & 34 & 147 & \mathbf{4} .3 \\ \text { Netherlands } & 79 & 137 & 1.7 \\ \text { Hungary } & 77 & 156 & 2.0 \\ \text { Germany (DDR) } & 77 & 136 & 1.8 \\ \text { Germany (FRG) } & 75 & 182 & 2.4 \\ \text { Republic of Ireland } & 73 & 157 & 2.2 \\ \text { Italy } & 74 & 172 & 2.3 \\ \text { Norway } & 76 & 156 & 2.1 \\ \text { Portugal } & 63 & 173 & 2.7 \\ \text { Spain } & 70 & 157 & 2.2 \\ \text { Switzerland } & 75 & 150 & 2.0 \\ \text { United Kingdom } & 83 & 141 & 2.7 \\ \text { Yugoslavia } & 78 & 171 & 2\end{array}$

The ratio is approximately 2.0 in most of the larger samples; (the value of 4.3 for France was based on a particularly small sample). The twofold variation between the 80 th and 20 th centile is a little greater than that referred to in the extended analysis of English general practice data (Fleming et al, 1991a), but since it is based on a shorter recording period and on individual doctors rather than practices, it is logical to expect some expansion. Nevertheless, it carries the same implications of a minimum twofold difference between the referral activity of the Highest recording doctors and the Lowest. From these data we conclude that the variation in the referral behaviour of individual general practitioners, was similar in all countries and the economic implications are equally applicable (Crombie Fleming, 1987. White 1989). The extent of variation is not a function of the healthcare system.

Personal characteristics of doctors

Table 6.2 CHARACTERISTICS OF DOCTORS/PRACTICES BY REFERRAL STATUS

\begin{tabular}{|c|c|c|c|}
\hline & $\begin{array}{c}\text { Lowest } \\
\text { Referrers }\end{array}$ & $\begin{array}{c}\text { Bighest } \\
\text { Referrers }\end{array}$ & $\begin{array}{c}\text { All } \\
\text { Doctore }\end{array}$ \\
\hline Mean Age (yrs) & 39.4 & 39.9 & 39.4 \\
\hline Mean Time in GP (yrs) & 11.2 & 11.3 & 10.9 \\
\hline Partnership Size (n) & 2.9 & 3.3 & 3.1 \\
\hline $\begin{array}{l}\text { Mean Distance from } \\
\text { hospital (kms) }\end{array}$ & 14.0 & 11.7 & 12.4 \\
\hline $\begin{array}{l}\text { In Table } 6.2 \text { average } \\
\text { the Lowest and the } \\
\text { age, the time spent in } \\
\text { the distance from hos } \\
\text { statistical signifi } \\
\text { environment as report }\end{array}$ & $\begin{array}{l}\text { alues are g. } \\
\text { ghest quint } \\
\text { general pr } \\
\text { ital. Ther } \\
\text { cance at } \\
\text { ed by the }\end{array}$ & $\begin{array}{l}\text { each of } \\
\text { ups in res } \\
\text { the partne } \\
\text { no differen } \\
\text { level. } \\
\text { practitior }\end{array}$ & $\begin{array}{l}\text { tors in } \\
\text { f their } \\
\text { ize and } \\
\text { hieving } \\
\text { ractice } \\
\text { a also }\end{array}$ \\
\hline
\end{tabular}


examined. The distribution between Lowest and Bighest referral categories (Table 6.3) shows a small bias towards rural practice amongat the Lowest referrers and towards urban practice amongst the Bighest referrers (chi squared $=5.9,2$ DF $p=.05$ ). Environmental data were not reported by 7 doctors.

Table 6.3 ENVIRONMENT OF PRACTICES BY REFERRAL STATUS (PERCENTAGE DISTRIBUTION)

$\begin{array}{lll}\text { Lowest } & \text { Bighest } & \text { All } \\ \text { Referrers } & \text { Referrers } & \text { Doctors } \\ 308 & 307 & 1535 \\ 39.9 & 44.3 & 42.9 \\ 31.8 & 35.8 & 33.2 \\ 28.2 & 19.9 & 23.9\end{array}$

Among the 311 Lowest referring doctors, 22.28 were female and among the 308 Highest referring doctors, 31.88 were female (Chi squared $6.8,1 D F \quad p<.01$ ). On further examination of the sex of doctors in all five quintile groups, there was some evidence of trend (Chi squared 5.08, 1DF, p<.05) (Table 6.4).

Table 6.4 NUMBER AND SEX DISTRIBUTION OF DOCTOR BY REFERRAI STATUS

Urban Below

Above All

\begin{tabular}{|c|c|c|c|c|c|c|}
\hline & Lowest & $\begin{array}{c}\text { Belon } \\
\text { Av. }\end{array}$ & Av. & $\begin{array}{c}\text { Above } \\
\text { Av. }\end{array}$ & Highest & $\begin{array}{c}\text { All } \\
\text { Doctors }\end{array}$ \\
\hline & $--\overline{3}$ & & & & & \\
\hline female & 22.2 & 28.2 & $\begin{array}{r}305 \\
26.6\end{array}$ & $\begin{array}{r}310 \\
24.8\end{array}$ & $\begin{array}{r}308 \\
31.8\end{array}$ & $\begin{array}{l}1542 \\
26.7\end{array}$ \\
\hline
\end{tabular}

\section{Workload}

The workload of doctors was considered in four measurements: the average number of consultations in a normal working week(AWW), percentage of consultations involving a home visit, the registered or estimated list size (available for 755 recorders only) and the rate of consultations per 1000 list during an average week (683 recorders). These data are presented in Table 6.5 .

Table 6.5 CHARACTERISTICS OF WORKLOAD IN RELATION TO REFERRAL GROUPINGS Below Above All

Lowest Av. Av. Av. Highest Doctors

Consultations in average working week(AWW)

15

Percent of Consultations

as home visits

$\begin{array}{llll}11.8 & 11.7 & 11.0 & 11.3\end{array}$

11.6

Average registered

persons where available 1910

$1933 \quad 1907 \quad 1857 \quad 1953$

1912

Consultations per 1000 persons

in AWW where available 81.3

$\begin{array}{lllll}76.6 & 70.9 & 67.5 & 63,7 & 72.0\end{array}$

Referral rate per

1000 consultations

$\begin{array}{llllll}28.6 & 44.1 & 55.5 & 68.4 & 96.9 & 50.8\end{array}$

Referrals per

doctor in AWW

$\begin{array}{llllll}4.3 & 6.3 & 7.3 & 8.3 & 11.2 & 6.8\end{array}$ 
There was a very highly significant inverse relationship between the number of consultations and the referral category (comparison of Highest and Lowest categories Wilcoxon Rank Sum Test $\mathrm{z}=-6.0$, $p<.0001)$. The small differences between the categories for the percentage of consultations involving a home visit did not achieve significance at the conventional 5 tevel. Amongat recorders reporting a list size estimate (per principal), there were no differences between the categories, though there was a significant inverse trend between consultations per 1000 list and referral category (comparison of Highest and Lowest referrers Wilcoxon Rank Sum test $z=-5.1, p<.0001$ ). The referral rate per 1000 consultations and the number of referrals made in an AWW by doctors in the five categories is also reported in the table. There was a factorial difference of 2.5 between the Highest and Lowest categories.

The statistic for AWW shows a clear and very highly significant inverse trend. This trend was seen in most of the individual national data sets though there were some exceptions. (Denmark, DDR, Netherlands \& Bungary). The results for Italy, Portugal, Spain, United Ringdom and Yugoslavia in each of which there were more than 100 doctors, are given in Table 6.6.

Table 6.6 CONSULTATIONS IN AN AVERAGE WORKING WEER BY REFERRAL STATUS FOR COUNTRIES WITH MORE THAN 100 RECORDERS

$\begin{array}{lcrrrrr} & \text { Lowest } & \begin{array}{c}\text { Av. } \\ \text { Av. }\end{array} & \text { Av. } & \begin{array}{c}\text { Above } \\ \text { Av. }\end{array} & \text { Bighest } & \begin{array}{c}\text { All } \\ \text { Doctors }\end{array} \\ \text { Italy } & 128 & 125 & 110 & 109 & 98 & 115 \\ \text { Portugal } & 86 & 94 & 83 & 65 & 74 & 81 \\ \text { Spain } & 133 & 161 & 139 & 121 & 113 & 134 \\ \text { U. R. } & 146 & 136 & 127 & 119 & 112 & 128 \\ \text { Yugoslavia } & 223 & 195 & 185 & 176 & 134 & 187\end{array}$

The available data concerning the population registered in the practices show that the averages in each of the five referral groups were similar. After indexation to the numbers of persons registered, the number of consultations (per 1000 persons registered), undertaken in an average working week, was significantly inversely related to the referral rate. Both the referral rate and the average number of referrals per doctor in an average working week, also show marked inverse trends.

The workload of a doctor bears on his referral behaviour but the relationship is not simple. High referring doctors though looking after a similar number of patients as low referring doctors provided less consultations but made more referrals per unit population. It has also been shown that in those countries where the general practitioners reported large numbers of consultations in an average week, they also reported large numbers of referrals. Part of the pressure for referral comes directly from the number of consultations undertaken regardless of the healthcare system. In this comparison of Highest and Lowest referring doctors however, the number of consultations provided by individual general practitioners was inversely related to his referral category. A general practitioner with a high consulting workload may indeed be a low referrer whether measured using consultations or registered population as the denominator. Though the overall level of referral from primary to secondary care in a country is related to the number of consultations undertaken, the referral behaviour of individual gps within a country is not. 
These conclusions relating to the workload of doctors are very important in their economic implications. It is essential first to consider how far they could arise because of some failure of the recording system. Bigh referring doctors may be identified as such if there is a relative failure to record consultations which provide the denominator for the study. Conversely, low referring doctors could be so identified by failure to record the referrals which provided the numerator. The possibility of bias caused by the inter-action between these two potential failures has been examined in several ways. Relevant points are as follows :-

1. The proportion of home visits in all referral groups was similar. This suggests that the recording quality was similar since from other morbidity surveys, poor quality recording is most evident in home visits.

2. Bach doctor was required to recruit thirty consecutive referrals and the data have been analysed in respect of the first ten, the second ten and the third ten referrals recorded. The proportions in each of these three groups referred in the various modes, the different types, the degree of urgency and the influence of the patient were all similar, suggesting that there was a consistency of recording throughout the period.

3. Referral rates per 1000 consultations by specialty were also examined for the first, second and third groups of ten recruited patients all with similar results.

4. The mean number of persons referred in an average working week for the Lowest group of recorders was 4.3 and for the group of recorders 11.2. The average working week contained 151 consultations for doctors in the Lowest referral group and 116 in the Highest group, whereas the difference in referral rate between the two groups was 29 per 1000 and 97 per 1000 respectively. These differences on the one hand of a 368 deficit of consultations in the Highest group compared with the Lowest and of an excess of 3408 in referral rates cannot be accounted by deficiencies in recording even making the worst possible assumptions for the quality of recording in the two groups.

\section{Distribution by major specialty}

Table 6.7 MEAN DISTRIBUTION (8) OF MEDICAL, SURGICAL AND OTAER REFBRRALS IN BACH QUINTILE GROUP OF REFERRERS

$\begin{array}{lcccccc} & \text { Lowest } & \begin{array}{c}\text { Below } \\ \text { Av. }\end{array} & \text { Av. } & \begin{array}{c}\text { Above } \\ \text { Av. }\end{array} & \text { Bighest } & \begin{array}{c}\text { All } \\ \text { Doctors }\end{array} \\ \text { Medical } & 38 & 37 & 37 & 36 & 38 & 37 \\ \text { Surgical } & 44 & 45 & 46 & 45 & 44 & 45 \\ \text { Other } & 17 & 18 & 17 & 18 & 19 & 18\end{array}$


The distribution of referrals by the major specialty groups is reported in Table 6.7 and is shown to be similar in all five referral categories. There were no significant differences. More detailed analysis by individual specialties showed that distributions among the specialties were similar in both the lighest and Lowest referring groups. Therefore, it is reasonable to conclude that case mix had no impact on the referral behaviour of the general practitioners. This conclusion accords with other data obtained in the United Ringdom (Fleming et al, 1991b).

\section{Degree of urgency and patients influence on the referral decision}

The distributions in the assessment of urgency and the degree to which patients influenced the referral decision as reported by the general practitioners are presented in Table 6.8.

TABLE 6.8 PROPORTION OF REFERRRALS BY URGENCY AND PATIENT INFLUENCB IN EACH QUINTILE OF REFERRING DOCTORS

$$
\begin{array}{cccc}
\text { Below } & \text { Above } & \text { All } \\
\text { Lowest Av. Av. Av. Highest Doctors }
\end{array}
$$

Proportion of

referrals in

immediate \&

$\begin{array}{llllll}40.8 & 37.5 & 36.3 & 34.4 & 36.2 & 37.0\end{array}$

urgent categories

Proportion of

$\begin{array}{lllllll}\text { referrals } & 41.3 & 42.5 & 40.5 & 41.1 & 40.6 & 41.5\end{array}$

expressing large or

small influence

The proportions in the immediate and urgent referral categories showed no evidence of trend. The value in the Lowest group (40.88) is not significantly different from that in the Higheat (36.28). The proportions of referrals reported to have been influenced by patient pressure, did not differ between the referral groups.

\section{Gender of patient}

The proportion of referred patients who were male is summarised by referral category in Table 6.9 .

Table 6.9 MALES AS PROPORTIONS OF PATIENTS REFERRED AND OF PATIENTS CONSULTING BY REFERRAL CATEGORY

$\begin{array}{lcccccc} & \text { Lowest } & \begin{array}{c}\text { Below } \\ \text { Av. }\end{array} & \text { Av. } & \begin{array}{r}\text { Above } \\ \text { Av. }\end{array} & \text { Bighest } & \begin{array}{c}\text { All } \\ \text { Doctors }\end{array} \\ \begin{array}{l}\text { \& of } \\ \text { Referrals }\end{array} & 45.0 & 42.3 & 42.8 & 41.1 & 40.4 & 42.3 \\ \begin{array}{l}\text { \& of } \\ \text { Consultations }\end{array} & 41.3 & 40.7 & 40.4 & 39.9 & 39.3 & 40.6\end{array}$


The difference between the Highest and Lowest referral category, in the proportion of patients who were male, though small, was neverthelese very highly significant. (Wilcoxon Rank sum Test $z$ $=-4.22, p<.0001$ ). There was a similar but smaller trend in the consultation data. Bearing in mind that the SRR on which the referral category was based, included the sex of the patient as a standardisation criterion, the result is particularly interesting. The findings suggest that lighest referring doctors are more likely to refer female patients (though only by a emall margin), than their colleagues in the Lowest referral category. The examination of the perceived influence of the patient on the referral decision showed no differences between the referral categories. This combination of findings suggests that many doctors may be influenced by the sex of the patient though they are unaware of it. This aspect of the study will be explored further.

Highest and Lowest referral categories were also compared with respect to the proportions referred to outpatients, those to the private sector and those to the national healthcare system and in all of these examinations, there were no significant differences.

In concluding this examination of practice characteristics and practitioner behaviour, the most important point shown in this study concerns the workload of the doctor which was associated with his referral pattern. A cause and effect relationship however is not established: it is possible and perhaps even likely that the doctor with a low referral pattern compensates by generating a high workload for himself. 


\section{CONCLUSIONS}

This chapter brings together the most important conclusions from this study. Some of these relate to the conduct of such surveys, some to the results and some to the implications. In the task of summarising these data, due weight has been given to the importance of significance tests in the evaluation of differences but the emphasis will be on the interpretation of the data. The pitfalls of statistical tests linked to an insecure denominator such as consultations are well known. However, in the same way as the results of laboratory tests assist the doctor in his evaluation of a clinical problem rather than determining it, so also tests assist in the interpretation of the data and are not a substitute for the intelligent use of data gathered in operational research.

Many of the difficulties of international studies have been rehearsed before (Crombie, 1975 \& White, 1989) and will not be repeated here.

\section{An international operational study}

This has been a major study in 15 countries involving approximately 1500 doctors, 860,000 consultations and 44,000 referrals. Satisfactory completion of the study has been achieved because a network of comitted general practitioner researchers had been meeting together over many years. In particular, these small groups have been involved with the basic definitions and meanings of terms and with their tranglation. It has been achieved in spite of the absence in some countries of any national network of general practitioners organised through formal academic or professional groups.

Apart from the motivation of the researchers, other important factors in achieving a successful outcome are:-

1. The survey was topical in the context of the place of general practice in primary care.

2. The issue of referrals from primary to secondary care is of fundamental importance both to individual general practitioners and for health services.

3. The package of objectives provided information as relevant to the individual recorders as to the national scene.

4. The recording booklet was printed in the various national languages. It was designed by general practitioners and presented no difficulties for routine operational use by service general practitioners engaged in daily and frequent consultation activity. The recording booklet in itself has provided a model for future operational surveys of this type.

5. The study design involved centralised numerical analysio using computer programmes applicable to all countries. The potential difficulty of involving persons in the various 
countries using different computers and possibly different programmes was avoided.

6. The data base generated allows examination of a variety of local health problems in individual countries.

\section{National differences}

Some important national differences in referral pattern identified in this study have been highlighted but these must be set against the background data about physician density and physician activity: and in particular, the large differences in consulting frequency.

There are substantial differences in physician density between European countries. Not only that, the relative proportions working within specialist or general practice also varies widely. Direct access to secondary care is virtually impossible in some countries where at the other extreme it may be encouraged. These differences are not related to the system of care (national health or insurance models), but have their roots in expectations of certain styles of care derived over many decades. Expectations in FRG for example are very strongly oriented towards intervention with very high drug consumption and active doctors with high contact rates between doctor and patient. An attitude of ready intervention enters the training system and medical education perpetuates the tradition. Opportunities for change have occurred recently in a number of countries. The system of healthcare delivery in DDR has changed; over the last ten years there has been a major revolution in the delivery of healthcare in Portugal ; Spain is in the midst of a change from singlehanded and isolated doctors now coming together to work in groups.

In some countries, the concept of general practitioner care is not comprehensive. Some groups of people are excluded; for example, paediatric, gynaecological and obstetric care are often provided by specialists accessible directly by patients. In some countries, an excess of doctors leads to competition for employment and encourages the consumerist approach to medical care with doctors responding to the demands of the consumer rather than interpreting the needs. An excess of doctors commonly arises because there is little or no control on medical student intake as for example in Italy.

In FRG the results from this study were particularly remarkable because:

1. Doctors undertook more consultations in a week than in any other country.

2. They made more direct referrals.

3. Independently of the direct referrals, they also authorised almost as many indirect referrals, greatly in excess of any comparable figure from other countries.

4. The referrals made were considered to require urgent attention in a greater proportion of cases than was seen in any other country.

5. Notwithstanding the high referral rates, the doctors did not 
perceive themselves as being substantially influenced by the patients when making the referral.

\section{There were only minimal delays in the referral system.}

The FRG is one of the highest spending countries on healthcare throughout the world. The material obtained in this study points to the conclusion that the healthcare system is driven by patient demand and ready doctor response because the system is favourable to both of them, though there does not seem adequate evaluation of interventions. Basic health statistics (life expectancy, perinatal mortality etc) are not noticeably better in FRG than in other European countries which might otherwise provide this country with some justification for its high expenditure.

The United Kingdom data show a relatively low rate of referral from primary to secondary care. Physician density is low for specialists and to a lesser extent for general practice. However in the United Kingdom, there is the clearest distinction between primary general practice care and specialist care. In many other countries where a national healthcare system exists, there are parallel systems of care financed by private insurance where the system of referral from primary to secondary care operates much less rigidly than it does in the United Kingdom.

In the United Kingdom, general practitioners had average consultation rates, low referral rates, were at the average for Europe in the extent that patients influenced the referral decision and also for the request for immediate and urgent referrals. However, the United Kingdom disclosed the greatest delays in the wait for specialist appointments.

A partisan approach to this problem viewed from the specialist position might suggest that these delays occur because there are insufficient specialists in the United Kingdom. An equally partisan approach from the general practitioner might suggest that the general practitioners in the United Kingdom were dealing with many problems that were addressed by specialists in other countries and this is why the referral rates are low and in consequence, there is no excuse for the delays. These are extreme view points but this study has clearly identified a major problem area for the national health service in the United Kingdom which needs to be addressed in a comprehensive manner examining:

1. The workload of general practitioners and specialists.

2. The organisation of specialist outpatient consultations: there are substantial differences between the countries in the way this is done. There are no direct incentives for consultants to maximise the number of outpatients they can or might see nor are there any generally accepted guidelines as to how frequently persons should be seen for follow up after an initial specialist referral.

3. The setting of the outpatient appointment (hospital or independent office).

4. The nature of the consultation and the issues relating to the transfer of responsibility.

For the Netherlands, as compared with other countries, the 
difference in the doctor's perception of the patient's influence on the referral decision was particularly interesting. This finding implies a sociological difference in the doctor/patient relationship. This may be a recent phenomenon but whether or not, it is a development which should be monitored with interest. Some doctors see their role as an adviser in informing patients what they should do ; others see themselves as advocates and act to satisfy the demands of patients and finally, there is the counsellor model. Doctors should be open to the possibility that all these models have their place but as methods of delivering healthcare, they should be subjected to proper evaluation. The fact that the patient influence was more often recognised in those countries with a strong gp training programme may be a direct result of improved communication skills developed by the training programme.

The high home visiting rate in Belgium is common knowledge and it was no surprise to verify that in this study. General practitioners in Belgium work largely in singlehanded practices in an environment in which (especially in the major centres), they are in open competition with specialists. There are no population denominators for presenting health data and among all the countries included in this study, there would appear maximum opportunity for inefficiencies for the delivery of healthcare. Notwithstanding these national peculiarities, as a nation, they may have evolved a system of delivering healthcare with which the population is completely satisfied. Taking a detached view however, there would appear to be a need to measure and to cost alternative forms of healthcare delivery.

The healthcare systems of Yugoslavia and Hungary are somewhat similar and this study has revealed efficiency in the handling of referrals. It was surprising however to find a relatively high rate of referrals from primary to secondary care in Yugoslavia and a low rate in Hungary. There will be some interest in identifying differences in the provision of specialist care which call for further investigation. In the Mediterranean countries of Southern Europe, ophthalmology was amongst the commonest referral specialties. There is a question for all healthcare systems with regard to the role of the general practitioner as gatekeeper. It is appropriate to consider the place of optometricians in the provision of primary care. Perhaps it would be a prudent use of resources to allow direct referrals from them to ophthalmologists? As a parallel, in most countries, dentists may refer patients directly to specialists.

In France and Italy, cardiologists were among the most popular specialists and in both of these countries, more females were referred to cardiologists than males. In Denmark dermatologists head the list. In many countries, general surgery and orthopaedics came first. These differences probably identify cultural attitudes rather than true differences in disease incidence. The material available from each of the countries will provide the basis of several additional reports dealing with the various topics included. These concern the operational data about doctor workload, referral activity in relation to gender, analysis of the data by diagnosis and differential study of delay patterns by specialty. 
This study has much to say about standards of care. Standards can only be defined from objective measurement. Standards derived from ideal protocols (Brook and Appel, 1973) provide expectations which discourage audit amongst doctors. Standards can sometimes do no more than define the direction of change. In a subject area such as referrals, it is difficult to define acceptable standards and these must relate to the parameters of the healthcare system. Nevertheless, this study has provided ample opportunity to provide some standards but more importantly to encourage self examination and self audit by exploring others. The basis of the standards suggested here is the dynamic process of target achievement and not the matching of personal achievement to static protocols. This approach is supported by the fact that the targets proposed here were achieved in a substantial number of countries. In the area of delays in the referral process, the following standards are suggested as appropriate immediate targets:

1. Fifty percent of patients referred should be seen within 4 weeks of referral and no one should be waiting 16 weeks.

2. Within any country, referral delays should not differ between the specialties.

3. The referring doctor should receive a communication within two weeks of referral in 808 of cases.

4. Once surgical intervention is decided, the patient should not have to wait more than 4 weeks. As a realistic goal, fifty percent of these patients should receive their operation within four weeks and none should be waiting than 16 weeks.

In the field of general practice activity, there needs to be a standard of competence which effectively ensures that high cost specialist resources are used efficiently. For a general practitioner working in a typical primary care setting, a referral rate of 100 per 1000 consultations might be considered a reasonable upper limit. A doctor referring with greater frequency should be prepared to justify his actions. At the opposite extreme, a rate of 20 per 1000 might be considered a lower limit. In suggesting these standards, neither an ideal nor a recommended rate applicable in all countries is proposed. However, it must be recognised that within a healthcare system, some doctors use resources extravagantly and others deny their patients adequate investigation of major problems. The standards proposed here are attempts to take a pragmatic view of a difficult problem. We should also encourage local audit a informed creative discussion between general practitioners and specialists where standards are not achieved.

In considering health economics, it cannot be rational for general practitioners in Portugal to be making only 28 of consultations as home visits whereas in Belgium, the equivalent figure was $45 \%$. Either healthcare can be delivered with equal costs and quality in the home setting as in the office or if not, some standards should be considered. Home visit proportions exceeding 208 of all consultations (age standardised) should be seen as an upper limit pending more detailed studies of health
economics. 
There are also opportunities here to consider standards in relation to overall levels of patient utilisation and doctor provision of services. There were very large national differences in the average number of consultations provided by general practitioners during a week. Iimits to the working week with acceptable degrees of resultant efficiency have been recognised in many occupations, where the working pattern of one person may produce risk for another. For example, the maximum number of working hours have been defined for people working in the transport industry, particularly for airline pilots, engine drivers, bus drivers etc. Perhaps there should be a daily limit on the number of consultations or home visits which a doctor can be expected to provide with an acceptable level of competence ?

The variation in the numbers between the countries however, partly reflects different utilisation rates by patients. Is it rational for example that patients in FRG should see their doctors alamost twice as frequently as those in Switzerland and four times as frequently as in the United Kingdom. If standards are to be applied to professional services, may be they should also be applied to patient demand? Demand for one person is a bill for someone else.

This study shows that in many countries the notion of an indirect referral virtually does not exist. Perhaps the place of the indirect referral from primary care is a subject that should be examined and discussed in more detail ?

The wHO Targets for Health for All by the Year 2000 (WHo, 1985) lists several targets which are directed at equality of healthcare in all countries and for all people within them. If progress is to be made towards these objectives, it is necessary for medical policy makers and resource managers to address the issues raised here. While it is healthy to challenge these preliminary attempts at defining standards concerning the delivery of healthcare, it is not acceptable to deny the need for atandards nor to ignore the importance of the measured performance reported here for the purpose not only of defining standards but of identifying where future enquiries should be concentrated.

\section{Understanding referral behaviour}

In studies of the referral behaviour of doctors, with the possible exception of that reported by Grol (1990) concerned with the defensive attitude of dactors, none have provided a worthwhile explanation for the considerable variation between them. In this study, workload stands out as an important factor. The analysis for the study included equal proportions of doctors in the various referral categories drawn from all the countries involved and showed an impressive gradient with low referring doctors undertaking high numberg of consultations compared with high referring doctors. This difference was recognisable as a trend in a consideration of the data from all referred groups and the possibility that the result might have arisen due to biassed recording, was critically examined. The conclusion drawn from this analysis was that doctors with low referring habits were compensating by providing additional care in the form of extra consultations. This conclusion is highly relevant to financial policy for the delivery of healthcare. It is applicable particularly where the funding of general practice is 
predominantly capitation based whether by insurance or by national health resources as in the United Kingdom. If healthcare in a defined area (general practice) is resourced to achieve economies in referrals, then it must be resourced in a way that allows a doctor/practice scope for him in defining and funding practice activities such as the basic consultation. A budget defined from referral experience which takes no account of the consultation rate could be manifestly unfair to a practice.

\section{The Comac Research Initiative}

This study has involved a considerable workload, especially for the national representatives of countries submitting large samples. It has had a considerable spin-off in encouraging liaison between the representatives which will generate and foster joint research in other areas of interest. There is still a considerable scope for critical evaluation of the referral process and complementary examinations of the problems as seen from the perspective of the patient and that of the specialist should be encouraged.

The important role of the COMAC in facilitating research of this type should not be under-estimated. A large element of the budget is absorbed by arranging meetings. In the interests of economy, all these meetings of the national representatives have been arranged to follow on the regular biennial meetings of the European General Practice Research Workshop. The activities of this workshop have been stimulated by involvement in this study. Participation in such studies enhances the position of general practice, especially in those countries where it's status is not high. There are many problems for international research in general practice, but an important one concerns the isolated position of general practitioners in some countries where there is little central and institutional support. By forging closer links between general practitioners, primary care will be strengthened. A strong primary care sector is essential to achieving reasonable containment of healthcare costs in all countries and for achieving the targets of the wHO initiative Bealth for All by the Year 2000 . 


\section{CHAPTER 8}

\section{SUMOARX}

\section{EUROPEAN STUDY OF REFERRALS FROM PRIMARY TO SECONDARY CARE}

\section{The Importance of Referrals}

The pace of technological advance in medicine is leading towards a situation in which even the richest nations need to 'take stock' and ask how far resources can be allocated to medical care. There is firstly a financial question - how much money can be made available for medicine? Medicine must compete with education, with national defence, with environmental issues etc. for an appropriate allocation of national resources. There is a moral question - how much value do we place on a man's life? The converse of this question is concerned with how much risk is acceptable in his medical management? Equally important, in the moral sense is the question of prioritising between competing problems. Few would argue against giving a person with cancer priority in treatment over one with inguinal hernia, even though the benefits of treatment in the broadest sense might be better for the patient with the inguinal hernia.

These questions and the related issues of manpower resources, medical training, the rights of the individual within a society etc., have steered the countries of Western Europe into differing systems for delivering healthcare. All however have systems of primary care (healthcare services available directly to people in the community) and of secondary care (services generally though not exclusively available by referral from the primary provider). In most cases, primary care is of a generalist nature and secondary care specialist. In all countries, specialigt or secondary care is experiencing the greatest pressure for increased resources (OECD,1987). It is also the area in which at least in the public eye, the moral dilemas are felt are seen most keenly - which patient should be chosen for a donor kidney? How long should a patient stay on a life support machine? In reality however, the entire medical profession is struggling with the question - how much risk is acceptable in medical management? The critical step for the general practitioner and for the financing of a health service is the decision to seek a second or specialist opinion.

National methods of delivering healthcare are a reflection of cultural norms and differing attitudes towards healthcare and medicine. They are governed by differing legislative arrangements for providing and financing it. As a result, there are substantial differences at the interface between primary and secondary care. These have been described in a related publication "The Interface Study"(Comac-HSR,1990), which was conducted as a collaborative exercise within the European General Practice Research Workshop (Hull, 1982). This report is concerned with the second stage of an analysis of the interface: an operational study of the referral process in European countries. 
The aims of the study were:

1. To define and compare national referral patterns.

2. To identify cohorts of general practitioners in each country with high and low referral patterns and to compare practice/doctor characteristics in each group both within each country and internationally.

3. To examine delay patterns for specialist consultation and for surgical treatment.

4. To provide individual general practitioners with sumuarised referral data.

The study was not conceptualised against a background of hypotheses to be tested. Rather, it was designed to exploit the information which could be made available at reasonable cost from participating doctors who, for the most part, were self selected. Each of the recruited doctors was required to describe thirty consecutive referrals. The method effectively produced a sample of referred patients who were representative of patients referred by that doctor. For some purposes such as the examination of delays in the referral process, the patients can be regarded as a representative selection of patients within the referral process of a country. For others, such as the influence of the patient on the decision to refer, this may not be the case. Self selection by definition implies recruitment of doctors who are willing to have their work examined, albeit to a limited extent. However, the pressures influencing recruitment are similar in each country and conclusions drawn from the comparisons between the countries have general application.

With regard to national referral patterns and delays within them, this study is chiefly concerned with an examination of the operational findings from the general practitioners in relation to six elements of healthcare structure:-

1. The availability of general practitioners as measured by their density per population.

2. The availability of specialists as measured by their density per population.

3. The remuneration system of general practitioners.

4. The remuneration system of specialists.

5. The means of access to specialist care.

6. The existence of training programmes for general practice.

This thesis also presents a detailed consideration of the influence of workload on general practitioner referral performance. For this purpose, each set of general practice referral data was standardised by the indirect method to the appropriate national distribution of consultations. There are undoubtedly major weaknesses in the use of consultations as a denominator but there is no suitable alternative. The issues are discussed in the report but the most important concerns the relative practice variation in consultation rates which is much less than variation in referral rates (however these are measured). 
1548 gps working in 15 European countries were recruited. The data base included details of 860,000 consultations and 44,000 referrala. Moat of the data were collected during the latter part of 1989 or early part of 1990. Consolidated data from each country are reported in the appendix.

Consultations and Visits:- During the study, recorders were required to describe all consultations by age and sex and place of consultation. They were also asked to define weeks which they considered were part of their normal working arrangements. General practitioners in FRG averaged 220 consultation in a normal week and at the other extreme, those in Norway averaged 60. In Belgium the gps made 58 visits per week(468 of all consultations), FRG was second with 36 (168) and in Portugal, home visiting was least with only one visit per week. These differences partly reflect differing arrangements for emergency care but there was some evidence within the data that consultation rates were influenced by general practitioner payment arrangements with more services provided where fee for service arrangements applied. In general, gps working in countries with strong gp training programmes, undertook fewer consultations than those where training was weak.

Referrals- The average number of referrals per week was greatest in FRG and Italy. As rates per 1000 consultations, Norway, Italy and Denmark took the first three positions though had indirect referrals been included (referrals without direct contact between patient and doctor at the time), FRG would have been ranked first. Interpretation of the national data was particularly difficult because of the unknown number of self referrals by open access to specialists. However, the data point to the rather obvious conclusion that in those country where a high density of specialists exists, referrals from gps are more frequent. Demands/needs are identified which effectively consume available resources. Countries with maximum opportunity for patients to consult specialists directly, disclosed lower referral rates than countries with restricted access. However, the proportion of gp referrals to medical specialists was higher in these countries relative to the proportion of referrals to surgical specialists.

Variation in referral rates:-The degree of variation in the referral rates reported in each country was similar (an approximate twofold variation between the 80 th and 20 th centile rates), suggesting that the problem of variability among doctors in the way they refer is independent of the healthcare structure within a country.

Patient influence on the referral decision:- In the description of each referral, recorders were asked to identify the extent to which they considered themselves influenced by the patient. In this context, patient influence was only considered in those circumatances in which the clinical indications for referral were not absolute, as for example for a patient with acute appendicitis. This analysis disclosed a particularly interesting result in the Netherlands where approximately 608 of referral decisions were perceived to be influenced by the patient. At the other extreme, in Italy only 328 of referral decisions were influenced in this way. Those countries in which gp training 
programmes were strong, generally had lower referral rates yet were more open to the influence of patients on the referral decision. There are perhaps three types of general practitioner:- one who sees his role as an advocate for the patient obtaining what services he can to satisfy patient demand but not recognising those demands to be a form of pressure: one who sees his role as an advocate for the health service rationing resources more in accordance with need and his judgement as to what the service can bear: and one who sees his role as a counsellor for the patient. This last model is of course much more open to recognise and to permit the patient's influence on medical decisions.

Delays for specialist appointment- There were some very striking differences in the delays experienced by patients waiting for specialist appointment. In Belgium at the one extreme, 878 of patients were seen within four weeks. There were many countries in which more than 808 of patients were seen in this time. Belgium, France, FRG, Italy, Spain and Switzerland. At the other extreme, delays were maximum in the United Kingdom where only 398 were seen within four weeks. Countries in which the specialists were remunerated by fee for service were reported with appreciably less delay for specialist appointment than those where specialists were remunerated by salary. Delays were also greater where gps were remunerated by capitation and these are commonly the same countries in which gp training programmes are strong.

A patient flow model:- The major findings in this international comparison of healthcare structures are summarised as a model in the figure.

MODEL ILLUSTRATING INFLUENCE OF STRUCTURAL VARIABLES ON CONSULTATION AND REFERRAL FLONS

(+open access to specialists)

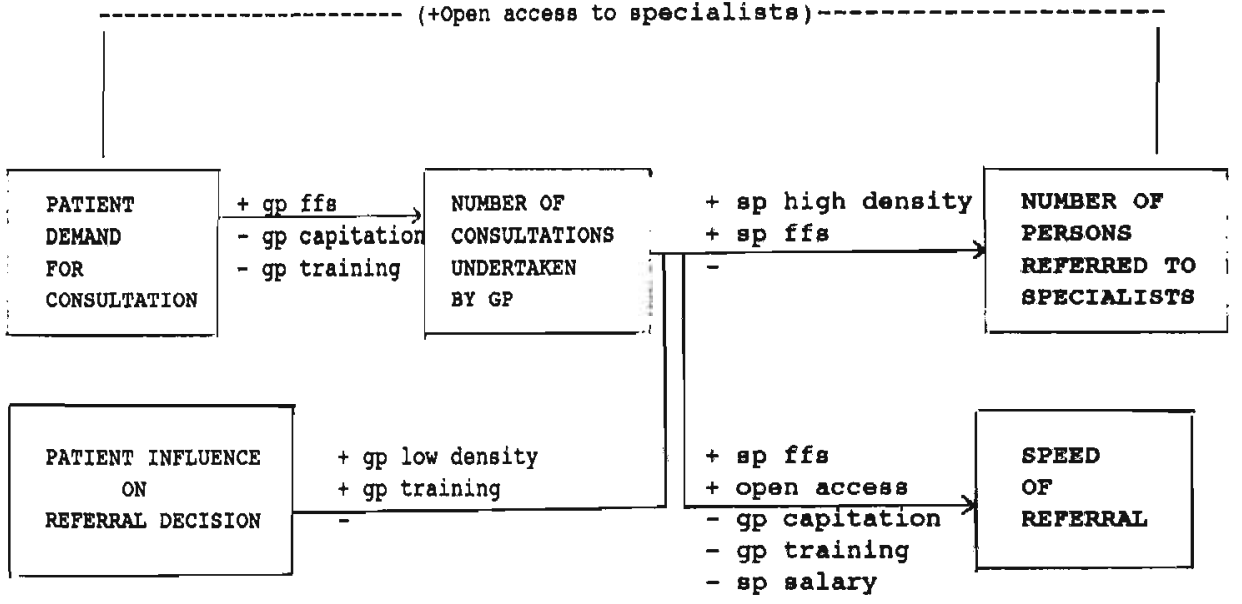

$g p=$ general practitioner $\quad s p=$ epecialist $\quad f f B=$ fee for service

The arrows represent patient flow. Identified above the arrows 
are the positive factors ( + ) which accelerate flow and beneath them, the negative ones (-) which retard it. At the top of the figure open access to specialists has been entered as an accelerating factor between patient demand for consultation and the number of persons referred to specialists though these data are not strictly available from this study.

Taking the United Kingdom and FRG as example countries with very different healthcare structures, this model explains the large differences in health utilisation rates. In the $u K$, a gp capitation system and strong training programme act to reduce patient demand for consultation and are associated with delays in referral. Patients are perceived to influence the referral decision but they have virtually no opportunity for direct access to specialists. In the FRG, gp fee for service increases patient demand for consultations, specialist fee for service increases the number of referrals and is associated with minimal delays. The absence of a strong training programe has no retarding effect on demand, though a low density of gps allows increased patient influence on the referral decision : a high density of opecialists increase the numbers of persons referred.

\section{Practice Characteristics in Relation to Referral Performance}

In order to study doctor/practice characteristics, a standardised referral ratio(SRR) was derived for each participating gp. SRR values were ranked in each of the countries and recorders were separated into quintiles (Bighest, Above Average, Average, Below Average, Lowest). The quintile groups from each country were consolidated into international groupings, each made up of approximately 300 recorders and therefore concerned with 9,000 referrals. The quintile groups were examined with regard to the composition of doctors by age and sex, the experience of the doctors, the location of the practices, the partnership structure, measures of the workload of doctors derived from the study, the relative distribution of referrals by major specialty group, the proportion of referrals deemed immediate or urgent and the proportion perceived to be influenced by the patient.

There were more female doctors in the Highest referral quintile than in the Lowest ( 31.08 compared with 22.28). There was statistical evidence of trend from Highest to Lowest. General practitioners in all quintiles were of similar age, reported similar time in practice and belonged to practices of similar partnership size. There was a small bias towards urban practice amongat Highest referrers though there were no consistent relationships between the referral category and the distance from hospital.

\section{General Practitioner Workload}

Workload was considered in four measurements - the average consultations in a normal working week, the percentage of consultations involving a home visit, the reported or estimated registered list of patients (available for 755 out of the 1548 recorders), and the rate of consultations per 1000 registered persons. There was a very highly significant inverse trend between referral category and the average consultations in a normal week. General practitioners in the Highest category reported 151 consultations compared with 116 in the Lowest. Comparison of the data from the upper two quintiles in each 
country compared with that from the lower two quintiles disclosed increased consultations among the gps with higher referral rates in each of the countries of Western Europe excepting Denmark and the Netherlands. The possibility that this result derived from some bias in the recording system was examined and refuted after careful consideration of the data.

No differences were disclosed with respect to percentage of consultations involving a home visit or the average registered list. The inverse trend between consultations and referral rate was also evident in the statistic for

consultations per person registered. The Lowest category of referring doctors referred on average 4.3 patients per week and the Highest, 11.2 per week. The threefold different contrasts sharply with the small difference in the opposite direction involving recorders in the Lowest category with 151 consultations per week and those in the Highest category with 116.

Thus in most countries, the workload of a gp is associated with his referral performance. Association does not distinguish cause from effect. The most plausible explanation here is that doctors with low referral rates see patients more frequently perhaps to minimise the risk of 'missing something'. This of course not only affects their working pattern for those persons who are referred to speciallsts but is a product of their style of consultation.

The economic implications for financing a health service using controlled gp budgets are considerable since this conclusion would suggest that a budget for referrals should permit expenditure on increased consultation facilities. However, in the United Kingdom at the moment the budget for consultations is in effect the capitation system for payment and cannot be supplemented from the budget for referrals.

\section{Standards of healthcare}

The results of this study contribute to quality assessment in healthcare delivery. In some areas of medical care, standards are derived from the results of clinical experiments : in others, the notion of target achievement is more appropriate. This study has measured elements of the delivery of healthcare and highlighted differences. A standard of care which is seen to be deliverable in one country or, in one specialty within a country can become a realistic target in another. It has also brought to the fore issues which assist national health policy makers to address matters such as the importance and content of postgraduate training for general practice, and the relative manpower resource provision between specialists and generalists. 


\section{SAMENVATTIMO}

\section{EUROPEES ONDERZOER NAAR VERWIJZIMGEN VAN DE EERSTE MAAR DE TWEEDE LIJN IN DE GEZONDHEIDSZORG.}

\section{De importantie van verwijzingen.}

De snelle technologische ontwikkelingen in de geneeskunde leiden tot een situatie waarin ook de rijkste landen de 'balans moeten opmaken' en moeten nagaan in hoeverre middelen kunnen worden gereserveerd voor medische zorg. Daar is allereerst de kwestie van financiën - over hoeveel geld kan de gezondheidszorg beschikken? Waar het gaat om een weloverwogen besteding van de nationale middelen moet gezondheidszorg het opnemen tegen onderwijs, defensie, milieuvraagstukken enzovoort. Het is ook een ethische kwestie - hoeveel waarde hechten wij aan een mensenleven? Daartegenover staat de vraag welke risico's in de medische behandeling nog aanvaardbaar zijn. En net zo zwaarwegend is, in moreel opzicht, de prioriteitsvraag met betrekking tot moeilijk tegen elkaar af te wegen gevallen. Slechts weinigen zouden bezwaar maken als bij de keuze tussen behandeling van een kankerpatiënt of een herniapatiënt prioriteit zou worden verleend aan de kankerpatiënt, ook al zou de herniapatiënt in de breedst mogelijke $z$ in meer baat hebben bij behandeling.

Deze vraagstukken, en de daarmee samenhangende kwesties van menskracht, medische opleiding, de rechten van het individu in de samenleving enzovoort, hebben geresulteerd in verschillende gystemen van gezondheidszorg in de landen van West-Europa. Al deze landen hebben echter zowel primaire (eerstelijns) zorgsystemen (waar de burgers rechtstreeks een beroep op kunnen doen) als secundaire (tweedelijns) voorzieningen (waartoe men zich over het algemeen, maar niet exclusief, kan wenden na verwijzing door eerstelijns hulpverleners). In de meeste gevallen is de eerstelijns zorg generalistisch, en de tweedelijns zorg speciallstisch van aard. In al die landen heeft de specialistische, of tweedelijns, zorgsector de grootste behoefte aan verruiming van de middelen (OECD, 1987). Daar zijn ook, zo denkt men tenminste, de morele dilemna's het grootst - welke patiënt komt het eerst in aanmerking voor een donornier? Hoe lang mag/moet een patiënt aangesloten blijven op beademingsapparatuur? Maar in werkelijkheid worstelt de hele medische beroepsgroep met de vraag: tot welke hoogte zijn risico's aanvaardbaar in het medische beleid? De beslissing om de mening van een collega of een specialist te vragen, is het kritieke punt voor de huisarts en voor de financiering van een nationaal gezondheidszorgsysteem.

De gezondheidszorgaystemen in de verschillende landen weerapiegelen de culturele normen en de verschillen in attitude ten opzichte van de geneeskunde en de gezondheidszorg. Zij zijn gebonden aan verschillende wettelijke voorschriften met betrekking tot de zorgverlening en de financiering daarvan. Dientengevolge zijn er aanzienlijke verschillen op het raakvlak van eeratelijns en tweedelijns zorg. Deze zijn beschreven in een publikatie getiteld "The Interface Study" (Comac-HSR, 1990), verslag van een gezamenlijk onderzoek in het kader van de European General Practice Research Workshop (日ull, 1982). Het 
onderhavige rapport betreft de tweede fase van een analyse van dit raakvlak: een onderzoek naar het verwijsproces in Europese landen.

\section{Doelstellingen}

De doelstellingen van het onderzoek waren:

1. Het definiëren en vergelijken van wetmatigheden in national verwijsgedrag.

2. Het per land identificeren van groepen huisartsen met hoge en lage verwijscijfers, en het zowel per land als op international niveau vergelijken van arts- en praktijkkenmerken van elke groep.

3. Het onderzoeken van de wetmatigheden in de wachttijden voor specialistenconsulten en chirurgische ingrepen.

4. De individuele huisarts van een kort overzicht van zijn verwijsgegevens te voorzien.

Het onderzoek was niet opgezet als een hypothesen toetsende studie. De opzet was veeleer on de informatie te gebruiken die zonder al te grote kosten kon worden verkregen van artsen die voor het merendeel op vrijwillige basis aan het onderzoek meewerkten. Ieder van hen werd gevraagd dertig achtereenvolgende verwijzingen te beschrijven. Deze methode resulteerde in een steekproef van verwezen patiënten die een goed beeld gaf van de patiënten die door de betreffende arts verwezen werden. Voor somige doeleinden, zoals het onderzoek naar wachttijden in het verwijsproces, kunnen de patiënten warden beschouwd als een representatieve selectie van de patiënten binnen het verwijsproces van een land. Voor andere, zoals de invloed van de patiënt op de beslissing om te verwijzen, hoeft dat niet altijd op te gaan. Vrijwillige deelname houdt per definitie in dat artsen worden gerecruteerd die bereid zijn hun werk, zij het in beperkte mate, te laten onderzoeken. De factoren die de recrutering beinvloeden, zijn in ieder land vrijwel gelijk, en conclusies die uit de vergelijkingen tussen de landen worden getrokken, $2 i j n$ algemeen van toepassing.

Met betrekking tot nationale verwijswetmatigheden en de wachttijden die daarmee gepaard gaan, beoogt deze studie vooral de bevindingen uit de huisartsenpraktijken te onderzoeken in verhouding tot zes elementen van het gezondsheidszorgsysteem:

1. De beschikbaarheid van huisartsen gemeten als het aantal betrokken op de totale bevolking (huisartsendichtheid).

2. De beschikbaarheid van specialisten gemeten als het aantal betrokken op de totale bevolking (specialistendichtheid).

3. Het hohoreringssysteem voor huisartsen.

4. Het vergoedingssysteem voor specialisten.

5. De toegankelijkheid van specialistische zorg.

6. De aanwezigheid van beroeps- en scholingsopleidingen voor huisartsen.

Dit proefschrift geeft behelst ook een gedetailleerde beschouwing van de invloed van de werklast op het verwijegedrag van de huisarts. Voor dit doel werden de cijfers per praktijk indirect gestandaardiseerd met behulp van de verdeling van praktijkcontacten per land.

Er kleven ongetwijfeld grote nadelen aan het gebruik van contacten als noemer, maar er is geen geschikt alternatief. Deze 
onderwerpen worden in het proefschrift behandeld, maar het belangrijkste onderwerp betreft de relatieve variatie tussen de praktijken in aantallen consulten, die veel kleiner is dan de variatie in verwijscijfers (hoe deze ook gemeten zijn).

Verschillen per land.

In 15 Europese landen werden in total 1548 huisartsen gerecruteerd. Het analysebestand bevatte de gegevens over 860.000 consulten en 44.000 verwijzingen. De meeste gegevens werden in de tweede helft van 1989 en de eerste maanden van 1990 vergaard. De voornaamste uitkomsten per land worden in de appendix vermeld.

Consulten en visites:- Gedurende de studie moesten de deelnemende artsen van elk consult zowel de leeftijd als het geslacht van de patiënt en de plaats van het consult noteren. Ook werd hen gevraagd aan te geven welke weken zij als normale werkweken beschouwden. De huisartsen in Duitsland noteerden gemiddeld 220 consulten in een normale werkweek en, het andere uiterste, de Noorse huisartsen kwamen uit op een gemiddelde van 60 . De Belgische huisartsen noteerden gemiddeld 58 visites per week (468 van alle consulten), gevolgd door hun Duitse collega's met 36 per week (16\%), terwijl Portugal het laagst scoorde met slechts één visite per week. Deze verschillen zijn deels een weerspiegeling van de verschillende wijzen warop spoedeisende hulp is georganiseerd, maar in de gegevens waren ook aanwijzingen dat consultcijfers werden beinvloed door de wijze waarop de huisarts wordt gehonoreerd, waarbij meer interventies werden verricht als huisartsen per verrichting werden betaald. over het algemeen noteerden hulsartsen die werkzaam waren in landen met goed georganiseerde opleidings- en scholingsprogrammes voor huisartsen minder consulten dan huisartsen in landen war dergelijke programma's zwak ontwikkeld zijn.

Verwijzingen:- De gemiddelde absolute aantallen verwijzingen per week waren het hoogst in Duitsland en Italië. Per 1.000 consulten berekend scoorden Noorwegen, Italië en Denemarken het hoogst, maar als ook indirecte verwijzingen (verwijzingen zonder direct contact tusien arts en patiënt op dat moment) zouden zijn meegerekend, dan zou Duitsland het hoogst hebben gescoord. De nationale gegevens waren bijzonder moeilijk te interpreteren vanwege het onbekende aantal patiënten dat rechtstreeks naar de specialist ging. De gegevens wijzen echter op de tamelijk voor de hand liggende conclusie dat huisartsen vaker verwijzen in de landen met een hoge specialistendichtheid. Vragen/behoeften waar de beschikbare middelen in feite aan worden besteed, worden vastgesteld. Landen met een maximum aan mogelijkheden voor rechtstreekse contacten tussen patiënt en specialist gaven lagere verwijscijfers te zien dan landen waar de toegankelijkheid van apecialistische zorg beperkt is. Het percentage verwijzingen van huisartsen naar medische (d.w.z. beschouwende) specialismen was in deze landen echter naar verhouding hoger dan het percentage verwijzingen naar snijdende specialismen.

Variatie in verwijacijfers:-De per land geregistreerde variatie In de verwijscijfers gaf nauwelijks verschillen te zien (ongeveer een factor twee tusgen het 20 ste en het 80 ste percentiel). Bieruit zou kunnen worden opgemaakt dat het probleem van de variabiliteit onder artsen met betrekking tot hun verwijsgedrag losstaat van het gezondheidszorgsysteem van het betreffende land. 
De invloed van de patiënt op de beslissing on te verwitzen:- De deelnemende huisartsen werd gevraagd in de beschrijving van iedere verwijzing aan te geven in hoeverre zij dachten door de patiënt te zijn beinvloed. In deze context werd de invloed van de patiënt alleen bekeken in situaties warin de klinische Indicatie voor verwijzing niet absoluut was, zoals in het geval van een patiënt met acute appendicitis. Voor Nederland leverde deze analyse het bijzonder interessante gegeven op dat ongeveer 608 van alle verwijsbeslissingen leek te zijn genomen onder invioed van de patiënt. In Italië, het andere uiterste, was bij slechts 328 van alle verwijsbeslissingen van deze invloed sprake. In de landen met sterke opleidingsprogramma's voor huisartsen waren de verwijscijfers over het algemeen lager, mar was de invloed van de patiënt op de verwijsbeslissing groter.

Er zijn mogelijk drie soorten huisartaen:

- de huisarts die zichzelf ziet als pleitbezorger van de patiënt en alles doet om aan diens eisen te voldoen, maar die eisen niet onderkent als een vorm van druk;

- de huisarts die zichzelf ziet als pleitbezorger van de gezondheidszorg en alleen die middelen gebruikt die nodig en naar zijn mening redelijk zijn;

- de huisarts die zichzelf als raadsman voor de patiënt beschouwt.

In dit laatste model is de huisarts natuurlijk veel meer geneigd de invloed van de patiënt op medische beslissingen te onderkennen en toe te laten.

Wachttitden voor afspraken met specialisten:- Er waren opvallende verschillen in de wachttijden alvorens patiënten een specialist konden spreken. In België, het ene uiterste, kon 878 van de patiënten binnen vier weken bij de specialist terecht. In veel landen gold dat voor ruim 808 van de patiënten: Belgiü, Frankrijk, Duitsland, Italië, Spanje en zwitserland. In het Verenigd Koninkrijk, het andere uiterste, had slechts 398 binnen vier weken een afspraak. In landen waar de specialiaten per verrichting worden betald waren de wachttijden aanmerkelijk korter dan in de landen war de specialisten een salaris uitbetaald krijgen. Daar waar de huisarts per abonnement wordt betaald zijn de wachttijden ook langer. Dat zijn gewoonlijk ook de landen met sterke opleidingsprogramma's. 
Patiëntenstroom.

De belangrijkste bevindingen van deze internationale vergelijking van gezondheidszorgsystemen zijn samengevat in de figuur.

MODEL TER ILLUSTRATIE VAN DE INVLOED VAN STRUCTURELE VARIABELEN OP DE STROOM VAN CONSULTEN EN VERWIJZINGEN

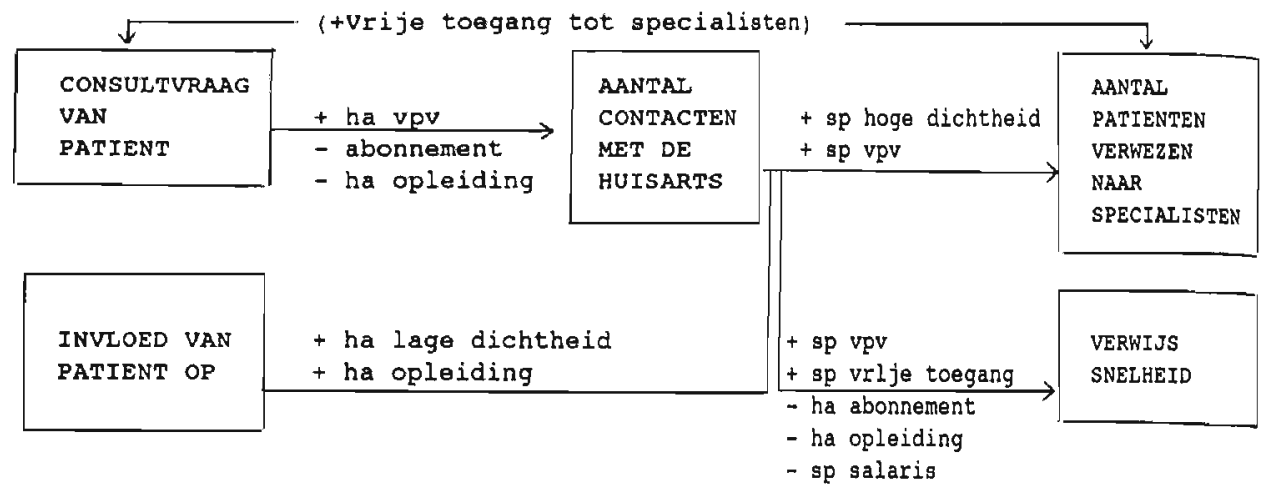

ha $=$ huisarts $\quad$ pp $=$ vergoeding per verrichting sp - specialist

De pijlen staan voor patiëntenstroom. Boven de pijlen worden de positieve factoren aangegeven $(+)$ die de stroom bevorderen, en onder de pijlen de negatieve (-) die de stroom afremmen. Bovenaan de figuur is rechtstreekse toegang tot specialisten vermeld als een factor die positief werkt op het aantal personen dat naar de specialist wordt verwezen, gegeven de behoefte van de patiënt aan contacten met de huisarts, hoewel deze uitspraak niet helemaal uit deze studie kan worden afgeleid.

Als wij het Verenigd Koninkrijk en Duitsland nemen als voorbeelden van landen met zeer uiteenlopende gezondheidszorgsystemen, verklaart dit model de grote verschillen in het gebruik van medische voorzieningen. In het verenigd Koninkrijk hebben een abonnementssysteem voor de huisarts en sterke huisartsenopleidingen een verlagend effect op de consultvraag van de patiënt en houden $z i j$ verband met uitstel van verwijzing. Patiënten lijken invloed te hebben op de beslissing om te verwijzen, maar zij hebben vxijwel geen mogelijkheden voor rechtstreekse toegang tot specialisten. In Duitsland leidt de vergoeding per verrichting voor de huisarts tot een hogere vraag om consulten, de honorering per verrichting voor specialisten leidt tot verhoging van het aantal verwijzingen en hangt samen met een minimum aan uitstel. De afwezigheid van een sterk opleidingsprogramma verlaagt de vraag naar consulten niet, hoewel een lage huisartsendichtheid weer positief samenhangt met grotere invloed van de patiënt op de verwijsbeslissing; een hoge apecialistendichtheid hangt in dit geval samen met hogere verwijscijfers. 
Voor het onderzoek naar de invloed van kenmerken van de huisarts en diens praktijk werd een gestandardiseerde verwijsratio voer iedere deelnemende huisarts berekend (Standardised Referral Ratio SRR). Deze SRR-waarden werden per land gerangschikt en de deelnemers werden in quintielen gegroepeerd (hoogst, boven het gemiddelde, gemiddeld, onder het gemiddelde, laagat). De quintilen per land werden in internationale groepen bij elkaar gevoegd die elk ongeveer 300 huisartsen en \pm 9.000 verwijzingen bevatten. De quintilen werden onderzocht op de verschillen in leeftijd en geslacht van de artsen, het aantal jaren ervaring als arts, de lokatie van de praktijk, de praktijkvorm, de verschillende maten voor de werklast uit de studie, de relatieve verdeling van de verwijzingen over de verschillende specialismen, de proportie van acute of urgente verwijzingen en de proportie van verwijzingen tot stand gekomen onder invloed van de patiënt.

In de hoogste verwijsgroep werden meer vrouwelijke artsen gevonden dan in de laagste $(31,08: 22,28)$. Deze verschillen waren significant. In alle quintilen waren de huisartsen ongeveer even oud, rapporteerden ze een vergelijkbare praktijkervaring on hadden ze een vergelijkbare praktijkvorm. In de hoogste verwijsgroep was er een lichte vertekening in de richting van stadspraktijken, ofschoon tussen verwijscategorie en de afstand tot het ziekenhuis geen verband werd gevonden.

\section{De werklast van de huisarts}

De werklast werd op vier onderdelen bekeken - het gemiddelde aantal consulten in een normale werkweek, het percentage huisbezoeken, de opgegeven of geschatte praktijkgrootte (van toepassing voor 755 van de 1548 deelnemers) en het aantal consulten per 1.000 ingeschreven personen. Br was een buitengewoon significant negatief verband tusaen de verwijscategorie en het gemiddelde antal consulten in en normale week. Buisartsen in de hoogste categorie rapporteerden 151 consulten vergeleken met 116 in de laagste categorie.

Vergelijking van de gegevens van de bovenste twee quintilen in elk land met de gegevens uit de laagste twee quintilen lieten een hoger antal consulten zien bij de huisartsen met hogere verwijscijfers in elk van de landen van west-Europa, met uitzondering van Denemarken en Nederland. De mogelijkheid dat deze uitkomst het gevolg was van een vertekening in het registratiesysteem werd onderzocht en verworpen na zorgvuldige beschouwing van de gegevens.

Geen verschillen werden gevonden met betrekking tot het percentage huisbezoeken of de gemiddelde praktijkgrootte. Het negatieve verband tussen consulten en verwijscijfers bleek ook uit het aantal consulten per ingeschreven patiënt. De laagste categorie van verwijzende artsen verwees gemiddeld 4,3 patiënten per week en de hoogste categorie 11,2 per week. Het drievoudige verschil contrasteert scherp met het kleine verschil in de tegenovergestelde richting: deelnemers in de laagste categorie noteerden 151 consulten per week en die in de hoogste categorie 116. 
Hieruit volgt dat in de meeste landen de werklast van de huisarts samenhangt met zijn verwijsgedrag. In de term samenhang kunnen oorzaak en gevolg niet onderscheiden worden. De meest voor de hand liggende verklaring hiervoor is dat artsen met lage verwijscijfers hun patiënten vaker zien, wellicht om het risico 'iets over het hoofd te zien' zoveel mogelijk te vermijden. Dit beïnloedt natuurlijk niet alleen hun werkwijze ten opzichte van degenen die daadwerkelijk naar een specialist worden verwezen, maar is te beschouwen als een gevolg van hun algmene werkstijl.

De economische implicaties voor de financiering van de gezondheidszorg van het gebruik van vastgestelde huisartsenbudgetten zijn aanzienlijk, aangezien deze conclusie zou kunnen suggereren dat een budget voor verwijzingen uitgaven voor uitbreiding van consultmogelijkheden mogelijk zou maken. In Engeland komt het budget voor consulten echter in feite neer op honorering per abonnement en kan het niet worden aangevuld uit het budget voor verwijzingen.

\section{Standearden van gezondheidszorq}

De resultaten van dit onderzoek dragen bij tot het vaststellen van de kwaliteit van de gezondheidszorgvoorzieningen. Op sommige terreinen in de geneeskundige zorg worden standaarden ontleend aan de resultaten van klinische experimenten; elders is de gedachte van het bereiken van bepaalde doelstellingen meer van toepassing. Dit onderzoek heeft elementen van de praktijk van de gezondheidszorg bekeken en verschillen belicht. Een zorgstandaard die in het ene land als mogelijk halbaar beschouwd zou kunnen worden, of in dat land binnen een bepaald specialisme, kan voor een ander land een realistisch doel worden. Ook zijn een aantal zaken aan de orde gesteld die tot steun kunnen zijn voor beleidsmakers van nationale gezondheidszorgsystemen zoals het belang en de inhoud van beroepsopleidingen voor huisartsen en de evenwichtige verdeling van menskracht over specialistische en generalistigche zorg. 


\section{ACRNOWLEDGEMENTS}

This project is the product of cooperation in the network of participanting general practitioners involved in the European General Practice Research Workshop. It is appropriate therefore to pay tribute to the many doctors who returned data for this study. The key national representatives for the project were:-

$\begin{array}{ll}\text { BELGIUM } & \text { J. Heyrman } \\ \text { DENMARK } & \text { D. Boulliez } \\ \text { FRANCE } & \text { J. Kelstrup } \\ \text { GERMANY } & \text { J. Nouch } \\ \text { (DDR) } & \text { C. Kohler } \\ \text { (FRG) } & \text { M. Kohle } \\ \text { HUNGARY } & \text { S. Thies-Zajonc } \\ \text { REPUBIC OF IRELAND } & \text { R. Botos } \\ \text { ITALY } & \text { F. Dobbs } \\ \text { NETHERLANDS } & \text { G. Passerini } \\ & \text { J. van der Zee } \\ \text { NORWAY } & \text { F. Gloerich } \\ \text { PORTUGAL } & \text { D. Bruusgaard } \\ & \text { J. Jordao } \\ \text { SPAIN } & \text { A. Brito de Sa } \\ & \text { J. Gervas } \\ \text { SWITZERLAND } & \text { M. Perez-Fernandez } \\ \text { UNITED KINGDOM } & \text { I. Garcia OImos } \\ \text { YUGOSLAVIA } & \text { R. Meyer } \\ & \text { D. Fleming } \\ & \text { M. Katic }\end{array}$

In addition to these key personnel, it is appropriate to pay tribute to the structure of the European General Practice Research Workshop in bringing this project to fruition. The existence of this organisation is critical to undertaking projects such as the European Referral Study and in this regard $I$ would like to thank Ekke kuennsberg (U.K) whose diplomatic skills as President of the organisation over many years did much to keep it functioning effectively; to Pille Krogh-Jensen (Denmark) whose logical approach to research in general practice has clarified many issues for me, to Remy Maas (Belgium), Theo van Stockum (Netherlands), Dag Bruusgaard (Norway), Robin Hull (U.K) whose regular attendances and contributions to the meetings of EGPRW have also contributed to its continuance: to Rene Rocken (Netherlands) and Paul Wallace (U.K), current officials of the organisation who also have acted as paranimfs for the formal procedures associated with the promotion to doctorate.

I would like to thank my examining committee for granting this promotion, but particularly I would like to single out the contribution of Paul Backer (Denmark) who has carried the task of representing European General Practice in the COMAC. This contribution has given general practice based research an importance that it certainly deserves, but would have been more difficult to establish without him.

Other large contributions to this study have been made by Robert Lancashire in the analysis of the data and by Joan Dainty in the preparation of the manuscript. Significant contributions have been made by Donald Crombie and Kenneth Cross partly in commenting on the text and providing statistical advice but also 
for the important part they have played in moulding my thinking over the years. Veer Ghasi of Birmingham University has provided assistance with computing and Christine Norbury in clerical help. Janet Paske and Brian Baley of Birmingham University assisted particularly in the analysis of the pilot study.

In the presentation of this material as a thesis, I have been particularly grateful for detailed and considered criticism and help from my sponsors Professor J. van der $2 e e$ and Professor A. Knottnerus. I would also like to thank them for their initiative in encouraging me to present this material to the University of Limburg. Mrs $S$ Notenboom(NIVEL) has kindly translated the sumary into Dutch. Valuable assiatance has been given to me by Winke Boerma of NIVEL in providing national data whereby the countries of Western Europe could be allocated to the healthcare structure variables considered. Many of the results from this study have been presented as an Occasional Paper in the Royal College of General Practitioner series and I am grateful to the Editor for permission to reproduce these here. 
Alderson, M., Dowie, M.R. (1979). "Health surveys and related studies". Oxford: Pergamon Press.

Andersen, R., Aday, L.A. (1978). "Access to medical care in the U.S. Realised and Potential". Medical Care, Vol.XVI.No.7.pp533546 .

Appleby, J. I. (1987). "Why doctors must grapple with economics". Brit.Med.Journal. 294. p326.

Armstrong, D., Fry, J., Armstrong, P. (1991). "Doctors" perceptions of pressure from patients for referral". Brit.Med.Journal. Vol.302. 001186-1188.

Aulbers, B.J.M.(1985). "Factors influencing referrals by general pracatitioners to consultants" In:Decision making in general practice. Edited by M Sheldon, J. Brooke, A. Rector. Macmillan.

Bensing, J. (1991)."Doctor-patient communication and the quality of care". NIVEL, Utrecht.

Birmingham Research Unit/RCGP. (1978). "Practice activity analysis - referrals to specialists". Journal of the Royal College of General Practitioners. 28. pp251-252.

Birmingham Research Unit of the Royal College of General Practitioners (1977). "Total care usage of a defined population". Journal of the Royal College of General Practitioners, 27, p306314.

Brook, R.H., Appel, F.A. (1973). Quality of care assessments; choosing a method for peer review. New England Journal of Medicine, 288, 1323-9.

Butler, J., Calnan M. (1987). "Too many patients? A study of the economy of time and standards of care in general practice". Avebury, Aldershot (U.K).

Cartwright, A., Anderson, R. (1981). "General Practice Revisited". A second Study of patients and their doctors. Institute for Social Studies in Medical Care. Tavistock Publications.

van Casteren, V(1987). "A descriptive study on sentinel health information systems with GPs in the countries of the European Community, Brussels. Institut d'Hygiene et d'Epidemiologie.

Centre de Sociologie et de Demographic Medicales (1987). Medical Manpower in Europe. Paris. CSDM.

COMAC-BSR in collaboration with European General Practice Research Workshop. (1990)., The Interface Study. Edited by D.L.Crombie, J. van der Zee, P. Backer.Occasional Paper 48. RCGP.

Coulter, A., Bradlow, J., Martin-=Bates, C., Agass, M., Tulloch, A. (1991). "Outcome of general practitioner referrals to specialist outpatient clinics for back pain". Brit.Journal of General Practice. 41. pp450-453. 
Coulter, A, Noone, A., Goldacre,M. (1989). "General practitioners referrals to specialist out patient clinics". I Why general practitioners refer patients to specialist outpatient clinics. Brit.Med.J. 299. pp304-6.

Coulter, A., Roland,. M., Wilkin, D. (1991). "GP Referrals to Hospital". A guide for Family Health Services authorities. Published by Centre for Primary Care Research, Dept. of General Practice, University of Manchester.

Crombie, D.L. (1975). "Rationale of clinical problem solving". Scientific Aids in Hospital Diagnosis. Ed: J. P. Nicholson. Plenum Press, pp251-265.

Crombie, D. L. (1975). Problems of co-operative studies. Allgemeinmedizin International - General Practice International 2. pp 56-68.

Crombie, D.L. (1983). Immunisation Procedures in Europe. Health Trends. Vol.15. pp86-90.

Crombie, D. L., Fleming, D. M. (1983). "Quality of care in general practice". Journal of the Royal College of General Practitioners, pp746-7.

Crombie, D.I., Fleming, D.M. (1988a)." General practitioner referrals to hospital: the financial implications of variability". Health Trends. 20. pp53-56.

Crombie, D.L., Fleming, D.M. (1988b). "Practice Activity Analysis". Occasional Paper 41. Published by The Royal College of General Practitioners.

Cummins, R.0., Jarman, B., White, P.(1981). "Do general practitioners have different "referral thresholds'?" Brit.Med.Journal. 282. pp1037-1039.

Darwin, C. (1874). "The descent of man". Second edition (republished 1901). Murray, London.

Dowie, R.(1983). "General Practitioners and Consultants: A study of outpatient referrals. King Edward's Hospital Fund for London.

Fleming, D. M.(1983). "The influence of increasing consultations on general practitioner activity rates in Belgium and United Kingdom". European Journal of Operational Research. 14. pp318322 .

Fleming, D. M. (1983). "The population at risk. The problem of the denominator for epidemiological study in general practice". Allgemeinmedizin International. General Practice International.3. pp135-139.

Fleming, D., M. (1985). "The Denominator for audit in general practice". Family Practice. Vol.2 pp76-81.

Fleming, D.M. (1989). "Consultation rates in English general practice". Journal of the Royal College of General Practitioners. 39. pp68-72. 
Fleming, D.M.(Ed)(1992). European Study of Referrals from Primary to Secondary Care. Report to the Concerted Action Committee of Bealth Services Research for the European Community. Published by The Royal College of General Practitioners, Occasional Paper 56.

Fleming, D.M., Cross, K.W., Crombie, DL.(1991a). The measurement of referrals for practice audit. Bealth Trends. Vol.23. No.2. pp66-69.

Fleming, D. M., Crombie, D. L., Cross, K. W. (1991b). "An examination of practice referral rates in relation to practice structure, patient demography and case mix". Health Trends, vol.23. No.3, pp100-104.

Eleming, D. M., Maes, R.M.J. (1980). "Facets in practice in the United Kingdom and Belgium". Allgemeinmedizin International $I$. pp5-11.

Flierman, B.A.(1991) "Changing the payment system of general practitioners". NIVEL, The Netherlands.

Fox, J.(1985). "Knowledge and judgement in decision-making". In: Decision making in general practice. Edited by $M$ Sheldon, $J$. Brooke, A. Rector, Macmillan.

Frankel, S., Farrow, A., West, R.(1989). "Non-attendance or noninvitation? A case-control study of failed outpatient appointments". Brit.Med.Journal.Vol.298.pp1343-1344.

Fry, J. (1965). "Present State and Future Needs". Lancaster, MTP Press for Royal College of General practitionera.

Gervas, J.J., Perez-Fernandez, M., Garcia Sagredo, P. , Abraira, v. (1990). Utilizacion de servicios santarios: pacientes $y$ visitas. Atencion Primaria. 7:346-348.

Gloerich, ABM., Schrijnemaekers, V., van der zee, J. (1989). Referrals in Sentinel Practices. In Bartelds, A.I.M., Fracheboud, $J$. and van der Zee, J (eds): The Dutch Sentinel Practice Network: Relevance for Public Health Policy. Utrecht, NIVEL.

Glynn, C., Crockford, G., Gavaghan, D., Price, D., Miller, J. (1990). Epidemiology of Shingles. Journal of the Royal Society of Medicine. Vol. 83. October. pp 617-619.

Grace, J., Armstrong, D. (1986). "Reason for referral to hospital: extent of agreement between the perceptions of patients, general practitioners and consultants". Family Practice. 3. pp143-147.

Grace, J., Armstrong, D.(1987). "Referral to hospital: perceptions of patients, general practitioners and consultants about necessity and suitability of referral". Family Practice. 4. pp170-175.

Grol, R., Whitfield, M., Maeseneer, J de., Mokkink, H. (1990). "Attitudes to risk taking in medical decision making among British, Dutch and Belgian general practitioners". Brit.Journal of General Practice. 40. ppl34-136. 
Groenewegen, P.P., Zee van der, J., Haaften van, R. (1991). "Remunerating general practitioners in Western Burope". Netherlands Institute of primary Health Care. Avebury.

Beaney, D.J., Howie, J.G.R., Porter, A.M.D.(1992). "Attaching prices to decision making in general practice". Family Practice. An International Journal. Vol.9. No.2. pp177-180.

Horder, J., Hordex, E. (1954). "Illness in general practice". The Practitioner. pp177-185.

Howie, J. G. R (1972). "Diagnosis - The Achilles heel ?". Journal of the Royal College of General Practitioners, 22, p310-315.

Howie, J. G. R. (1985). "The Consultation: A Multi-purpose Framework" In Decision-Making in General Practice. Ed: M.Sheldon, J. Brook, A Rector, Macmillan (pp1-12).

Eull, F. M. (1978). The management of vaginal discharge in general practice. Journal of the Royal College of General Practitioners, 28. $p$ p 714-8.

Hull, F.M.(1981). International Sore Throats. Journal of the Royal College of General Practitioners. 31. pp45-48.

Hull, F.M. (1982). The Elropean General Practice Research Workshop 1971-1981. Journal of the Royal College of General Practitioners 32, 106-8.

Bull, F. M. (1982b). Diagnosis and prognosis of low back pain in three countries. Journal of the Royal College of General Prractitioners. 32. pp352-6.

HuIl, F.M., Westerman, R.F.(1986). Referral to medical outpatients departments at teaching hospitals in Birmingham and Amsterdam. Brit.Med.Journal. 293. pp311-314.

Hull, F. M. (1988). Communication between general practitioner and epecialist In: J.M.Bosman, H. Kroon, and J. Van der Zee (Bds). Hospitals and primary health care in the Netherlands, Utrecht. NIVEL.

Huygen, F.J.A., Mokkink, H.G.A., Smits, A.J.A., van Son, J.A.J., Meyboom, W.A., van Eyk, J.Th.M. (1992). Relationship between the working styles of general practitioners and the health status of their patients. Brit.Journal of General Practice. 42. pp141-144.

Jones, R., Lydeard, S.(1989). Prevalence of symptoms of dyspepsia in the community. Brit.Med.Journal, Vol.298. pp30-32.

Jost, T.S.(1990). Assuring the quality of medical practice. An international comparative study. King Edward's Hospital Fund.

Journal of the Royal College of General Practitioners (1983). Research: The role of the general practitioner. Editorial, 33. pp469-71.

Knottnerus, J.A., Joosten, J., Daams, J.(1990). Comparing the quality of referrals of general practitioners with high and average referral rates: an independent panel review. Brit.Journal of Gen.Pract. pp178-181. 
Lambert, H.M., Wood, M. Bofmans-0kkes, I.M. The International Classification of Primary Care (ICPC) in the European Community. Fleming D.M - Chapter on the use of ICPC coding in the European Study of Referrals from Primary to Secondary Care. Oxford University Press. (Anticipating publication 1992).

Loudon, I. S.L., Stevens, R.(1980). Chapter 7. Primary Care and the Hospital. In: Primary Care, Ed. John Fry. Heinemann Medical Books, London.

Marinker, M., Wilkin, D., Metcalfe, D.H. (1988). Referrals to Bospital: can we do better? Brit.Med.Jourenal. 297. pp461-464.

Morrell, D. C., Cage, B. G. Robinson, (1970). Patterns of demand in general practice. Journal of the Royal College of General Practitioners. 19. p331.

Morrell, D. C., Gage, H. G., Robinson, N.A. (1971). Referrals to hospital by general practitioners. Journal Royal College of General Practitioners. 21. pp77-85.

National Center for Health Statistics (1989). Vital and Bealth Statistics. Ambulatory Care: Republic of Germany and United States 1981-83. U.S.Department of Health and Human Sciences. Public Health Service, Centers for Disease Control. DHHS Publication No(PBS) 89-1481.

Noone, A., Goldacre, M., Coulter, A., Seagroatt, V. (1989). Do referral rates vary widely between practices and does supply of services affect demand?. A study in Milton Keynes and the Oxford region. Journal Royal College of General Practitioners. 39. pp404-407.

Office of Health Economics (1987). "Compendium of Health Statistics". 6th Edition 1987.

Office of Population Censuses \& Surveys (1989). "General Household Survey 1986". Social Survey Division, Series GHS no 16.

Organisation for Economic Co-operation and Development (OECD).(1987). "Financing and delivering health care". A comparative analysis of OECD countries. Social policy studies No.4.

Paterson, J.K.(1959). "Second Opinions". J.Coll.Gen.Practit. 2. pp160-169.

Rethans, J.J., Sturmans, F., Drop, R., Cees, van der V, Bobus, P.(1991). "Does competence of general practitioners predict their performance? Comparison between examination setting and actual practice". Brit.Med.Journal. Vol.303. pp1377-1380.

Reynolds, G. A., Chitnis, J.G., Roland, M.O.(1991). "General practitioner outpatient referrals: do good doctors refer more patients to hospital". Brit.Med.Journal. pp1250-1252.

Robra, et al (1991). "Die haufigkeit der arztlichen Inanspruchnahme im Spiegel zweier reprasentativerhebungen: DHPSurvey und EVaS-Studie. Off.Gesundh. Wes.53.pp228-32. 
Roland, M., Morris, R.(1988). "Are referrals by general practitioners influenced by the availability of consultants?" 297. pp599-600.

Roland, M. O., Bartholomew, J., Morrell, D. C., McDermott, A., Paul, E.(1990). "Understanding hospital referral rates: A user's guide". Brit.Med.Journal. Vol.301. pp98-102.

Ross, A. K., Davis, W.A., Horn, G., Williams, R. (1983). "General practice outpatient referrals in North Staffordshire". Brit.Med.Journal. 287. pp1439-1441.

Royal College of General Practitioners (1983). "To heal or to harm". The Prevention of Somatic Fixation in General Practice. Edited by Richard Grol.

Royal College of General Practitioners (1986). "In pursuit of quality". Approaches to performance review in general practice. Bd.David Pendleton, Theo Schofield, Marshall Marinker. Published by The Royal College of General Practitioners.

Royal College of General Practitioners, office of Population Censuses and Surveys, Department of Health and Social Security(1974). "Morbidity statistics from general practice". Second National study 1970-71. London BMSO.

Royal College of General Practitioners, office of population Censuses and Surveys, Department of Health and Social Security (1982). Morbidity statistics from general practice. 1970-71 socio-economic analyses. Studies on Medical and population Subjects No.46. HMSO.

Royal College of General Practitioners, office of Population Censuses and Surveys, Department of Bealth and Social Security (1986). Morbidity Statistics from General Practice 1981-1982. Third National Study. A publication of the Government statiatical Service. Series MB5.no.1. HMSO.

Senior, J.R.(1976). "Towards the measurement of competence of medicine". Philadelphia: National Board of Medical Examiners.

Stower, M. J.(1989 (. "Delays in diagnosing and treating bladder cancer". Brit.Med.Journal. 296. pp1228-1229.

Todd, J. W. (1984). Wasted resources: Referrals to hospital. Lancet. p1089.

Wennberg, J.E., (1990). "Outcomes research, cost containment and the fear of health care rationing". The New England Journal of Medicine. Vol.323. No.17. pp1202-1204.

White, K. L. (1989). "Preface to vital and health statistics. Ambulatory Care: France, Federal Republic of Germany and United States". Comparative International vital and health statistics. Report No.5. Natinial Center for Health Statistics. US Department of Bealth and Buman Services.

Wilkin, D., Smith, A. G. (1987). "Explaining varlation in general practitioner referral to hospital". Family Practice.4. 160-169. 
Wilkin, D., Dornan, C.(1990). "General practitioner referrals to hospital". A review of research and its implications for policy and practice". Centre for Primary Care Research, Department of General Practice, University of Manchester.

Wilkin, D., Smith,. A.G. 1990). "Variation in general practitioners' referral rates to consultants. Journal of the Royal Colege of General Practitionerzs. 37. pp350-353.

World Health Organisation (1978). Primary Health Care. Report of the International Conference on Primary Health Care Alma-Ata, USSR.

World Health Organisation (1985). Targets for Health for all by 2000. Targets in support of the Buropean Regional stategy for Health for All. Copenhagen, WHO Regional Office for Europe.

World Organisation of National Colleges, Academies and Academic Associations of General Practitioners/Family Physicians.(1987). International Classification of Primary Care (ICPC). Edited by Henk Lamberts and Maurice Wood. Oxford Medical Publications.

Zee, van der, J.(1982). The Demand for general practitioner services. A Ph.D Thesis. Netherlands Huisartsen Instituut, University of Limburg. 
Data for each country are presented separately in a standardised format. The largest data set was obtained in the United Kingdom and these data are presented first providing detailed explanaton of the statistics used and illustrating the standardised format. Thereafter, data are presented alphabetically by country. Bach national report will be presented briefly with the fully detailed explanations being confined to that presentation concerned with the U.K. data. The names of the responsible national representatives will be given as each national data set is introduced. At the end of each presentation, appropriate national acknowledgements and references are provided.

Each item of information presented will be described in relation to available national material for that country. For simplicity in the text, all rates will be given per 1000 consultations unless stated otherwise, and percentages will be presented to the nearest whole number, except for those values which are less than 5 which will be presented to one place of decimals. Some internal comparisons of data within a country are presented as each national data set is considered but most differences between countries are considered in Chapter 5.

The data set for each country includes:

Fig.1 Percentage distribution of recruited doctors by age with national comparable data where available.

Fig.2 Percentage distribution of consultaitons by age and sex.

Fig.3 Age/sex specific referral rates per 1000 consultations.

Table 1 Numbers of referrals, percentage of total referrals and rates per 1000 consultations by sex in individual specialties.

Table 2 Percentage of referrals in each sex distributed by mode, type, urgency and patient influence on the decision to refer.

Table 3 Delay patterns between referral and first appointment in major specialty groups.

Figures $1,2,3$ and Table 1 specify the numbers concerned in each category which are in most cases very slightly less than the total because of small deficiencies in the data: for example in the data for the United Kingdom, Fig.l concerns 401 recorders, there being a further 6 for whom age data were not available.

The computer programme used in the preparation of this manuscript was not capable of entering many of the vowel accents used particularly in the German, Portuguese and Spanish languages. The authors apologise to recorders in the relevant countries for the occasional difficulty in reading the text, which this causes. 
UNITED KINGDOM - National Representative D M Fleming

Figure 1

Recorders ( $n=401$ ) : Distribution by Age

Compared with national data

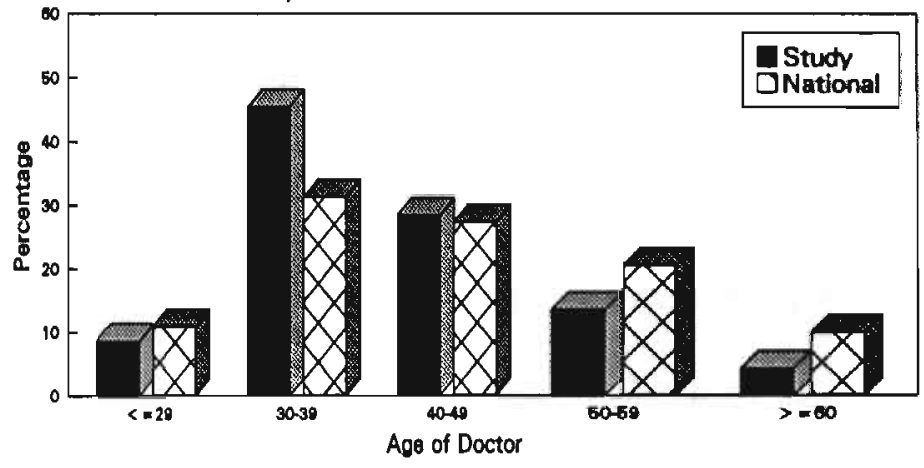

Figure 2

Consultations : Distribution by Age ( $n=97720$ males, 153104 females)

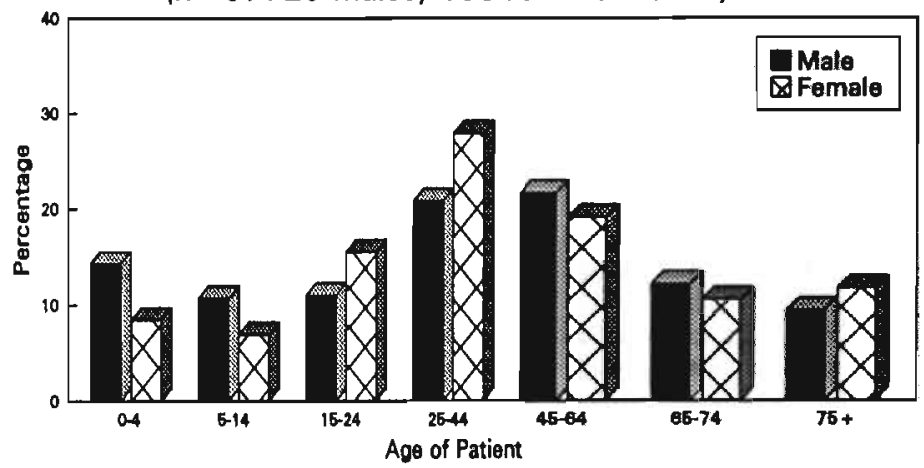

Figure 3

Referral Rate (per 1000 consultations)

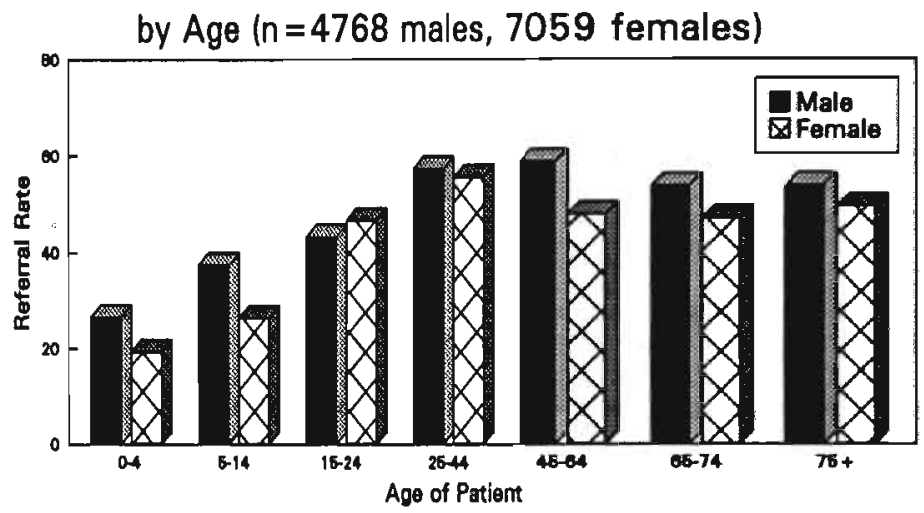


TABLE 1 - REFERRALS BY SPECIALTY NUMBER AND PERCENT OF TOTAL RATE PER 1000 CONSULTATIONS GY SEX
TABLE 2 - DISTRIBUTION OF REFERRALS (8) BY MODE, TYPB, URGENCY AND REPORTED PATIENT INFLUENCE

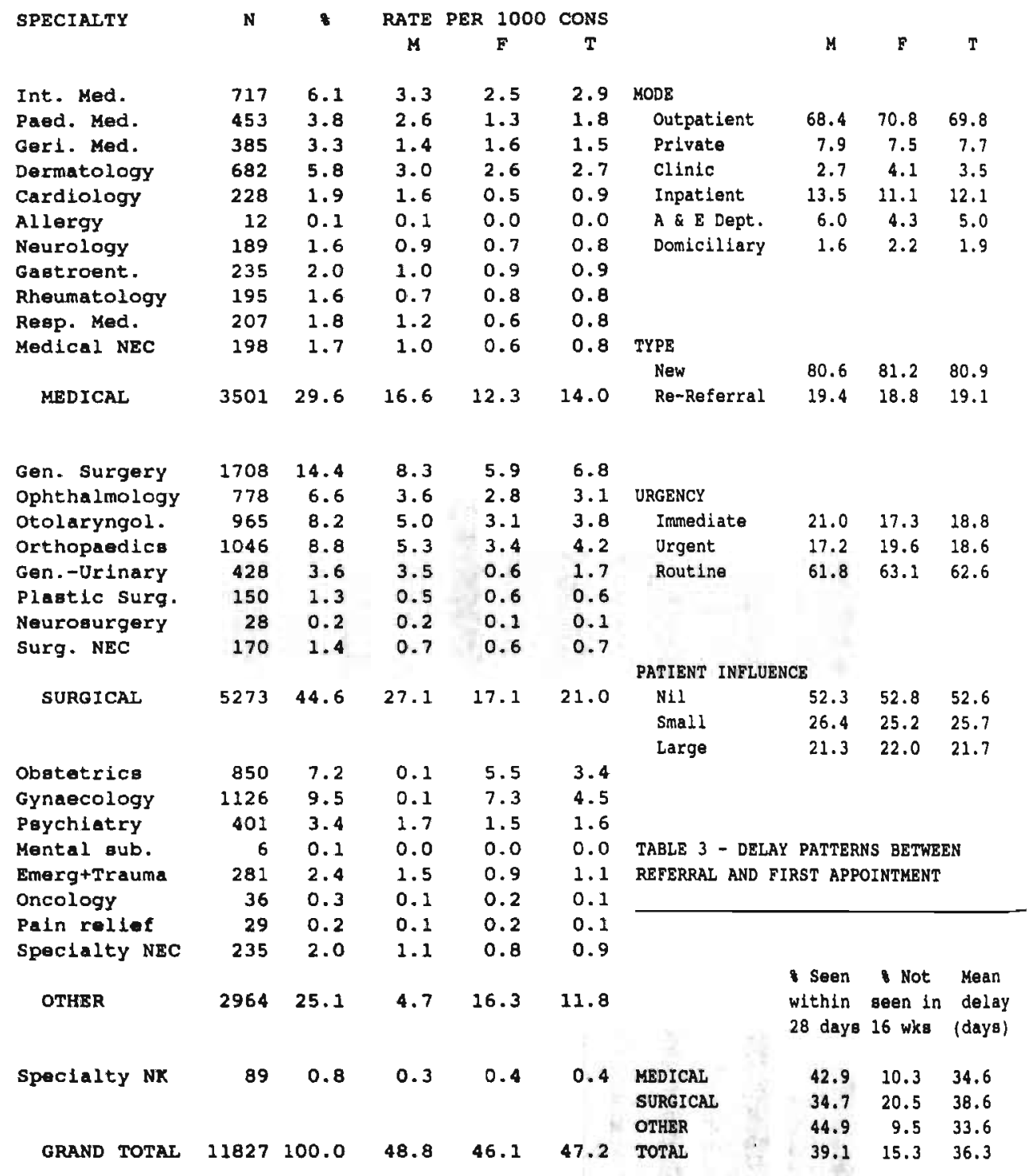


There were 407 general practitioners recruited and 389 (958) of these were principals. The percentage distribution by age is compared with national data in Fig. 1. The sample of recruited doctors was biassed by the presence of a large number of doctors in their thirties and a relative deficiency aged 50 years or more. There were 96 females, equivalent to 248 of recruited doctors compared with a nationally comparable figure of $23 \%$. Data are available about the time spent in general practice by each participant but these convey no substantial additional information to that concerning age. 198 of the recruited doctors had spent more than 20 years in general practice. An attempt to recruit a subset of doctors by random means using a mailshot approach was unsuccessful.

The average list per principal in the study was 1939 compared with the national average of 1965. The distribution of recruited general practitioners by list size was very similar to the national distribution. About half of the principals recruited had a trainee in the practice. The distribution by size of partnership when compared with national data showed a study bias against singlehanded doctors and towards larger partnerships.

Half of the recorders (51\%) practised within $5 \mathrm{kms}$ of a major hospital and $24 \%$ were $15 \mathrm{kms}$. or more distant. Recorders were widely distributed across the whole of the United Kingdom. They described the environment of their practices by the degree of urbanisation : $48 \%$ were in urban practice, 408 mixed and 128 rural. (No national data are available distributing practices in this way).

\section{Consultation data}

Altogether the data included referrals from 250,824 consultations. The distribution by age and sex groups (Fig.2) should be considered in relation to the age composition of the population generally in which the number of young persons is approximately equal in both sexes but the number of elderly females substantially exceeds that of elderly males. The consultation pattern shown here is typical of that found in the major consultation based studies in the United Kingdom such as the third national morbidity survey (MSGP-3, Royal College of General Practitioners et al, 1986 : The General Household Survey (GHS), Office of Population Censuses \& Surveys, 1986). There is a small excess of consultations with male compared to female children $0-4$ years. equal numbers in the age groups 5-14 years, a large excess among females in the childbearing years (15-44 years), a moderate excess in females in the age group 45-64 years, and in the older age groups an excess in females commensurate with that in the total population. 38353 consultations (158) involved a home visit, a value similar to that found in the GHS and in consolidated material from Practice Activity Analysis (Crombie \& Fleming, 1988) but a little greater than that reported in the MSGP-3. This order of magnitude in the percentage of home visits provides evidence of good quality recording since it is particularly easy to overlook home visits when undertaking studies of this type. 
Recorders were asked to specify which of the working weeks could be described as normal in the sense that they were not disrupted by holidays, sickness or other disturbance. From these reports we were able to calculate the value of 128 consultations in an average working week which is roughly equivalent to 3.4 consultations per patient per annum and is in keeping with estimates from other sources (Fleming, 1989).

\section{Direct referral data}

Altogether there were 11827 direct referrals, 4768 in males $(408), 7059$ in females $(608)$ and a further 61 in which the age or sex was not specified. Distribution by age groups was similar to that of the 36,000 referrals in MSGP-3. In Fig.3, referrals are expressed in age and sex groups as rates per 1000 consultations. Excepting in the age group 15-24 years, rates in males exceeded those in females.

The distribution by specialty is given in Table 1 . Material presented includes the number of referrals in each specialty, the percentage distribution and the sex specific rates per 1000 consultations.

Referrals were examined by type, mode, urgency and the general practitioner's estimate of the degree to which a patient influenced each referral decision. The results for all referrals are summarised as percentage distributions (Table 2) and provide reference values for the discussion (below) of referrals in individual specialties. Results here concern total referrals but data are also available for outpatients exclusively.

In the interests of national comparability, delay statistics are reported here for outpatients, private and clinic referrals combined. The results for the United Kingdom are dominated by outpatient referrals though separate analyses are available for individual modes of referral. The size of the data base has been summarised earlier (Table 5.1). Delays were analysed in three intervals: the number of days between referral and first specialist appointment, between first appointment and communication with the general practitioner, and between appointment and surgical intervention where planned. The delay between referral to specialist appointment is considered in three statistics (Table 3): the percentage of persons seen within 4 weeks of referral, the percentage of persons not recorded as seen within 16 weeks and the mean interval in days (mean delay) of those patients recorded as seen within 16 weeks. (The limiting effect of failed appointments on the validity of the second of these statistics is described elsewhere - Fleming(Ed), 1992).

Delay statistics are presented for referrals in the major gpecialty groups and for all referrals combined. Approximately 398 of referred patients were seen by the specialist within 4 weeks, 158 were not seen within 16 weeks and the mean delay was 36 days. The first of these statistics provides an indication of the efficiency of a referral system; the second, an indication of failure and the third a statistic whereby mean delays can be compared between specialties.

Delays were also examined in respect of the intervals between the specialist appointment and the first communication received by the general practitioner and between the appointment and surgical 
intervention where planned. In 848 of cases, communication was received within 2 weeks and in 38 , no communication had been received within 12 weeks. There were no major differences between the results in most of the commonly used specialties. Among surgical referrals where surgical intervention was planned, $18 \%$ received their surgical procedure within 2 weeks, 318 within 4 weeks and 428 had not received their operation within 12 weeks. The mean delay among those receiving surgical intervention within 12 weeks was 30 days.

\section{Analysis by specialty}

The overall rate of referral was 47 per 1000 consultations apportioned respectively between the major specialty groups as 14 medical, 21 surgical and 12 other specialties. The numbers of referrals (and percentages of total), are given for each specialty in Table 3, together with sex specific rates per 1000 consultations. The four specialties with the most referrals were general surgery, gynaecology, orthopaedics and otolaryngology.

The material presented in Figs.1,2,3 and Tables $1,2,3$ provide background references to the examination of referrals in individual specialties where there were sufficient numbers to justify comment. The numbers in each sex reported in the recruitment phase are given for each specialty.

Internal medicine ( 327 males, 390 females):- This specialty included the largest proportion referred directly as inpatients (48\%). Referrals in the private sector were low and the influence of the patient on the decision to refer was also low. When referral takes place as an emergency, the option to refer to a specific specialist is not usually available. All three of the delay statistics were favourable relative to the results for all specialties combined.

Paediatric medicine (254 males, 199 females):- Half (518) of all children aged 0.4 years were referred to specialists in paediatric medicine compared with (198) of children aged 5-14 years. There were more male children than females. Forty one percent of referrals involved hospital admission as inpatients, only 28 were in the private sector. The influence of the patient(parents) on the decision to refer was similar to that found in other specialties. Delay statistics were broadly similar to those in all other medical specialties.

Geriatric medicine (136 males, 249 females):- 478 of all referrals involved inpatient admission and 248 domiciliary consultation. Only two persons out of a total of 385 were referred privately whereas 139 out of 2775 (58) of persons aged 65 years and over were referred to the private sector. There were 228 domiciliary consultations in this study and 93 of these were in geriatric medicine. 708 were seen within 4 weeks of referral. The mean delay was significantly less than in most other specialties.

Dermatology (291 males, 391 females):- There were more females than males referred to dermatologists (excepting in children $0-4$ years). 128 of referrals were in the private sector. The influence of the patient on the decision to refer was higher than in all other medical specialties. 1648 of referral decisions were reported to be influenced at least to some extent). All three 
delay statistics were unfavourable, 308 seen within 4 weeks, 208 not seen within 16 weeks and the mean delay was 41 days.

Cardiology (152 males, 76 females):- The twofold excess of males accords with the relative prevalence between the sexes for ischaemic heart disease. Delay patterns in cardiology were comparable with most other specialties (mean delay interval 33 days).

Gastro-enterology (93 males, 142 females):- The excess among females was distributed across all age groups. $13 \%$ of referrals were in the private sector. In 50\%, the general practitioner reported being influenced in the referral decision. Delay statistics were average.

Rheumatology ( 68 males, 127 females):- There was a strong patient influence on the decision to refer - nil influence 38\%, small influence 328, large influence 318. 158 of the referrals took place in the private sector. Delay statistics were similar to those in other medical specialties.

Respiratory medicine (114 males, 93 females):- There were more males than females notably among those aged over 45 years. The delay patterns showed particularly favourable results with 598 seen within 4 weeks, 18 not seen within 16 weeks and a mean delay interval of 28 days. The proportion not seen within 16 weeks was one of the lowest.

General surgery (810 males, 898 females):- 95 male children 0-14 years were referred to general surgeons compared with 24 females and in the age range 15-44 years, 299 males compared with 412 female日. The distributions of referrals by the various characteristics examined were unremarkable relative to the results for all specialties combined. 508 of referred patients received appointments within 4 weeks and 118 were not seen within 16 weeks, the mean delay interval was 33 days. All three of these delay indicators were favourable relative to the equivalent combined values for all specialties.

Ophthalmology ( 354 males, 424 females):- The numbers of referrals in each age group were similar for both males and females with the exception of the age group 75+ years where there were 50 males and 105 females. The proportion referred to the private sector was $8 \%$. The distribution by patient influence on the referral decision was similar to that for combined data. The delay statistics were unfavourable: only 268 were seen within 4 weeks and the same proportion were not seen within 16 weeks: the mean delay was 43 days.

Otolaryngology (486 males, 479 females) :- In the age group 0-14 years, 127 male children were referred compared with 80 females, the numbers were similar in other age groups. 118 of all referrals took place in the private sector, 118 were considered urgent. There was a strong patient influence on the referral decision; $388 \mathrm{nil}$ influence, 318 small influence and 318 large influence. Delay statistics were very unfavourable; 268 were seen within 4 weeks, 248 not seen within 16 weeks and a mean delay interval of 43 days. 498 of patients for whom surgery was planned were still waiting 12 weeks after specialist appointment. 
Orthopaedics (520 males, 526 females):- In each age group below 65 years there were more males than females and thereafter more females than males. $13 \%$ of all referrals occurred in the private sector. The influence of the patient on the referral decision was stronger here than any other of the commonly used specialties (nil influence 368 , small influence 358 , large influence 308 ). Delays were also greater than in any other commonly used specialty; 278 seen within 4 weeks, 298 not seen within 16 weeks and the mean delay was 43 days. 568 of persons for whom surgery was planned were still waiting 12 weeks after specialist appointment.

Genito-urinary Surqery (338 males, 90 females):- This specialty mainly concerns males: even in the $0-14$ years age group there were 25 males compared with one female. Distributions by the characteristics examined were similar to the values for all specialties combined. Delay statistics were unfavourable ( 358 seen within 4 weeks, 188 not seen in 16 weeks and a mean delay interval of 37 days).

plastic surqery (53 males, 97 females):- The numbers were amall and patient influence on the referral decision was very strong. 26 persons were referred privately and of these, 18 were meeting their own costs as opposed to reimbursement through insurance schemes.

Gynaecology (1112 females) :- More than half the referrals occurred among women aged between 25 and 44 years. 98 were referred privately and the distributions by the degree of urgency and by patient influence on the referral decision did not differ from those in all specialties combined. Delay statistics were comparable with the combined values for all specialties.

Psychiatry (164 males, 237 females):- There were more female referrals in total but in the age groups less than 45 years, the numbers were similar in both sexes. From the pattern of consultations in the Second and Third general practice morbidity surveys in England and Wales, there were many more consultations for psychiatric problems among females than males in the age group 15-44 years. There is an inference here however that there is no difference for the more serious psychiatric illnesses. $35 \%$ were re-referrals and this was the highest value for this statistic among the commonly used specialties. Sixty four referrals (16\% of all psychiatric referrals) involved domiciliary consultation, 2.08 were private, 168 were classified "immediate" and $27 \%$ "urgent". Patient influence and delay pattern analyses were unremarkable.

\section{Overview of the data for the United Rinqdom}

The database for the United Kingdom was large and though the age distribution of the general practitioners was biassed towards a younger distribution than national average, the sample was representative in characteristics such as list size and consulting pattern. The referrals recruited to the study provide a satisfactory representative sample of referred patients generally even though not random. Referral rates provide a useful yardstick against which the referral patterns of individual doctors/groups of doctors/groups of patients can be compared. 
The delay pattern analysis confirms widely held opinions in many of its details but also provides the basis for deriving standards for quality assurance. It identifies differences between the specialties which can hardly be considered acceptable. In the first instance, 508 of all patients seen in 4 weeks is a target achieved in some specialties and perhaps appropriate for all. In addition, perhaps there should be no persons still unseen 16 weeks after the date of referral.

\section{Acknowledgements}

We are pleased to acknowledge the assistance of The Department of Health who provided a small grant to cover the cost of postage and publicity in the United Kingdom.

\section{References}

Royal College of General Practitioners, office of population Censuses Surveys, and Department of Health and Social Security (1986). "Morbidity statistics from General Practice. Third National study 1981-2". Series MB5. No.1. London, BMSO.

Office of Population Censuses and Surveys (1989). "General Household Survey 1986". Social Survey Division. Series GHS.No.16. Social Survey.

Crombie, D. L., Fleming, D.M. (1988). "Practice Activity Analysis". Occasional Paper 41 . Published by the Royal College of

Fleming, D. M. (1989). Consultation rates in English general practice". Journal of the Royal College of General Practitioners. 
BELGIUM - National Representatives J Heyrman, D Bouilliez

Figure 1

Recorders $(n=45)$ : Distribution by Age

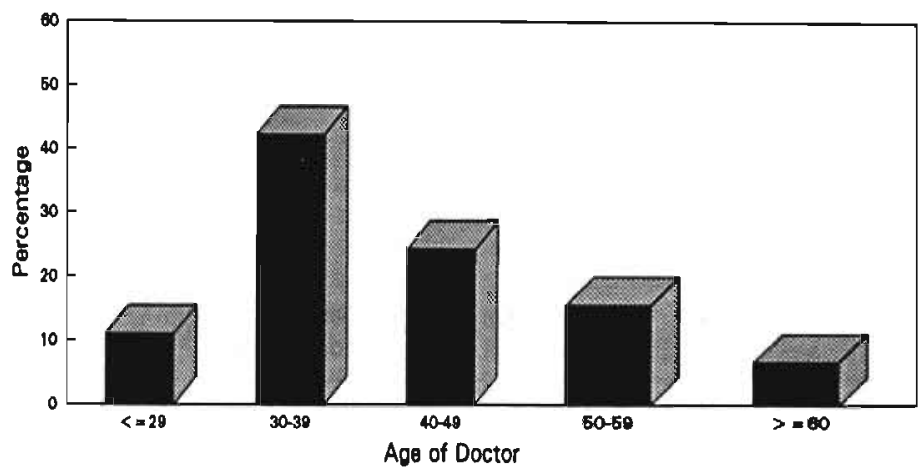

Figure 2

Consultations : Distribution by Age

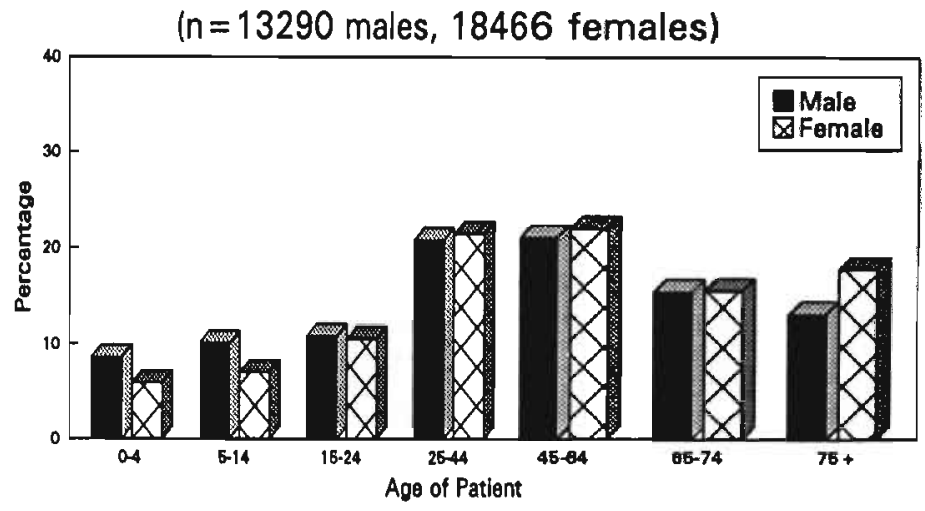

Figure 3

Referral Rate (per 1000 consultations)

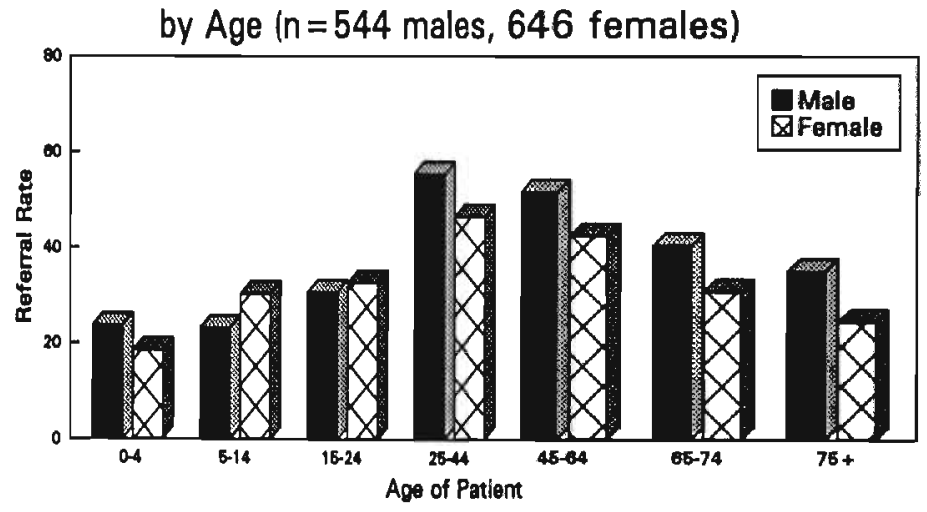


TABLE 1 - REFERRALS BY SPECIALTY NUMBER AND PERCENT OF TOTAL RATE PER 1000 CONSULTATIONS BY SEX
TABLE 2 - DISTRIBUTION OF REFERRALS ( BY MODE, TYPE, URGENCY AND REPORTED PATIENT INFLUENCE

\begin{tabular}{|c|c|c|c|c|c|c|c|c|c|}
\hline SPECIALTY & $\mathbf{N}$ & t & $\begin{array}{c}\text { RATE } \\
\mathbf{M}\end{array}$ & $\begin{array}{l}\text { PER } 1000 \\
F\end{array}$ & $\begin{array}{c}\text { CONS } \\
T\end{array}$ & & M & $F$ & $\mathbf{T}$ \\
\hline Int. Med. & 93 & 7.8 & 3.1 & 2.8 & 2.9 & MODE & & & \\
\hline Paed. Med. & 31 & 2.6 & 1.4 & 0.6 & 1.0 & Outpatient & 47.0 & 50.8 & 49.0 \\
\hline Ger1. Med. & 14 & 1.2 & 0.6 & 0.3 & 0.4 & Private & 17.2 & 17.4 & 17.3 \\
\hline Dermatology & 42 & 3.5 & 1.4 & 1.3 & 1.3 & clinic & 1.3 & 0.8 & 1.0 \\
\hline cardiology & 98 & 8.2 & 3.8 & 2.6 & 3.1 & Inpatient & 18.8 & 18.4 & 18.6 \\
\hline Allergy & 7 & 0.6 & 0.3 & 0.2 & 0.2 & A \& E Dept. & 13.9 & 11.0 & 12.3 \\
\hline Neurology & 66 & 5.5 & 2.2 & 2.0 & 2.1 & Domiciliary & 1.8 & 1.7 & 1.7 \\
\hline Gastroent. & 70 & 5.9 & 2.6 & 1.9 & 2.2 & & & & \\
\hline Rheumatology & 32 & 2.7 & 0.8 & 1.2 & 1.0 & & & & \\
\hline Resp. Med. & 42 & 3.5 & 2.0 & 0.8 & 1.3 & & & & \\
\hline Medical NEC & 40 & 3.4 & 1.4 & 1.2 & 1.3 & TYPE & & & \\
\hline & & & & & & New & 73.2 & 69.0 & 70.9 \\
\hline MEDICAL & 535 & 45.0 & 19.4 & 15.0 & 16.8 & Re-Referral & 26.8 & 31.0 & 29.1 \\
\hline Gen. Surgery & 95 & 8.0 & 3.2 & 2.8 & 3.0 & & & & \\
\hline Ophthalmology & 32 & 2.7 & 0.9 & 1.1 & 1.0 & URGENCY & & & \\
\hline otolaryngol. & 82 & 6.9 & 3.2 & 2.2 & 2.6 & Immediate & 19.8 & 19.2 & 19.5 \\
\hline Orthopaedics & 149 & 12.5 & 5.0 & 4.5 & 4.7 & Urgent & 22.4 & 14.7 & 18.2 \\
\hline Gen.-Urinary & 61 & 5.1 & 3.5 & 0.8 & 1.9 & Routine & 57.8 & 66.1 & 62.3 \\
\hline Plantic surg. & 10 & 0.8 & 0.2 & 0.4 & 0.3 & & & & \\
\hline Neurogurgery & 14 & 1.2 & 0.9 & 0.1 & 0.4 & & & & \\
\hline Surg. NEC & 18 & 1.5 & 0.7 & 0.5 & 0.6 & & & & \\
\hline & & & & & & PATIENT INFLUENC & & & \\
\hline SURG ICAL & 461 & 38.7 & 17.5 & 12.3 & 14.5 & $\mathrm{Nil}$ & 52.1 & 47.8 & 49.7 \\
\hline & & & & & & Small & 28.3 & 29.6 & 29.0 \\
\hline & & & & & & Large & 19.6 & 22.6 & 21.2 \\
\hline obatetrica & 17 & 1.4 & 0.1 & 0.9 & 0.5 & & & & \\
\hline Gynaecology & 51 & 4.3 & 0.0 & 2.8 & 1.6 & & & & \\
\hline Psychiatry & 35 & 2.9 & 1.1 & 1.1 & 1.1 & & & & \\
\hline Mental aub. & 5 & 0.4 & 0.1 & 0.2 & 0.2 & \multirow{3}{*}{\multicolumn{4}{|c|}{$\begin{array}{l}\text { TABLE } 3 \text { - DELAY PATTERNS BETWEEN } \\
\text { REFERRAL AND FIRST APPOINTMENT }\end{array}$}} \\
\hline Emerg+Trauma & 8 & 0.7 & 0.3 & 0.2 & 0.3 & & & & \\
\hline Oncology & 20 & 1.7 & 0.7 & 0.6 & 0.6 & & & & \\
\hline Pain relief & 0 & 0.0 & 0.0 & 0.0 & 0.0 & & & & \\
\hline Specialty NEC & 22 & 1.8 & 0.6 & 0.8 & 0.7 & & & & \\
\hline OTHER & 158 & 13.3 & 2.9 & 6.5 & 5.0 & & $\begin{array}{l}\text { Seen } \\
\text { within } \\
28 \text { days }\end{array}$ & $\begin{array}{l}\text { Not } \\
\text { seen in } \\
16 \text { wks }\end{array}$ & $\begin{array}{c}\text { Mean } \\
\text { delay } \\
\text { (days) }\end{array}$ \\
\hline Spocialty NK & 36 & 3.0 & 1.1 & 1.1 & 1.1 & MEDICAL & 89.3 & 5.6 & 7.3 \\
\hline & & & & & & SURGICAL & 81.5 & 12.1 & 7.5 \\
\hline & & & & & & OTHER & 91.8 & 4.1 & 8.4 \\
\hline GRAND TOTAL & 1190 & 100.0 & 40.9 & 35.0 & 37.5 & TOTAL & 86.9 & 7.7 & 7.5 \\
\hline
\end{tabular}


Data were provided by 45 Belgian doctors (33 Flemish and 12 Walloon). In the presentation of this report, numerical data will be provided for both groups combined except where indicated. The age distribution of the doctors (Fig.1) is typical of that in the country generally. Twenty four percent had spent more than 20 years in practice and $16 \%$ of all recorders were female which is about the national average.

In Belgium there is no patient registration and hence the population cared for by a general practitioner can only be estimated very roughly. A third of the recorders estimated their practice populations at about 1500 patients and the rest rather more. National data include many young doctors who are not properly established in practice and even some who have left the profession. From such national data (Deliege, 1986) estimates have been made of one doctor per 1200 persons in the Flemish part of Belgium, 1 per 920 in the Walloon part and 1 per 820 in Brussels. The sample of doctors recruited to this study is thus over represented by doctors with large lists. It is also over represented by doctors working in group practices: 338 compared with a national estimate of $25 \%$. Twenty six (598) of the recorders practised within $5 \mathrm{kms}$ of a major hospital and only one doctor practiced more than $20 \mathrm{kms}$ distant. Twenty nine percent described their practice area as urban, $36 \%$ mixed and $36 \%$ rural.

\section{Consultation Data}

The data includes referrals from 31756 encounters. The distribution of consultations by age and sex is given in Fig 2 . The distribution for those in the Flemish part accords with that recently reported by de Maeseneer (1989) in respect of the sex of the patients though by comparison, there were more elderly and fewer adults aged between 25 and 44 years.

Forty six percent of all consultations involved home visita, which is a particularly high value compared with most other countries in Europe but consistent with other data (de Maeseneer, 1989). Home visits among the elderly (aged $75+$ years) were 788 compared with 868 reported by Heyrman (1989).

\section{Direct referral data}

There were 1190 referrals included in this study 468 of which were for male patients. The overall rate of referral was 37 per 1000 consultations (Fig 3) and, with the exceptions of the age group 15-24 years, rates for males exceeded those for females.

The distribution of referrals by individual specialty is summarised in Table 1. Numbers of referrals were greatest in orthopaedics, general surgery and internal medicine.

Twenty nine percent of referrals were re-referrals (subsequent referrals for the same problem within 3 years). Distribution by mode, urgency and patient influence are summarised in Table 2 . Routine arrangements were made for 628 of referrals, and in 50 \% of cases, the referral decision was reported by the doctor as having not been influenced by the patient. The data base for the analysis of delay patterns contained 644 referrals. Eighty seven percent were seen within 4 weeks of referral (Table 2) and 
88 were not seen within 16 weeks. Of those seen in the first 16 weeks, the mean delay was 8 days and generally similar for all specialties. Communication between specialist and general practitioner was efficient with 858 communication within 2 weeks of specialist appointment. It is important to realise however that there is no measurement here of communication (or lack of it) for those patients seen by specialists following self referral. For the surgical referrals where surgical intervention was planned, $62 \%$ received it within 2 weeks of appointment and only 178 were still waiting for surgery after 12 weeks.

\section{Analysig by specialty}

The overall rate of referral was 37 per 1000 consultations including 17 medical, 15 surgical and 5 other specialties.

Internal medicine (41 males, 52 females):- Referrals in this specialty were confined to adults and comnonly involved hospital inpatient admission in emergency situations. The proportion of private referrals was low compared with that in other specialties.

Paediatric medicine:- (19 males, 12 females):- 78 of all consultations occurred in the age group $0-4$ years : 48 of all referrals occurred in this age group but less than half of these were referred to paediatricians. Half of the referrals were urgent and admitted to hospital. Appointment delays were least in this specialty, but communication was not as efficient as for most other specialties.

Dermatology (18 males, 24 females):- Ninety one percent were described as new referrals and 458 were referred to private specialists which is a particularly high value.

Cardiology (50 males, 48 females):- Approximately 108 of all referrals were to cardiologists and $18 \%$ among patients aged 65 and over.

Ophthalmology (12 males, 20 females):- The system of referral to ophthalmologistg was very efficient with minimal delays for appointment and rapid communication.

Otolaryngology (42 males, 40 females):- Rates of referral in this specialty were relatively high. Most were routine referrals and there were minimal delays for appointments.

Genito-urinary Surgery (46 males, 15 females):- By comparison with most other specialties, there was a long delay for first appointment (14 days).

Gynaecology (51 females):- 378 of all referrals were arranged in the private sector compared with 178 for all specialties. The roles of the specialist paediatrician and gynaecologist as primary care providers are similar, but the referral patterns from general practitioners were different in the two specialties.

Psychiatry ( 15 males, 20 females):- Fifty five percent were categorised as immediate or urgent and in $60 \%$ of referrals, the decision was influenced by the patient. 


\section{Overview of the data from Belgium}

The samples from the two parts of Belgium were rather small and there were some substantial differences between the doctors in these two parts. Doctors in the Flemish part were slightly older and undertook more consultations than their walloon colleagues. There were some small differences between them with regard to the relative numbers of referrals in the various specialist departments. Generally speaking, delays in the referral process were small suggesting that for most referrals from primary care, the system was efficient. Because in Belgium direct access to specialists is freely available and widely used, it is not possible to extrapolate these conclusions to the total use of specialist care in this country.

\section{$\underline{\text { References }}$}

Deliege, D.(1986). Imbalance in medical manpower : recent evolutions and prospects in Europe. Ed. UCLouvain. 58pp.

Heyrman, J. (Ed). "Huisartspraktijk in Vlaandersen" - een doorlichting van het patientenaanbod, klachten en ziektebeelden met advies voor praktijkregistratie. Eigen Dimensien 10, ACCO (1984).

Maeseneer, J. de, Huisartsgeneeskunde : een verkenning. Diss. Gent 1989.

Heyrman, J. en Dessers Luc : een geintegreerd dossier voor de huisarts betreffende 75 plussers, Leuven 1989. 


\section{DENMARK - National Representative J Kelstrup}

Figure 1

Recorders $(n=54)$ : Distribution by Age

Compared with national data

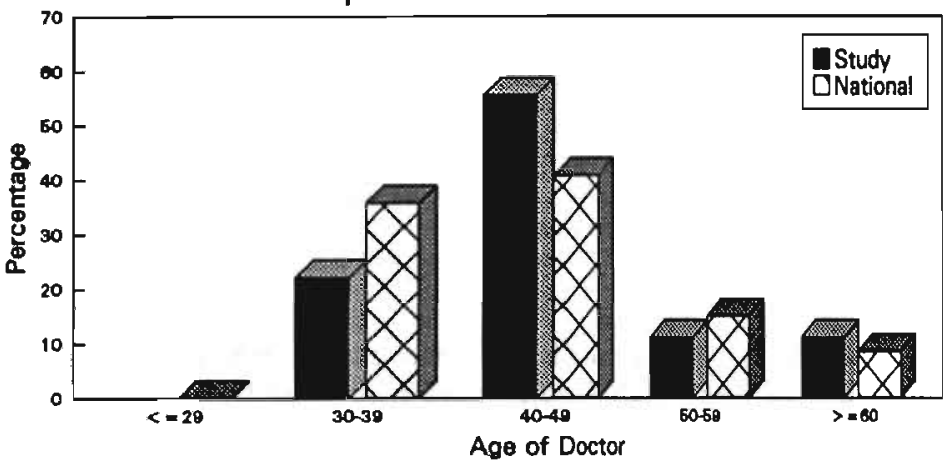

Figure 2

Consultations : Distribution by Age ( $n=9668$ males, 14419 females)

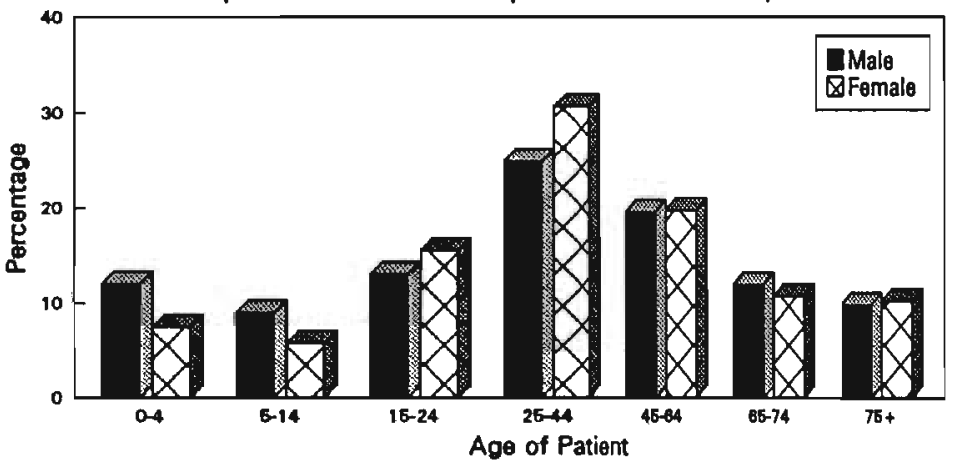

Figure 3

Referral Rate (per 1000 consultations) by Age ( $n=596$ males, 936 females)

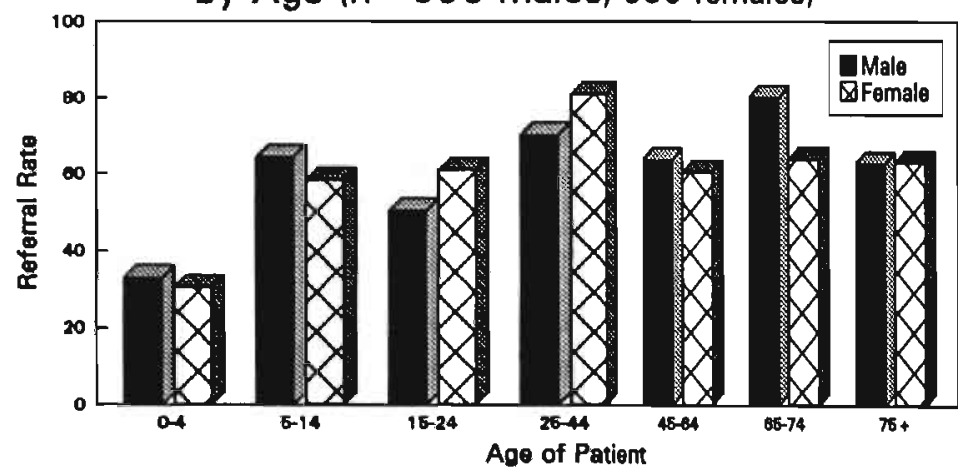


OENMARK

TABLE 1 - REFERRALS BY SPECIALTY

NUMBER AND PERCENT OF TOTAL

RATE PER 1000 CONSULTATIONS BY SEX
TABLE 2 - DISTRIBUTION OF REFERRALS BY MODE, TYPE, URGENCY AND REPORTED PATIENT INFLUENCE

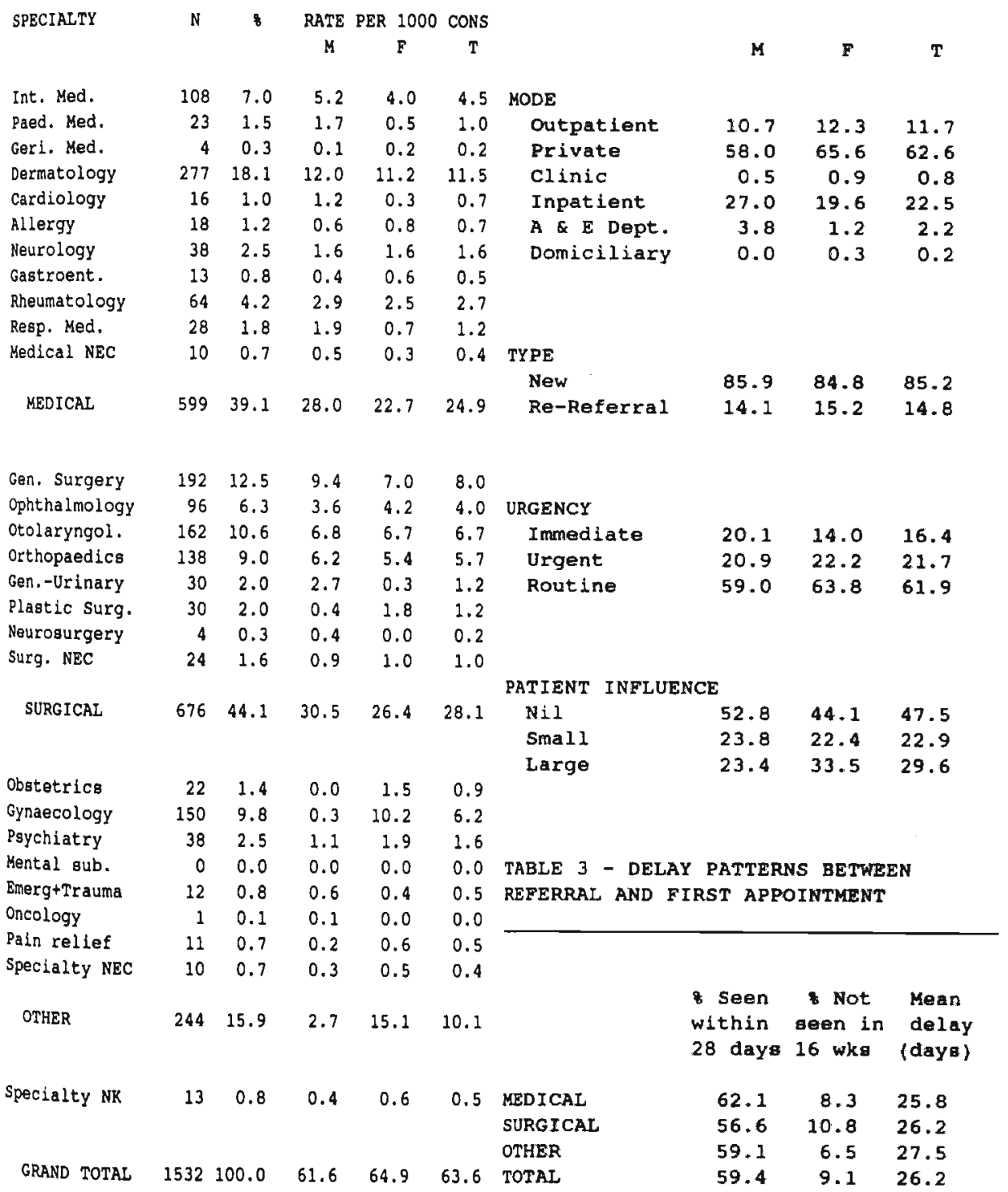




\section{Characteristics of General Practitioners}

At the end of 1988 there were 3038 general practitioners in a total of 13,679 active doctors in Denmark. A random selection of 200 general practitioners was made and 54 of these participated in the recruitment phase of the study with 37 continuing to the follow-up. Distribution of recorders by age is compared with the national distribution in Fig.l and is shown to be reasonably similar.

Approximately half (528) of the participating general practitioners practised within $5 \mathrm{kms}$ of a major hospital and $30 \%$ were $15 \mathrm{kms}$ or more distant. The distribution throughout the country and that dividing urban and rural areas was random. 528 described their area of practice as urban and 158 rural. Detailed list sizes are not available in Denmark for persons aged under 16 and hence reliable data for list size are not available.

The total number of consultations in the study was 24,087 of which 78 were made as home visits. The distribution of consultations in age and sex groups (Fig.2) shows higher proportions of females in all age groups except small children and is similar to that seen in other studies.

The study included 596 males and 936 females who were referred for specialigt care with equivalent referral rates of 62 and 65 per 1000 consultations respectively. Though fewer men were referred than women, the referral rates based on consultations for men were generally higher than those for women excepting in the age group $15-44$ years.

The four specialties with the most referrals were dermatology, general surgery, otolaryngology and gynaecology (Table 3). In Denmark, specialists largely work in private practices. Either they are consultants/chief of service in a hospital and have a part-time practice for one or two afternoons a week, or they are in full time specialist practice as for example in dermatology, ophthalmology, otolaryngology and gynaecology. For ophthalmology and otolaryngology, there is a longstanding tradition that patients may refer themselves. The data obtained in this study for these two specialties therefore under-estimates the persons seen by specialists. For all other specialties, a referral from the general practitioner is necessary if the consultation is to be paid for by the National Health Service. The private sector, where patients may refer themselves and pay their own costs, is so small as to be of no importance for this study. 638 of the referrals were to specialists working in their practices, 128 to outpatient departments and 28 to accident and emergency departments. 238 of referrals involved immediate hospital admission.

Paediatrics ( 16 males, 7 females):- The referral rate was very low. 168 of all consultations in this study were for children aged $0-14$ years whereas only 1.58 of referrals were in this age group. A third of these involved hospital admission.

Dermatology (116 males, 161 females):- There is easy access to dermatologists working in private practice whereas there are only a few hospital departments in dermatology and hence 988 of referrals were seen by private specialists. There were 12 
referrals per 1000 consultations and the waiting times were relatively short. 698 were seen within 28 days and only 68 were not seen within 16 weeks.

General Surgery (91 males, 101 females):- There were 8 referrals per 1000 consultations. 398 of all referrals were seen by specialists working in private practices. 498 were admitted to hospital. The rest were seen in $A \& E$ departments $(48)$ or hospital outpatient departments (98), 588 were seen within 28 days of referral.

Gynaecology (147 females):- There were 10 referrals per 1000 consultations (females only). 58z of referred patients were seen by specialists in private practice. 708 were seen within 28 days and in $28 \%$ of cases, hospital admission was involved.

Overview of the data for Denmark

Although the participating recorders in this survey were not a complete set of randomly sampled doctors, it is nevertheless important to recognise that recorders were originally identified using a random method. 
FRANCE - National Representative J Nouchi

Figure 1

Recorders ( $n=26)$ : Distribution by Age Compared with national data

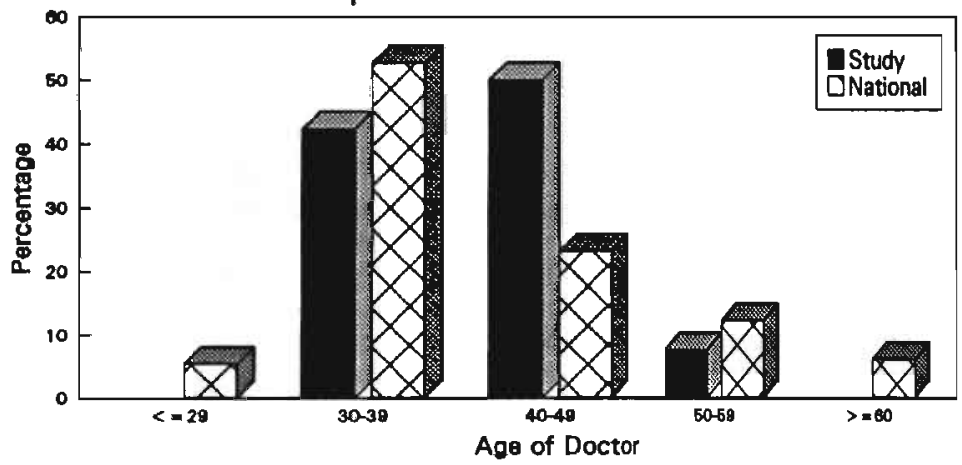

Figure 2

Consultations : Distribution by Age

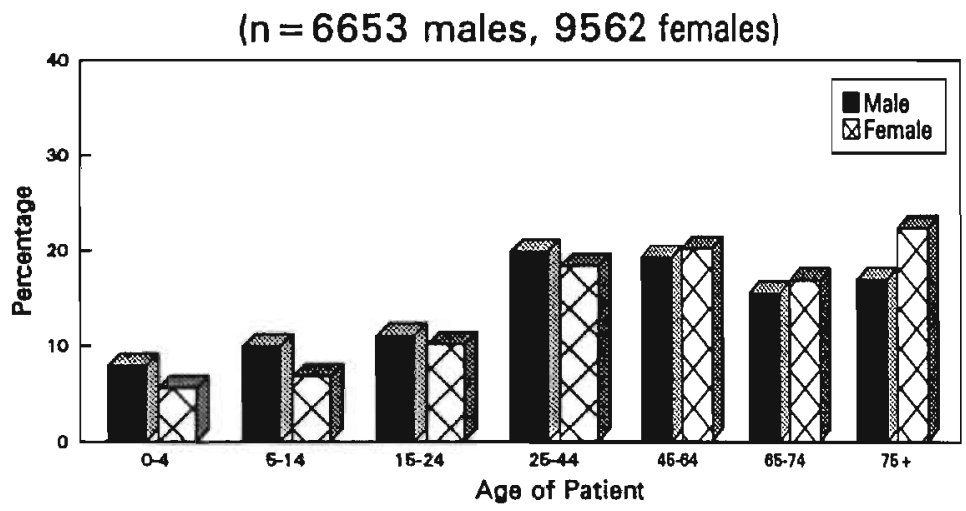

Figure 3

Referral Rate (per 1000 consultations) by Age ( $n=184$ males, 212 females)

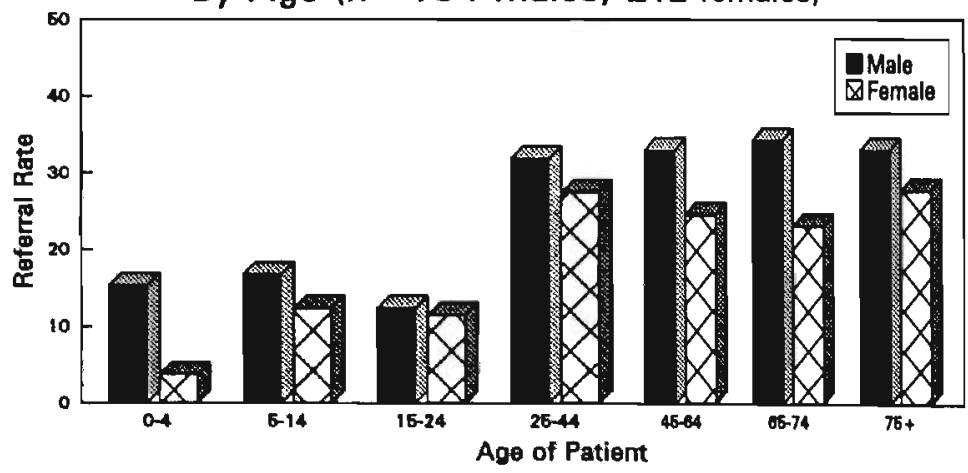


FRANCE

TABLE 1 - REFERRALS BY SPECIALTY

NUMBER AND PERCENT OF TOTAL

RATE PER 1000 CONSULTATIONS BY SEX
TABLE 2 - DISTRIBUTION OF REFERRAIS (1) BY MODE, TYPE, URGENCY AND REPORTED PATIENT INFLUENCE

\begin{tabular}{|c|c|c|c|c|c|c|c|c|c|}
\hline SPECIALTY & $\mathbf{N}$ & 8 & $\begin{array}{c}\text { RATE } \\
\text { M }\end{array}$ & $\begin{array}{c}\text { PER } 1000 \\
F\end{array}$ & $\begin{array}{c}\text { CONS } \\
T\end{array}$ & & $\mathbf{M}$ & $\mathbf{E}$ & $\mathbf{T}$ \\
\hline Int. Med. & 15 & 3.8 & 1.1 & 0.8 & 0.9 & MODE & & & \\
\hline Paed. Med. & 3 & 0.8 & 0.3 & 0.1 & 0.2 & outpatient & 66.3 & 68.8 & 67.6 \\
\hline Geri. Med. & 1 & 0.3 & 0.2 & 0.0 & 0.1 & Private & 0.5 & 1.4 & 1.0 \\
\hline Dermatology & 18 & 4.5 & 1.5 & 0.8 & 1.1 & clinte & 0.0 & 0.9 & 0.5 \\
\hline Cardiology & 63 & 15.9 & 3.8 & 4.0 & 3.9 & Inpatient & 13.7 & 8.6 & 10.9 \\
\hline Allergy & 5 & 1.3 & 0.5 & 0.2 & 0.3 & A $\approx$ E Dept. & 14.2 & 13.6 & 13.9 \\
\hline Neurology & 23 & 5.8 & 1.1 & 1.7 & 1.4 & Domlciliary & 5.3 & 6.8 & 6.1 \\
\hline Gastroent. & 42 & 10.6 & 2.0 & 3.0 & 2.6 & & & & \\
\hline Rheumatology & 17 & 4.3 & 1.1 & 1.0 & 1.0 & & & & \\
\hline Resp. Med. & 9 & 2.3 & 0.6 & 0.5 & 0.6 & & & & \\
\hline \multirow[t]{2}{*}{ Medical NEC } & 18 & 4.5 & 2.0 & 0.5 & 1.1 & TYPE & & & \\
\hline & & & & & & New & 69.3 & 64.8 & 66.9 \\
\hline MEDICAL & 214 & 54.0 & 13.8 & 12.8 & 13.2 & Re-Referral & 30.7 & 35.2 & 33.1 \\
\hline Gen. Surgery & 27 & 6.8 & 2.3 & 1.3 & 1.7 & & & & \\
\hline ophthalmology & 24 & 6.1 & 1.5 & 1.5 & 1.5 & URGENCY & & & \\
\hline Otolaryngol. & 32 & 8.1 & 2.1 & 1.9 & 2.0 & Immediate & 24.7 & 20.5 & 22.4 \\
\hline Orthopaedics & 24 & 6.1 & 1.8 & 1.3 & 1.5 & Urgent & 25.3 & 18.2 & 21.5 \\
\hline Gen.-Urinary & 27 & 6.8 & 3.2 & 0.6 & 1.7 & Routine & 50.0 & 61.4 & 56.1 \\
\hline Plastic surg. & 1 & 0.3 & 0.0 & 0.1 & 0.1 & & & & \\
\hline Neurosurgery & 3 & 0.8 & 0.2 & 0.2 & 0.2 & & & & \\
\hline \multirow[t]{2}{*}{ Surg. NEC } & 8 & 2.0 & 0.9 & 0.2 & 0.5 & & & & \\
\hline & & & & & & PATIENT INFLUENC & & & \\
\hline \multirow[t]{3}{*}{ SURGICAL } & 146 & 36.9 & 11.9 & 7.0 & 9.0 & Nil & 70.7 & 63.2 & 66.7 \\
\hline & & & & & & Sma11 & 17.3 & 21.4 & 19.5 \\
\hline & & & & & & Large & 12.0 & 15.5 & 13.9 \\
\hline Obstetrics & 2 & 0.5 & 0.0 & 0.2 & 0.1 & & & & \\
\hline Gynaecology & 9 & 2.3 & 0.0 & 0.9 & 0.6 & & & & \\
\hline Paychiatry & 12 & 3.0 & 0.9 & 0.6 & 0.7 & & & & \\
\hline Mental sub. & 0 & 0.0 & 0.0 & 0.0 & 0.0 & TABLE 3 - DELAX & PATTERNS & IS BETWEE & \\
\hline Bmerg+Trauma & 7 & 1.8 & 0.6 & 0.3 & 0.4 & REFERRAL AND FIF & RST APPOI & INTMENT & \\
\hline Oncology & 2 & 0.5 & 0.2 & 0.1 & 0.1 & & & & \\
\hline Pain relief & 2 & 0.5 & 0.0 & 0.2 & 0.1 & & & & \\
\hline Specialty NEC & 2 & 0.5 & 0.3 & 0.0 & 0.1 & & & & \\
\hline OTHER & 36 & 9.1 & 2.0 & 2.4 & 2.2 & & $\begin{array}{l}\text { Seen } \\
\text { Nithin } \\
28 \text { days } 1\end{array}$ & $\begin{array}{l}\text { Not } \\
\text { seen in } \\
16 \text { wkB }\end{array}$ & $\begin{array}{l}\text { Mean } \\
\text { delay } \\
\text { (daya) }\end{array}$ \\
\hline \multirow[t]{3}{*}{ Specialty NK } & 0 & 0.0 & 0.0 & 0.0 & 0.0 & MEDICAI & 93.8 & 1.5 & 7.1 \\
\hline & & & & & & SURGICAL & 88.6 & 9.1 & 5.2 \\
\hline & & & & & & OTHER & 100.0 & 0.0 & 5.0 \\
\hline GRAND TOTAL & 396 & 100.0 & 27.7 & 22.2 & 24.4 & TOTAL & 92.2 & 4.3 & 6.3 \\
\hline
\end{tabular}




\section{Characteristics of General Practitioners}

Data for France are summarised in Tables 1-3 and Figures 1-3. since the recruitment of doctors in France was localised to the area of Alpes-Maritimes which has a population of approximately 1 million people compared with the 56 million people in France generally, it is inappropriate to make detailed comparisons with national data sources. However, in this study it is worth commenting that 198 of the general practitioners were female and the mean age was 41.1 years which compares with national data in which $20 \%$ are female and the average age was 41.6 years (Carnets Statistiques No.47, 1988)

It is evident that the number of referrals made by French general practitioners is very low compared with most of their European colleaques. This is because French patients are able to see specialists directly, and even if referral is suggested by the general practitoner, there is not necessarily a comunication between him and the specialist.

The data provide an insight into the workload of the French general practitioner. The average working week in France included 82 consultations of which 23 involved a home visit. Comparable statistics from the national material already referred to are 78 consultations with 26 involving home visits.

It is interesting to note the emphasis based on certain types of referral. In particular, the most comon referrals made in the French experience were cardiology and gastroenterology. It is also relevant to note that the delay statistics in France for those persons referred from general practitioners were extremely favourable.

\section{Reference}

Carnets Statistiques No.47, du la CNAMTS, 1988. 


\section{GERMANY (DDR) - National Representative C Kohler}

Figure 1

Recorders $(n=23)$ : Distribution by Age

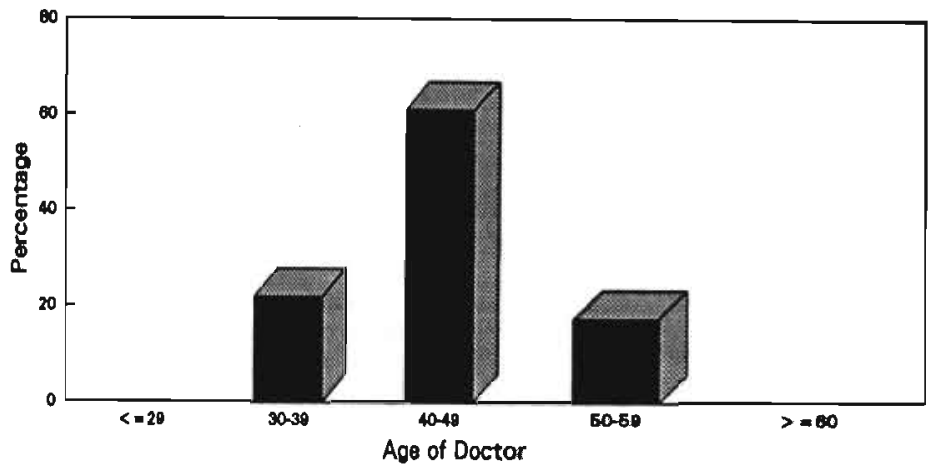

Figure 2

Consultations : Distribution by Age

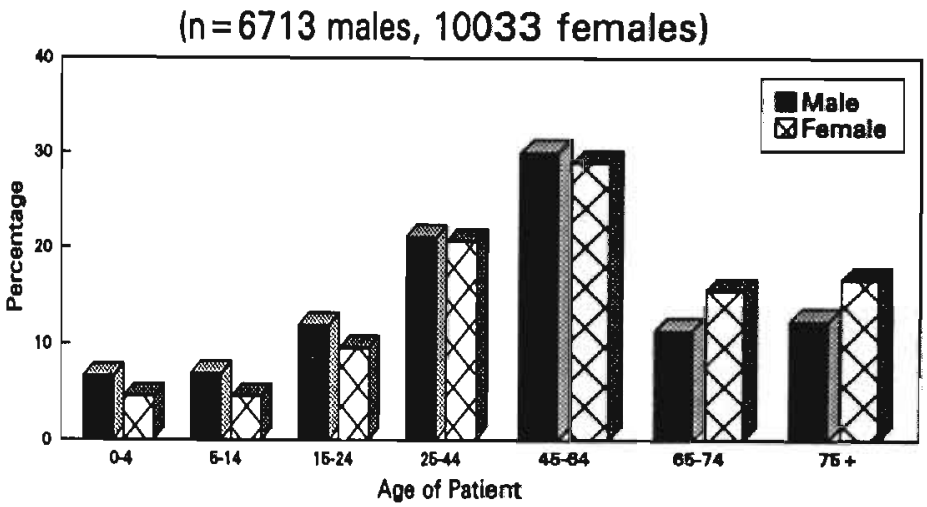

Figure 3

Referral Rate (per 1000 consultations) by Age ( $n=306$ males, 382 females)

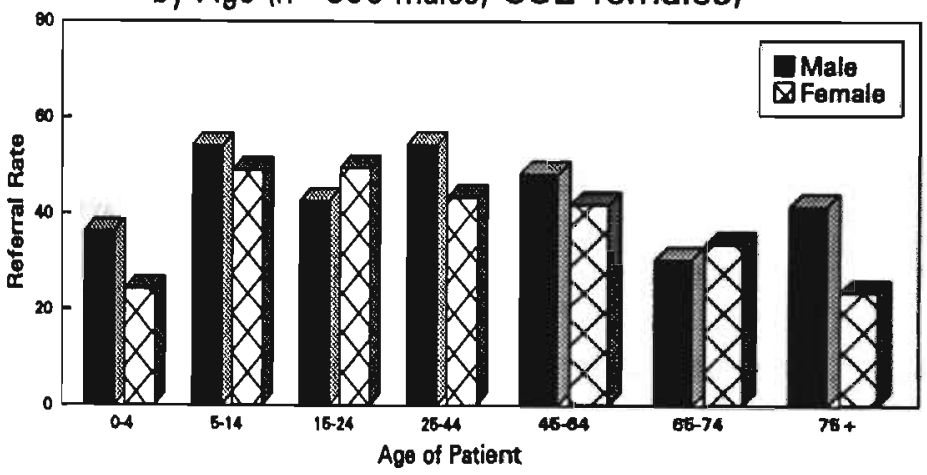


TABLE 1 - REFERRALS BY SPECIALTY NUMBER AND PERCENT OF TOTAL RATE PER 1000 CONSULTATIONS BY SEX
TABLE 2 - DISTRIBUTION OP RERERRALS (\$ BY MODE, TYPE, URGENCY AND REPORTED PATIENT INFLUENCE

\begin{tabular}{|c|c|c|c|c|c|c|c|c|c|}
\hline SPECIALTY & $\mathbf{N}$ & 8 & $\begin{array}{c}\text { RATE } \\
M\end{array}$ & $\begin{array}{c}\text { PER } 1000 \\
E\end{array}$ & $\begin{array}{c}\text { CONS } \\
\mathrm{T}\end{array}$ & & $M$ & $\mathbf{F}$ & $T$ \\
\hline Int. Med. & 86 & 12.5 & 6.1 & 4.5 & 5.1 & MODE & & & \\
\hline Paed. Med. & 11 & 1.6 & 1.0 & 0.4 & 0.7 & Outpatient & 69.0 & 70.7 & 69.9 \\
\hline Geri. Med. & 0 & 0.0 & 0.0 & 0.0 & 0.0 & Private & 21.2 & 18.8 & 19.9 \\
\hline Dermatology & 42 & 6.1 & 2.5 & 2.5 & 2.5 & clinic & 0.0 & 0.0 & 0.0 \\
\hline Cardiology & 9 & 1.3 & 0.4 & 0.6 & 0.5 & Inpatient & 8.2 & 8.6 & 8.4 \\
\hline Allergy & 0 & 0.0 & 0.0 & 0.0 & 0.0 & A \& Dept. & 1.6 & 1.8 & 1.7 \\
\hline Neurology & 22 & 3.2 & 1.3 & 1.3 & 1.3 & Domiciliary & 0.0 & 0.0 & 0.0 \\
\hline Gastroent. & 16 & 2.3 & 1.3 & 0.7 & 1.0 & & & & \\
\hline Rheumatology & 5 & 0.7 & 0.1 & 0.4 & 0.3 & & & & \\
\hline Resp. Med. & 16 & 2.3 & 1.5 & 0.6 & 1.0 & & & & \\
\hline Medical NEC & 18 & 2.6 & 0.9 & 1.2 & 1.1 & TYPB & & & \\
\hline & & & & & & New & 85.9 & 84.8 & 85.3 \\
\hline MEDICAL & 225 & 32.7 & 15.3 & 12.2 & 13.4 & Re-Referral & 14.1 & 15.2 & 14.7 \\
\hline Gen. Surgery & 137 & 19.9 & 10.4 & 6.7 & 8.2 & & & & \\
\hline Ophthalmology & 44 & 6.4 & 3.6 & 2.0 & 2.6 & URGENCY & & & \\
\hline Otolaryngol. & 89 & 12.9 & 5.2 & 5.4 & 5.3 & Immediate & 40.2 & 35.3 & 37.5 \\
\hline Orthopaed lca & 68 & 9.9 & 3.6 & 4.4 & 4.1 & Urgent & 50.0 & 52.4 & 51.3 \\
\hline Gen. -Urinary & 26 & 3.8 & 2.5 & 0.9 & 1.6 & Routine & 9.8 & 12.3 & 11.2 \\
\hline Plastic surg. & 1 & 0.1 & 0.1 & 0.0 & 0.1 & & & & \\
\hline Neuroaurgery & 1 & 0.1 & 0.0 & 0.1 & 0.1 & & & & \\
\hline surg. NEC & 33 & 4.8 & 2.2 & 1.8 & 2.0 & & & & \\
\hline & & & & \multicolumn{6}{|c|}{ PATIENT INFLUENCE } \\
\hline SURGICAL & 399 & 58.0 & 27.7 & 21.2 & 23.8 & N11 & 67.6 & 69.4 & 68.6 \\
\hline & & & & & & Small & 19.3 & 16.5 & 17.7 \\
\hline & & & & & & Large & 13.1 & 14.1 & 13.7 \\
\hline Obgtetrics & 0 & 0.0 & 0.0 & 0.0 & 0.0 & & & & \\
\hline Gynaecology & 22 & 3.2 & 0.0 & 2.2 & 1.3 & & & & \\
\hline Paychiatry & 14 & 2.0 & 0.9 & 0.8 & 0.8 & & & & \\
\hline Mental sub. & 0 & 0.0 & 0.0 & 0.0 & 0.0 & \multirow{3}{*}{\multicolumn{4}{|c|}{$\begin{array}{l}\text { TABLE } 3 \text { - DELAY PATTERNS BETWEEN } \\
\text { REFERRAL AND FIRST APPOINTMENT }\end{array}$}} \\
\hline Emerg+Trauma & 15 & 2.2 & 0.9 & 0.9 & 0.9 & & & & \\
\hline Oncology & 0 & 0.0 & 0.0 & 0.0 & 0.0 & & & & \\
\hline Pain relief & 2 & 0.3 & 0.0 & 0.2 & 0.1 & & & & \\
\hline Specialty NEC & 7 & 1.0 & 0.4 & 0.4 & 0.4 & & & & \\
\hline OTHER & 60 & 8.7 & 2.2 & 4.5 & 3.6 & & $\begin{array}{l}\text { Seen } \\
\text { ithin } \\
8 \text { daye }\end{array}$ & $\begin{array}{l}\text { Not } \\
\text { seen in } \\
16 \text { wks }\end{array}$ & $\begin{array}{l}\text { Mean } \\
\text { delay } \\
\text { (days) }\end{array}$ \\
\hline Specialty NK & 4 & 0.6 & 0.3 & 0.2 & 0.2 & $\begin{array}{l}\text { MEDICAL } \\
\text { SURGICAL } \\
\text { OTHER }\end{array}$ & & & \\
\hline GRAND TOTAL & 688 & 100.0 & 45.6 & 38.1 & 41.1 & TOTAL & & & \\
\hline
\end{tabular}


The contribution for the DDR was arranged later than that for most other countries. It arose out of the involvement of Dr. C. Kohler in the activities of the EGPRW at a stage after the protocol for the study had been agreed. In addition, the followup phase of the study were totally disrupted by the political upheavals of the winter of 1989 which gave rise to German reunification. For this reason, no contribution is included covering the follow-up study. Nevertheless, the data from 23 doctors in DDR are presented here for two reasons. Even though the sample is small, it provides an interesting comparison with the situation in the Federal Republic of Germany. Secondly, the data in summary form are included as a recognition of the contribution of the 23 doctors.

Among the 23 doctors there were 12 ( 7 male, 5 female) aged between 45 and 49 years. Altogether, 11 of the doctors were female. The age distributions of male and female doctors were similar. Five were located within $5 \mathrm{kms}$ of a district hospital and 5 were more than $20 \mathrm{kms}$ distant.

There were 688 referrals, 448 male and 568 female, 538 were aged 45 years or more. The three commonest specialties were General Surgery (208), Otolaryngology (138) and Internal Medicine (138). Data covering the type and mode of referrals and the distribution of consultations is given in the tables. The average working week included 207 consultations. 518 of referrals were described as urgent and 388 as immediate, but in 698 of cases, the referral was reported not to be influenced by the patient. 
GERMANY (FRG) - National Representatives S Thies-Zajonc, M Kohle

Figure 1

Recorders $(n=71)$ : Distribution by Age

Compared with national data

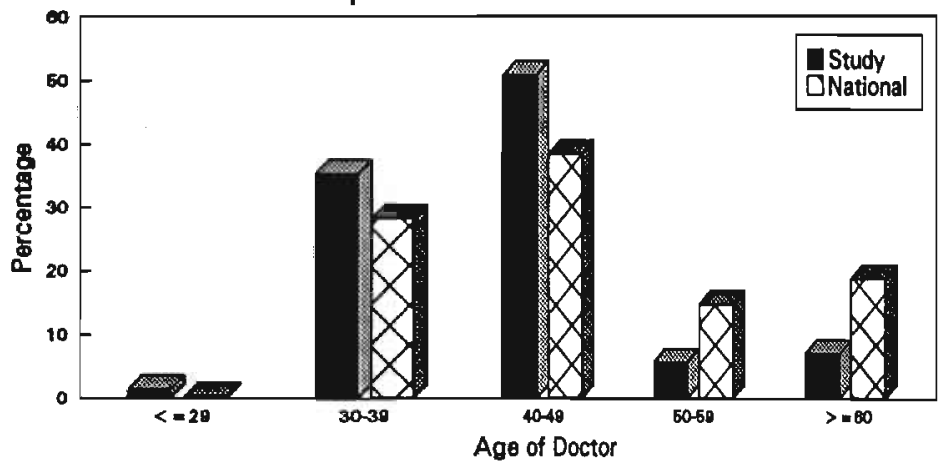

Figure 2

Consultations : Distribution by Age

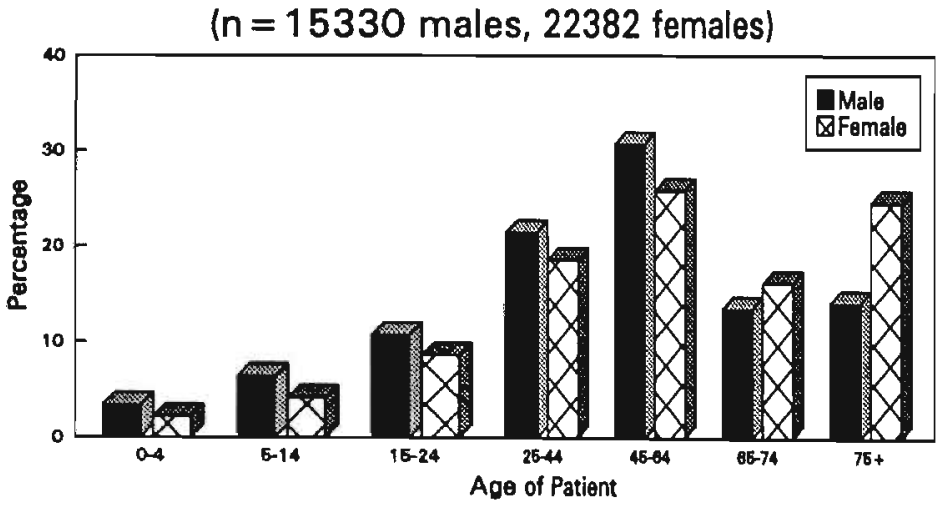

Figure 3

Referral Rate (per 1000 consultations)

by Age ( $n=922$ males, 1155 females)

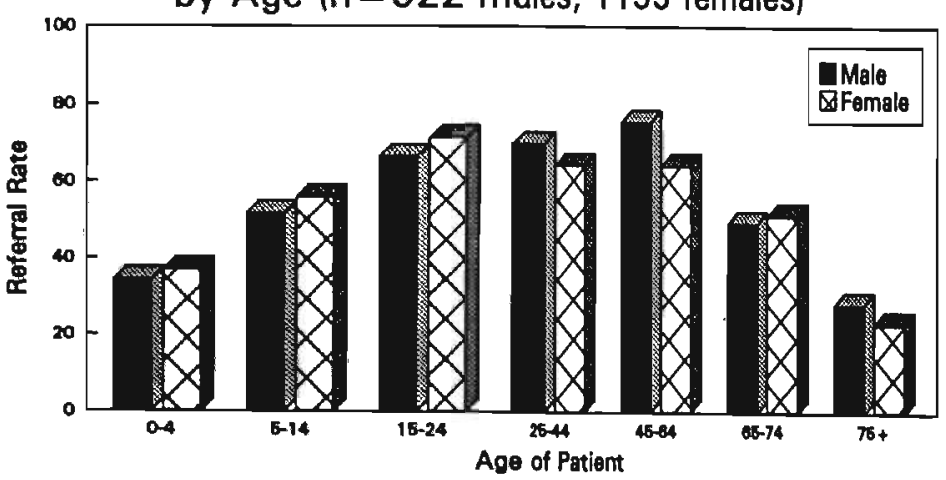


GERMANY (FRG)

TABLE 1 - REFERRALS BY SPECIALTY NUMBER AND PERCENT OF TOTAL RATE PER 1000 CONSULTATIONS BY SEX
TABLE 2 - DISTRIBUTION OF REFERRALS BY MODE, TYPE, URGENCY AND REPORTED PATIENT INFEUENCE

\begin{tabular}{|c|c|c|c|c|c|c|c|c|c|}
\hline \multirow[t]{2}{*}{ SPECIALTY } & \multirow[t]{2}{*}{$\mathbf{N}$} & \multirow[t]{2}{*}{ 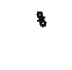 } & \multirow{2}{*}{$\begin{array}{c}\text { RATE } \\
M\end{array}$} & \multirow{2}{*}{$\begin{array}{c}\text { PER } 1000 \\
F\end{array}$} & \multirow{2}{*}{$\begin{array}{c}\text { cons } \\
T\end{array}$} & \multirow{2}{*}{\multicolumn{2}{|c|}{$\mathbf{M}$}} & \multirow[b]{2}{*}{$\mathbf{F}$} & \multirow[b]{2}{*}{$\mathbf{T}$} \\
\hline & & & & & & & & & \\
\hline Int. Ked. & 210 & 10.1 & 7.0 & 4.6 & 5.6 & MODE & & & \\
\hline Paed. Med. & 25 & 1.2 & 0.6 & 0.7 & 0.7 & outpatient & 15.4 & 15.2 & 15.3 \\
\hline Gerl. Med. & 0 & 0.0 & 0.0 & 0.0 & 0.0 & Private & 75.5 & 78.2 & 77.0 \\
\hline Dermatology & 128 & 6.2 & 3.3 & 3.4 & 3.4 & Clanic & 0.0 & 0.0 & 0.0 \\
\hline Cardiology & 50 & 2.4 & 1.9 & 0.9 & 1.3 & Inpatient & 8.5 & 6.1 & 7.2 \\
\hline Allergy & 6 & 0.3 & 0.1 & 0.2 & 0.2 & A \& E Dept. & 0.5 & 0.3 & 0.4 \\
\hline Neurology & 113 & 5.4 & 3.5 & 2.7 & 3.0 & Domlciliary & 0.1 & 0.2 & 0.1 \\
\hline Gastroent. & 32 & 1.5 & 1.0 & 0.7 & 0.8 & & & & \\
\hline Rheumatology & 6 & 0.3 & 0.1 & 0.2 & 0.2 & & & & \\
\hline Resp. Med. & 38 & 1.8 & 1.0 & 1.0 & 1.0 & & & & \\
\hline \multirow[t]{2}{*}{ Medical NEC } & 124 & 6.0 & 2.9 & 3.5 & 3.3 & TYPE & & & \\
\hline & & & & & & New & 72.5 & 68.8 & 70.5 \\
\hline MEDICAL & 732 & 35.2 & 21.4 & 18.1 & 19.4 & Re-Referral & 27.5 & 31.2 & 29.5 \\
\hline Gen. Surgery & 245 & 11.8 & 9.0 & 4.8 & 6.5 & & & & \\
\hline Ophthalmology & 185 & 8.9 & 4.6 & 5.1 & 4.9 & URGENCY & & & \\
\hline otolaryngol. & 178 & 8.6 & 5.4 & 4.2 & 4.7 & Immediate & 34.7 & 29.7 & 31.9 \\
\hline Orthopaedics & 283 & 13.6 & 9.0 & 6.5 & 7.5 & Urgent & 53.7 & 53.3 & 53.5 \\
\hline Gen. -Urinary & 104 & 5.0 & 4.9 & 1.3 & 2.8 & Routine & 11.6 & 17.0 & 14.6 \\
\hline Plastic surg. & 4 & 0.2 & 0.2 & 0.0 & 0.1 & & & & \\
\hline Neurosurgery & 10 & 0.5 & 0.3 & 0.2 & 0.3 & & & & \\
\hline \multirow[t]{2}{*}{ surg. NEC } & 76 & 3.7 & 2.6 & 1.6 & 2.0 & & & & \\
\hline & & & & & & PATIENT INFLUENCE & & & \\
\hline \multirow[t]{3}{*}{ SURGICAL } & 1085 & 52.2 & 36.0 & 23.8 & 28.8 & Nil & 48.6 & 44.9 & 46.5 \\
\hline & & & & & & Small & 30.1 & 28.4 & 29.2 \\
\hline & & & & & & Large & 21.2 & 26.7 & 24.3 \\
\hline Obstetrics & 4 & 0.2 & 0.0 & 0.2 & 0.1 & & & & \\
\hline Gynaecology & 116 & 5.6 & 0.1 & 5.1 & 3.1 & & & & \\
\hline Paychlatry & 35 & 1.7 & 0.8 & 1.0 & 0.9 & & & & \\
\hline Mental sub. & 2 & 0.0 & 0.0 & 0.0 & 0.0 & TABLE 3 - DELAY & PATTERNS & IS BETWEE? & \\
\hline Emerg+Trauma & 11 & 0.5 & 0.3 & 0.3 & 0.3 & REFERRAL AND FIRS & ZST APPOI & INTMENT & \\
\hline Oncology & 22 & 1.1 & 0.1 & 0.9 & 0.6 & & & & \\
\hline Pain relief & 1 & 0.0 & 0.1 & 0.0 & 0.0 & & & & \\
\hline \multirow[t]{2}{*}{ Specialty NEC } & 45 & 2.2 & 0.8 & 1.4 & 1.2 & & & & \\
\hline & & & & & & & Seen & Not & Mean \\
\hline \multirow[t]{2}{*}{ OTHER } & 235 & 11.3 & 2.2 & 9.0 & 6.2 & & $\begin{array}{l}\text { Jithin } \\
8 \text { days }\end{array}$ & $\begin{array}{l}\text { seen in } \\
16 \text { wkg }\end{array}$ & $\begin{array}{l}\text { delay } \\
\text { (daya) }\end{array}$ \\
\hline & & 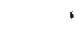 & & & & & & & \\
\hline \multirow[t]{3}{*}{ Specialty NK } & 25 & 1.2 & 0.6 & 0.7 & 0.7 & MEDICAI & 82.9 & 11.8 & 7.5 \\
\hline & & & & & & SURGICAL & 84.1 & 12.4 & 6.3 \\
\hline & & & & & & OTHER & 80.3 & 13.4 & 7.9 \\
\hline GRAND TOTAL & 2077 & 100.0 & 60.1 & 51.6 & 55.1 & TOTAL & 83.3 & 12.3 & 6.9 \\
\hline
\end{tabular}


In the Federal Republic of Germany, patients have open access to doctors working in primary care. A patient may choose to consult a general practitioner or specialist working in primary care which particularly includes specialists in internal medicine and in paediatrics. General practitioners and specialists in primary care work from their own private offices. The remuneration of both is usually obtained by reimbursement through health insurance schemes. There are both national and private insurance schemes. Access to hospitals and to other institutions of secondary care is dependent on a referral from a general practitioner or specialist in primary care

\section{Chaxacterigtics of general practitioners}

For this study we hoped to recruit 100 general practitioners. Information about it was published in journals and medical newspapers and a representative sample of 1000 general practitioners was mailed. A total of 227 doctors expressed interest and received recording booklets but of these, only 75 were recruited. The recruitment difficulties reflect attitudes to research among general practitioners with little research experience in a country where general practitioners are remunerated by fee for service. The booklets from 71 general practitioners were fully completed and could be analysed. All were principals mostly aged between 35 and 49 years (Fig.1). The cohort was younger than the national pattern for the FRG.

There were 6 female participants, equivalent to 98 of the total which compares with a national figure of 238 . Sixty four participants provided data about the time spent in general practice, 568 - 5-9 years, and 178 - 10-19 years.

There are no routine patient registration procedures in the FRG and thus practices cannot be examined in relation to list size. In a simple comparison using available data about quarterly attendances, we found that recruited doctors had lower quarterly attendances than the national sample.

Half of the recorders (51\%) practised within $5 \mathrm{~km}$ of a hospital and 208 were $15 \mathrm{~km}$ or more distant. The practitioners were widely distributed across the whole area of the FRG. The environment of their practices were described by the degree of urbanisation: 358 urban, 258 mixed and 408 rural, which can be roughly compared with national data showing 128 urban, 388 mixed and 498 rural.

\section{Consultation data}

The data from 71 recorders included referrals from 37,712 consultations. These were distributed by age and sex (Fig.1) with an excess of females aged $45+$ years and similar to that published nationally (Statistisches Bundesamt, 1989).

Bome visits accounted for 168 of all consultations, which is higher than the 88 reported in the EVaS-Study of $1981 / 82$ (Schach et al 1989), though this was based on a smaller sample. The doctors were asked to identify normal working weeks (i.e. not interrupted by holidays, sickness etc) and in the average such week there were 220 consultations. The average quarterly consultation rate per patient (direct contacts) in the FRG has been estimated at 3.7 for females and 2.7 for males in the Deutsche Herz-Kreislaufa-Praventionsstudie (DHP) and 3.5 for 
females and 2.5 for males in the Erhebung uber die ambulante Versogung in der Bundesrepublik Deutschland (EVaS, Robra et al, 1991). These consultation rates are based on a quarterly period and are much higher than in most other countries of Western Europe.

\section{Direct referral data}

There were 2077 direct referrals, slightly more than half (568) were for females. No nationally comparable data are available.

In Fig.3, referrals are expressed in age and sex groups as rates per 1000 consultations. Excepting the age groups 15-24 years, and $75+$ years, rates in males exceeded those in females.

Referrals were examined by type, mode, urgency and patient influence (Table 1). The definition of mode as used in the FRG is slightly different to that commonly used in other countries of Western Europe and suitable headings are included in the table. 778 of the patients were referred to specialists in their own private practice. Just over half the referrals were described by the doctors as being influenced by the patients and only a small proportion (158) as routine. More detailed information by specialty is presented in Table 2, which includes the number of referrals, the percentage of total and sex specific rates per 1000 consultations.

Delay statistics are summarised in Table 3.838 of patients were seen within 14 days of referral: in $85 \%$ of cases, communication between specialist and the general practitioner was made within 14 days. $56 \%$ of patients referred to surgeons for whom surgery was planned were operated on within 14 days.

\section{Analysis by specialty}

The overail rate of referral was 55 per 1000 consultations. The four specialties with the greatest number of referrals were orthopaedics, general surgery, internal medicine and ophthalmology. Sex specific information about referrals in each specialty is given in Table 1 . A study comparing the distribution of referrals to specialists in 22 practices in West Germany gave broadly similar results (Mader, 1987).

Internal medicine(107 males, 103 females):- The patient influence on the decision to refer was low, 428 of all referrals were described as immediate, 498 as urgent and 98 as routine.

Dermatology(51 males, 77 females):- There was a female excess except among children aged $0-4$ years. The patient influence on the decision to refer was higher than in all other medical specialties. $85 \%$ of the direct referrals were described as immediate or urgent.

Ophthalmology (70 males, 115 females):- 448 of the referrals were for persons aged 65 years or more with a predominance of females. Numbers were similar in the other age and sex groups. 708 of the referrals were described as immediate or urgent. Patient influence was strong (small and large influence $=648$ ). 
Otolaryngology ( 83 males, 95 females):- Patient influence was low. Only 108 of these referrals was described as routine.

Orthopaedics(138 males,145 females):- This was the most frequently used specialty: $87 \%$ of the referrals were described as immediate or urgent and in $61 \%$, the doctor reported being influenced at least to some extent by the patient.

Gynaecolocy (115 females):- Nearly $30 \%$ of the referrals occurred among women aged between 25 and 44 years. In this specialty there were more indirect referrals than direct referrals.

\section{Overview of the data for the FRG}

As a national group, the study sample was small and biassed towards younger doctors working in smaller practices than is general for German doctors. Female doctors were under represented. In the FRG, there are no comparable data addressing similar questions from primary care. Several databases exist: for example, in national and health insurance institutions and though they collect relevant data, they do not analyse and aggregate them in a comparable manner. There are still great obstacles to obtaining and interpreting basic data about primary health care though some recent projects will help to fill this gap (Brecht et al, 1990).

One of the big problems for interpreting the data from the FRG is the system of indirect referrals. In the FRG the ratio of indirect to direct referrals was $88-100$. The equivalent ratio in the Netherlands was 30-100, Italy 27-100 and in the United Kingdom, 2-100. Indirect referrals will be discussed in a separate publication.

\section{Acknowledgements}

The study was facilitated by generous financial support from the Zentralinstitut der Kassenarztlichen Versorgung (2I), Cologne, for which we are very grateful.

\section{References}

Brecht,JG (1990).Forschungsgruppe Gesundheitsberichterstattung: Aufbau einer Gesundheitsberichterstattung - Bestandsaufnahme und Ronzeptvorschlag, Endbericht, Sankt Augustin 1990.

Extra analysis by the $\mathrm{zI}=$ =zentralinstitut(1989) fur die Kassenarztliche Versorgung, Cologne.

Mader FH (1987). Analyse der Gezielten und Ungezielten Uberweisungen in 22 bundesdeutschen Allgemeinarztpraxen. DER ALLGEMEINARZT. 18: 1193-1196.

Robra, BP. et al (1991). Die Haufigkeit der arztlichen Inanspruchnahme im Spiegel zweier Reprasentativerhebungen: DHPSurvey und EVasS-Studie. Off Gegundh.-Wes.53:228-232.

Schach E, et al. (1989). Die EVaS-Studie. Bine Brhebung uber die ambulante medizinische Versorgung in der Bundesrepublik Deutschland. Daten und Analysen einer bundesweiten Studie des Zentralinstitutes der kassenartlichen Versorgung, Wissenschaftliche Reihe, Band 39, 1. Deutscher Arzteverlag Koln.

Statistisches Bundesamt (Hrsg) (1989), Fachserie A Reihe 2: Naturliche Bevolkerungsbewegung. Stuttgart. 


\section{HUNGARY - National Representative K Botos}

Floure 1

Recorders $(n=74)$ : Distribution by Age Compared with national data

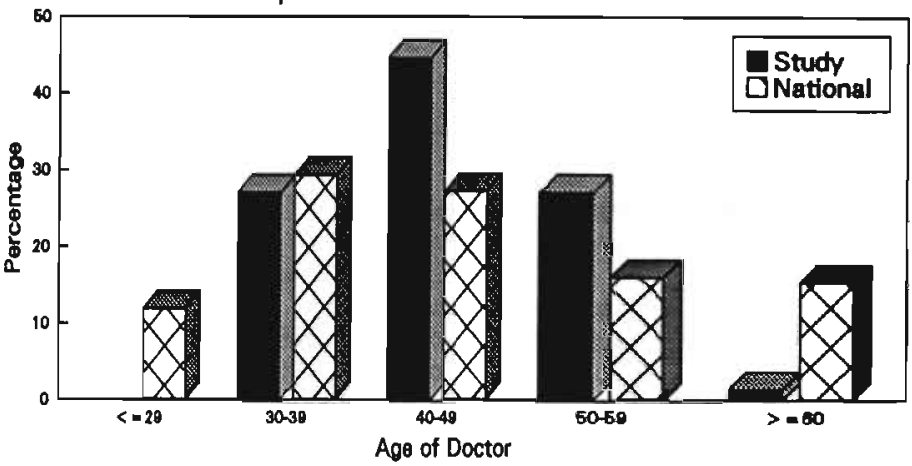

Figure 2

Consultations : Distribution by Age

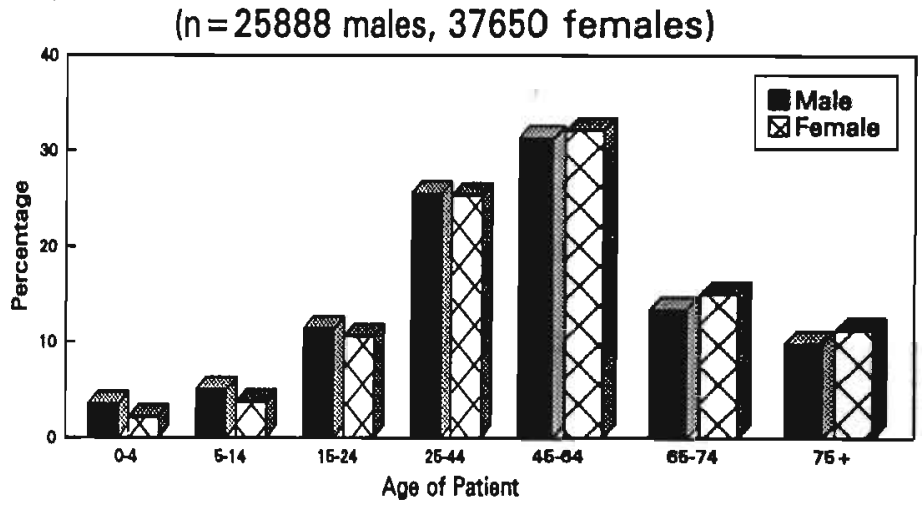

Figure 3

Referral Rate (per 1000 consultations) by Age ( $n=962$ males, 1234 females)

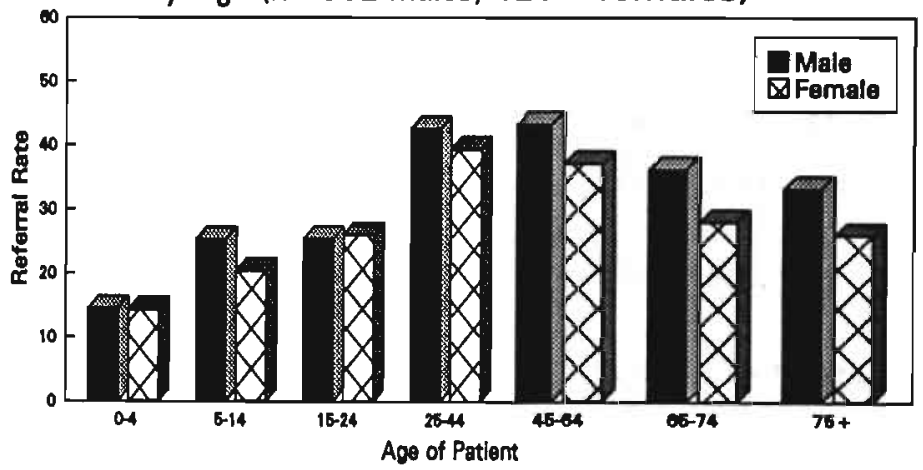


TABLE 1 - REFERRALS BY SPECIALTY NUMBEA AND PERCENT OF TOTAL RATE PER 1000 CONSULTATIONS BY SEX
TABLE 2 - DISTRIBUTION OF REFERRALS (V) BY MODE, TYPE, URGENCY AND REPORTED PATIENT INFLUENCE

\begin{tabular}{|c|c|c|c|c|c|c|c|c|c|}
\hline SPECIALTY & $\mathbf{N}$ & 8 & $\begin{array}{c}\text { RATE } \\
\text { M }\end{array}$ & $\begin{array}{c}\text { PER } 1000 \\
F\end{array}$ & $\begin{array}{c}\text { CONS } \\
T\end{array}$ & & $\mathbf{M}$ & $\mathbf{F}$ & $\mathrm{T}$ \\
\hline Int. Med. & 431 & 19.6 & 6.8 & 6.7 & 6.8 & MODE & & & \\
\hline Paed. Med. & 23 & 1.0 & 0.3 & 0.4 & 0.4 & Outpatient & 79.7 & 80.4 & 80.1 \\
\hline Ger1. Med. & 1 & 0.0 & 0.0 & 0.0 & 0.0 & Private & 0.1 & 0.2 & 0.1 \\
\hline Dermatology & 48 & 2.2 & 0.8 & 0.7 & 0.8 & Clinic & 11.6 & 11.1 & 11.4 \\
\hline Cardiology & 107 & 4.9 & 2.0 & 1.5 & 1.7 & Inpatient & 8.1 & 7.8 & 7.9 \\
\hline Allergy & 5 & 0.3 & 0.0 & 0.2 & 0.1 & A E Dept. & 0.1 & 0.1 & 0.1 \\
\hline Neurology & 151 & 6.9 & 2.8 & 2.1 & 2.4 & Domiciliary & 0.4 & 0.4 & 0.4 \\
\hline Gastroent. & 43 & 2.0 & 0.9 & 0.5 & 0.7 & & & & \\
\hline Rheumatology & 275 & 12.5 & 4.1 & 4.5 & 4.3 & & & & \\
\hline Resp. Med. & 112 & 5.1 & 2.2 & 1.5 & 1.8 & & & & \\
\hline Medical NEC & 61 & 2.8 & 1.0 & 0.9 & 1.0 & TYPE & & & \\
\hline & & & & & & New & 57.3 & 55.0 & 56.0 \\
\hline MEDICAL & 1258 & 57.3 & 20.9 & 19.0 & 19.8 & Re-Referral & 42.7 & 45.0 & 44.0 \\
\hline Gen. Surgery & 201 & 9.2 & 4.0 & 2.6 & 3.2 & & & & \\
\hline Ophthalmology & 104 & 4.7 & 1.4 & 1.8 & 1.6 & URGENCY & & & \\
\hline Otolaryngol. & 111 & 5.1 & 1.8 & 1.7 & 1.7 & Immediate & 20.7 & 18.6 & 19.5 \\
\hline Orthopaedica & 48 & 2.2 & 0.8 & 0.7 & 0.8 & Urgent & 40.4 & 32.1 & 35.8 \\
\hline Gen.-Urinary & 91 & 4.1 & 1.9 & 1.1 & 1.4 & Routine & 38.8 & 49.3 & 44.7 \\
\hline Plastic Surg. & 1 & 0.0 & 0.0 & 0.0 & 0.0 & & & & \\
\hline Neurosurgery & 14 & 0.6 & 0.2 & 0.2 & 0.2 & & & & \\
\hline Surg. NEC & 54 & 2.5 & 1.0 & 0.7 & 0.8 & & & & \\
\hline & & & & & & PATIENT INFLUENC & & & \\
\hline SURG ICAL & 624 & 28.4 & 11.2 & 8.9 & 9.8 & Nil & 66.2 & 57.2 & 61.1 \\
\hline & & & & & & Small & 20.3 & 23.1 & 21.9 \\
\hline & & & & & & Large & 13.5 & 19.8 & 17.0 \\
\hline Obstetrics & 3 & 0.1 & 0.0 & 0.1 & 0.0 & & & & \\
\hline Gynaecology & 44 & 2.0 & 0.0 & 1.2 & 0.7 & & & & \\
\hline Paychiatry & 63 & 2.9 & 1.0 & 1.0 & 1.0 & & & & \\
\hline Mental aub. & 2 & 0.1 & 0.0 & 0.1 & 0.0 & \multirow{3}{*}{\multicolumn{4}{|c|}{$\begin{array}{l}\text { TABLE } 3 \text { - DELAY PATTERNS BETWEEN } \\
\text { REFERRAL AND FIRST APPOINTYENT }\end{array}$}} \\
\hline Emerg+Trauma & 72 & 3.3 & 1.9 & 0.6 & 1.1 & & & & \\
\hline Oncology & 15 & 0.7 & 0.2 & 0.2 & 0.2 & & & & \\
\hline Pain relief & 1 & 0.0 & 0.0 & 0.0 & 0.0 & & & & \\
\hline Specialty NEC & 62 & 2.8 & 1.0 & 1.0 & 1.0 & & & & \\
\hline OTHER & 262 & 11.9 & 4.1 & 4.1 & 4.1 & & $\begin{array}{l}\text { Seen } \\
\text { ithin } \\
8 \text { dayo }\end{array}$ & $\begin{array}{l}\text { Not } \\
\text { geen In } \\
16 \text { wks }\end{array}$ & $\begin{array}{l}\text { Mean } \\
\text { delay } \\
\text { (days) }\end{array}$ \\
\hline Specialty NK & 52 & 2.4 & 0.9 & 0.7 & 0.8 & MEDICAL & 98.2 & 0.8 & 1.7 \\
\hline & & & & & & SURGICAL & 98.9 & 0.4 & 1.2 \\
\hline & & & & & & OTHER & 98.9 & 0.5 & 1.1 \\
\hline GRAND TOTAL & 2196 & 100.0 & 37.2 & 32.8 & 34.6 & TOTAL & 98.5 & 0.7 & 1.5 \\
\hline
\end{tabular}


Seventy four general practitioners contributed to the study in Hungary with 65 also providing follow-up data. Some Hungarian doctors used German language recruitment booklets and others the Bnglish version. 308 were female compared with 478 of all doctors in Bungary (not exclusively general practitioners). There are now more female than male doctors aged under 45 years in Bungary. The distribution by age is compared with national data in Figure 1 though these data cover all registered doctors and some of the older ones will be retired. 278 of the recruited doctors had spent less than 10 years in practice and 388 more than 20 years. 428 of the doctors were within $5 \mathrm{kms}$ of a hospital and 288 more than $20 \mathrm{kms}$ distant. 458 worked in urban practice, 218 mixed and 348 rural.

\section{Consultation data}

The study included 63538 consultations, of which $55 \%$ were for female patients and 118 involved a home visit. Though there were more consultations for females, the distributions by age group were similar with the exception of consultations for young children where there was a small male excess (Figure 2). The average working week included 200 consultations.

\section{Direct referral data}

Altogether there were 2196 referrals for which age and sex specific data were available and $56 \%$ of these were for female patients. Referral rates by age and sex are described in Figure 3. The overall rate of 34 per 1000 consultations is divided between medical specialties 20 , surgical specialties 10 and other specialties 4. Expressed as rates per 1000 consultations, referral activity was very similar in both sexes. More detail about direct referrals in individual specialties is given in Table 1 which includes relative proportions and sex specific referral rates.

Forty four percent of referrals were described as re-referrals (Table 2), indicating previous consultation with the specialist for that problem within the last 3 years. Only 6 of the referrals were outside the national health system for Hungary and 3 of these were funded by the employer. 208 of referrals were described as immediate and $368 \mathrm{as}$ urgent. The influence of the patient on the referral decision was reported as nil in 618 of cases.

Delays between referral and first appointment are summarised in Table 3 for the 3 major specialty groups. They are all very small.

\section{Analysis by specialty}

Internal medicine (177 males, 254 females):- 208 of all referrals were in this specialty. The excess among females was evident in all adult age groups. Referrals as inpatients (158) were more frequent than in all other specialties combined ( $8 \%)$. The urgency of referral and the patient influence on the referral decision was similar to the average for all specialties. 988 of those for whom there were available data were seen within 2 weeks of referral. 
Cardiology (51 males, 56 females):- The numbers of referred patients were similar in both sexes. The proportion of rereferrals (58\%) was higher than the average for all specialties (448), but paradoxically, the influence of the patient on the referral decision (698 nil, 198 small, 128 large), was lower than average $(618,228,178)$. Delays in the referral process were minimal.

Neurology (72 males, 79 females):- As rates per 1000 consultations, referral rates were high in the age group 25-44 years. The referrals to psychiatrists were in general at a low level. No other features of the referral process in this specialty differed from the general pattern for medical referrals.

Rheumatology (105 males, 170 females):- This was the second most comunon specialty. More females were referred than males and this difference was observed in all adult age groups. It was maximal in the age group 45-64 years where 48 males were referred compared with 86 females. 598 were re-referrals which was particularly high value (overall value 448 ). $98 \%$ were referred as outpatients, urgency was less than average $167 \%$ were routine referrals compared with 458 overall), but patient influence was increased - 518 nil influence, 318 small influence, $18 \%$ large influence compared with 618,228 and 178 overall. There were only short delays in the referral process.

The relatively high numbers of referrals in this specialty should be viewed against a background of low numbers 122 males, 26 females) referred to oxthopaedic specialists.

General surgery ( 104 males, 97 females):- Only 238 of referrals were re-referrals compared with 448 overall and 128 involved inpatient admission. There was a higher level of urgency than in all specialties combined - immediate 328 (compared with 208 overall), urgent $428(36 \%)$, routine $27 \%(458)$. There were only minimal delays between referral and first appointment with 978 of patients seen within 2 weeks Among 53 persons scheduled for surgical intervention, $76 \%$ had received their surgery within one week and $87 \%$ within four weeks.

Qphthalmology ( 37 males, 67 females):- The excess of females over males was evident in all age groups after 45 years but particularly in the 45-64 years age group. Most were referred via the outpatient department but nevertheless 398 of patients were considered as requiring immediate or urgent referral. Statistica covering patient influence were similar to those for all specialties combined and delays in the referral process were minimal, 948 of those referred were seen within two weeks of referral.

Otolaryngology ( 46 males, 65 females):- The excess among females largely occurred in the age group 15-64 years. There were no unusual features about the urgency of referral or the patient influence on the referral decision or delays in the referral process. 
Hungary is not a large country and the recruitment of 74 doctors into this study was a considerable success. The average workload of general practitioners measured as the number of consultations was relatively high but consultation rates in Bungary are also high. Thus referrals expressed as a rate per consultation might seem to be less than those in other countries.

The dominance of referrals to the specialty 'internal medicine' and the comparatively high rate of re-referrals, suggest a dependence or weak role for general practitioners relative to their specialist colleagues for the investigation of medical problems. The administrative procedures covering the re-referral process should perhaps be examined in further detail in the light of these results. The study has demonstrated some interesting comparisons of referral patterns between the specialties. It has also demonstrated an extremely efficient delivery of specialist services with minimal delays for specialist opinion following referral from general practice.

\section{Acknowledgements}

We are pleased to acknowledge the co-operation of M. Szatsmari of the Department of Bealth in facilitating the involvement of Bungary in this study. 
Figure 1

Recorders $(n=20)$ : Distribution by Age Compared with national data

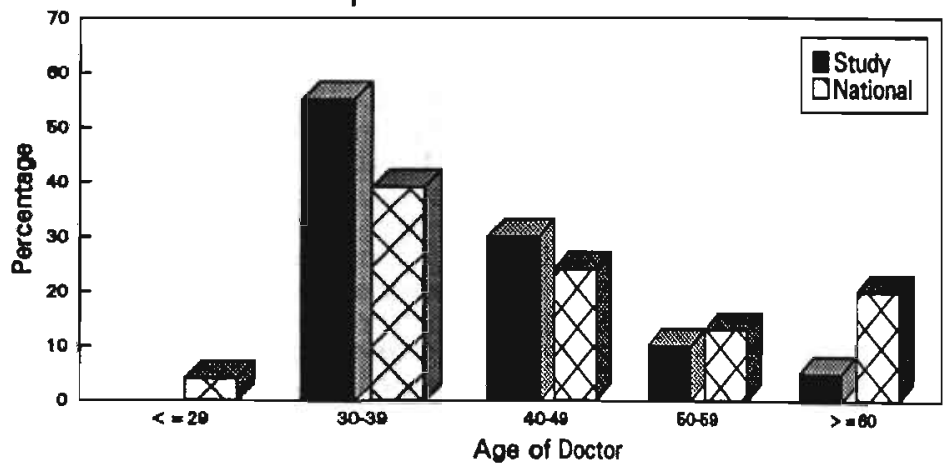

Floure 2

Consultations : Distribution by Age ( $n=5121$ males, 7453 females)

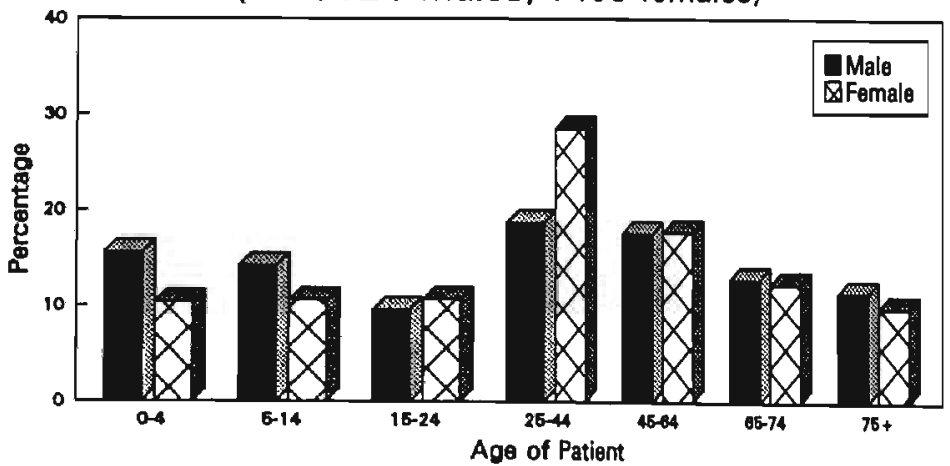

Figure 3

Referral Rate (per 1000 consultations) by Age ( $n=228$ males, 300 females)

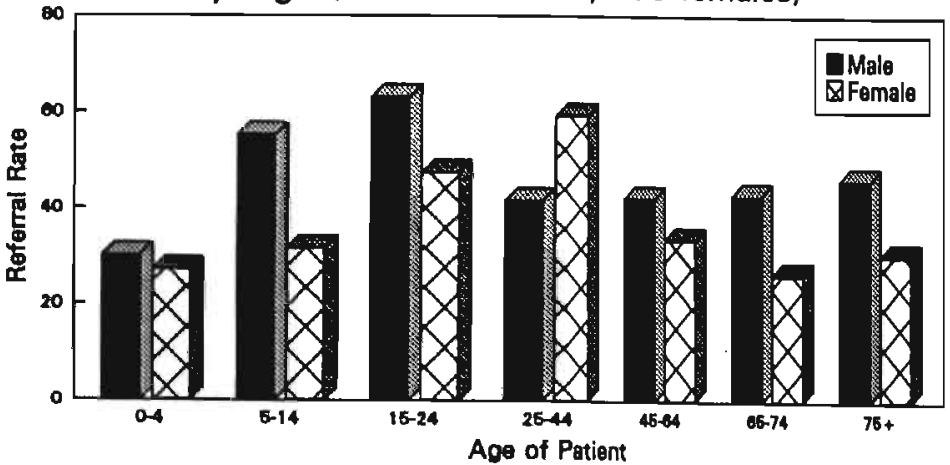


TABLE 1 - REPERRALS BY SPECIALTY NUMBER AND PERCENT OF TOTAL RATE PER 1000 CONSUETATIONS BY SBX
TABEE 2 - DISTRIBUTION OF REFERRALS BY HODE, TYPE, URGENCY AND REPORTED PATIENT INFLUENCE

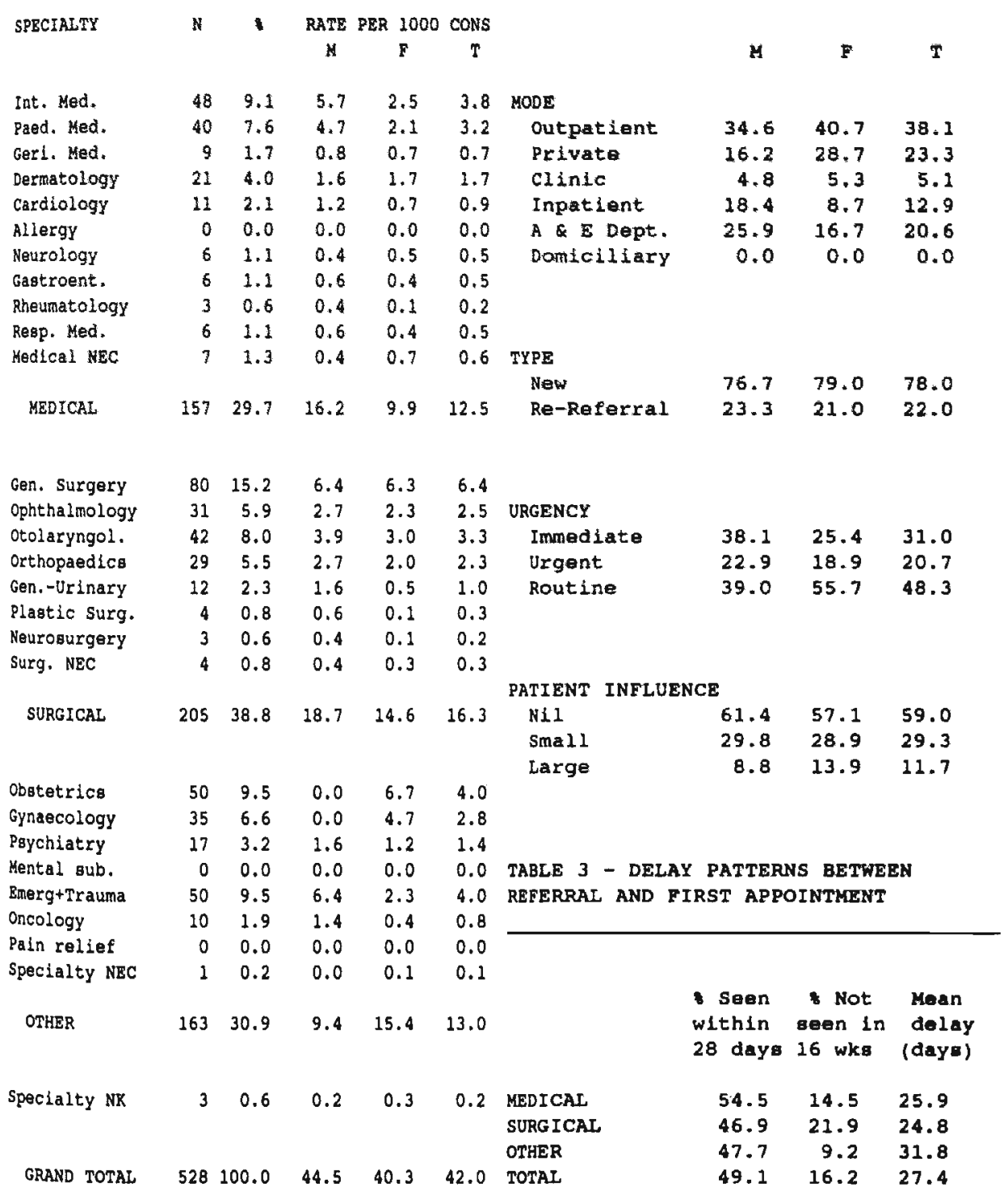


Twenty general practitioners were recruited (roughly 18 of the total in the country). The sample (Fig.1) was biassed in comparison with national data (Comber, 1990) by inclusion of more doctors in their thirties and only one doctor over the age of 60 years. (208 of the national doctor pool is in this age group). 208 were female, compared with the national figure of 198. Size of practice partnerships agreed with the national figures with 538 single-handed (National 578), 268 in 2 person practice (278). An attempt to recruit a subset by random means using a mailshot was unsuccessful.

There was also some bias by inclusion of more doctors in rural practice: 448 were more than $30 \mathrm{kms}$ distant from a major hospital compared with $28 \%$ nationally. 208 were in urban practice which can be compared with national data where 358 were working in communities with more than 10,000 people. 30 were in rural practice which compared with a national figure of 278 working in communities of less than 1000 people. The sample was distributed across the entire Republic of Ireland.

\section{Consultation data}

The data included referrals from 12,574 consultations. The distribution by age and sex groups (Fig. 2) is virtually identical to national data such as the National Workload Study (Comber, 1990). 598 of consultations were with female patients (National data 578 ).

2170 consultations (178) involved a home visit which is rather more than the national figure of 118 . Home visits may be overlooked when recording, so this provides some evidence for good quality of data collection. The average normal working week included 135 consultations.

\section{Direct referral data}

There were 528 direct referrals, 438 males and 578 females. The overall referral rate of 42 per thousand consultations was similar to national data (52 per thousand, Comber 1990). In Fig.3 the rates are presented for age-sex groups. The rate for females aged 25 to 44 years is ahead of all other groups. This is mainly due to the high referral rate for Obstetrics and Gynaecology associated with the (still) high birth rate in Ireland. Referral rates for all other specialties were lower for females than for males.

The distribution by specialty is given in Table 1. Numbers are large enough in only a half dozen specialties to allow sufficient accuracy for comparisons.

Data concerning the analysis of referrals by type, mode, urgency and patient influence are given in Table 2.

Delay statistics (Table 2) show that 498 of referred patients were seen within 28 days and 168 had still not been seen by 16 weeks. The mean delay was 27 days. The samples were not sufficient to permit reliable comparison between individual specialties. 
Although the Irish sample comprised only 20 doctors, this was 18 of the Irish doctor population. The sample was biassed away from urban areas and older doctors: however, the sample was well distributed geographically and the consulting pattern, sex breakdown, and partnership sizes matched national data. The referrals should therefore provide a satisfactory representative sample, even if not random.

Numbers are sufficient to provide a national overview, but not to compare individual specialties.

Acknowledgements

We would like to thank the Republic of Ireland Faculty of the Royal College of General Practitioners for funding.

\section{References}

Comber, H. Preliminary Report of the National Workload Study. Irish College of General Practitioners. 1990. 
ITALY - National Representative G Passerini

Figure 1

Recorders $(n=213)$ : Distribution by Age

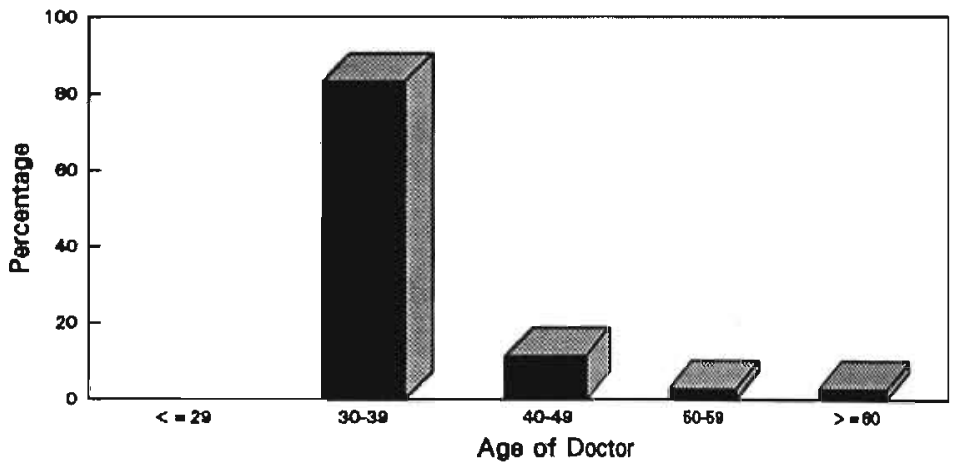

Figure 2

Consultations : Distribution by Age

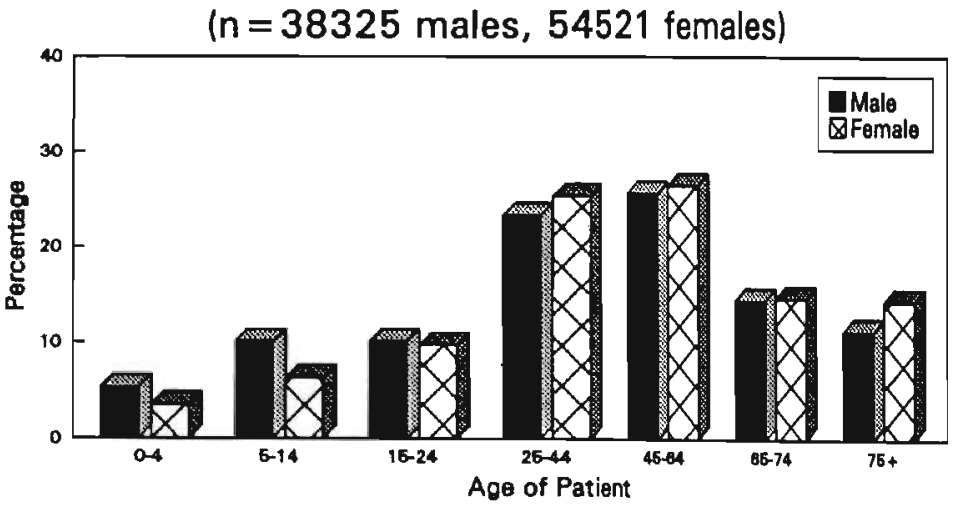

Figure 3

Referral Rate (per 1000 consultations)

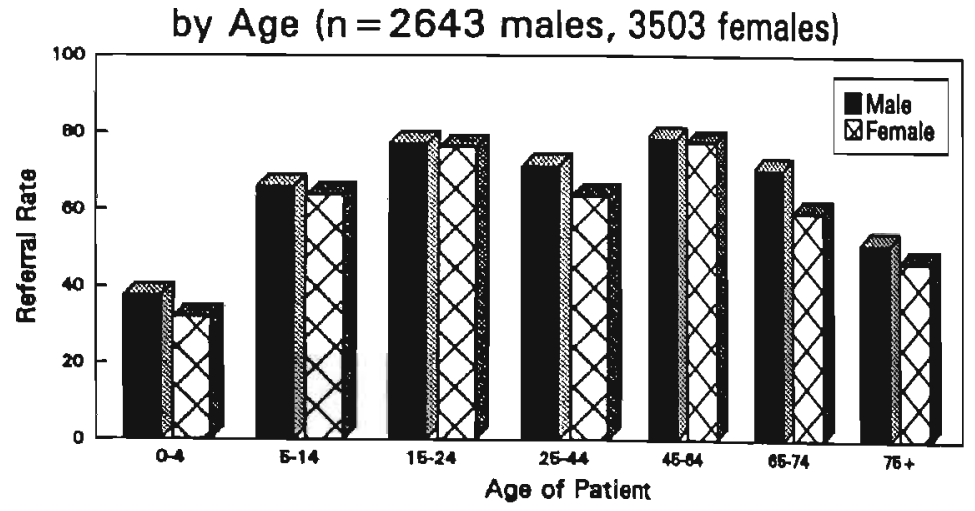


TABLE 1 - REFERRALS BY SPECIALTY NUMBER AND PERCENT OF TOTAL RATE PER 1000 CONSULTATIONS BY SEX
TABLE 2 - DISTRIBUTION OF REFERRALS (*) BY MODE, TYPE, URGENCY AND REPORTED PATIENT INELUENCE

\begin{tabular}{|c|c|c|c|c|c|c|c|c|c|}
\hline \multirow[t]{2}{*}{ SPECIALTY } & $\mathrm{N}$ & 8 & RATE & PER 1000 & CONS & & & & \\
\hline & & & M & $\mathbf{F}$ & $T$ & & $\mathbf{M}$ & $\mathbf{F}$ & $\mathbf{T}$ \\
\hline Int. Med. & 143 & 2.3 & 2.0 & 1.2 & 1.5 & \multicolumn{4}{|l|}{ MODE } \\
\hline Paed. Med. & 41 & 0.7 & 0.7 & 0.3 & 0.4 & outpatient & 84.5 & 85.4 & 85.0 \\
\hline Gorl. Med. & 20 & 0.3 & 0.3 & 0.2 & 0.2 & Private & 6.9 & 8. $B$ & 8.0 \\
\hline Dermatology & 515 & 8.4 & 5.3 & 5.7 & 5.5 & clinic & 0.9 & 1.0 & 0.9 \\
\hline Cardiology & 659 & 10.7 & 7.9 & 6.6 & 7.1 & Inpatient & 4.8 & 3.1 & 3.8 \\
\hline Allergy & 77 & 1.3 & 1.1 & 0.6 & 0.8 & A $\mathbf{E}$ Dept. & 2.6 & 1.5 & 2.0 \\
\hline Neurology & 227 & 3.7 & 2.6 & 2.4 & 2.4 & Domiciliary & 0.3 & 0.2 & 0.2 \\
\hline Gastroent. & 73 & 1.2 & 0.9 & 0.7 & 0.8 & & & & \\
\hline Rheumatology & 53 & 0.9 & 0.4 & 0.7 & 0.6 & & & & \\
\hline Resp. Med. & 80 & 1.3 & 1.3 & 0.5 & 0.9 & & & & \\
\hline \multirow[t]{2}{*}{ Medical NEC } & 332 & 5.4 & 3.1 & 3.9 & 3.6 & \multicolumn{4}{|l|}{ TYPE } \\
\hline & & & & & & New & 59.8 & 59.5 & 59.6 \\
\hline MEDICAL & 2220 & 36.1 & 25.6 & 22.7 & 23.9 & Re-Referral & 40.2 & 40.5 & 40.4 \\
\hline Gen. Surgery & 567 & 9.2 & 6.4 & 5.9 & 6.1 & & & & \\
\hline Ophthalmology & 727 & 11.8 & 7.6 & 8.0 & 7.8 & URGENCY & & & \\
\hline otolaryngol. & 646 & 10.5 & 7.7 & 6.4 & 7.0 & Immediate & 5.4 & 3.6 & 4.3 \\
\hline Orthopaedics & 836 & 13.6 & 10.8 & 7.7 & 9.0 & Urgent & 10.9 & 8.7 & 9.6 \\
\hline Gen.-Urinary & 217 & 3.5 & 4.7 & 0.7 & 2.3 & Routine & 83.7 & 87.8 & 86.0 \\
\hline Blastic Surg. & 33 & 0.5 & 0.5 & 0.2 & 0.4 & & & & \\
\hline Neurosurgery & 28 & 0.5 & 0.5 & 0.2 & 0.3 & & & & \\
\hline \multirow[t]{2}{*}{ Surg. NEC } & 181 & 2.9 & 1.7 & 2.1 & 1.9 & & & & \\
\hline & & & & & & \multicolumn{4}{|l|}{ PATIENT INFLUENCE } \\
\hline \multirow[t]{3}{*}{ SURGICAL } & 3235 & 52.6 & 40.1 & 31.2 & 34.8 & Nil & 71.1 & 65.4 & 67.9 \\
\hline & & & & & & Small & 19.0 & 20.9 & 20.1 \\
\hline & & & & & & Large & 9.8 & 13.7 & 12.1 \\
\hline Obstetrics & 57 & 0.9 & 0.0 & 1.0 & 0.6 & & & & \\
\hline Gynaecology & 282 & 4.6 & 0.1 & 5.1 & 3.0 & & & & \\
\hline Pgychiatry & 88 & 1.4 & 0.7 & 1.2 & 0.9 & & & & \\
\hline Mental sub. & 6 & 0.1 & 0.1 & 0.0 & 0.1 & \multirow{3}{*}{\multicolumn{4}{|c|}{$\begin{array}{l}\text { TABLE } 3 \text { - DELAY PATTERNS BETKEEN } \\
\text { REFERRAL AND FIRST APPOIMTMENT }\end{array}$}} \\
\hline Emerg+Trauma & 24 & 0.4 & 0.3 & 0.2 & 0.3 & & & & \\
\hline Oncology & 104 & 1.7 & 0.8 & 1.4 & 1.1 & & & & \\
\hline Pain relief & 19 & 0.3 & 0.2 & 0.2 & 0.2 & & & & \\
\hline Specialty NEC & 101 & 1.6 & 1.1 & 1.1 & 1.1 & & & & \\
\hline OTHER & 681 & 11.1 & 3.2 & 10.3 & 7.3 & & $\begin{array}{l}\text { Seen } \\
\text { ithin } \\
8 \text { days }\end{array}$ & $\begin{array}{l}\text { Not } \\
\text { seen in } \\
16 \text { wks }\end{array}$ & $\begin{array}{l}\text { Mean } \\
\text { delay } \\
\text { (days) }\end{array}$ \\
\hline \multirow[t]{3}{*}{ Specialty NK } & 10 & 0.2 & 0.2 & 0.1 & 0.1 & MEDICAL & 87.2 & 2.7 & 10.5 \\
\hline & & & & & & SURGICAL & 87.0 & 2.3 & 10.9 \\
\hline & & & & & & OTHER & 89.7 & 2.3 & 9.9 \\
\hline GRAND TOTAL & 6146 & 100.0 & 69.0 & 64.3 & 66.2 & TOTAL & 87.4 & 2.4 & 10.7 \\
\hline
\end{tabular}




\section{Characteristics of the Italian referral system}

The Italian National Health Service covers the whole population. General practitioners are paid on a capitation fee basis but their practice registered list must not exceed 1800 patients. Patients are free to select and change their general practitioner as they wish. Referral to specialists within the national health service can only be arranged by the general practitioner.

\section{Characteristics of general practitioners}

215 general practitioners provided data for the recruitment phase of the study and for 142 of them, there were also follow-up data. Unfortunately, one parcel of follow-up booklets was lost in mailing from Italy to Birmingham. $13 \%$ of participating general practitioners were female and 838 were aged between 30 and 39 years (Fig.1). These values are comparable with other national data (FNOMCEO, 1989). There was a small over representation of doctors aged less than 30 years and doctors from the northern region of Italy. An attempt to recruit a random sample of 50 general practitioners was not successful.

The average list per principal was 1241 ranging from 220-4000 which exceeds the national average of 833 (Il Medico d'Italia 1991). 908 of the doctors worked in solo practice which is usual in Italy. 408 described their working location as urban, 238 rural and $37 \%$ mixed. 678 of doctors were located within $5 \mathrm{kms}$ of a local hospital and only 4 s were more than $20 \mathrm{kms}$ distant.

\section{Consultation data}

92846 consultations were included in the study among which 598 were for female patients and 148 involved a home visit. There was an excess of females in all age groups from 15 years upwards: the distribution (Fig.2) being typical of that in Italian general practice. The average working week of doctors included 115 consultations. The situation reflects the typical pattern of consultations in general practice in Italy (Stiassi et al, 1988).

\section{Direct referral data}

The study included 6146 direct referrals, 578 of which were for female patients. Referral rates per 1000 consultations in age and sex categories (Fig.3), show broadly similar rates in both sexes. Distribution by specialty is sumarised in Table 1: orthopeedics, ophthalmology, cardiology and otolaryngology were the commonest referral specialties.

Distributions by referral type, by mode of referral, by urgency of referral and by the influence of the patient on the referral decision are summariged in Table 2. 408 of referrals were classified as re-referrals reflecting the need in the Italian healthcare system for the general practitioner to reauthorise referral if necessary after 12 months have elapsed from the previous referral. Continuing specialist involvement in the management of some conditions, for example diabetes, has to be authorised annually. 918 of patients were referred within the national health service and 858 of all referrals were in the outpatient mode. $3.8 \%$ were referred directly for admission and B8 were referred to private medical services. 
Only 148 of referrals were classified immediate or urgent and the extent of patient influence on the referral decision was comparatively low with 128 expressing an influence considered large by the doctor and a further 208 expressing a amall influence. The distributions by type, mode, urgency and patient influence were similar in both sexes.

\section{Analysis by specialty}

The overall referral rate was 66 per 1000 consultations divided between the major specialty groups with rates of 24 for medical specialties, 35 surgical specialties and 7 other specialties. The delay between referral and first specialist appointment (outpatients, clinic and private referrals only), is summarised by major specialty groups in Table 3. In 858 of relevant cases, the general practitioner received a communication from the specialist within 2 weeks of the appointment and where surgical intervention was deemed necessary after referral to a surgeon, 558 received it within 4 weeks. For the common specialties, specific comments are provided below.

Internal medicine (76 males, 67 females):- A third of referrals $\frac{138)}{(33 v o l v e d ~ a d m i s s i o n ~ t o ~ h o s p i t a l . ~ P a t i e n t ~ i n f l u e n c e ~ o n ~ t h e ~}$ referral decision was smaller than in all specialties (218 small or large influence compared with 328 ) overall. Delay statistics were average.

Paediatric medicine (27 males, 14 females):- A predominance of males was seen in both age groups $0-4$ and 5-14 years. Less than $20 \%$ of all children referred in the age group $0-4$ years were referred to paediatricians. 15 out of the total of 17 children were referred to the outpatient department were seen within two weeks. Most children in Italy are looked after by community based paediatricians who were not included in this study.

Dermatology (205 males, 310 females):- A female excess over males was particularly evident in the age groups 25-44 years and 45-64 years. In $40 \%$ of cases compared with 328 overall, the patient exerted some influence on the referral decision. The interval between referral and the first appointment was relatively ohort 898 being seen within 4 weeks.

Cardiology (301 males, 358 females):- This was the third ranked specialty. More females than males were referred. 908 of those referred to outpatient facilities were seen within 4 weeks of referral and there was no difference in the patient's influence on the referral decision as compared to the result for all specialties.

Neurology (98 males, 129 females):- Neurology was ranked third to cardiology and dermatology amongst the medical referrals. Interestingly, referral rates in all age and sex groups aged 25+ years were similar (between 2.0 and 3.4 per 1000 consultations). 898 were seen within 4 weeks of referral. 498 were re-referrals (compared with 408 overall), and patient influence on referral was similar to that for all referrals combined.

Rheumatology (16 males, 37 females):- Comparatively few people were referred to rheumatologists. There are very few specialist rheumatologists in Italy. 
Reapiratory medicine (51 males, 29 females):- The sex distribution differs from cardiology though probably in both these illness categories, there are more male sufferers than females. 138 involved hospital admission.

General surgery (247 males, 320 females):- General surgery was ranked as the fifth commonest individual specialty. Re-referrals (288 of total) were less frequent than in other specialties. 938 of referred patients were seen within 4 weeks of appointment. of the 87 people reported in the follow-up study and known to be scheduled for surgical procedures, 55 had received this attention within 2 weeks of appointment, and a further 8 within 4 weeks.

Ophthalmology (293 males, 434 females):- Ophthalmology was the second most frequently referred specialty. The excess among females was widely distributed across the age groups except in persons 0-4 years and 25-44 years. Surprisingly, 418 were rereferrals (which was the same as for all specialties), but fewer might have been expected in this specialty where specialist advice is unlikely to extend to long-term disease management for more than a few cases. The influence of the patient on the referral decision was higher in this specialty than in most others (nil 588, small 268, large 16\%).

Otolaryngology (296 males, 350 females): 115 of the referrals concerned children under 14 years. 868 of referred persons were seen within 4 weeks.

Orthopaedics (414 males, 422 females):- This was the most frequently used specialty. Though the numbers in each sex are about the same, there were differences in the age distribution with more younger males than females and less aged 45 years and over. Statistics for patient influence on the referral decision were above the average for all specialties. 928 were seen by the specialist within 4 weeks of referral. Among 43 planned surgical cases, 17 had received their operation within 4 weeks of appointment.

Gynaecology (280 females):- 18 z of referrals to gynaecologists were arranged privately (compared with 88 for all specialties). Patient influence on the referral decision did not differ from that in other specialties. 888 were seen within 4 weeks of referral.

Paychiatry (25 males, 63 females):- Only 88 people were referred for psychiatric care, 67 of whom were aged between 25 \& 64 years.

Qverview of the data for Italy

The sample of general practitioners, consultations and referrals was large enough to provide reliable data. However, there was an inevitably biassed distribution of doctors from the North. It is also possible that doctors willing to participate in research of the referral process may have particular views about the division of labour between general practitioners and specialists. Their motivation towards the study and towards general practice may thus bias the results towards lower referral rates than would be the case generally. The results reported here indicate lower referral rates than would be expected from other data sources. Notwithstanding these reservations, differences between 
specialties, trends among doctors with widely differing referral rates and delays in the referral process can all be examined. A high rate of re-referrals has been found. This arises largely because of administrative reasons, the patient requiring rereferral in those cases where continued management by a specialist is desirable.

Though it is not relevant here to make international comparisons, it is necessary when interpreting these data to note the arrangements in Italy for healthcare provision with paediatric and obstetric services widely available outside general practice and with the administrative obligation to reauthorise every rereferral.

\section{Acknowledgements}

These data have been obtained as a result of the initiatives taken at the Monte-Negro Institute for Primary Care research. No national funding was given for this study and we are therefore particularly indebted to the individual initiatives of all concerned.

\section{References}

FNOMCEO : Rilevazione statistica sulla popolazione medica in Italia 1989. Supplemento a "Il Medico d'Italia", Roma, 1989.

Il Medico d'Italia, No.28. 16. Febbraio, 1991, pag.2.

Stiassi, R., Taroni, F., Traversa, G. 1988). The AMeBEV Survey: Quality Assurance of Care in General Practice. Come, Dept. of Social Security of the Emilia-Romagna Region, $n$, year vI, August. 
NETHERLANDS - National Representatives Fons Gloerich, J van der Zee

Figure 1

Recorders $(n=55)$ : Distribution by Age

Compared with national data

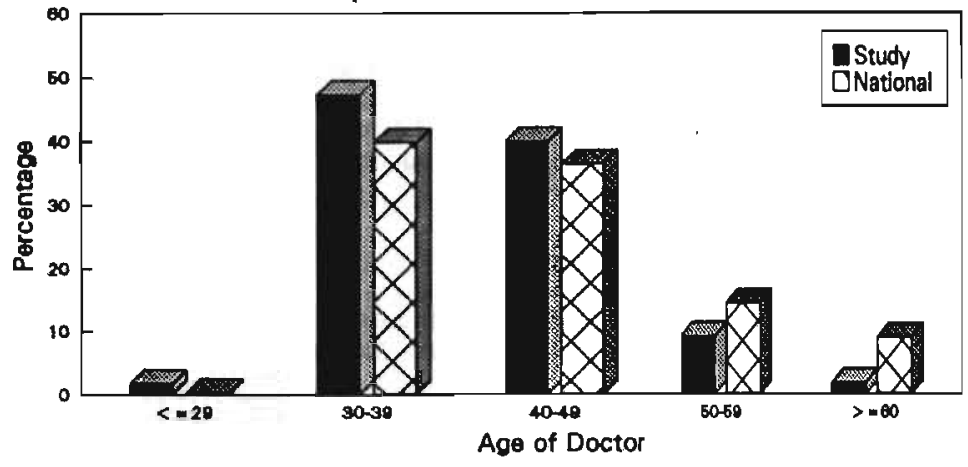

Figure 2

Consultations : Distribution by Age ( $n=14320$ males, 21090 females)

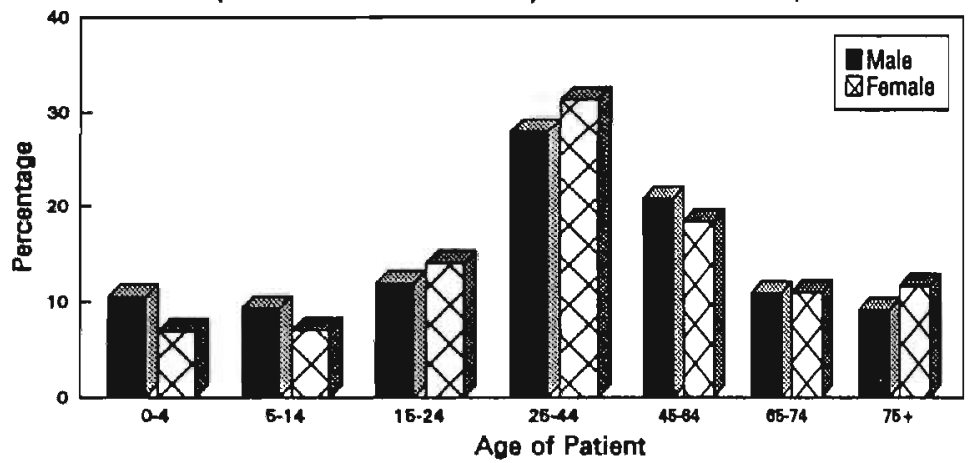

Figure 3

Referral Rate (per 1000 consultations) by Age ( $n=731$ males, 835 females)

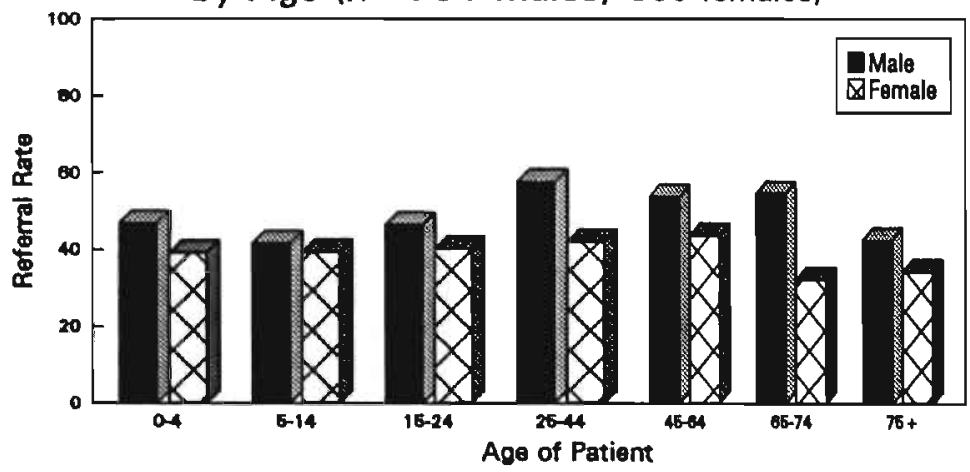


NETHERLANDS

TABLE 1 - REFERRALS BY SPECIALTY NUMBER AND PERCENT OF TOTAL RATE PER 1000 CONSULTATIONS BY SEX
TABLE 2 - DISTRIBUTION OF REFERRALS (8) BY MODE, TYPE, URGENCY AND REPORTED PATIENT INFLUENCE

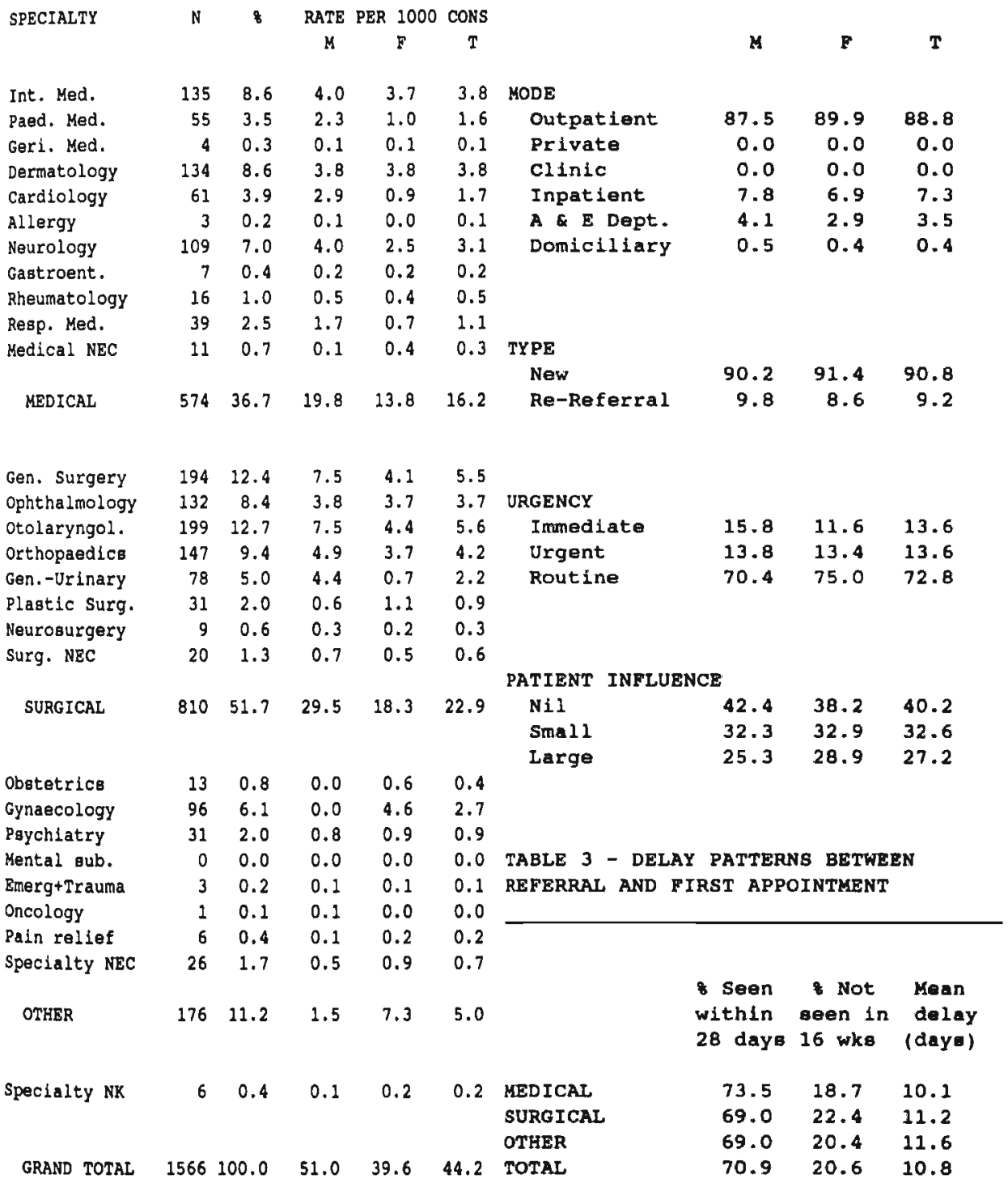


The Dutch healthcare system is in two parts: directly accessible primary care is provided by general practitioners (gps), physiotherapists, community nurses and home helps; and specialist care accessible by referral from gps is provided by specialists in hospital inpatient and outpatient departments. Most specialists are self employed.

The majority of patients (two thirds of the population), are insured in a public scheme and the rest, belonging largely to the higher income group (in 1989 with an annual income greater than DFL 51000) are privately insured. General practitioners are paid by capitation for patients who are publicly insured and by fee for service for those privately insured whereas specialists are paid on a fee for service basis for all patients. Like their British colleagues, gps in the Netherlands are gatekeepers to secondary care. In the public insurance scheme, the patient is given a referral card valid for one year which is passed on to the specialist effectively authorising his fee. Continuing treatment after one year requires further authorisation (extended referral). When specialist care is provided in emergency without referral, the authorisation is obtained retrospectively
(posterior referral). Both extended and posterior referrals are passive referrals and commonly authorised indirectly without conaultation. Referrals involving the gp in consultation are direct referrala. In this study there was considerable variability in the extent to which doctors authorised indirect referrals. Some gps see almost all their patients when authorising extended and posterior referrals including referrals for refraction.

In the Netherlands, general practitioners are very actively involved in providing obatetric care with one third of the deliveries taking place at home and a quarter in clinics supervised by midwives or general practitioners. Referrals to a specialist are only made when complications occur. When a referral has been authorised by a general practitioner, the onus for making the appointment with the specialist rests with the patient. The delay between the referral and first appointment applies to the interval between the first appointment and surgical intervention when appropriate. The interval between appointment and communication with the gp is dependent upon the
epecialist.

The comparative data used in this summary of the Dutch statistics is obtained from the Dutch National Survey(DNS) conducted between 1st April, 1987 and 31st March, 1988. About 160 gps recorded from every consultation during three months covering aspects of location, diagnosis and intervention. Demographic data were recorded for the whole practice population whether consulting or not (Foets and van der Velden, 1991).

\section{Characteristics of general practitioners}

Fifty five general practitioner principals were recruited 10.98 of the gp population). As a group, they were younger than the gps in the Netherlands (Fig.1). compared with 118 nationally. Haif $(518)$ of the gps had spent 
less than 10 years in practice which is comparable to national data (508). The average list size in the study was 2181 compared with a national figure of 2343 . The proportion of gpg working in singlehanded practice was close to the national figure (538 compared with 548 nationally). About 418 of the practices of participating gps were situated within $5 \mathrm{kms}$ of a hospital and 218 were more than $15 \mathrm{kms}$ distant. The nearest comparable material from national data are 508 and 98 respectively. Among recruited gps, 448 were working in urban areas, 318 in mixed and $25 \%$ in rural areas. There are no directly comparable national data, but these compare favourably with data obtained from the information system on professionals in Dutch Primary Health Care in 1989, in which 528 worked in cities, 158 in commuter areas, 198 in mixed city/rural areas, and $13 \%$ in rural areas (Pool and Hingstman, 1990).

\section{Consultation data}

The $55 \mathrm{gps}$ reported 35410 consultations distributed by age and sex (Fig.2) in a manner very similar to that reported in the Dutch National Survey, Nineteen percent of the consultations involved a home visit compared with 16 nationally. In the average working week, the gps undertook 142 consultations which is equivalent to 60 per 1000 patients or approximately 3.1 consultations per patient per year and compares with 3.2 in the Dutch national survey. The Dutch Central Bureau of Statistics (CBS) reported an annual consultation rate including telephone contacts of 3.6 in 1988 .

\section{Direct referral data}

1586 patients were referred to specialists: 1566 included complete age and sex details of which 478 were for males and 538 for females.

Referral rates per 1000 consultations are presented in sex and age groups in Fig.3. The rates for males exceed those for females in all age groups. There are no comparable data available because the distinction between direct and indirect referrals for this study is not quite the same as that between active and passive referrals. The mean direct referral rate in this study was 44 per 1000 consultations. We estimated that for every 100 direct referrals, there were a further 30 indirect referrals. Thus the overall referral rate in this study was appraximately 59 per 1000 consultations which compares with 64 per 1000 as reported in the Dutch National Survey.

The distribution by specialty is given in Table 1 which includes the number of referrals, percentage distribution and sex specific rates per 1000 consultations. With the exception of ophthalmology, these data are very similar to those reported in the DNS (ophthalmological referrals are commonly passive). Some comparisons with the DNS include, otolaryngology 138 in this study and 108 in DNS; other surgical specialties $298,(278)$; the combined medical specialties of internal medicine, gastroenterology, cardiology, respiratory medicine and rheumatology 168, (198); gynaecology 68, (88); dermatology 98, (78); paediatric medicine $38,(38)$; psychiatry/neurology $98,(78)$. 
Referrals were examined by type, mode, urgency and patient influence. The understanding of the various modes of referral is slightly different in the Netherlands than in some of the Buropean countries and thus in Table 2 no referrals are recorded in the 'private or clinic' modes. The results for all referrals are summarised as percentage distributions (Table 2) and provide reference values for the discussion of referrals in individual specialties. Results concern total referrals and not just outpatient referrals.

Follow-up data about datea of appointment, communication and surgical intervention were collected by $49 \mathrm{gps}$, about 1410 referrals. Delay statistics are summarised in Table 3 .

For the interval between referral and first appointment, 1027 valid cases were available (i.e. cases in which all necessary data were recorded). 718 of these referred patients were seen within 4 weeks, 21 were not seen within 16 weeks. Mean delay in patients seen within 16 weeks was 11 days. The mean delay in medical specialtieg was 10 days which was one day less than that for surgical specialties. The 218 of patients not seen within 16 weeks after referral probably over estimates the true position because in some cases, the patient may have delayed or failed to make an appointment with the specialist. For the interval between first appointment and communication with the $g p_{\text {, there }}$ were 817 valid referrals. In 608 of cases, commuication was received within 2 weeks; in 3.7\%, this interval exceeded 12 weeks. There were some small differences between the specialties. There were 230 valid cases describing the interval between appointment and surgical intervention. For surgical specialties, 408 took place within 14 days and 17 \% were still waiting after 12 weeks.

\section{Analysis by specialty}

The overall referral rate (direct referrals) was 44 per 1000 consultations: 16 per 1000 medical, 23 per 1000 surgical and 5 per 1000 for others. Further detail is provided below about the specialties in which there were a minimum of 100 cases.

Internal medicine (57 males, 78 females):-Compared with most specialties, referrals here were more often immediate and urgent (518 compared with 278 overall). The influence of the patient on the referral decision was less in this specialty than for most others. The mean delay between referral and appointment was 9 days and the interval between appointment and comunication 21 days. The delay may have been greater in this specialty than in others because of the recognised delays in establishing the diagnosis. The reason for referral in this specialty was commonly expressed in vague terms. 135 referrals covered 72 different diagnostic labels. Surgical intervention was deemed necessary in 9 cases.

Dermatology (54 males, 80 females):- Though the referral rates in both sexes were similar, there were differences in total numbers referred, especially in the age group 45-64 years where there was a female excess. 998 of referrals were to outpatient clinics and comparatively few were considered urgent. The mean delay between referral and first appointment was 13 days which slightly exceeds the average for all specialties but comunication was in general quicker with a mean interval of 9 days. 
Neurology (57 males, 52 females):- There was a notable excess of male referrals over females in the age group 25-44 years. Referrals in this specialty were more frequently considered urgent than in most other specialties. Mean delay between referral and appointment was longer than for most referrals 114 days), and the interval between appointment and communication was also longer (17 days).

Otolaryngology (107 male, 92 female):- Referral rates in this specialty were particularly high among children. There was an excess of males over females. The referral rate of male children aged 0-4 years was particularly high - 21 per 1000. Compared with referrals generally, those to otolaryngologists were characterised as being less urgent, more to the outpatient departments and somewhat influenced by patients' wishes. Delays between referral and first appointment and between first appointment and communication were about average for all specialties and delays between appointment and intervention were generally shorter - mean delay of 15 days with 918 of surgical interventions undertaken within 12 weeks.

General surgery (107 males, 87 females):- 408 of general surgery referrals were classified immediate or urgent against 278 overail. The mean delay between referral and first appointment to specialists was comparatively short - 6 days compared with 11 days overall. $76 \%$ of patients were seen within four weeks but of the remainder, 218 were not seen within 16 weeks. Communication was efficient in this specialty. The mean delay between appointment and surgical intervention was 16 days though a residual 98 of interventions were not undertaken within 12 weeks.

Orthopaedics( 70 males, 77 females):- Referrals of young male patients were more frequent than females whereas the converse was true after the age of 65 years. Between 15 and 44 years of age, the referral rate among males was twice that for females. 898 of referrals were described as routine mostly to the outpatient clinics. In 748 of cases, the patient was reported to have influenced the decision. Delay between referral and first appointment was longer than in most specialties (16 days) and the delay between appointment and communication was also a little extended. For those requiring surgery, 628 received their treatment within 12 weeks. The mean delay was longer in this specialty than most others.

Ophthalmology (54 males, 78 females):- Below the age of 45 years, there were 53 females referred, compared with 26 males. There was greater urgency here than in most other specialties and the degree of patient influence was reported to be less. Almost all patients were referred to outpatient clinics. The referral pattern for ophthalmology was strongly influenced by the passive indirect referral and therefore these data have only a limited value. The mean delay between referral and first appointment was 13 days and 328 of patients were not seen within 16 weeks.

Gynaecology (96 females):- The sex specific referral rate was 5 per 1000 consultations and most referrals were for patients between the ages of 25 and 44 years. The mean delay between referral and first appointment was 15 days and the delay between appointment and communication was 11 days. The mean delay between appointment and surgical intervention was 19 days. 
The database for the Netherlands was fairly representative in many aspects of the Dutch healthcare system. However, the participating gps were somewhat younger than the national average. After making adjustment for the indirect referrals, the referral rate per 1000 consultations and consultation frequency were similar to those reported in the DNS. The distribution of referrals by specialty conforms to other sources of national data. The interpretation of the results relating to some apecialties has to be made in the light of the arrangements for referral in the Netherlands particularly in relation to the indirect and passive referrals.

\section{Acknowledgements}

This study was supported by a grant from the Ministry of Welfare, Health and Cultural Affairs to cover the cost of data acquisition in the Netherlands.

\section{References}

Foets, M. , van der Velden, J. Een nationale studie van ziekten en verrichtingen in de huisartspraktijk. Basisrapport: Meetinstrumenten en procedures. Utrecht, NIVEL. 1990.

Pool, JB., Hingstman, L. Cijfers uit de registratie van beroepen in de eerstelijns gezondheidszorg 1989. Utrecht, NIVEL, 1990. 


\section{NORWAY - National Representative D Bruusgaard}

Figure 1

Recorders $(n=32)$ : Distribution by Age

Compared with national data

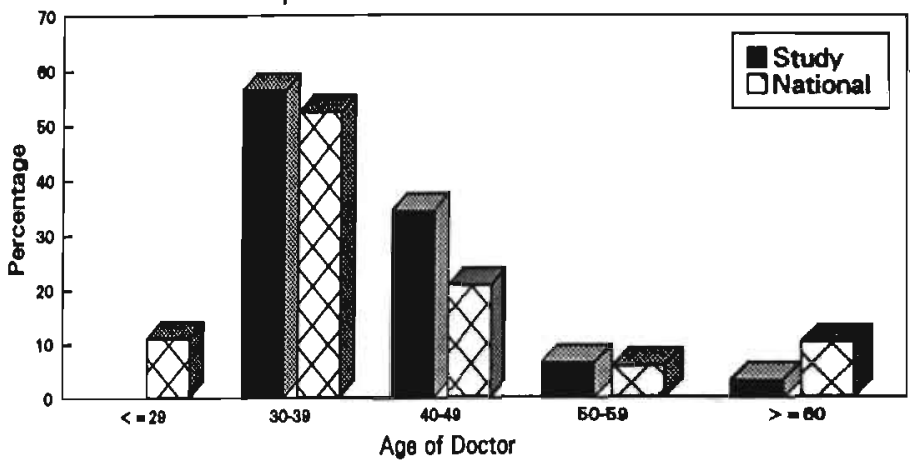

Figure 2

Consultations : Distribution by Age

$(n=4686$ males, 6652 females)

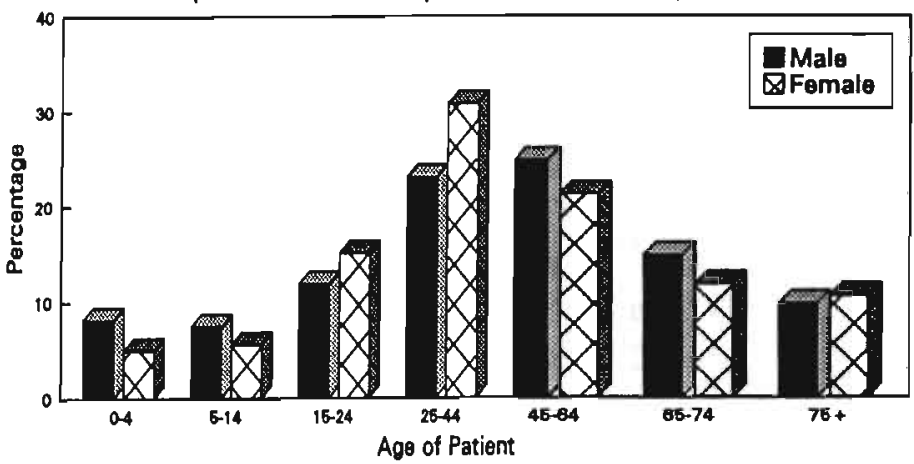

Figure 3

Referral Rate (per 1000 consultations)

by Age ( $n=395$ males, 518 females)

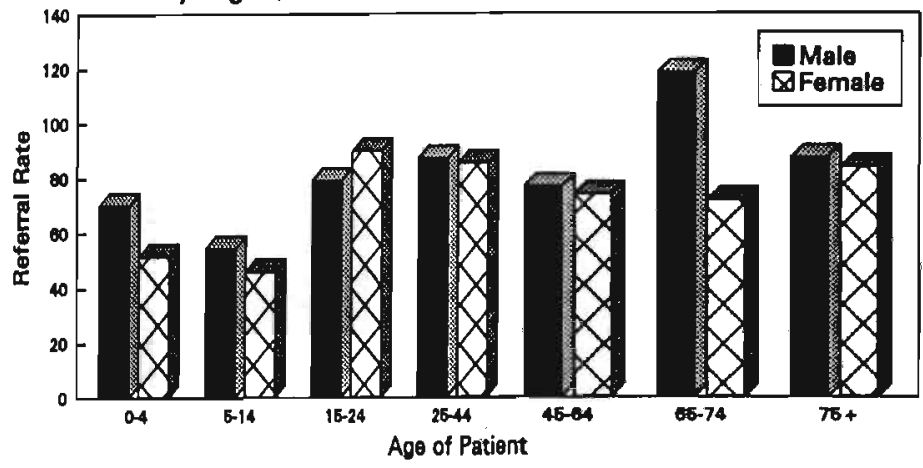


NORWAY

TABLE 1 - REFERRALS BY SPECIALTY

TABLE 2 - DISTRIBUTION OF REPERRALS (8) NUMBER AND PERCENT OF TOTAL

RATE PER 1000 CONSULTATIONS BY SEX

BY MODE, TYPE, URGENCY AND REPORTED PATIENT INFLUENCE

\begin{tabular}{|c|c|c|c|c|c|c|c|c|c|}
\hline SPECIALTY & $\mathbf{N}$ & 8 & $\begin{array}{c}\text { RATE } \\
\text { M }\end{array}$ & $\begin{array}{c}\text { PER } 1000 \\
F\end{array}$ & $\begin{array}{c}\text { CONS } \\
\mathrm{T}\end{array}$ & & $M$ & $r$ & $\mathrm{~T}$ \\
\hline Int. Med. & 120 & 13.1 & 12.2 & 9.5 & 10.6 & MODE & & & \\
\hline Paed. Med. & 31 & 3.4 & 3.6 & 2.1 & 2.7 & Outpatient & 52.8 & 56.0 & 54.6 \\
\hline Geri. Med. & 2 & 0.2 & 0.2 & 0.2 & 0.2 & Private & 13.6 & 13.6 & 13.6 \\
\hline Dermatology & 41 & 4.5 & 3.8 & 3.5 & 3.6 & clinic & 1.0 & 1.5 & 1.3 \\
\hline Cardiology & 14 & 1.5 & 2.1 & 0.6 & 1.2 & Inpatient & 32.3 & 28.8 & 30.3 \\
\hline Allergy & 1 & 0.1 & 0.0 & 0.2 & 0.1 & $A \& E$ Dept. & 0.3 & 0.0 & 0.1 \\
\hline Neurology & 33 & 3.6 & 4.9 & 2.5 & 2.9 & Domiciliary & 0.0 & 0.0 & 0.0 \\
\hline Gastroent. & 30 & 3.3 & 3.0 & 2.4 & 2.6 & & & & \\
\hline Rheumatology & 17 & 1.9 & 0.4 & 2.3 & 1.5 & & & & \\
\hline Reep. Med. & 6 & 0.7 & 0.9 & 0.3 & 0.5 & & & & \\
\hline Medical NEC & 7 & 0.8 & 0.4 & 0.8 & 0.6 & TYPE & & & \\
\hline & & & & & & New & 80.2 & 82.5 & 81.5 \\
\hline MEDICAL & 302 & 33.1 & 31.6 & 23.2 & 26.6 & Re-Referral & 19.8 & 17.5 & 18.5 \\
\hline Gen. Surgery & 165 & 18.1 & 16.4 & 13.2 & 14.6 & & & & \\
\hline Ophthalmology & 73 & 8.0 & 6.6 & 6.3 & 6.4 & URGENCY & & & \\
\hline otolaryngol. & 74 & 8.1 & 9.4 & 4.5 & 6.5 & Immediate & 27.9 & 17.6 & 22.1 \\
\hline orthopaedica & 54 & 5.9 & 8.1 & 2.4 & 4.8 & Urgent & 20.2 & 24.8 & 22.8 \\
\hline Gen.-Urinary & 26 & 2.8 & 3.0 & 1.8 & 2.3 & Routine & 51.9 & 57.6 & 55.1 \\
\hline Plantic surg. & 7 & 0.8 & 0.4 & 0.8 & 0.6 & & & & \\
\hline Neuroburgery & 1 & 0.1 & 0.2 & 0.0 & 0.1 & & & & \\
\hline Surg. NEC & 11 & 1.2 & 1.3 & 0.8 & 1.0 & & & & \\
\hline & & & & & & PATIENT INFLUENC & & & \\
\hline SUAGICAL & 411 & 45.0 & 45.5 & 29.8 & 36.2 & Nil & 50.4 & 49.0 & 49.6 \\
\hline & & & & & & Small & 26.0 & 25.2 & 25.5 \\
\hline & & & & & & Large & 23.7 & 25.8 & 24.9 \\
\hline Obetetrics & 43 & 4.7 & 0.0 & 6.5 & 3.8 & & & & \\
\hline Gynaecology & 90 & 9.9 & 0.0 & 13.5 & 7.9 & & & & \\
\hline Paychiatry & 37 & 4.1 & 4.1 & 2.7 & 3.3 & & & & \\
\hline Mental aub. & 1 & 0.1 & 0.0 & 0.2 & 0.1 & \multirow{3}{*}{\multicolumn{4}{|c|}{$\begin{array}{l}\text { TABLE } 3 \text { - DELAY PATTERNS BETWEEN } \\
\text { REFERRAL AND FIRST APPOINTMENT }\end{array}$}} \\
\hline Emerg+Trauma & 0 & 0.0 & 0.0 & 0.0 & 0.0 & & & & \\
\hline Oncology & 3 & 0.3 & 0.4 & 0.2 & 0.3 & & & & \\
\hline Pain relief & 1 & 0.1 & 0.2 & 0.0 & 0.1 & & & & \\
\hline speclalty NEC & 5 & 0.5 & 0.4 & 0.5 & 0.4 & & & & \\
\hline OTHER & 180 & 19.7 & 5.1 & 23.5 & 15.9 & & $\begin{array}{l}\text { Seen } \\
\text { within } \\
28 \text { days }\end{array}$ & $\begin{array}{l}\text { Not } \\
\text { seen in } \\
16 \text { wks }\end{array}$ & $\begin{array}{c}\text { Mean } \\
\text { delay } \\
\text { (dayg) }\end{array}$ \\
\hline Specialty NK & 20 & 2.2 & 2.1 & 1.5 & 1.8 & MEDICAL & 37.5 & 12.5 & 34.5 \\
\hline & & & & & & SURGICAL & 42.3 & 12.9 & 33.8 \\
\hline & & & & & & OTHER & 46.7 & 16.0 & 31.7 \\
\hline GRAND TOTAL & 913 & 100.0 & 84.3 & 77.9 & 80.5 & TOTAL & 41.6 & 13.4 & 33.7 \\
\hline
\end{tabular}


33 general practitloners were recruited to thi ctudy from an initial traw in which 200 doetors vere circulated uh datail 29 if those recruited went on to provide atafactory follow-ip material. of the 31 general practitioners who recorded their sex, only 3 were female. The age distribution of the Iecorder (Pig.1) is similar to other national data. 19 of the doctor had spent less than 10 years in practice. The sample induded one assistant and one trainee generel practitioner. 11 (33\%) of the recorders practised within $5 \mathrm{~km}$ of a major hospitil and the (98) were more than $20 \mathrm{kms}$ distant. 8 of thent (25) described the environment as urban, $15(47$ t) as mixed and $9(28)$ as rural.

\section{Consultation data}

The study included 11338 consultations, 59 were for female patients and 10 inwolved a home visit. This latter flgura exceeds the 6 value reported by Rutle (1978) which is generally accepted as the reference point for Norwegian general practloe though this study is now rather dated. The distribution of consultations by age and sex is given in Figure 2 and is generally similar to that reported by Rutle. The average nimber of consultations undertaken by recruited general practitioners in what they described as a normal working week was 68 ,

\section{Direct referral data}

The study included 913 referrals (plus 13 in which the age or $80 x$ were not reported). 578 of referrals were for female patients. Referral rates per 1000 consultations in both sexes were broadly similar (Figure 3) and were not substantially different by age. 198 of referrals were described as re-referrals (Table 2). 308 of referrals involved direct admission to hospital and 148 were to the private sector. 458 of referrals were described as immediate or urgent. In 508 of referrals, the patient was said to have had no influence on the referral decision, in 258 a small influence and in 258, a large influence, (analysis confined to outpatients, private and clinic referrals only, gave respective figures of $448,288$ and 288$)$.

The delay between referral from a general practitioner and the first appointment with the specialist is summarised in major specialty groups in Table 3. Altogether 428 of patients were seen within 4 weeks of referral and 138 were not seen within 16 weeks. We also collected data about the delay between the appointment and communication received by general practitioners. In 738 of cases, the general practitioner had received a communication within 2 weeks of appointment. The study included 50 persons who were referred to surgery and were scheduled to have surgical procedures. of these, 28 (568) received their operation within 4 weeks of appointment.

\section{Analysis by specialty}

The sample of 913 referrals provides only limited opportunitiea for examination by individual specialty. The three commonest specialties were general surgery (188 of total), internal medicine (13\%) and gynaecology (108). Referrals in these specialties made to outpatient departments, private practice or to clinics only, amounted to 158,88 and 108 respectively. Rutle 
A short commentary follows for information about the larger referral specialties.

Internal medicine (57 males, 63 females):- 608 of persons referred in this specialty were referred directly as inpatients and 708 were described as immediate or urgent referrals. The patient influence on the referral decision was lower in this specialty than in most others with 658 of patients reported with nil influence.

General surgery ( 77 males, 88 females):- The numbers of persons referred in each age group were similar in both sexes. Forty percent of patients were seen within 4 weeks of referral and 528 of those going on to surgery, received their operation within 4 weeks.

Ophthalmolocy (31 males, 42 females):- $46 \%$ of referred patients went privately. Patient influence on the referral decision was similar to that in other specialties. 408 were seen within 4 weeks of referral.

Otolaryngology ( 44 males, 30 females):- The excess of male referrals in this specialty was largely confined to persons aged 65 and over. $33 \%$ were referred to the private sector and there was a strong patient influence on the referral decision by comparison with other specialties, (nil influence 408 , small 318 and large 298 ). 56 were seen within 4 weeks of referral.

Orthopaedica (38 males, 16 females):- Although this report is primarlly concerned with national data for Norway, comments are made specifically about this specialty because it was not ranked anywhere near so high as in most other Western and Northern European countries. The excess of male cases were largely within the 25-64 year age groups. There were no unusual features about the detailed statistics.

Gynaecology ( 90 females):- 598 of patients were seen within 4 weeks of appointment and amongst them 17 persons who were scheduled for surgery, 12 of them had received their operation within 4 weeks of appointment.

\section{Overview of data for Norway}

In comparison with the data provided by Rutle, there is a relative increase of home visits and a small shift towards older patiento. This accords with expectation given the time interval between the two studies. The distribution as between the specialties was also slightly different but again the time interval must be borne in mind.

The delays in the Norwegian system are considerable and this is a subject for discussion in Norway at the moment.

\section{$\underline{\text { References }}$}

Rutle, 0., Pasienten fram i lyset; analyse av legekontaktar i primaerhelsetenesta (Focus on the patient; an analysis of contacts with primary health care). Rapport 1/1983; 0slo: Gruppe for helsetjenesteforskning, 1983. 
PORTUGAL - National Representatives J Jordao, A Brito de Sa

Figure 1

Recorders ( $n=123)$ : Distribution by Age

Compared with national data

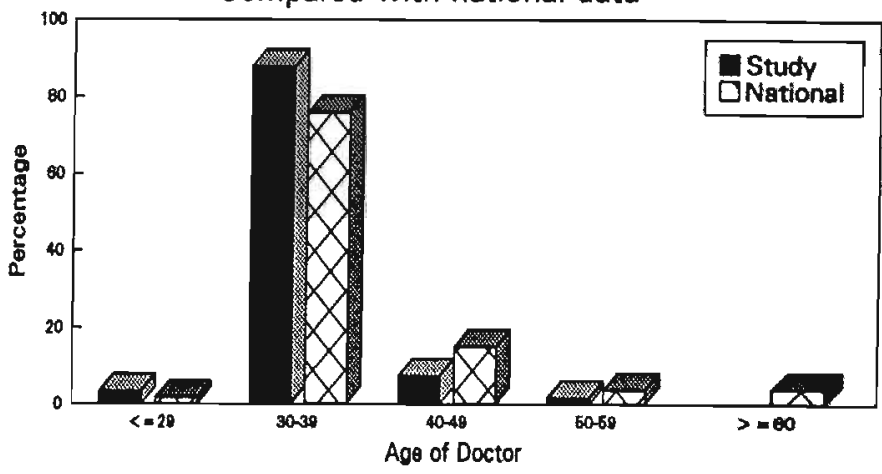

Figure 2

Consultations : Distribution by Age

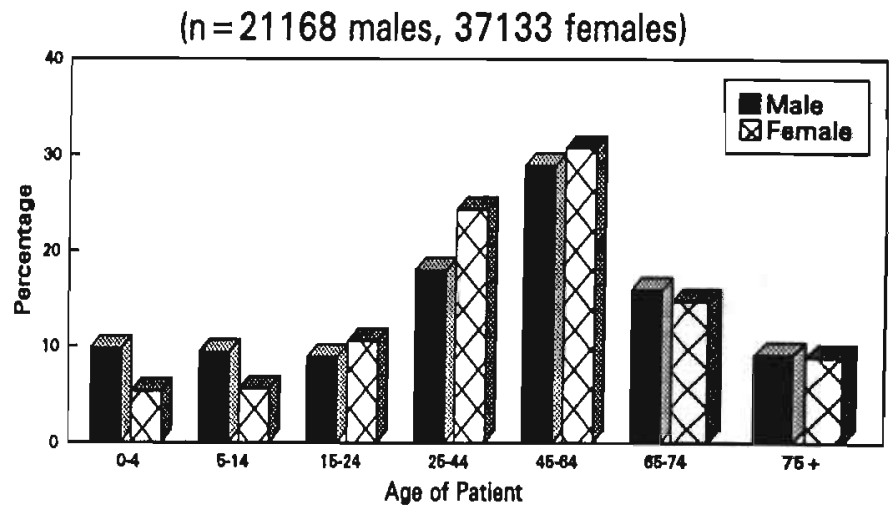

Figure 3

Referral Rate (per 1000 consultations)

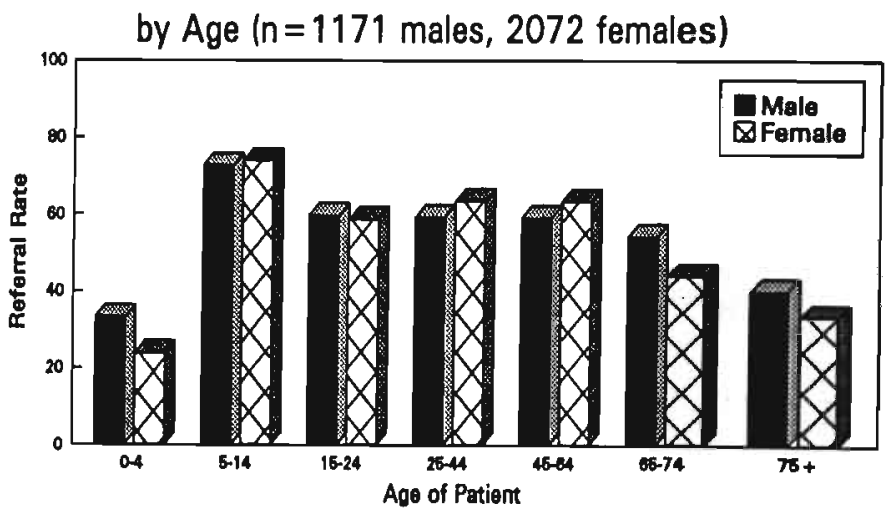


PORTUGAL

TABLE 1 - REFERRALS BY SPECTALTY NUMBER AND PERCENT OF TOTAL RATE PER 1000 CONSULTATIONS BY SEX
TABLE 2 - DISTRIBUTION OF REFERRALS (1) BY MODE, TYPE, URGENCY AND REPORTED PATIENT INFLUENCE

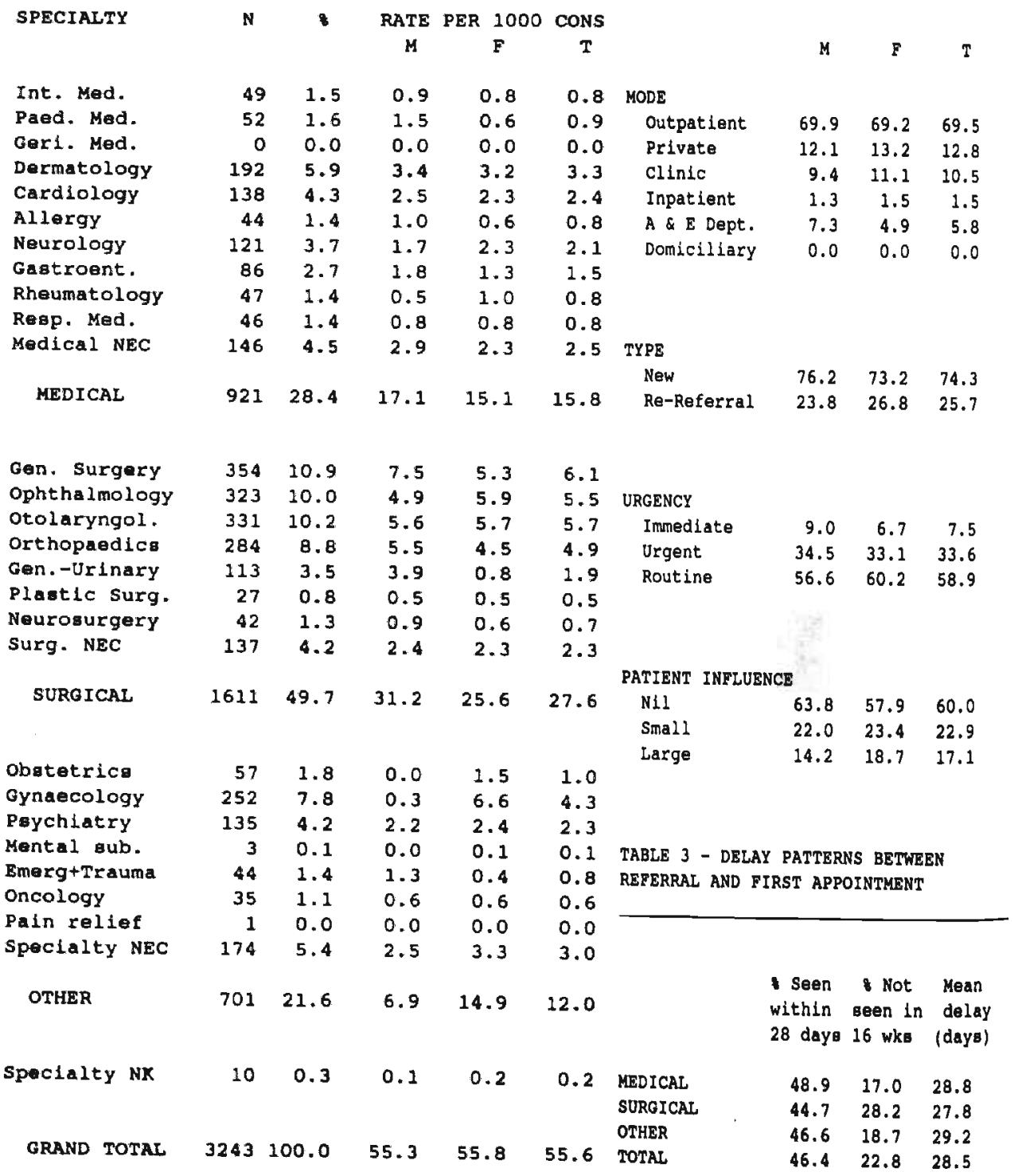


There were 124 general practitioners taking part in the data collection; of these, 99 (808) completed the follow-up study. The mean age of participants was 35 years with the majority aged between 30 and 39 years. By comparison with national data (DRHS, 1990), the distribution was biassed towards the younger age groups (Fig.1). Female doctors were predominant $(n=65,528)$.

The time spent in practice was less than 10 years for 978 of the participants, reflecting the fact that general practice in Portugal is relatively new. More than half (62\%), had between 5 and 9 years experience of general practice (mean 5.5 years).

The average list size was 1780 ; there are no national comparable data though the Portuguese network (Medicos-Sentinela, 1990) reported an average list size of 1397 at the end of 1990 .

Participating general practitioners reported an average of $15 \mathrm{kms}$ from the nearest hospital; 498 practised within $5 \mathrm{kms}$ and 328 were $15 \mathrm{kms}$ or more distant. The Portuguese population is concentrated near the sea and the recruited gps were similarly located. 448 of participants were working in urban health centres, 318 in mixed and 258 in rural areas.

\section{Consultation data}

A total of 58301 consultations were recorded, 850 (1.5\%) of which were home visits. Few home visits are performed by Portuguese general practitioners. The age and sex distribution of patients consulting, showed a predominance of females in every age group, with the exception of children $0-14$ years where the numbers were similar (Fig.2), a finding which accords with other smaller studies (Rodrigues, 1988). An average number of 81 consultations per normal week was calculated, giving an average of 2.4 consultations per patient, per year.

\section{Direct referral data}

During the study, there were 3243 direct referrals, and five more in which age and sex data were missing.

Referral rates per 1000 consultations divided by age and sex are described in Fig.3. Rates in males exceeded those in females in the $0-4$ years and $65+$ years age groups, the rates were similar for both sexes.

Table 1 shows the distribution of referrals by specialty which are analysed in detail later in this chapter.

Table 2 shows the distribution by mode, type, urgency and reported patient influence on the referral decision. About 708 of patients were sent to outpatient hospital departments. Almost three quarters were new referrals and $59 \%$ of referrals were routine. Patient influence was considered nil in 608 of the referrals, women exerting a little more influence than men.

Delay patterns between referral and first appointment, between appointment and first communication and between appointment and surgical intervention are summarised in Table 3 . 468 of patients were seen within 4 weeks, $23 \%$ were not seen within 16 
weeks and the mean delay was 29 days. The first communication from the specialist reached the general practitioner within 2 weeks in 418 of cases and no communication was received within 12 weeks in 508. Surgical procedures were performed within 2 weeks for 208 of patients needing surgery: 268 had their operations within 4 weeks and 578 were still waiting at 12 weeks. Mean delay for patients who had surgery within 12 weeks was 26 days.

\section{Analysis by specialty}

The overall rate of referral was 56 per 1000 consultations. of these, 16 were medical, 28 surgical and 12 referred to other specialties. Table 1 gives information on the number and percentages of referrals by specialty and rates per 1000 consultations by sex.

The four most frequent referred specialties were general surgery, otolaryngology, ophthalmology and orthopaedics.

Internal medicine ( 20 males, 29 females):- 558 were referred for outpatient consultation, a third, (338) went to the Accident and Emergency departments. Some of these were undoubtedly referred with a view to expediting admission and should be added to the referrals as inpatients - 10\%. The costs associated with these referrals were covered by the National Health Service in every case. Urgency was classified 'immediate' in 438 of patients.

Paediatric medicine ( 31 males, 21 females):- More male children were referred. Out of 116 children aged $0-4$ years who were referred, 25 of them (228) were referred to paediatric medicine. $77 \%$ of paediatric referrals were sent to outpatient clinics and 10 \% to $A$ \& $E$ departments. 55 were considered routine. Patient influence was small ( $80 \%$ reporting nil influence) as compared with 608 in all specialties combined. Delay between referral and first appointment was higher than in all other medical specialties; delay between appointment and communication was slightly less.

Dermatology (72 males,120 females):- There were more females referred (excepting the age group $0-4$ years). 82 were new referrals. 148 were referred to the private sector and patient influence was reported nil in 638 of cases. Delay statistics compared favourably (mean delay for first appointment 22 days).

Cardiology (52 males, 86 females):- There were more females referred than males. 418 were re-referrals, and 238 were sent to the private sector, the second highest of the specialties. Delay between referral and first appointment was unfavourable (39 days), but the first communication from the specialist was received more quickly than for most other specialties (558 within 14 days, mean delay 5 days).

Allergy (21 males, 23 females):- 14 (328) were referred privately, the highest referral rate to private practice in the study. Patient influence was reported in 468 of referrals.

Neurology ( 37 males, 84 females):- Twice as many females as males were referred, this bias was evident in all age groups. Type, mode and patient influence were similar to all the medical specialties combined. Delay statistics were near average. 
Gastroenterology (39 males, 47 females):- There was a small excess of women referred in relation to men, with a similar age distribution. 178 were sent to the private sector. Mode and patient influence were average. 61 of patients were seen within 4 weeks.

Rheumatology (11 males, 36 females):- This group had the highest re-referral rate $(56 \%)$. 81 were referrals for outpatient consultation. Patient influence was reported in 458 of the referral decisions. Delay statistics were above average.

Respiratory medicine (17 males, 29 females):- 638 of referrals were considered urgent and 138 immediate. Reported patient influence was one of the lowest in the study (small and large combined 218). Delay statistics were favourable in relation to all specialties combined.

General surgery (159 males, 195 females):- General surgery had the highest number of referrals and included more females than males, but in the 0-14 years and 65+ years age groups, there were more males. 198 had not been seen within 16 weeks and mean delay was 27 days. Surgery was performed within 2 weeks in 218 of patients and 538 were on a waiting list at 12 weeks.

Ophthalmology (104 males, 219 females):- There were twice as many females referred as males, predominating in every age group with the exception of the $0-4$ years age group, in which numbers were similar. Type, mode and urgency were average. There was a strong patient influence in the referral process - 57z. Delay statistics were unfavourable, only 348 were seen within 4 weeks, and 418 had not been seen within 16 weeks.

Otolaryngology (118 males, 213 females):- This specialty was ranked second highest in the study. Children aged $0-14$ years were strongly represented, 188 of all males and 218 of all females aged $0-14$ years who were referred to specialists were referred in this specialty. Type, mode and urgency were average. Some patient influence in the referral decision was reported in 468 of the cases. Delay between referral and first appointment was about average but other delay statistics were unfavourable compared with the other specialties.

Genito-urinary surgery (82 males, 31 females)- There was a clear excess of males with older age groups predominating. Type, mode and urgency were average. Patient influence was smelier than average (698 nil influence). Delays for appointments were average but for patients waiting for surgery they were considerable with 788 still waiting after 12 weeks.

Gynaecology (246 females):- 80 \% of women referred were in the age group 25-64 years. 228 were referred to the private sector compared with 138 for all specialties. Type, urgency and patient influence were average. Delay patterns were generally unfavourable when compared with all the other specialtiea.

Psychiatry (47 males, 88 females):- There were approximately twice as many females referred; 398 were re-referrals. and 198 were referred privately. There were no immediate referrals, but 408 were considered urgent. Patient influence was slightly higher than average. 588 were seen within 4 weeks, 108 had not been seen at 16 weeks and the mean delay between referral and appointment 
was 24 days. There were increased communication delays when compared with other specialties.

Surgery NEC and Specialty NEC:- These referrals accounted mainly for patients referred to the dentist.

\section{Overview of the data for Portugal}

The sample size of general practitioners was considered good though it is difficult to assess its representativeness for lack of comparative data on list size and consultation patterns. Age was biassed towards the younger age groups. The age and sex distribution of patients consulting accords with expectation.

Referral rates of individual general practitioners were widely variable suggesting the need for more detailed study.

General surgery was the specialty in most demand followed by otolaryngology which was dominated by children identified in routine practice based screening programes for hearing.

Approximately 138 of patients were referred to the private sector. Most referrals were new, routine and without reported patient influence.

Delay statistics were poor: less than 508 of patients were seen within 4 weeks in most specialties. Problems of communication between secondary and primary care levels were identified. More than half of the patients in need of surgery were still waiting after 12 weeks.

This study has provided an important database to be used in future studies.

\section{Acknowledgementa}

We are pleased to acknowledge the General Practice Institute of the South, the Portuguese Association of General Practitioners and the Regional Health Administrations for their support during the study.

\section{References}

Direcco Geral dos Cuidados de Saude Primarios. Projecto MedicosSentinela, 1990 (unpublished data).

DRHS. Recursos Humanos da Saude 1989. Depaartamento de Recursos Humanos da Saude, Ministerio da Saude, Lisboa, 1989.

Rodrigues, J.G. "Handling of data in general practice/family medicine: Characterisation of a practice". Rev.Port Clin.Geral $1988,5(35): 12-16$. 
SPAIN - National Representatives

$J$ Gervas, M Perez-Fernandez and L M Garcia-Olmos

Figure 1

Recorders $(n=249)$ : Distribution by Age

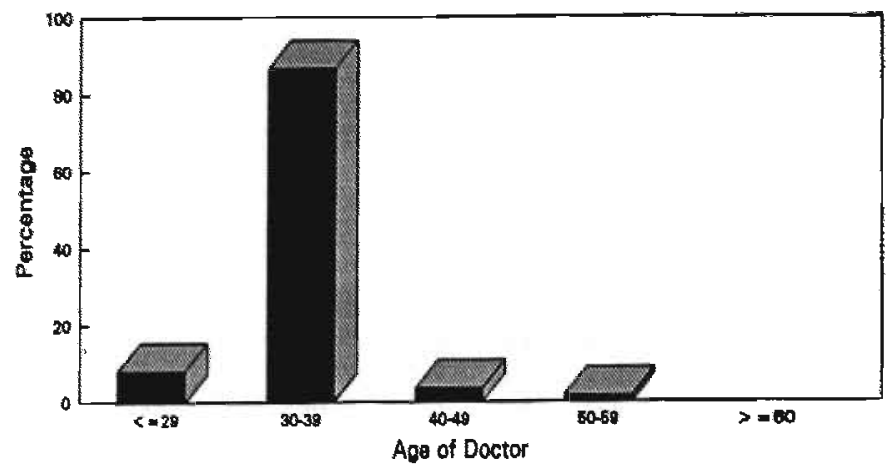

Figure 2

Consultations : Distribution by Age

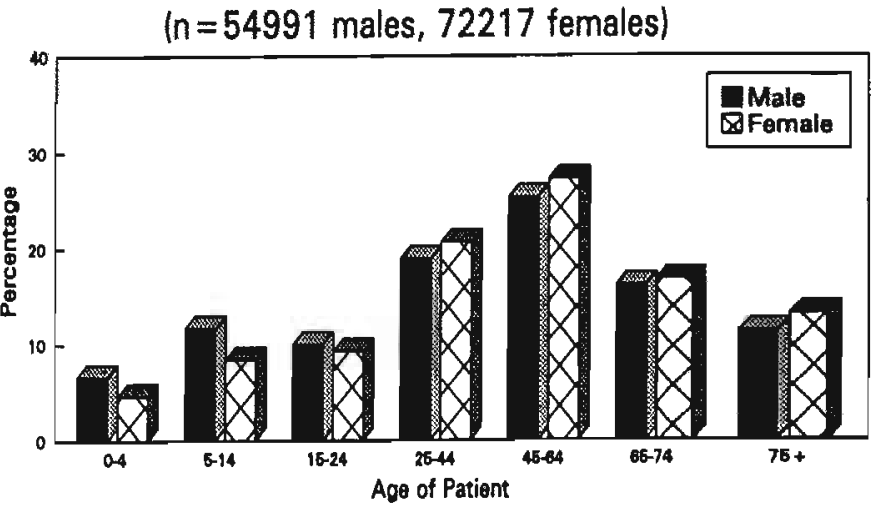

Figure 3

Referral Rate (per 1000 consultations)

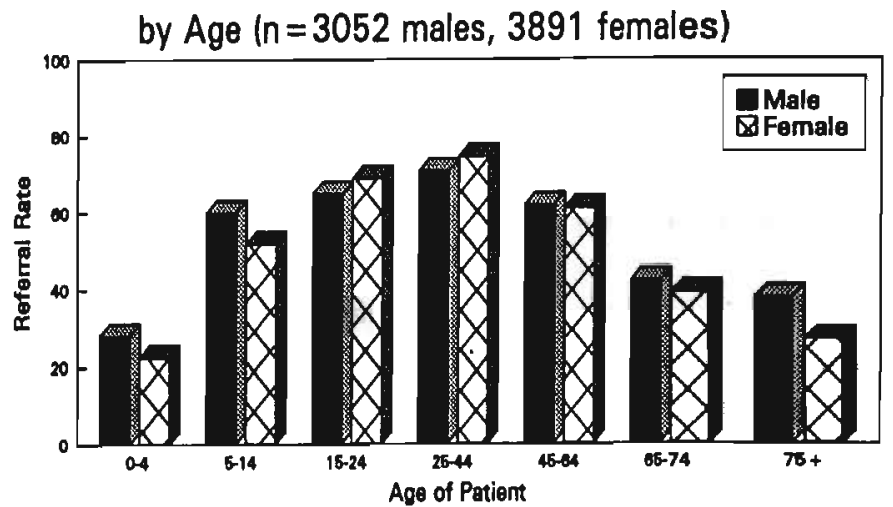


TABLE 1 - REFERRALS BY SPECIALTY NUMBER AND PERCENT OF TOTAL RATE PER 1000 CONSULTATIONS BY SEX
TABLE 2 - DISTRIBUTION OF REPERRALS (1) BY MODE, TYPE, URGENCY AND REPORTED PATIENT INFLUENCE

\begin{tabular}{|c|c|c|c|c|c|c|c|c|c|}
\hline SPECIALTY & $\mathbf{N}$ & 8 & $\begin{array}{c}\text { RATE } \\
\text { M }\end{array}$ & $\begin{array}{c}\text { PER } 1000 \\
F\end{array}$ & $\begin{array}{c}\text { CONS } \\
\mathrm{T}\end{array}$ & & M & $F$ & $\mathbf{T}$ \\
\hline Int. Med. & 167 & 2.4 & 1.7 & 1.1 & 1.3 & MODE & & & \\
\hline Paed. Med. & 6.1 & 0.9 & 0.6 & 0.4 & 0.5 & outpatient & 22.5 & 20.8 & 21.5 \\
\hline Ger1. Med. & 4 & 0.1 & 0.1 & 0.0 & 0.0 & Private & 1.8 & 1.3 & 1.5 \\
\hline Dermatology & 552 & 8.0 & 4.5 & 4.2 & 4.3 & Clinic & 65.0 & 70.8 & 68.3 \\
\hline Cardiology & 346 & 5.0 & 3.0 & 2.5 & 2.7 & Inpatient & 2.1 & 1.2 & 1.6 \\
\hline Allergy & 79 & 1.1 & 0.7 & 0.6 & 0.6 & A \& E Dept. & 8.5 & 5.7 & 7.0 \\
\hline Neurology & 192 & 2.8 & 1.5 & 1.5 & 1.5 & Domiciliary & 0.2 & 0.1 & 0.1 \\
\hline Gastroent. & 382 & 5.5 & 3.7 & 2.5 & 3.0 & & & & \\
\hline Rheumatology & 106 & 1.5 & 0.7 & 0.9 & 0.8 & & & & \\
\hline Resp. Med. & 161 & 2.3 & 1.9 & 0.8 & 1.3 & & & & \\
\hline Medical NEC & 1042 & 15.0 & 8.7 & 7.8 & 8.2 & TYPE & & & \\
\hline & & & & & & New & 74.3 & 71.0 & 72.5 \\
\hline MEDICAL & 3092 & 44.5 & 27.1 & 22.2 & $24 \cdot 3$ & Re-Referral & 25.7 & 29.0 & 27.5 \\
\hline Gen. Surgery & 516 & 7.4 & 5.1 & 3.3 & 4.1 & & & & \\
\hline Ophthalmology & 985 & 14.2 & 7.1 & 8.2 & 7.7 & URGENCY & & & \\
\hline Dtolaryngol. & 719 & 10.4 & 6.3 & 5.1 & 5.7 & Immediate & 12.7 & 8.0 & 10.1 \\
\hline Orthopaedicg & 148 & 2.1 & 1.4 & 1.0 & 1.2 & Urgent & 10.8 & 7.9 & 9.2 \\
\hline Gen.-Urinary & 69 & 1.0 & 0.9 & 0.2 & 0.5 & Routine & 76.5 & 84.0 & 80.7 \\
\hline Plastlc Surg. & 4 & 0.1 & 0.0 & 0.0 & 0.0 & & & & \\
\hline Neurosurgery & 15 & 0.2 & 0.1 & 0.1 & 0.1 & & & & \\
\hline Surg. NEC & 133 & 1.9 & 1.2 & 0.9 & 1.0 & & & & \\
\hline & & & & & & PATIENT INFLUENC & & & \\
\hline SURG ICAL & 2589 & 37.3 & 22.1 & 19.0 & 20.4 & Nil & 67.0 & 61.0 & 63.6 \\
\hline & & & & & & Small & 17.3 & 18.4 & 17.9 \\
\hline & & & & & & Large & 15.8 & 20.6 & 18.5 \\
\hline obstetrics & 100 & 1.4 & 0.1 & 1.3 & 0.8 & & & & \\
\hline Gynaecology & 545 & 7.8 & 0.4 & 7.2 & 4.3 & & & & \\
\hline Paychlatry & 192 & 2.8 & 1.5 & 1.5 & 1.5 & & & & \\
\hline Mental oub. & 3 & 0.0 & 0.0 & 0.0 & 0.0 & \multirow{3}{*}{\multicolumn{4}{|c|}{$\begin{array}{l}\text { TABLE } 3 \text { - DELAY PATTERNS BETWEEN } \\
\text { REFERRAL AND FIRST APPOINTMENT }\end{array}$}} \\
\hline Emerg+Trauma & 327 & 4.7 & 3.5 & 1.9 & 2.6 & & & & \\
\hline Oncology & 10 & 0.1 & 0.1 & 0.1 & 0.1 & & & & \\
\hline Pain relief & 2 & 0.0 & 0.0 & 0.0 & 0.0 & & & & \\
\hline specialty NEC & 31 & 0.4 & 0.1 & 0.3 & 0.2 & & & & \\
\hline OTHER & 1210 & 17.4 & 5.8 & 12.3 & 9.5 & & $\begin{array}{l}8 \text { Seen } \\
\text { within } \\
28 \text { days }\end{array}$ & $\begin{array}{l}\text { Not } \\
\text { seen in } \\
16 \text { wks }\end{array}$ & $\begin{array}{c}\text { Mean } \\
\text { delay } \\
\text { (days) }\end{array}$ \\
\hline Specialty NK & 52 & 0.7 & 0.4 & 0.4 & 0.4 & MEDICAL & 84.8 & 2.5 & 12.4 \\
\hline & & & & & & SURGICAL & 86.2 & 3.2 & 11.0 \\
\hline & & & & & & OTHER & 84.0 & 1.2 & 12.5 \\
\hline GRAND TOTAL & 6943 & 100.0 & 55.5 & 53.9 & 54.6 & TOTAL & 85.1 & 2.5 & 12.0 \\
\hline
\end{tabular}


In Spain, the National Health system covering 998 of the population provides general practice and paediatric services by direct access and specialist services by referral. General practices are required to authorise referrals to the Accident and Emergency departments of the hospital. The system of specialist referral is not personal with referrals made by general practitioners to the local district specialist who may work in an ambulatory clinic setting or in a hospital outpatient department.

\section{Characteristics of general practitioners}

250 general practitioners were recruited: 241 (98\%) were principals. The sample was biassed by the presence of a large number of doctors in their thirties (878) and a deficiency aged 45 years or more. (Fig.1) The 30-39 years group belong to the generation of doctors involved in the "reform" of primary care in Spain which started in 1979 and has been implemented since 1984 (Gervas, 1988, Tudor Hart, 1990, Crombie et al, 1990). The average age of Spanish physicians is quite low: 43 were younger than 30 years in 1985 (the youngest doctors are often unemployed - Marcos et al, 1985). 82 of the recruited doctors were female, equivalent to 338 of the total. Although 208 of spanish physicians are women, there are no national data concerning their distribution by specialty (Marcos et al, 1985) .

488 of the recruited doctors had spent 5-9 years in general practice; 418 10-19 years; and only 28 more than 20 years.

The average list per principal in the study was 1906. There is an uneven distribution of the list per principal from 388 with less than 999 persons to 4.18 with more than 4000 (278 reported between 1500 and 2500). These data reflect the considerable geographical variation in the distribution of doctors throughout Spain.

Almost half of the recorders (428), practised within $5 \mathrm{kms}$ of a major hospital ; $28 \%$ were $30 \mathrm{kms}$ or more distant. These data convey no substantial additional information to that concerning the environment of doctors' practices, 428 urban, 218 mixed and 388 rural. Recorders were widely distributed across the whole of Spain with the exception of a low representation from the Canary and Balearic islands. Three general practitioners worked in Andorra.

\section{Consultation data}

The data included referrals from 127,208 consultationa. The distribution by age and sex groups accords with the age/sex composition of the population generally and their health service utilisation. In the urban areas, general practitioners only attend children aged over 7 years (or in the new health centres over 14 years). The consultation pattern shown here is typical for general practice in Spain with paediatricians working as general practitioners in urban areas (Segura et al, 1986, Insalud, 1987). 
6029 consultations (5\%) involved a home visit, a value similar to that found in other studies, one visit per doctor per working day (Anonymous, 1990).

In an average working week, the gps reported 134 consultations, (direct encounters), which is roughly equivalent to 3.6 consultations per patient per annum. Including indirect encounters, a typical Spanish gp undertakes 185 consultations per week which is equivalent to approximately 4.5 consultations per patient per annum (Anonymous Reporta, 1984\&1990).

\section{Direct referral data}

There were 6,943 direct referrals. 3052 in males $(448), 3,891$ in females (568). In a further 88 cases the age or sex was not specified. In Fig.3 referrals are expressed in age and sex groups as rates per 1000 consultations. Rates in males exceeded those in females in the younger groups (0-4 years and 5-14 years) and in the older groups (65-74 years and 75+ years). Three age groups (15-24 years, 25-44 years and 45-64 years) produced 688 of the referrals. The global referral rate was 55 per 1000 consultations. The published data in Spain which includes indirect referrals vary from 35 to 180 per 1000 (Gervas et al 1984, Alonso et al, 1987, Alonso et al, 1987, Garcia Olmos et al, 1987, Llobera, 1988, Buitrago \& Chavez, 1990, Anonymous, 1990, Garcia Olmos, 1990). In this study there were 7 indirect referrals for every 100 direct referrals.

The distribution by specialty is given in Table 1. The material presented includes the number of referrals in each specialty, the percentage distribution and the sex specific rates per 1000 consultations.

Referrals were examined by type, mode, urgency and the general practitioner's estimate of the degree to which a patient influenced each referral decision. The results, as percentage distributions are sumarised in Table 2 .

Delay statistics covering the period between referral and first appointment are given in Table 3 . The analysis of delays was confined to approximately 508 of the patients recruited to the follow-up study. The remaining patients had for one reason or another been lost to the study, largely because of the poor communication system between specialists and general practitioners.

Approximately 858 of referrals were seen within 4 weeks (Table 3), 38 were not seen within 16 weeks and the mean delay among those seen within 16 weeks was 12 days. There were no major differences between the results in most of the commonly used specialties but delays were slightly increased in paediatric medicine and allergy (26 days and 34 days).

In 728 of cases, communication was received within 2 weeks and in 48, no communication had been received within 12 weeks. Among surgical referrals where surgical intervention was planned, 388 received their surgical procedure within 2 weeks and 198 had not received their operation within 12 weeks. The mean delay among those receiving surgical intervention within 12 weeks was 22 days. 
The overall rate of referral was 55 per 1000 consultations apportioned respectively between the major specialty groups as 24 medical, 20 surgical and 10 other specialties, (Table 1). The five specialties with the most referrals were ophthalmology, otolaryngology, dermatology, gynaecology and general surgery. From other published data, the five specialties with the most referrals were ophthalmology, gynaecology, otolaryngology, "trauma", (orthopaedics, plus trauma, plus rheumatology) and dermatology - (Llobera 1988).

The material presented in the tables provides background references to the examination of referrals in individual specialties.

Internal medicine (91 males, 76 females):- This specialty included the largest proportion referred directly as inpatients (248). In 498, referral was immediate (the mean in medical specialties was $10 \%$ ). The influence of the patient of the decision to refer was very low (nil influence 788 ).

Paediatric medicine ( 35 males, 26 females):- 448 of referrals were as outpatients. The influence of the parents on the decision to refer was large in $25 \%$ of cases (the mean in medical specialties was 178 ). 188 of all referred children aged $0-4$ years were referred to specialists in paediatric medicine compared with only 38 of children aged 5-14 years. In 27\%, the referral was an immediate one $; 818$ of referrals were 'new' (the mean in medical specialties were 718$)$.

Dermatology (246 males,306 females):- 808 of referrals were to clinics, to the specialists working in ambulatory care (Gervas, 1988, Tudor Hart 1990). The mean in medical specialties was 658 . There were more females than males except in children aged $0-14$ years.

Cardiology (167 males, 179 females):- This specialty included the second largest proportion referred as re-referrals (398). Rereferrals may be an indicator of specialist initiated referral. $41 \%$ of referred patients were aged 45-64 years.

Allergy (36 males, 43 females):- This specialty included the largest proportion referred as re-referrals (428). 35\% were aged 0-14 years. 668 were referred as outpatients, (the mean in medical specialties was 248). The influence of the patient on the decision to refer was higher than in all other medical specialties $(468$ of referral decisions were reported to be influenced at least to some extent). All three delay indicators were unfavourable, 318 not seen within 16 weeks and the mean delay was 34 days. 58 of the referrals were private (the mean in medical specialties was 2\%). $97 \%$ of referrals were described as routine (the mean in medical specialties was 828 ).

Neurology ( 84 males, 108 females):- Referrals in this specialty included 23 children aged less than 14 years.

Gastroenterology (202 males, 180 females):- Delay patterns were average. 
Rheumatology ( 38 males, 68 females):- The patient influence on the decision to refer was average. 758 of referrals were aged 2564 years.

Respiratory medicine (106 males, 55 females):- There were more males than females. 918 of patients were seen within 4 weeks. 548 involved clinic consultations (the mean in medical specialties was 658). Referrals were categorised immediate or urgent in 378 of cases (overall mean 198).

General surgery (279 males, 237 females):- The rate was increased in patients aged 15-44 years. 848 of referrals were new ones. There was a weak patient influence. The mean delay was less than in most other surgical specialties.

Ophthalmology (392 males, 593 females):- 368 were re-referrals (the mean in surgical specialties was 26\%). There was a strong patient influence on the decision to refer - nil influence 538, small influence $21 \%$ and large influence $25 \%$.

Otolaryngology (348 males, 371 females):- The numbers of referrals in each age group were similar for both males and females. $21 \%$ were re-referrals.

Genito-urinary surgery (51 males, 18 females):- In the age group $65+$ years, there was only one female. $25 \%$ referrals in the outpatient mode (the mean in surgical specialties was 198). The influence of the patient on the decision to refer was very low (nil influence 738).

Gynaecology (523 females):- Almost half the referrals occurred among women aged between $25-44$ years. Delay pattern analysis was unfavourable ( $\mathrm{BO}$ \% were seen within 4 weeks, 38 not seen in 16 weeks and mean delay interval of 15 days).

Paychiatry (85 males, 107 females):- 678 of referrals were aged 25-64 years and 368 were re-referrals compared with 288 overall.

\section{Overview of data for spain}

The age distribution of the general practitioners was younger than national average. The data base for Spain was large and the sample was representative in characteristics such as list size and consulting pattern.

Before 1990, the list of specialists in the Spanish NISH included three confusing specialties:-"Corazon y pulmon" (cardiology and respiratory medicine); "Traumatologia" - (orthopaedics, trauma and rheumatology); "Neuropsiquiatria" (neurology and psychiatry).

This confusion explains the large number of referrals in the category specialty "medical not elsewhere classified".

The data base gives the first national picture of referrals in spain. The delay pattern analysis confirms that 858 of all patients were seen in 4 weeks, an excellent result, though there was considerable loss to follow-up which may bias these results. The loss to follow-up was largely due to poor communication between specialist and general practitioner and is a subject which will be further investigated. This loss is well known and has been noticed before (Garcia et al, 1987). 
Acknowledgements We would like to acknowledge financial support from "Fondo de Investigaciones Sanitarias" (Grant 89/141).

\section{References}

Alonso, E. Manzanera, R., Varela, J., Picas, J.(1987). "Estudios observacionales de la demanda en asistencia primaria". Atencion Primaria. 4: 148-154.

Anonymous. Cada espanol acudio al medico de Atencion Primaria mas de cinco veces al ano, segun datos estadisticos. Bol Indicatores Saniotarios $1984 ; 8: \mathrm{P} 3-4$.

Anonymous. (1990). "Los servicios de atencion primaria del INSALUD en la Comunidad de Madrid. Madrid. Direccion Provincial INSALUD.

Buitrago, F., Chavez, L.M. (1990). "Analisis de la interconsulta y pruebas complementarias solicitadas por un centro de salud en un periodo de tres anos". Atencion Primaria : 7: $200-204$.

Crombie, D.L., Zee, J., Backer, P. (1990). "The Interface Study". Occasional Paper 48. The Royal College of General Practitioners, HMSO : London.

Gervas, J., Garcia 0lmos, I. M., Perez-Fernandez, M.M., Abraira, V. (1984). "Asistencia medica ambulatoria: estudio estadistico de una consulta de medicina general en la Seguridad Social. Med. Clin. Barcelona. 82: 479-483.

Gervas, J.J. (1988). "Primary healthcare in Spain". WONCA News. 14: pp 7-8.

Tudor Hart, J. (1990). "Primary medical care in Spain". British Journal of Gen.Practice. Vol,40. No.335. pp225-258.

INSALUD. Memoria (1987). Madrid. Direccion Provincial INSALUD.

Llobera, J. (1988). "La derivacion de pacientes de la atencion primaria a la especializanda". Gac San : 2: 271275 .

Marcos, J.A., Casas, X., Anto, J.M. (1985). "Sistema sanitario y personal medico (1970-1990)". CAPS, Barcelona.

Garcia Olmos, L.M., Perez-Fernandez, M.M., Bassolls, A., Abraira, V., Gervas, J.J. (1987). "Estudio de morbilidad ambulatoria: que muestra elegir ?. Atencion Primaria. 4: 136-139.

Garcia 0lmos, L. M. (1990). "Demanda derivada en las consulta de medicina general de los equipos de atencion primaria gestionados por el INSALUD. Gac San: 4: 218-221.

Segura, A., Andrews. J., Homedes, N. et al. (1986). "Enquesta morbiditat". Programa Altebrat. Generalititat de Catalunya, Barcelona. 


\section{SWITZERLAND - National Representative R Meyer}

Figure 1

Recorders $(n=37)$ : Distribution by Age

Compared with national data

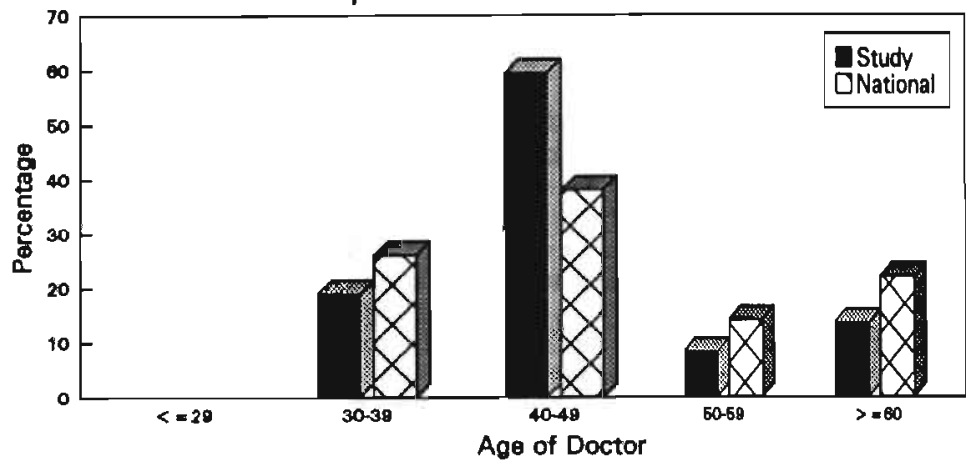

Figure 2

Consultations : Distribution by Age $(n=13196$ males, 15350 females)

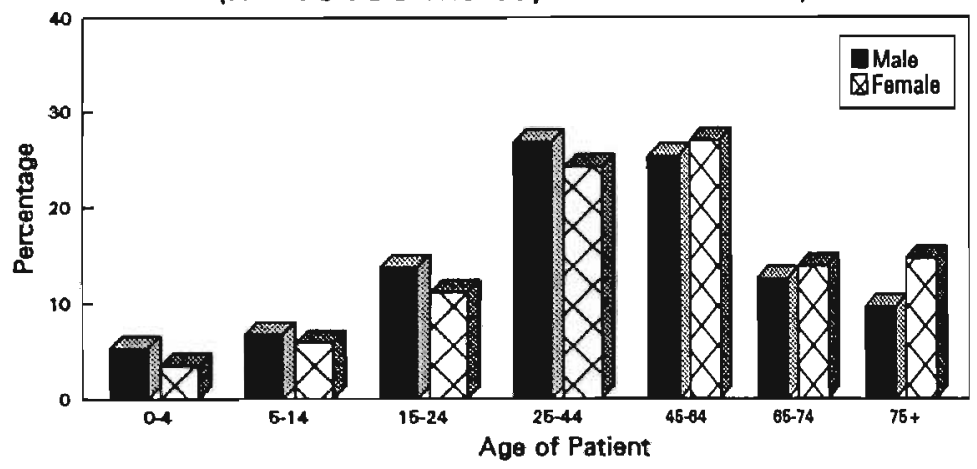

Figure 3

Referral Rate (per 1000 consultations)

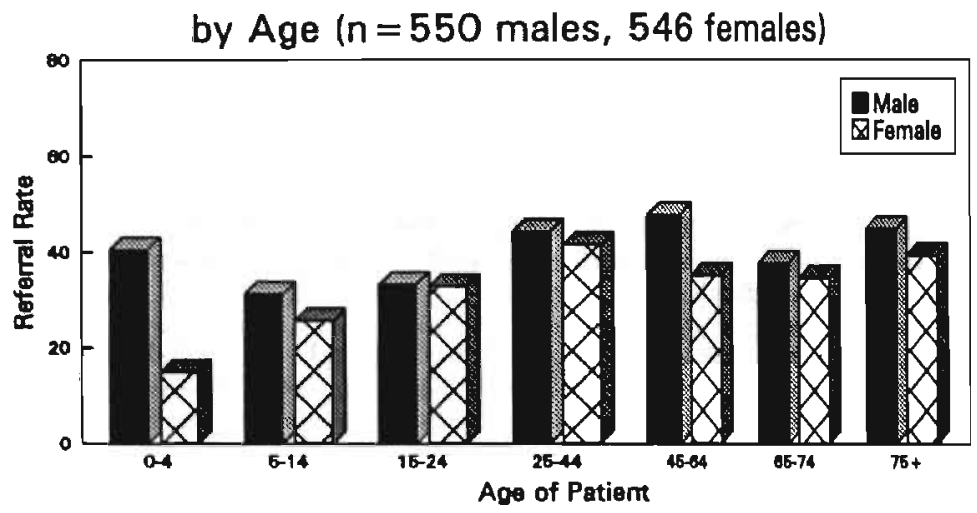


TABLE 1 - REFERRALS BY SPECIALTY NUMBER AND PERCENT OF TOTAL RATE PER 1000 CONSULTATIONS BY SEX
TABLE 2 - DISTRIBUTION OF REFERRALS BY MODE, TYPE, URGENCY AND REPORTED PATIENT INFLUENCE

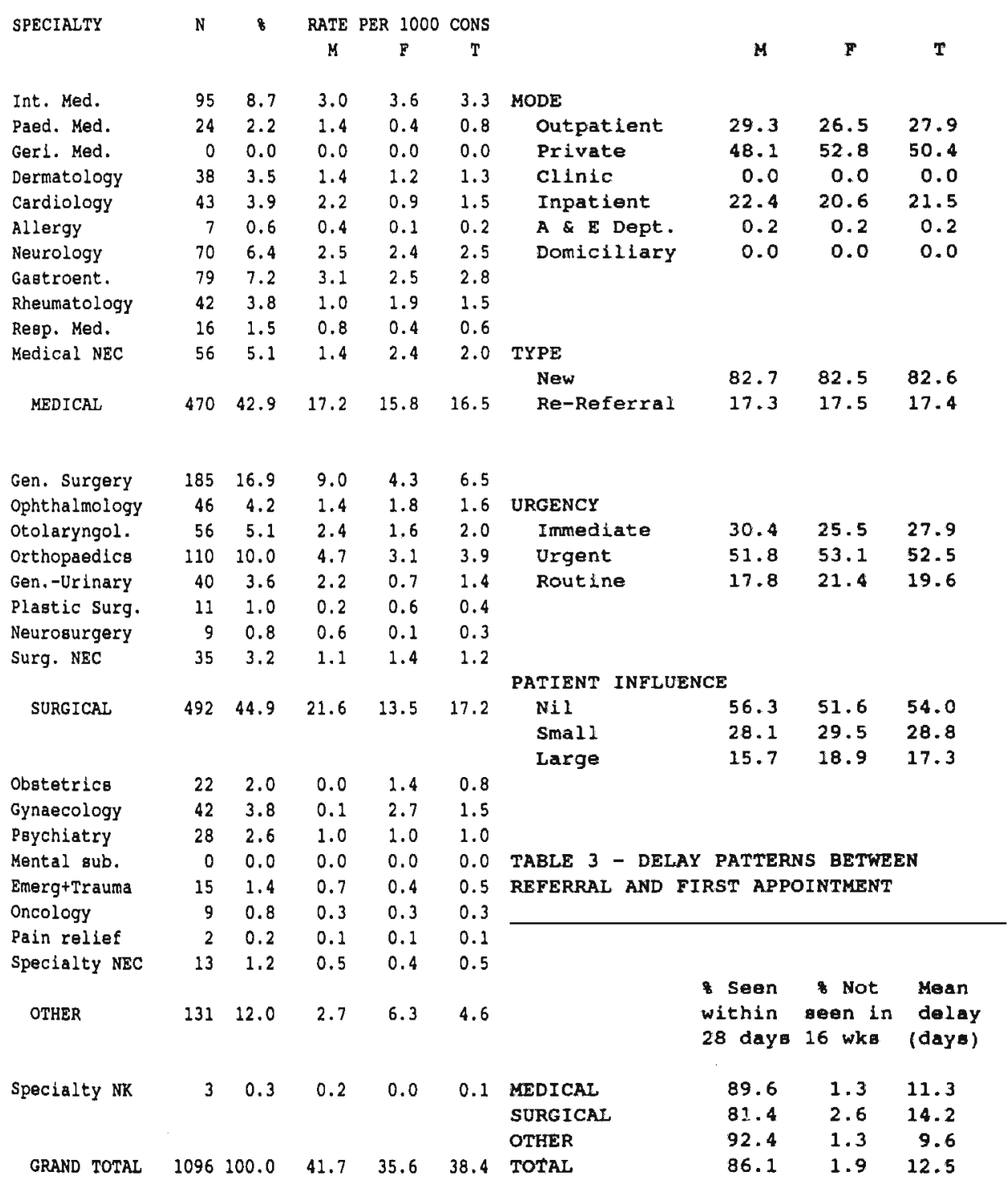


Recruitment data from 37 general practitioners were analysed, representing approximately 1 of Swiss general practitioners, (data from a further $3 \mathrm{gps}$ were not included because of recording deficiencies). In 1989, 3833 gps were active in Switzerland (2181 Aerzte fur Allgemeinmedizin FMH and 1652 doctors without the qualification FMH (FMH, 1990). 36 of the 37 also provided follow-up data. No independent funds were used to promote recruitment. Participation was invited by advertising in Medicina Generalis Helvetica, the journal of the Swiss society of General Practitioners, but this was not very successful. Invitations given during courses of continuing education and by personal letters to members of working groups of the Swiss Society of General Practitioners were more successful though this approach produced a biassed sample of gps. Female gps were under represented ( 2.78 of recruited doctors compared with 14.38 nationally) and there was an excess of German speaking doctors ( 838 compared with national data of 728 ).

The age distribution of recorders with 598 aged between 40 and 49 years (Fig 1) accords with national data. 438 of recorders practised within $5 \mathrm{kms}$ of the nearest hospital. 418 were $6-14 \mathrm{kms}$ distant and $16 \% 15 \mathrm{kms}$ or more distant. Environment of the practices was described as urban for 148 , rural 438 and mixed 438 .

\section{Consultation data}

Altogether the data from 28,546 consultations were analysed. The distribution in age and sex groups (Fig 2) shows a predominance of female patients in the higher age groups which accords with expectation from the distribution of the Swiss population. 548 of all consultations were with female patients and 468 were with males. Recorders reported 150 doctor-patient contacts in an average working week which included 10 home visits. A comparable estimate from the 'Swiss Index of Diagnoses' (Bachmann, 1989), is 137 consultations per week : however this figure includes 'abnormal weeks' where the doctor was not working in his practice for the entire week because of holiday, continuing education, military service sickness etc. In a survey in the Canton of Berne conducted by the Department of Social and Preventive Medicine of Berne University, an average of 150 consultations per week was reported (Abelin and Zahnd, 1982). Altogether, 20212 home visits were made which is approximately 7 of of all consultations.

\section{Direct referral data}

There were 1096 direct referrals equally distributed among males (550) and females (546). Referral rates (per 1000 consultations) were higher for males in all age groups. The distribution by specialty included 438 to medical, 458 to surgical and 128 to other specialties. Half the referrals (508) were sent to specialisto in private practice, 288 were sent to hospital outpatient departments and 228 for inpatient treatment. Urgency was considered immediate in 288, urgent in 528 and routine in 208 of all referrals. In the German version of the questionnaire, the term 'urgent' was translated as 'bald' and used colloquially to indicate 'as soon as possible but not an emergency'. 938 of all referrals to the Accident and Emergency department were 
considered immediately necessary by the referring doctor. The equivalent proportions in some of the specialties were 68 for internal medicine, 458 for general surgery, 448 for oncology, 428 for paediatric medicine and $28 \%$ for all specialties combined.

The influence of the patient on the referral decision was registered nil in 548 of referrals, a small influence in 298 and a large influence in $17 \%$. The influence was particularly strong in dermatology (378), ophthalmology (308), otolaryngology (298) and gynaecology $(298)$.

838 of referrals were categorised as new referrals and 178 rereferrals. High re-referral rates occurred in psychiatry (258) cardiology (378) respiratory medicine (388) and oncology (788). For 968 of female referrals and 848 of males, costs were covered by the sick funds (Krankenkassen). For $7 \%$ of females and 138 of male referrals, costs were paid by accident insurances and for 38 of all referrals, costs were paid by private insurance schemes or by the patients themselves.

\section{Delay patterns}

In 868 of all referrals (admissions excluded), the patienta received their first appointment within 28 days (medical specialties 908 , surgical specialties 818 , other specialties $928)$. Only 1.98 of referrals were not seen within 16 weeks. The mean delay between referral and first appointment was 13 days (medical 11, surgical 14, others 9).

In 828 of all cases (medical 838, surgical 828 , others 748) a communication was received by the referring general practitioner within 14 days of appointment and only in 2.68 of cases was no communication received within 12 weeks. The mean delay among those reported was 7 days.

Surgical intervention was reported as planned in 155 of the cases referred to surgical specialists. In 97 of these referrals, the surgical procedure was undertaken within 4 weeks and only in 168 was there a delay exceeding 12 weeks.

\section{Overview of the data for Switzerland}

The database for Switzerland was almost equivalent to 18 of Swise gps. The age-digtribution of the participating gps coincides approximately with the national average, but the sample was biassed by the under representation of female gps and an excess of German speaking doctors. The rate of 35.6 referrals per 100 is similar to the result from a survey of ambulatory medical care in Switzerland with 3.58 referrals for the general practitioners (Abelin and Messerli, 1981, Abelin, 1983). At that time, a similar study was performed in two French speaking Cantons with other aspects by Paccaud and Pult in the framework of health services research sponsored by the swiss National sience Foundation(PNR 8,1982. Paccaud et al, 1982, Pult \&accaud, 1982). Because of the small number of referrals sent to the different specialities, no analysis by specialty was made in this report. 


\section{Acknowledgements}

The quality of the data collection by the participating Swiss colleagues was remarkable : not one of the 1096 referrals was without age or sex notation and the participants were also very motivated in the study. All but one were engaged in the follow-up study. The excellent collaboration is greatly appreciated.

\section{References}

Abelin, Th., Messerli, HR. (1981). Ueberweisungen in der ambulanten Medizin. Ergebnisse einer Studie ueber die ambulante aerztliche versorgung in der Schweiz. Schweizerische Rundschau fuer Medizin (PRAXIS), Vol.70, 1153-1159.

Abelin Th. (1982). Die Berner Untersuchung ueber ambulante aerztliche versorgung. Allgemeinmedizin International. Vol. 11. 63-69.

Abelin Th. (1983). "General Practice as part of a multi disciplinary ambulatory medical care network". Paper prepared for the European General Practice Research Workshop, Rheinfelden, Switzerland, 22/23 October.

Bachmann, H.P. (1989). "Der Schweizerische Diagnosen-Index 1988. Patientenvorfalle in den ambulanten Arztpraxen der Schweiz". Schweizerische Aerztezeitung. Vol. 70. 1633-1636.

FMH (1990). "Mitglieder-Statistik 1989 der Verbindung der Schweizer Aerzte". Schweizerische Aerztezeitung, Vol.71, pp 916929.

Paccaud F., Pult, G., Kleiber, H. (1982). Releve des consultations et des transferts de patients par enquete directe aupres des medecins - methode d'une enquete, acceptabilite et limites d'interpretation. Sozial - und Praeventivmedizin, Vol.27, 294-298.

Pult, G. Paccaud, F. (1982). L'analyse des renvois regionaux et interregionaux en pratique medicale ambulatoire. Sozial - und Praeventivmedizin, Vol.27, 299-303. 


\section{YUGOSLAVIA - National Representative M Katic}

Figure 1

Recorders ( $n=111)$ : Distribution by Age

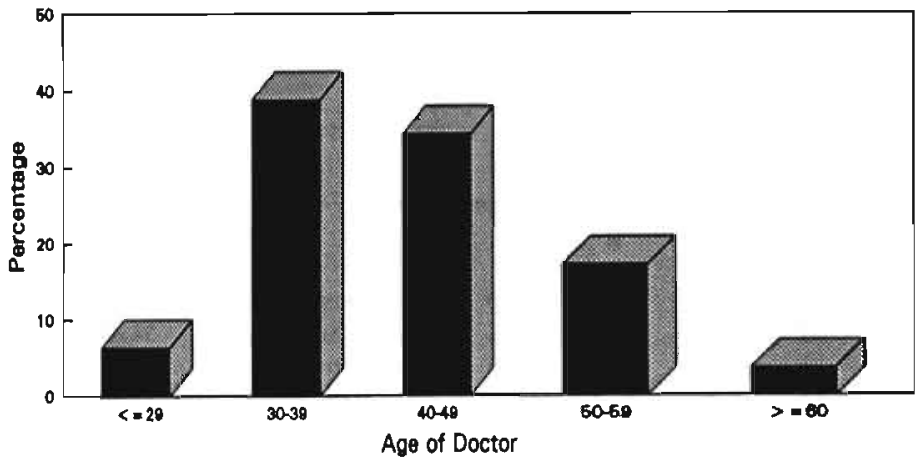

Figure 2

Consultations : Distribution by Age

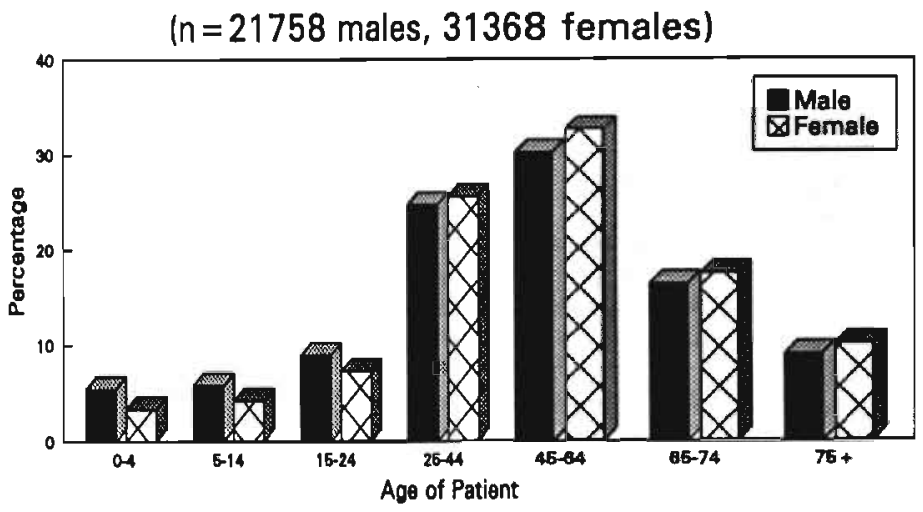

Figure 3

Referral Rate (per 1000 consultations)

by Age ( $n=1384$ males, 2000 females)

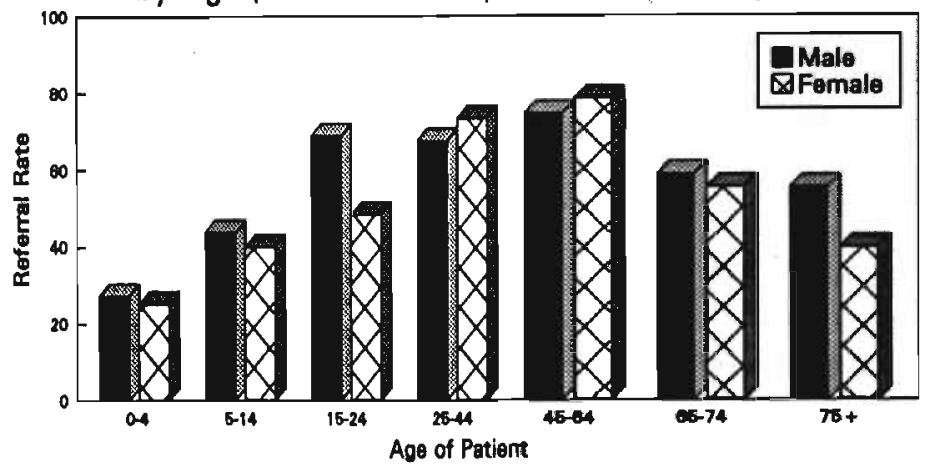


TABLE 1 - REFERRALS BY SPECIALTY NUMBER AND PERCENT OF TOTAL RATE PER 1000 CONSULTATIONS BY SEX
TABLE 2 - DISTRIBUTION OF REFERRALS (8) BY MODE, TYPE, URGENCY AND REPORTED PATIENT INFLUENCB

\begin{tabular}{|c|c|c|c|c|c|c|c|c|c|}
\hline SPECIALTY & $\mathbf{N}$ & 8 & $\underset{M}{\text { RATE }}$ & $\begin{array}{c}\text { PER } 1000 \\
F\end{array}$ & $\begin{array}{c}\text { CONS } \\
T\end{array}$ & & M & $\mathbf{F}$ & $\mathbf{T}$ \\
\hline Int. Med. & 300 & 8.9 & 5.1 & 6.0 & 5.6 & MODE & & & \\
\hline Paed. Med. & 32 & 0.9 & 0.6 & 0.6 & 0.6 & outpatient & 74.6 & 77.4 & 76.3 \\
\hline Ger1. Med. & 1 & 0.0 & 0.0 & 0.0 & 0.0 & Private & 0.1 & 0.3 & 0.2 \\
\hline Dermatology & 122 & 3.6 & 2.2 & 2.4 & 2.3 & clinic & 7.0 & 9.1 & 8.2 \\
\hline Cardiology & 226 & 6.7 & 4.7 & 3.9 & 4.3 & Inpatient & 16.4 & 11.6 & 13.6 \\
\hline Allergy & 33 & 1.0 & 0.3 & 0.8 & 0.6 & A \& E Dept. & 2.0 & 1.6 & 1.7 \\
\hline Neurology & 177 & 5.2 & 2.8 & 3.7 & 3.3 & Domiciliary & 0.1 & 0.0 & 0.0 \\
\hline Gagtroent. & 94 & 2.8 & 2.1 & 1.5 & 1.8 & & & & \\
\hline Rheumatology & 121 & 3.6 & 1.7 & 2.7 & 2.3 & & & & \\
\hline Reap. Med. & 95 & 2.8 & 2.2 & 1.5 & 1.8 & & & & \\
\hline Medical NEC & 127 & 3.8 & 1.6 & 2.9 & 2.4 & TYPE & & & \\
\hline & & & & & & New & 51.0 & 47.6 & 49.0 \\
\hline MEDICAL & 1328 & 39.2 & 23.4 & 26.1 & 25.0 & Re-Referral & 49.0 & 52.4 & 51.0 \\
\hline Gen. Surgery & 394 & 11.6 & 9.6 & 5.9 & 7.4 & & & & \\
\hline Ophthalmology & 307 & 9.1 & 5.2 & 6.2 & 5.8 & URGENCY & & & \\
\hline Otolaryngol. & 242 & 7.2 & 5.2 & 4.1 & 4.6 & Immediate & 20.5 & 14.9 & 17.2 \\
\hline Orthopaedica & 215 & 6.4 & 4.1 & 4.0 & 4.0 & Urgent & 14.3 & 12.4 & 13.2 \\
\hline Gen.-Urinaxy & 158 & 4.7 & 4.7 & 1.8 & 3.0 & Routine & 65.2 & 72.7 & 69.6 \\
\hline Plastic surg. & 41 & 1.2 & 0.8 & 0.7 & 0.8 & & & & \\
\hline Neurosurgery & 36 & 1.1 & 0.9 & 0.5 & 0.7 & & & & \\
\hline surg. NEC & 104 & 3.1 & 2.3 & 1.7 & 2.0 & & & & \\
\hline & & & & & & PATIENT INFLUENC & & & \\
\hline SURGICAL & 1497 & 44.2 & 32.9 & 24.9 & 28.2 & Nil & 71.9 & 66.7 & 68.8 \\
\hline & & & & & & Small & 17.9 & 22.4 & 20.5 \\
\hline & & & & & & Large & 10.2 & 10.9 & 10.6 \\
\hline Obstetrica & 9 & 0.3 & 0.0 & 0.3 & 0.2 & & & & \\
\hline Gynaecology & 131 & 3.9 & 0.1 & 4.1 & 2.5 & & & & \\
\hline Paychiatry & 161 & 4.8 & 2.8 & 3.2 & 3.0 & & & & \\
\hline Mental sub. & 5 & 0.1 & 0.0 & 0.2 & 0.1 & \multirow{3}{*}{\multicolumn{4}{|c|}{$\begin{array}{l}\text { TABLE } 3 \text { - DBLAY PATTERNS BETWEEN } \\
\text { REFERRAL AND FIRST APPOINTMENT }\end{array}$}} \\
\hline Emerg+Trauma & 79 & 2.3 & 1.9 & 1.2 & 1.5 & & & & \\
\hline Oncology & 115 & 3.4 & 1.3 & 2.7 & 2.2 & & & & \\
\hline Pain relief & 5 & 0.1 & 0.2 & 0.0 & 0.1 & & & & \\
\hline Specialty NEC & 41 & 1.2 & 0.7 & 0.8 & 0.8 & & & & \\
\hline OTHER & 546 & 16.1 & 7.1 & 12.5 & 10.3 & & $\begin{array}{l}\text { Seen } \\
\text { within } \\
28 \text { days }\end{array}$ & $\begin{array}{l}\text { Not } \\
\text { seen in } \\
16 \text { wks }\end{array}$ & $\begin{array}{l}\text { Mean } \\
\text { delay } \\
\text { (days) }\end{array}$ \\
\hline Speclalty NK & 13 & 0.4 & 0.2 & 0.3 & 0.2 & MEDICAL & 88.9 & 1.9 & B.6 \\
\hline & & & & & & SURGICAL & 93.0 & 1.1 & 6.0 \\
\hline & & & & & & OTHER & 94.6 & 1.3 & 6.1 \\
\hline GRAND TOTAL & 3384 & 100.0 & 63.6 & 63.8 & 63.7 & TOTAL & 91.6 & 1.5 & 7.1 \\
\hline
\end{tabular}


National data published by the Institute of Public Health of the SFR Yugoslavia for 1989, report 8407 doctors employed in general practice (Statisticki godisnjak, 1990). 2085 (258) of these were specialists in general practice. The proportion of specialists in general practice varies widely between the Yugoslav republics with 358 in the Republic of Croatia, 338 in slovenia and approximately 148 in Bosnia-Herzegovina, and Macedonia. 150 general practitioners (1.88 of all general practitioners in Yugoslavia) agreed to participate in this study and 113 (758) collected the required data. Among the 37 who did not complete the study, five changed their work place during the study, two withdrew for health reasons and eight returned incomplete booklets. The remaining 22 excused themselves due to pressure of work.

The 113 recorders included 49 (438) men and 64 (578) women which compares with national estimates of 418 and 598 respectively.

The age distribution of the recorders is shown in Fig. 1: 81 (728) were aged between 30 and 49 years. All medical graduates in Yugoslavia may describe themselves as general practitioners regardless of the medical field in which they work. Of the national total of 22191 doctors, 638 are aged less than 35 years, $6859(318)$ between 35 and 54 years and $1213(68)$ aged 55 years or more. Though these data are not directly comparable with the age distributions recorded in this study, it is nevertheless evident that participating general practitioners were as a group, older than doctors in Yugoslavia.

Only 64 (56\%) provided data on the size of the population under their care, ranging from less than 1000 to more than 4000 . Until recently, Yugoslavian general practitioners were organised in health centres and independent health stations and did not have a fixed list of patients but were responsible for the population in a specified area (one or two gps depending on the size of the population). As a rule, urban gps had a smaller population under their care so that the average number for big cities such as Belgrade and Zagreb was about 1500-2000 while in the rural areas this number was considerably larger. In the Republic of Croatia, a fixed list of 2000 patients per general practitioner was introduced in 1991.

of 101 gps where data exists on the distance between their practice and a major hospital, 438 practised within $5 \mathrm{~km}, 258$ within 6 and $19 \mathrm{kms}$, and 328 over $20 \mathrm{kms}$ distant. Sixteen percent described the environment of their practices as rural, 418 as mixed and, 438 as urban: (there are no comparable national data). of the total 113 general practitioners, $45 \%$ had worked in general practice for between 10 and 19 years and 348 for longer than 20 years. Recorders who participated in this study, had long professional experience.

\section{Consultation data}

During the study, there were 53126 consultations, including 50284 (948) office encounters and 2842 (58) home visits. Although the number of home visits was small, it was nevertheless considerably higher than the average number of home visits made by general 
practitioners in Yugoslavia estimated at only 2.38 of all consultations in general practice, (i.e. only 173 home visits by general practitioners annually or less than one home visit a day). Fig. 2 shows the distribution of patients by sex and age. There was a small excess of consultations with male children aged 0-4 years: near equal numbers in the age group 5-14 years and in the older age groups an excess of females relative to males. The distribution by sex and age differs from that in the population generally where there is an excess of males in the age groups from $0-39$ years. In age group 40-49 years, the numbers are almost equal while in the older age groups, females exceed males.

For this study, the average number of consultations in a normal week was $18 \mathrm{~B}$ in the sense that it was not disturbed by holidays, sickness or other disturbances. From data available from the Institute of Public Health, the average number of consultations was 168 a week which in a population of 2000, amounts to approximately 4 consultations annually per patient.

\section{Direct referral data}

Altogether there were 3384 direct referrals, 2000 (598) females and 1384 (418) males and a further four in which the age was not specified. In Fig.3, referrals are expressed in age and sex groups as rates per 1000 consultations.

The distribution by specialty is given in Table 1. Material presented includes the number of referrals in each specialty, the percentage distribution and the sex specific rates per 1000 consultations. Referrals were examined by type, mode, urgency and the general practitioner's estimate of the degree to which a patient influenced each referral decision. The results for all referrals are summarised as percentage distributions(Table 2).

\section{Analysis by specialty}

The overall rate of referrals was 64 per 1000 consultations, apportioned respectively between the major specialty groups as follows: 25 medical, 28 surgical and 10 other specialties. National data on referral rates are not available, although there are data from the study by Budak et al on referral rates from health centres in zagreb which amount to 100 per 1000 consultations (referrals in different health centres range from 50 per 1000 consultations to 300 per 1000 consultations). The four specialties with the most referrals in Yugoslavia were general aurgery, ophthalmology, internal medicine and otolaryngology; a grouping broadly similar to that reported by Budak et al, (1987).

Internal medicine (111 males, 189 females):- Internal medicine was the most commonly used specialty in the group of medical apecialties, and included the largest proportion of referred patients in the age group 45-64 years. The majority of patients were re-referred $(618)$ and the referral was described as routine indicating no special degree of urgency in 718 of cases.

Paediatric medicine 14 males, 18 females):- In the organisation of health care in Yugoslavia, the majority of children aged 0-14 years are cared for by paediatricians and specialists in school medicine who, together with general practitioners in health 
centres, provide primary health care. Only a small proportion of children (about 308), primarily in rural areas, are cared for by general practitioners.

Dermatology (47 males, 75 females):- Approximately 408 of referrals in this specialty were re-referrals.

Cardiology (103 males, 123 females):- The highest referral rates were in males in the age group 45-64 years 18 per 1000 consultations), and in females in age group $65-74$ years $(6$ per 1000). 748 of patients were re-referrals which is more than that in any other specialty. 228 of patients were reported to have influenced the referral decision to a small extent and 128 to a large extent.

Neurology (61 males, 116 females):- The highest referral rate occurred in females in the age group 25-44 years (6 per 1000 consultations). There were 458 new referrals and 138 were referred for hospital admission. The influence on the decision to refer was similar to that in other specialties, 248 patients exerted a small influence and $11 \%$ a large influence.

Gastroenterology (46 males, 48 females):- The highest referral rate was found in males aged 45-64 years (3 per 1000 consultations). The urgency of referral was higher than the average for all specialties (immediate 158 and urgent 178). Direct referral for hospital inpatient treatment occurred in $17 \%$ of cases.

Rheumatology ( 35 males, 85 females):- There was a strong female bias especially in the age group 45-64 years (referral rate 5 per 1000 consultations). 848 of patients were referred routinely and 148 exerted a large influence on the decision to refer.

Respiratory medicine (48 males, 47 females):- The highest referral rate was in males aged 45-64 years ( 3 per 1000 consultations), three times more than in females. The urgency of referral was considerably higher than in other medical specialties except in paediatrics (288 immediate and 158 urgent).

General surgery (208 males, 186 females) :- Males aged 15-24 years reported three times the referral rate of females and in the age group 25-44 years, twice the rate. 648 of patients were new referrals which is significantly higher than the average for all other specialties except Emergency and Trauma, Plastic Surgery and Obstetrics. There were also considerably more urgent referrals (308 immediate and 178 urgent) 768 of patients were reported not to have exerted particular influence on the decision to refer.

Ophthalmology (114 males, 193 females):- This is the most frequently referred specialty among patients of both sexes in the age group 45-64 years. The distribution by patient influence on the referral decision did not differ from the average of all other specialties.

Otolaryngology (114 males, 128 females):- Referral rates are similar for both sexes in all age groups except in age group $0-4$ years where there were more males. Besides paediatrics, this is the most frequently used specialty in the age group 0-4 years. Patient influence on the referral decision is higher than that in 
most of the other specialties, 22 oxerted a small influence and 138 a large influence.

Orthopaedics (90 males, 125 females):- In the age group 5-14 years, this is the most frequently referred specialty in both sexes. There were some differences between the sexes with higher rates for males in the age group 45-64 years and for females in the age group $0-4$ years and $65+$ years. The influence of the patient on the decision to refer was higher than the average of all other specialties, 258 exerted a small influence and 148 a large influence.

Genito-urinary surgery (102 males, 56 females):- Among males aged 75 and over, the referral rate of 14 per 1000 consultations was the highest rate among the specialties and accounted for $25 \%$ of all referrals in that age group.

Gynaecology (129 females):- More than half of the referred patients were in the age group 25-44 years. Patient influence on the decision to refer was higher than in any other specialty, (30\% small influence and $13 \%$ large influence).

Psychiatry(62 males, 99 females):- Males in the age group 15-44 years had a much higher referral rate than females. For males in the age group 15-44 years, peychiatry ranked third place in frequency behind surgery and orthopaedics. There were 688 rereferrals which is more than the average of all other specialties except oncology and cardiology.

Oncology (29 males, 86 females):- There was a female excess, especially in age groups between 25-64 years. 80 t were rereferrals which is more than in any other specialty. 118 were referred for inpatient hospital treatment and 408 to specialised oncological institutes.

\section{Overview of the data for Yugoslavia}

Data were collected on the age and sex structure of patient consultations with general practitioners. In comparison with national consulting patterns, the general practitioners in this survey probably cared for a population which was biassed towards older persons since in the towns especially, younger people are cared for by specialists in occupational health or by paediatricians and school doctors. This study has shown that despite these administrative arrangements, general practitioners were providing some primary health care for children in all areas. This is a significant argument for the reorganisation of primary health care towards the family concept and for the reaffirmation of general practice.

Data on consultation and aspects of the work in general practice provided in this study, are more complete than official statistical data. Data on referrals, describing not only the quantitative but also the qualitative characteristics of referrals, will be well used in postgraduate and continuing education of general practitioners, notably to improve the quality of the care provided. 


\section{References}

Budak, A., Katic, M., Sucur M. Odnos izmedju primarne i sekundarne zdravstvene zastite. Praxis Medici 1987; 18 (4): 7-20.

Statisticki godisnjak o narodnom zdravlju i zdravstvenoj zastiti u SFR Jugoslviji 1989. Beograd: Savezni zavod za zdravstvenu zastitu, 1990. 


\section{CURRICULUM VITAE}

Douglas Munro Fleming born December 9, 1936 Birmingham (UK). 1947-1954 King Edward VI School, Birmingham.

1954-1959 Birmingham Medical School. Graduated MB, ChB 1959.

After graduation, Douglas Fleming completed three house officer posts at Selly Oak Hospital, Birmingham and shortly afterwards, entered general practice nearby. He is now the senior partner in a training practice of five partners and one assistant caring for 10,500 patients. The practice has been involved in several research activities particularly in the fields of Practice Activity Analysis, the Weekly Returns Service of sentinel practices and the Fourth General Practice Morbidity Survey.

In 1964 he first became associate of the Royal College of General Practitioners, in 1967 a member and in 1979 he was made a Fellow. His initial link with the Birmingham Research Unit was made in 1964 with involvement in a study of the Outcome of Pregnancy especially in relation to potential teratogenic effects of drugs. His first task involved the development of a classification of drugs for use in that project and later he was responsible for the analysis and interpretation of the findings. Since 1976, he has had an increasing role in the development and management of the National Morbidity Surveys in England and Wales. He has represented general practice on the management board of both of the last two surveys.

The Birmingham Research Unit has played an important part in encouraging practice audit and together with Donald Crombie, he has been concerned in the development of simple methods of practice activity analysis. This activity centres on the belief that the willingness to measure our own performance and to be open about it in discussion with our colleagues, is the route which leads to quality in general practice.

He has had a long association with the European General Practice Research Workshop and in the last five years has been particularly concerned with international cooperative studies. He was involved in the Interface Study concerned with describing the interface between primary and secondary care in Europe, he has played a prominent role in the Eurosentinel organisation which has been concerned with monitoring infectious diseases in general practice. This has lead to the establishment of the Early Warning System for Influenza, one of the Care-Telematics Projects managed from CITI-2 University in Paris. Finally, he has lead the team which prosecuted the study reported in this thesis.

In 1987 he was made Deputy Director of the Birmingham Unit and in 1990 became its Director. 


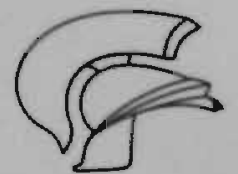

THESIS PUBL.ISHERS AMSTERDAM 